\title{
SPECIES-SPECIFIC PATTERNS IN BIVALVE LARVAL SUPPLY TO A COASTAL EMBAYMENT
}

\author{
By \\ Christine Mingione Thompson \\ B.S., University of Notre Dame, 2005 \\ Submitted in partial fulfillment of the requirements for the degree of \\ Doctor of Philosophy \\ at the
MASSACHUSETTS INSTITUTE OF TECHNOLOGY
and the \\ WOODS HOLE OCEANOGRAPHIC INSTITUTION
}

February 2011

\section{(C) 2011 Christine M. Thompson \\ All rights reserved}

The author hereby grants to MIT and WHOI permission to reproduce and to distribute publicly paper and electronic copies of this thesis document in whole or in part in any medium now known or hereafter created.

Signature of Author

Joint Program in Oceanography/Applied Ocean Science and Engineering Massachusetts Institute of Technology and Woods Hole Oceanographic Institution January 31,2011

Certified by

Scott M. Gallager Associate Scientist Woods Hole Oceanographic Institution Thesis Supervisor

Accepted by

Simon R. Thorrold

Chair, Joint Committee for Biological Oceanography

Woods Hole Oceanographic Institution 


\title{
Species-Specific Patterns in Bivalve Larval Supply to a Coastal Embayment
}

by

\section{Christine Mingione Thompson}

Submitted to the Massachusetts Institute of Technology - Woods Hole Oceanographic Institution Joint Program in Biological Oceanography on January 31, 2011 in Partial Fulfillment of the Requirements for the Degree of Doctor of Philosophy

\begin{abstract}
Larval supply is an important process linking reproductive output to recruitment of benthic marine invertebrates. Few species-specific studies of bivalve larvae have been performed due to the lack of suitable methods for species identification. This thesis focused on applying a method to identify larvae from field samples from Waquoit Bay, MA using shell birefringence patterns. This method was then used to address variability in larval supply for three bivalve species on weekly, tidal, and hourly scales.

Sampling weekly for six months during two years showed large variability in larval concentrations on this time scale. Abundances of most species were related to bay temperature, and species distributions among sampling sites were indicative of transport potential and population coherence. Greater growth of larvae in 2009 compared to 2007 was attributed to more wind-induced mixing and better food availability in 2009.

Integrative samples over each tidal event for a 14-day period demonstrated that larvae were mostly constrained by water masses. During a period when there were sharp tidal signals in temperature and salinity, larval concentrations were higher in bay water compared to coastal waters on incoming tides. After a storm event, water mass properties were less distinct between tidal events and a semidiurnal signal in larval concentrations was no longer apparent. The timing of periods of high larval concentrations did not always coincide with periods of highest water mass flux reducing net export in some cases. On an hourly scale, the vertical distribution of larvae affected by water column stratification and strength of tidal flow. Strong currents and a fresh upper layer both prevented larvae from concentrating at the surface. There was little evidence of peaks in larval concentrations associated with a given tidal period.

Species-specific data can provide new perspectives on larval transport. For the three species studied, Anomia simplex, Guekensia demissa, and Mercenaria mercenaria, different source areas, patterns for growth, and potential for export were observed. Applying species-specific identification methods to future studies of bivalve larval transport has the potential to relate larval abundance to settlement patterns, an important component of larval ecology and shellfish management.

Thesis Supervisor: Scott M. Gallager

Associate Scientist, Woods Hole Oceanographic Institution
\end{abstract}




\section{ACKNOWLEDGEMENTS}

When I was an undergraduate working with Ph.D. students at the University of Notre Dame, I found it overwhelming how they could pursue such intensive, independent research. It was never something I saw myself doing until I was encouraged by my professors at Notre Dame and Columbia Univeristy's Biosphere II Program to apply for this program and pursue a Ph.D. Now that I am on the other side I can say that although a $\mathrm{Ph}$.D. is definitely achievable, this degree would not have been possible without the contributions of many people to this work and my life these past five and a half years.

I would first like to thank my advisor, Scott Gallager, for taking a chance on a student straight out of college with little oceanographic experience. He remedied that by putting me to work at sea the third day I was here. He always encouraged me to take risks with my research and come up with creative and innovative solutions to problems. I have learned so much about doing research and being a scientist, and I am grateful for all the experiences he has provided for me beyond my work in Waquoit Bay.

I would also like to thank my thesis committee (Lauren S. Mullineaus, Jesús G. Pineda, Glenn R. Fierl and Matthew P. Hare) for being available for our many meetings and offering advice and support even through my setbacks. I am thankful to Lauren for including me in her lab's larval ecology meetings, giving me advice for my papers and presentations, teaching me how to communicate ocean science, and always challenging me to think harder and more productively. Jesús was always a friendly face in the MRF hallways and always offered useful advice for field sampling and data interpretation. Although I did not end up including modeling in my thesis, Glenn introduced me into the world of bio-physcial modeling, knowledge I hope to one day pursue further. And finally, I am grateful to Matt for joining my committee rather late, but I felt like his contributions to this work definitely deserved him a spot. I am so grateful for him being able to host me for a week at his lab in Cornell to learn PCR and then communicate with me as I attempted to recreate everything I did there back at WHOI. I would also like to thank Ellen Kenchington for serving on my committee at my thesis proposal defense.

Beyond my committee, there were many others at WHOI who donated their time and expertise to me. I am grateful to Tim Shank for opening his lab up to me to perform the molecular work in this thesis as well as being the chair of my thesis defense. I am also thankful for the help of his post-doc, Walter Cho, with sequencing and alignments of my data. Vickie Starczak and Andy Solow were always available and ready to meet with me to help with my statistical problems. I would also like to thank Stace Beaulieu for everything from classroom instruction and research advice to being a motivating running buddy and life coach.

I would also like to thank those outside of WHOI who contributed to the development of this work. Although she did not serve on my committee, Elizabeth North provided much needed advice and direction for developing my sampling projects and interpreting results. Vitalii Sheremet influenced my research direction extensively by providing his SeaHorse current meters. This enabled me to get a much wider range of current measurements that I could have imagined! 
As this research became an extensive field program, I must acknowledge those that made all this work possible. Rick York was instrumental with this research from the beginning. I will be forever grateful for the time and effort he put into this project which went well above and beyond his job description. His enthusiasm for my project was often what kept me going through the long days and nights of sampling. I am also truly grateful for all the staff at the Waquoit Bay National Estuarine Research Reserve. Not only did they assist with my sampling, but they also included me in their events, gave me an office when Woods Hole became an hour drive in the summer, and provided me the opportunity to participate in their programs to develop my science communication skills. I would also like to thank the people at the Menauhant Yacht Club, the Mashpee Harbormasters and staff at Little River Boatyard, and the staff at Childs River boatyard for accommodating my intensive sampling schedules. And I am especially grateful for all of the summer students, WHOI graduate students, and friends and family who volunteered their time with my sampling program. I am only sorry that I could not include all of the data they helped me collect into this work.

I would like to thank all the great people I've gotten to meet and work with here at WHOI that have helped make my time here enjoyable. I have been challenged in so many ways over my time here, and I am grateful for the amazing people that have helped shape the person I have become and given me stories and memories to take with me. I am especially thankful for everyone who has helped me find my keys, otherwise I might still be locked out of my car/house/office etc.

I would like to thank my family for supporting my decision to go to graduate school and follow my passion even if it wasn't entirely focused around math, physics or running. I hope I have been a suitable role model for my younger sisters as one of them has been silly enough to pursue a Ph.D. herself. I would also like to thank my husband's family who has now officially become my family, even though they were always welcoming and supportive of me while I was in school. I would like to thank my husband, Matthew, who has given me the all the strength I've needed to complete this goal and didn't let me quit both grad school and our relationship even when things got rough. It definitely has not been easy being apart for over five years, but I think it has only made us stronger for our future together.

And finally, none of this would have been possible without money. Funding for this thesis research was provided by an award to from NOAA Sea Grant to S. Gallager (grant NA06OAR417002), an award to S. Gallager and C. Mingione Thompson from the Estuarine Reserves Division, Office of Ocean and Coastal Resource Management, National Ocean Service, National Oceanic and Atmospheric Administration (grant NA07NOS42000024), the WHOI Academic Programs Office, a WHOI Coastal Ocean Institute student grant, the WHOI Biology Department, and the WHOI Ocean Life Institute. 


\section{TABLE OF CONTENTS}

Title Page

Abstract

Acknowledgements

Page No.

Table of Contents

1

3

4

List of Tables

List of Figures

Chapter 1: An Introduction to Biological and Physical Controls on Larval Supply in Estuarine Systems

1.1 Bivalve Larval Ecology 16

1.2 Supply-Side Ecology 18

1.3 Bio-Physical Interactions and Transport in Estuaries 20

1.4 Limitations of Field Studies 23

1.4.1 Sampling Limitations 23

1.4.2 Identification Limitations 24

1.5 Thesis Research 25

1.5.1 Study Site - Waquoit Bay 25

1.5.2 Study Species 27

1.5.3 Goals and Objectives of Thesis Work 29

1.6 Literature Cited 31

Chapter 2: Automated Image-Analysis for the Identification of Bivalve Larvae from a Cape Cod Estuary

2.1 Introduction

2.2 Materials and Procedures $\quad 47$

2.2.1 Sample Collection $\quad 48$

2.2.2 Image Acquisition $\quad 48$

2.2.3 Image Pre-Processing 49

2.2.4 Image Sorting 49

2.2.5 Feature-Extraction and Cross-Validation: Training Sets $\quad 50$

2.2.6 Classification: Unknown Images 57

2.3 Assessment 52

2.3.1 Optimizing Training Sets $\quad 52$

2.3.2 Comparison with Molecular Method 54

2.3.3 Field Application $\quad 60$

2.3.4 Improving Classifier Performance 64

2.4 Discussion 66

2.5 Comments and Recommendations 71

2.6 Acknowledgements 74

2.7 Literature Cited 74 
Chapter 3: Species-Specific Abundance and Growth of Bivalve Larvae in

Relation to Biological and Physical Conditions in Waquoit Bay, MA

3.1 Introduction

95

3.2 Methods

98

3.2.1 Study Site and Sampling Locations 98

3.2.2 Larval Sampling Procedure 99

3.2.3 Sample Processing and Larval Identification 99

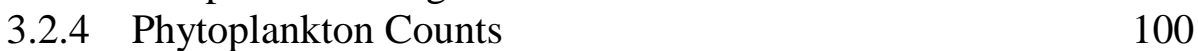

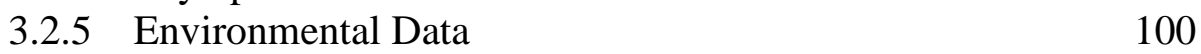

3.2.6 Time-Series Analysis 101

3.2.7 Cohort Analysis 102

$\begin{array}{ll}3.3 \text { Results } & 104\end{array}$

$\begin{array}{lll}\text { 3.3.1 Environmental Data } & 104\end{array}$

$\begin{array}{ll}\text { 3.3.2 Larval Abundance and Size } & 105\end{array}$

$\begin{array}{ll}\text { 3.3.3 Relationship to Environmental Factors } & 107\end{array}$

3.3.4 Larval Cohorts and Growth 109

$\begin{array}{ll}3.4 \text { Discussion } & 110\end{array}$

3.4.1 Relationships with Environmental Conditions 111

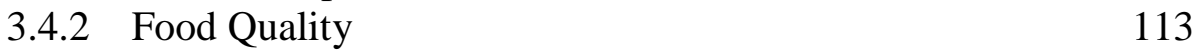

3.4.3 Site-Specific Abundance 114

3.4.4 Species-Specific Abundance and Growth 115

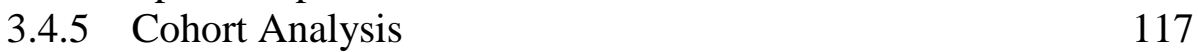

$\begin{array}{lll}3.4 .6 & \text { Summary } & 118\end{array}$

$\begin{array}{ll}3.5 \text { Acknowledgements } & 119\end{array}$

$\begin{array}{lr}3.6 \text { Literature Cited } & 119\end{array}$

Chapter 4: Flux and Vertical Distribution of Three Species of Bivalve $\quad 143$

Larvae During Transport Through an Estuarine System

4.1 Introduction 145

$\begin{array}{lr}\text { 4.2 Methods } & 150\end{array}$

$\begin{array}{ll}\text { 4.2.1 Study Site } & 150\end{array}$

4.2.2 Environmental Data 151

$\begin{array}{lll}4.2 .3 & \text { Flux Study } & 151\end{array}$

4.2.4 Vertical Distribution Study 153

4.2.5 Sample Processing and Larval Identification 154

4.2.6 Data Analysis 155

$\begin{array}{ll}4.3 \text { Results } & 157\end{array}$

$\begin{array}{lll}\text { 4.3.1 Physical Setting } & 157\end{array}$

4.3.2 Flux Study: Tidal and Water Mass Patterns 158

4.3.3 Flux Study: Flux Patterns 160

4.3.4 Vertical Distribution: Depth and Tide Effects 161

4.3.5 Vertical Distribution: Flow 163 
$\begin{array}{ll}\text { 4.4 Discussion } & 164\end{array}$

4.4.1 Flux Study: Tidal and Water Mass Patterns 164

4.4.2 Flux Study: Flux Patterns 165

4.4.3 Vertical Distribution: Depth and Tide Effects 168

$\begin{array}{ll}\text { 4.4.4 Vertical Distribution: Flow } & 170\end{array}$

4.4.5 Comparing Studies 171

$\begin{array}{ll}4.5 \text { Acknowledgements } & 174\end{array}$

$\begin{array}{ll}4.6 \text { Literature Cited } & 174\end{array}$

Chapter 5: A Summary of Bivalve Larval Transport Patterns in 201

Waquoit Bay

5.1 Spatial and Temporal Variability in Bivalve Larvae 202

$\begin{array}{ll}5.2 \text { Species-Specific Transport Mechanisms } & 204\end{array}$

5.2.1 Anomia simplex (Jingle Clam) 204

5.2.2 Geukensia demissa (Ribbed Mussel) 205

5.2.3 Mercenaria mercenaria (Quahog) 207

$\begin{array}{ll}5.3 \text { General Conclusions } & 208\end{array}$

5.3.1 Total Bivalves vs. Species-Specific Trends 208

5.3.2 Passive vs. Active Transport 209

5.3.3 Larval Supply to Waquoit Bay 210

5.3.4 Image Processing a Tool for Identification 210

$\begin{array}{ll}\text { 5.3.5 Cumulative Error } & 211\end{array}$

$\begin{array}{ll}5.4 \text { Future Directions } & 214\end{array}$

$\begin{array}{ll}5.5 \text { Literature Cited } & 216\end{array}$

$\begin{array}{ll}\text { Appendix A: Supplemental Environmental Data } & 218\end{array}$

Appendix B: Gaussian Separation Method Example $\quad 221$

Appendix C: Testing Assumption of Homogeneity Between Sites 222

$\begin{array}{ll}\text { C.1 Introduction and Methods } & 222\end{array}$

C.2 Results and Discussion $\quad 222$

Appendix D: Flux and Vertical Distribution of Competent Larvae in $\quad 228$

Waquoit Bay

$\begin{array}{ll}\text { D.1 Introduction and Methods } & 228\end{array}$

$\begin{array}{ll}\text { D.2 Results and Discussion } & 229\end{array}$

D.2.1 Vertical Distribution and Relationships to Velocity 229

D.2.2 Flux and Transport 232

$\begin{array}{ll}\text { D.3 Summary } & 234\end{array}$

D.4 Literature Cited 234 


\section{LIST OF TABLES}

Table 2.1 Details of larvae collected from Cape Cod, MA hatcheries

Page No.

for use in creating image training sets

Table 2.2 Confusion matrix and classification accuracies for raw and cleaned shells using the leave-one-out method

Table 2.3 Classification results for 250 images of each hatchery species

Table 2.4 Multiplex PCR and 18S sequencing identifications for larvae from 79 live field samples of 2008 and 2009

Table 2.5 Molecular and computer identification results for known hatchery 80 larvae used to calculate error rate for the two methods

Table 2.6 Confusion matrix for the images that were positively identified 80 using the molecular methods and then classified using the SVM

Table 2.7 Manual classification error for the four hatchery species

Table 2.8 Leave-one-out cross validation accuracies for the six-species training set of manually classified field images

Table 2.9 Leave-one-out cross validation accuracies for the nine-species training set of manually classified field images

Table 2.10 Confusion matrix comparing manual and computer classifications 82 for the 6-category field training set

Table 2.11 Confusion matrix comparing manual and computer classifications 83 for the 9-category field training set

Table 3.1 Matrix of cross-correlation coefficients (r) for concentration and shell length data between sites for each species in 2007

Table 3.2 Matrix of cross-correlation coefficients (r) for concentration and shell length data between sites for each species in 2009

Table 3.3 Significant Pearson correlation coefficients (r) from crosscorrelations to temperature, salinity and chlorophyll for each species in 2007 
Table 3.4 Significant Pearson correlation coefficients (r) from crosscorrelations of temperature and chlorophyll for each species in 2009

Table 3.5 Mean growth rate (GR) and period present for all cohorts of each 128 species in 2007

Table 3.6 Mean growth rate (GR) and period present for all cohorts of each 129 species in 2009

Table 4.1 Properties of bivalve larval and physical time series

Table 4.2 Flux calculations of water volume and larvae for spring and neap 180 48 hour periods

Table 4.3 ANOVA tables of the effects of depth and tide on larval Concentrations

Table 4.4 Cross-correlations between larval concentration and temperature, 182 salinity and velocity for the vertical distribution study

Table 4.5 Flux calculations for each tidal period for the Little River spring 184 and neap tide sampling events

Table C.1 Mean growth rate (GR) and period present for Anomia simplex 225 cohorts from grouped sites

Table C.2 Mean growth rate (GR) and period present for Mercenaria 225 mercenaria cohorts from grouped sites

Table D.1 ANOVA tables testing the effects of depth and tide on pedi-veliger 235 larval concentrations

Table D.2 Net flux of pedi-veliger larvae for spring and neap 48 hour periods 236 


\section{LIST OF FIGURES}

Figure 1.1 Life cycle diagram of a bivalve scallop

Page No.

38

Figure 1.2 Spatial and temporal diagram of physical processes affecting

39

biological processes

Figure 2.1 Image processing technique and training set images

84

Figure 2.2 Diagram of optical path for microscope cross polarization setup 85 for image acquisition

Figure 2.3 Accuracy test for hatchery training set with size of species

86 categories and age of larvae

Figure 2.4 Manual sorting and computer classifier results for four species using the two field training sets

Figure 2.5 Receiver Operating Characteristic plot for the two classifiers 88

Figure 2.6 Improved classification results for the 6 species category

89 training set

Figure 2.7 Bland-Altman plot of residuals for classifier agreement after

90 addition of a seventh "other" category

Figure 2.8 Bland-Altman plot of residuals for classifier agreement with manual correction

Figure 3.1 Reserve boundary map of Waquoit Bay showing the four larval sampling sites

Figure 3.2 Daily averaged (a) temperature (b) salinity and (c) chlorophyll a 131 for Waquoit Bay - Metoxit Point

Figure 3.3 Phytoplankton counts for all sites in 2007 and 2009

Figure 3.4 Time-series of wind vectors for Waquoit Bay for 2007 and $2009 \quad 133$

$\begin{array}{lll}\text { Figure } 3.5 & \text { Total larvae for all sites in } 2007 \text { and } 2009 & 134\end{array}$

Figure 3.6 Time series of concentration and mean size of Anomia simplex 135 larvae from the four sampling sites in 2007 and 2009 
Figure 3.7 Time series of concentration and mean size of Geukensia demissa 136 larvae from the four sampling sites in 2007 and 2009

Figure 3.8 Time series of concentration and mean size of Mercenaria mercenaria larvae from the four sampling sites in 2007 and 2009

Figure 3.9 Temperature-salinity-plankton plots of three species of bivalve 138 larvae at all four sites in 2007 and 2009

Figure 3.10 Cohort graphs for Anomia simplex

Figure 3.11 Cohort graphs for Geukensia demissa

Figure 3.12 Cohort graphs for Mercenaria mercenaria

Figure 4.1 Reserve boundary map of Waquoit Bay showing sampling 185 locations for flux and vertical distribution study

Figure 4.2 Classification comparisons by the manual and automated methods 186

Figure 4.3 Bivalve larval concentrations, temperature/salinity, depth, and chlorophyll for Little River during study period

Figure 4.4 Bivalve larval concentrations, temperature/salinity, depth, and 188 chlorophyll for Menauhant during study period

Figure 4.5 Velocity and wind for Little River and Menauhant for the two-week study period

Figure 4.6 Autocorrelation functions for total bivalves at Little River

Figure 4.7 Relationships of larvae at Little River and Menauhant to tidal features

Figure 4.7 Temperature-Salinity-Plankton plot for total bivalve larvae and larvae of three species for Little River and Menauhant

Figure 4.9 Relative flux of larvae and water volume for all species

Figure 4.10 Larval concentrations with temperature, salinity, and depth for Little River spring sampling period 
Figure 4.11 Temperature-Salinity-Plankton plot for total bivalve larvae and larvae of three species for each vertical distribution study

Figure 4.12 Larval concentrations with temperature, salinity, and depth for Little River neap sampling period

Figure 4.13 Larval concentrations with temperature, salinity, and depth for Childs River spring sampling period

Figure 4.14 Larval concentrations with temperature, salinity, and depth for Childs River neap sampling period

Figure 4.15 Larval concentration in relation to average tidal velocity for all four sampling periods

Figure 5.1 Sample estimation error as a function of species composition

Figure A.1 Daily averaged temperature, salinity and chlorophyll a for Little River

Figure A.2 Daily averaged temperature, salinity and chlorophyll a for Menauhant

Figure A.3 Daily averaged temperature, salinity and chlorophyll a for Childs 220 River

Figure B.1 Example of Gaussian-separation method for determining larval Cohorts

Figure C.1 Cohort graphs for Anomia simplex grouped by sites

Figure C.2 Cohort graphs for Mercenaria mercenaria for three out of the four sites

Figure D.1 Competent larval concentration and velocity time series for all pedi-veliger larvae during vertical distribution study

Figure D.2 Competent larval concentration and velocity time series for Anomia simplex pedi-veliger larvae during vertical distribution study

Figure D.3 Competent larval concentration and velocity time series for study 
Figure D.4 Competent larval concentration and velocity time series for Mercenaria mercenaria pedi-veliger larvae during vertical distribution study

Figure D.5 Total larval flux and water volume exchange for pedi-veliger larvae for the Little River and Menauhant flux studies

Figure D.6 Relationships of pedi-veliger larvae at Little River and Menauhant 242 to tidal features 


\section{CHAPTER 1}

\section{An Introduction to Biological and Physical Controls on Larval Supply in Estuarine Systems}


Estuaries are excellent environments to study how biological and physical processes influence larval supply. Larval supply is defined here as the rate of delivery of larvae to a settlement site (Gaines and Bertness 1993). Estuaries provide important nursery grounds and adult habitats for many marine species with pelagic larval stages, so it is crucial for larvae originating from an estuary to find a suitable estuary for settlement. The enclosed nature of estuaries and predictable nature of tidal flows make it relatively easy to measure physical processes and larval distributions. Commercial interests in many marine species make it important to consider larval supply in light of climate change, water quality deterioration, and habitat decline. This thesis investigates larval supply of three species of estuarine bivalves on three timescales in order to determine the processes most influential to supply, how these patterns change with time, and the importance of species-specific behaviors influencing transport.

\subsection{BIVALVE LARVAL ECOLOGY}

Marine bivalves have evolved reproductive strategies ranging from complete viviparity where adults brood their offspring for their full developmental period, to spawning pelagic larvae offering no parental protection, to a combination of the two. The dispersal potential for these developmental modes increases as the time spent in the plankton increases (Thorson 1950). Most coastal bivalves in New England spawn planktonic larvae during spring and summer, and larvae develop over one to two weeks. Larval bivalves have four main developmental stages (Fig. 1.1). The first trochophore stage is ephemeral, lasting up to a day. The second stage occurs after the larva first develops a shell, which begins as a straight-hinged veliger larva. With the aid of a ciliated 
appendage called a velum, the larva is capable of swimming vertically and feeds on phytoplankton at the surface. As the larva grows, the shell thickens and becomes more rounded, and the larva develops into an umbonate veliger. During these stages, larvae are most susceptible to transport by currents as their swimming speeds cannot overcome horizontal currents (Chia et al. 1984). When the larva becomes competent to settle, it becomes a pedi-veliger and develops an appendage called a foot which allows it to seek out settlement substrate and spend more time in the benthos. When a larva finds a suitable settlement site, it will settle and metamorphose into a juvenile. If it can escape post-settlement pressures on survival, the juvenile eventually develops into an adult.

During the planktonic period, larvae are subject to many pressures on survival. Predation, starvation, and physiological stress are some of the most important factors causing mortality. Larvae may also be transported to unsuitable environments and eventually die (Morgan 2001). Some species of bivalves can delay metamorphosis during periods of low growth and/or before they encounter a suitable settlement substrate (Scheltema 1986, Davis and Calabrese 1994). The timing of larval release can influence the ability of larvae to be retained (Sponaugle et al. 2002). However, even with these adaptations, only a very small percentage of larvae released end up surviving to settle (Thorson 1950).

From an evolutionary standpoint, there are several advantages associated with larval dispersal. Given high mortality rates, releasing many larvae increases the odds of survival. Having a pelagic stage allows populations to spread to other locations and to contribute to gene flow across populations (Thorson 1950, Strathman 1985, Gaines et al. 
2007). It also makes populations resilient to local disturbances by supplementing larvae from other areas (Palmer et al. 1996). However, recent information from modeling, environmental signatures, and genetic studies suggests that many populations are capable of being retained near their parental sources (Paris and Cowen 2004, Jones et al. 2005, Hedgecock et al. 2007). The discrete nature of estuarine environments and the predictable nature of estuarine flows make them suitable environments for retention (Sponaugle et al. 2002).

\subsection{SUPPLY-SIDE ECOLOGY}

Larval supply has been established as a strong structuring force for benthic communities in marine environments. The term supply-side ecology first emerged in a seminal paper by Lewin (1986) but had been well established for years in fisheries ecology (Cushing and Harris 1973). The principle states that the variation in the supply of propagules arriving at a given habitat can predict the density of assemblages in space and time (Grosberg and Levitan 1992). Larval supply broadly encompasses (1) dispersal, which refers to where larvae go, (2) transport, the physical and behavioral processes they use to get there, and (3) settlement, where and when they find a suitable habitat to metamorphose (Pineda et al. 2007). Recruitment is defined as survival after an arbitrary period of time post-settlement when the individual is considered to have entered the adult population (Connell 1985, Todd 1998). Linking larval supply with recruitment involves integrating many processes (Underwood and Keough 2001), and it is still debated whether the most influential processes occur pre or post-settlement. 
Relationships between larval supply and subsequent recruitment have been demonstrated in coastal upwelling systems for barnacles (Roughgarden et al. 1988) and bivalves (Ma 2005), and barnacle larvae in bays and estuarine systems (Gaines and Bertness 1993). In these examples, the main factors responsible for regulating the supply of larvae were physical processes. Studying larval supply is challenging as one must integrate reproduction, larval mortality, physical processes, and larval behavior in order to understand how each process influences population structure in space and time.

For coastal bivalve species, supply-side ecology can be relevant in a management context. By understanding processes that influence larval supply, populations of commercial species can be managed more effectively. Over-harvesting, eutrophication, habitat loss, and harmful algal blooms have all affected populations of coastal marine bivalves (Ambrose et al. 1992, Valiela et al. 1992). This has necessitated population management through artificial seeding of commercial species on an annual basis (Kassner and Malouf 1982, Peterson and Summerson 1992). In some cases, it might be enough to simply transplant individuals to locations that maximize survival (e.g. Peterson et al. 1995, Doall et al. 2008), but if population sustainability is a goal then these efforts must also consider larval dispersal and retention capabilities to encourage selfrecruitment (e.g. Peterson et al. 1996). Population decline has led to recruitment limitation, where populations can no longer be sustained by a weakened supply of larvae (Peterson and Summerson 1992). Knowledge of larval dispersal and supply of individual species would make restoration efforts more successful by knowing when and where the best times for settlement occur. 


\subsection{BIO-PHYSICAL INTERACTIONS AND TRANSPORT IN ESTUARIES}

Much of the variability in larval distributions is controlled by oceanographic processes operating on a variety of spatial and temporal scales (Fig. 1.2). On the smallest scale, molecular diffusion and turbulent mixing can distribute plankton on the order of centimeters to meters (Yamazaki et al. 2002), but oceanic gyres can transport larvae across ocean basins (Scheltema 1986, Pineda et al. 2007). When larval behavior acts in concert with physical processes, larvae can either enhance or reduce transport from passive distribution by currents. To investigate these processes, one must assume either a Eulerian or Lagrangian reference frame. In a Eulerian reference frame, a particle is advected past a fixed point in space and patterns are recorded as temporal fluctuations. However, a Lagrangian reference frame assumes the point-of-view of the drifter and transport pathways and interactions of the organism with its environment can be realized (Boicurt 1988, Gawarkiewicz et al. 2007). In the case of most observational studies, a Eulerian reference frame is held, and Lagrangian trajectories are inferred from those data.

Transport capabilities of estuaries are difficult to generalize because they can vary by topography, tidal forcing, stratification, and flushing. Basin shape, tidal circulation, freshwater runoff, wind-driven flow, and residence time can all influence the ability for larvae to be retained in the system (Boicourt 1988, Wiseman et al. 1988, Janzen and Wong 1998, Sponaugle 2002). In many estuaries, a net seaward flow and two-layer density-driven currents can allow plankton to choose a vertical layer to reside in and affect their net horizontal transport. The specific characteristics of an estuary may 
contribute to its ability to be a source or a sink for larvae, and even a single estuarine system may contain micro-environments more suitable for larval retention.

In estuarine systems, physical phenomena operating over various spatial and temporal scales can control larval transport and retention. On seasonal timescales, temperature can induce adult spawning and affect larval developmental time (Loosanoff 1951, Keck et al. 1975). Phytoplankton blooms occur in seasonal patterns (TomaskyHolmes 2008) and if timed appropriately to seasonal spawning, can offer a food source to enhance larval growth and survival (Townsend and Cammen 1988). Seasonal patterns in freshwater runoff can affect net flow and lead to fluctuations in residence time (Gaines and Bertness 1993). On daily to weekly timescales, fluctuations in tidal amplitude and strength with the lunar cycle (Herter and Eckert 2008), wind-driven transport (Boicourt 1988, Eggleston and Armstrong 1995), frontal formations (Mann 1988, Clancy and Epifanio 1989) and internal waves (Pineda 1991) can control the strength of larval flux to an estuarine system. Short-term phytoplankton variability in estuaries on daily or diel periods (Litaker et al. 1987) may also affect larval feeding and vertical position (Raby et al. 1994). Finally, on the timescale of hours to days, tidal mixing, current velocities, and diffusive processes can re-suspend larvae or enable larvae to exhibit behavioral responses to control their vertical positions and thus affect transport (Alldredge and Hamner 1980, Levin 1986, Janzen and Wong 1988).

The roles of larval behavior in active vs. passive transport have been debated in many field studies of larval dispersal (Andrews et al. 1983, Siegel et al. 2003), and retention mechanisms have been proposed based on currents and mixing alone (Pringle 
and Franks 2001). Larvae that are strong swimmers have shown convincing evidence of vertical distribution enhancing transport by operating with a tidal periodicity. Such is the case for many species of brachyuran zoea larvae that can respond to both salinity and turbulent kinetic energy cues to swim upward on a flood tide and cause shelf-ward transport (Welch 1999). These behaviors change with developmental stage as the megalopae larvae must migrate back to estuarine environments. A nocturnal rhythm can be superimposed on these behaviors, resulting in surface swimming in nighttime hours to avoid predation (DeVries et al. 1994, Forward and Tankersley 2001).

For bivalve larvae, these behaviors are less obvious and involve tradeoffs between a negatively buoyant shell and the need to feed at the surface. It has been demonstrated that bivalve larvae go through an early surface-seeking phase involving a smaller shell, buoyant lipid reserves and continuous beating of cilia. The following feeding/transport phase is where the larvae alternately swim upward and then sink, aided by a denser shell, pausing of ciliary beating, and retracting into the shell, all of which increase sinking potential. The final stage of the larval cycle is a substrate- seeking phase in which sinking behavior outweighs swimming behavior (Cragg 1980, Chia et al. 1984). Although laboratory studies have shown bivalve larval responses to a variety of stimuli, less convincing responses have been observed in the field. Salinity avoidance, changes in behaviors with ontogeny, and diel vertical migration have been observed in some cases (Carriker 1951, Mann 1988, Raby et al. 1994, Gallager et al. 1996). Different behaviors have even been shown to exist in different populations of the same species based on the hydrographic regime of the source population (Manuel et al. 1996). In general, the ability 
for a bivalve larva to regulate its vertical distribution is highly dependent on local current strength (Roegner 2000, Tremblay and Sinclair 1990).

\subsection{LIMITATIONS OF FIELD STUDIES}

1.4.1 Sampling Limitations. To estimate larval transport in the field, it is necessary to sample at the spatial and temporal resolution of the physical mechanisms involved. Sampling larval distributions repeatedly over time can give insight into the processes involved in larval transport (Roegner 2000, Nantunewicz and Epifanio 2001). There are often tradeoffs to be made involving site replication versus sample replication (Gaines and Bertness 1993), and sample replication versus sample error (Kjerfva and Wolaver 1988). Even in enclosed basins, samples must be replicated in time to avoid extrapolation of patterns from "snapshot data." In general, higher frequency physical processes require a higher frequency of sampling. Sampling at hourly or daily frequencies often requires long-term use of boat and sampling equipment and generates large volumes of samples. In addition, the patchiness of plankton distributions can make it more difficult to observe these processes. Larval abundances can vary by orders of magnitude over several hours (Seliger et al. 1982, Levin 1986) and many of the processes that supply larvae are episodic (i.e. wind events, spawning), so not every study may observe them (Pineda et al. 2007).

Modeling has emerged as a tool to investigate the effects of physical processes on transport for larger spatial and temporal scales and compare them to observations (e.g. Chen et al. 1997, Paris et al. 2005). The effects of vertical behavior on transport and retention has been modeled for bivalves in estuarine systems (North et al. 2008). 
However, many models are limited by their ability to resolve small-scale physical and behavioral responses, such as vertical and horizontal gradients in velocity (Largier 2003), which often operate over small spatial scales in estuaries (Seabergh 1988).

Automated sampling systems have proven useful for generating high frequency samples (Garland 2000), but they are most useful when combined with automated methods for analysis. Optical sampling techniques have greatly benefited the plankton community by enabling identification and enumeration of both zooplankton and phytoplankton taxa, often in real-time (Benfield et al. 2007). However, identification of bivalve larvae using these methods has proven challenging (Hendricks et al. 2005).

1.4.2. Identification limitations. Before one can generalize about processes affecting larval distributions, it is necessary to make comparisons among species (Gregg 2002). Different species of bivalves have different salinity tolerances, growth rates, habitat requirements, and behaviors that might affect their transport potential within estuarine systems. Bivalve larvae are difficult to identify at the earliest stages due to lack of distinguishing morphological features, and studies attempting morphological identification are risky due to high rates of misidentifications (Perino et al. 2008). Studies attempting species identification by electron microscopy (Lutz et al. 1982), DNA-based methods (Bell and Grassle 1998, Hare et al. 2000, Larsen et al. 2005), or immunological based methods (Garland 2000), are often expensive and time-consuming and thus are difficultly performed on the large numbers of samples required to assess spatial and temporal variability. This has resulted in relatively few field studies of bivalve larvae (Garland and Zimmer 2002, Vadopalas et al. 2006). 
Molecular methods are useful for achieving taxnomoic resolution for difficult-toidentify plankton. A recent method for larval identification of bivalves using Fluroescence In-Situ Hybridization and Cell Sorting (FISH-CS) shows promise not only for identification of species, but the ability to sort them from a sample would enable follow-up analysis (Henzler et al. 2010). However, this method still requires a significant start-up period to develop species-specific probes and comes with a steep price-tag. Although classification accuracy for optical systems is somewhat lower than what could be achieved by manual sorting or molecular identification, it can be applied with high accuracy to larval bivalves by using color patterns of the larval shell under polarized light (Tiwari and Gallager 2003a, b). This method differs from traditional image identification methods of using shape and texture features of black and white images (Hendricks et al. 2005), and instead uses species-specific color patterns reflecting the optical orientation of calcium carbonate crystals forming the larval shell. Application of this method to field studies of bivalve larvae would prove extremely useful to generate species-specific information on larval distribution, behavior, and transport in different systems, and it is ultimately less expensive and time-consuming than most molecular approaches.

\subsection{THESIS RESEARCH}

1.5.1 Study Site - Waquoit Bay. Waquoit Bay is a shallow embayment (average depth $1.5 \mathrm{~m}$ ) on the south shore of Cape Cod, MA. It covers an area of $16 \mathrm{~km}^{2}$ exchanging waters tidally with Nantucket Sound through two inlets. This two inlet system allows for greater tidal exchange and flow (Orson and Howes 1992). Waquoit Bay contains many sub-embayments exchanging water with the main basin of Waquoit 
Bay via tidal rivers. These areas have more estuarine characteristics with large areas of salt marshes and tidal flats and large salinity fluctuations, while the main bay has characteristics of open waters with fringing salt marshes, stable salinity gradients, and a large basin volume relative to the tidal prism. The tide propagates through these subembayments with relatively little attenuation creating well-flushed conditions throughout (Howes 1992).

The primary freshwater source to Waquoit Bay is through groundwater flow, although surface freshwater flows contribute to some sub-embayments (Howes 1992). In these areas with freshwater flow, stratification is less sensitive to flushing events but highly dependent on wind events (Geyer 1997). During periods of onshore winds (as is the predominant wind direction in the summer), freshwater piles up in these channels creating stratified waters with limited exchange, increasing residence time. Offshore wind events, although sporadic in summer, can cause rapid flushing of freshwater, more exchange within Waquoit Bay waters, and shorter residence times. In recent years, nutrient-related water quality issues have appeared as a result of increased urbanization and septic-system flow of nitrogen into the groundwater. Increased nitrogen loading of the systems have threatened habitat quality for shellfish in many of the enclosed basins of Wauqoit Bay (Valiela et al. 1992). In particular, a loss of eelgrass habitat essential for bay scallops has led to a marked decline in the bay scallop fishery within the bay (Bowen and Valiela 2001). Currently, the only populations of bay scallops are subsidized using hatchery seed. Waquoit Bay is an important commercial and recreational fishery for the 
Cape Cod towns that border it, it is a site of much recreational boating and camping, and it is a significant wetland habitat for many coastal species.

The Waquoit Bay National Estuarine Research Reserve (WBNERR) is part of a national system of estuaries devoted to research and water quality monitoring. Water quality data generated from the SeaWater Monitoring Program (or SWMP) from three locations in the bay proved essential for this study. In addition, the long history of research at this site provided necessary background for historical issues of water quality, habitat decline, and management practices within Waquoit Bay.

1.5.2 Study Species. In this research, I focused on three abundant bivalve species in the plankton that have both commercial and ecological relevance: Mercenaria mercenaria (quahog), Geukensia demissa (ribbed mussel), and Anomia simplex (jingle clam). Although much is known about these species in relation to reproductive cycles and larval development, most of these studies are specific to a given locale and do not contain information relating adult reproductive cycles to presence of larvae in the field.

M. mercenaria is the most abundant commercial species in Waquoit Bay and chief commercial clam of the east coast (Abbot and Morris 1995), with both natural and artificially seeded populations. Adults inhabit sandy bottom habitats in shallow water and can tolerate salinities above 15 PSU (Chanley and Andrews 1971). M. mercenaria are relatively long-lived clams with adult lifespans greater than five years. Gonad studies in Delaware Bay indicated that spawning first appears in May-June and continues through September. Spawning times are specific to geographical location and water depth. Initial spawning depends on water temperature with spawning temperatures decreasing 
northward into its range (Keck et al. 1975). M. mercenaria has been documented to spawn in Virginia waters from May through October (Chanley and Andrews 1971). Laboratory studies have demonstrated that M. mercenaria can develop over 10-12 days at $22^{\circ} \mathrm{C}$, reaching setting size between $175-235 \mu \mathrm{m}$ (Loosanoff et al. 1951, Chanley and Andrews 1971). Larval growth for M. mercenaria is highest between temperatures of 20$30^{\circ} \mathrm{C}$ and salinities between 25-30 PSU (Davis and Calabrese 1964).

Guekensia demissa (ribbed mussel) is abundant along the banks of the sub-inlets and tidal marshes, and it plays an important ecological role in the bay removing excess nutrients by filtering particles (Jordan and Valiela 1982). Adults can live for five or more years, they can tolerate the lowest salinities of these three species (above 5 PSU), and they are also tolerant of partially polluted waters (Chanley and Andrews 1971, Abbot and Morris 1995). A Connecticut population showed spawning activity continuously occurring between June and August demonstrating a narrower spawning window for a more northern population, with $G$. demissa larvae being present from June through September in Virginia (Brousseau 1982, Chanley and Andrews 1971). Little documentation of studies on larval growth and behavior exists, but it has been demonstrated that $G$. demissa larvae reach settling size between 200-300 $\mu \mathrm{m}$ (Chanley and Andrews 1971).

The third species, Anomia simplex (jingle clam), is a common fouling organism, often attaching to exposed rocks and shells and is abundant in both coastal and estuarine environments with salinities greater than 10 PSU (Chanley and Andrews 1971, Eckman 1987). These species have a much shorter lifespan, lasting only 1-2 years (Andrews 
1953). Little documentation exists for adult spawning, but larval presence in Virginia waters indicate spawning between June and September (Chanley and Andrews 1971). Laboratory studies on growth and tolerances for A. simplex larvae are generally absent from the literature. A. simplex has the smallest larvae of the three species, starting at 60 $\mu \mathrm{m}$. The larval period is estimated to be $12-33$ days at $22^{\circ} \mathrm{C}$ with metamorphosis occurring between 180 and $215 \mu \mathrm{m}$ (Chanely and Andrews 1971, Loosanoff 1961).

For all these of these species, limited information is available on spawning on Cape Cod. Spawning windows presented for the more southern locations may be narrower for the cooler waters of Cape Cod, but this remains to be documented. In addition, each of these species has been documented to delay metamorphosis on some level (Loosanoff et al. 1951, Loosanoff 1961, Baker and Mann 1997). If these post-larvae remain planktonic, this ability could result in a larger dispersal potential during these stages than might be expected based on observed size distributions and growth.

1.5.3 Goals and Objectives of Thesis Work. This thesis was a three-part study to investigate the role that estuarine processes play in transporting bivalve larvae in Waquoit Bay and how this affects larval supply. By applying a state-of-the-art method for identifying bivalve larvae, I was able to successfully employ a species-specific analysis to compare patterns of transport for three species. Two of the locations sampled in this study allowed for the installation of an automated sampling system that allowed for longer-term, integrative sampling. Combining this sampling method with high-frequency point samples, I was able to generate a more detailed depiction of transport processes during the period of highest larval abundance in Wauqoit Bay in 2009. 
Chapter 2 describes the image-analysis method of using color patterns from polarized-light images of larval shells to distinguish species. Results of this method were compared for hatchery reared larvae and larvae sampled from the field. This method was compared with a molecular method for larval identification in order to validate identifications of some species as well as compare accuracies using known hatchery reared larvae. To apply this method, I identified four species from a time-series of weekly field samples and compared it to manually classified images in order to find the optimal settings for automated classification of our field image sets.

In Chapter 3, we used species-specific data from manually classified image sets to compare larval abundance and distributions between two years in Waquoit Bay. This chapter focused on determining the biological and physical parameters that regulated larval abundance on a weekly to monthly scale, and employed a cohort analysis to compare species-specific growth between years. Based on what is known about each species' life histories, it was hypothesized that $M$. mercenaria would have longest spawning window, and that A. simplex would show the greatest variability in growth and abundance between years due to its short adult lifespan. The longer larval duration of $A$. simplex might enable it to disperse further than the other species appearing well-mixed with respect to location. $G$. demissa was expected to be most abundant in marsh channels and expected to have the most upstream sources due to adult salinity tolerances. As larval salinity tolerances were unknown for both A. simplex and G. demissa, I hoped to uncover relationships to physical factors for these species. 
Chapter 4 focuses specifically on transport processes within Waquoit Bay by estimating tidal flux through an inlet and sub-embayment over a two week-period superimposed with high-frequency studies of larval vertical distribution. By investigating larval distributions over tidal and hourly scales, I addressed relationships of larvae with water masses and tidal features. The vertical distribution study investigated whether passive or active transport was occurring, how larvae respond to stratified conditions, and species-specific behaviors that might result in differential transport. It was predicted that out of all three species, G. demissa would be most associated with bay water and would have to show retention behavior in order settle in the bay. M. mercenaria and A. simplex may be less constrained to bay water and could show different transport behaviors.

The final chapter summarizes the data and conclusions reached for each study and proposes a mechanism for transport for each species based on the observations during the summer of 2009. Finally, it speculates on the importance of new perspectives gained from this study to the future of bivalve larvae research and suggests future directions for work in Waquoit Bay and beyond.

\subsection{LITERATURE CITED}

Abbot, R.T. and P.A. Morris. 1995. Shells of the Atlantic and Gulf Coasts and the West Indies. Houghton Mifflin Company, New York, NY.

Alldredge, A.L. and W.M. Hamner. 1980. Recurring aggregation of zooplankton by a tidal current. Est. Coast. Mar. Sci. 10: 31-37.

Andrews, J.D. 1953. Fouling organisms of Chesapeake Bay. Inshore Survey Program Interim Report XVII. The Chesapeake Bay Instiute of the John Hopkins University. Ref 53-3.

Andrews, J.D. 1983. Transport of bivalve larvae in James River, Virginia. J. Shellfish Res. 3(1): 29-40.

Ambrose, W.G., C.H. Peterson, H.C. Summerson, J. Lin. 1992. Experimental tests of factors affecting recruitment of bay scallops (Argopecten irradians) to spat collectors. Aquaculture 108: 67-86. 
Baker, P. and R. Mann. 1997. The postlarval phase of bivalve mollusks: a review of functional ecology and new records of postlarval drifting of Chesapeake Bay bivalves. Bull. Mar. Sci. 61(2) 409-430.

Bell, J.L. and J.P. Grassle. 1998. A DNA probe for identification of the larvae of the commercial surf clam (Spisula solidissima). Molec. Mar. Biol. Biotechnol. 2: 129-136.

Benfield, M.C., P. Gorsjean, P.F. Culverhouse, Irigoien, M.E. Sieracki, A. Lopez-Urrutia, H.G. Dam, Q. Hu, C.S. Davis, A. Hansen, C.H. Pilskain, E. Riseman, H. Schultz, P.E. Utgoff, and G. Gorsky. 2007. RAPID: Research on Automated Plankton Identifcation. Oceanography 20(2): 13-26.

Boicurt, W.C. 1988. Recruitment dependence on planktonic transport in coastal waters. In: Rothschild, B.J. (ed.), Toward a Theory on Biological-Physical Interactions in the World Ocean. Kluwer Academic Publishers, pp. 183-202.

Bowen, J.L. and I. Valiela. 2001. The ecological effects of urbanization of coastal watersheds: historical increases in nitrogen loads and eutrophication of Waquoit Bay estuaries. Can. J. Fish. Aquat. Sci. 58: 1489-1500.

Brosseau, D.J. 1982. Gmetogenesis and spawning in a population of Geukensia demissa from Westport, Connecticut. The Veliger 24(3): 247-251.

Carriker, M.R. 1951. Ecological observations on the distribution of oyster larvae in New Jersey estuaries. Ecological Monographs 21(1): 19-38.

Chanley, P. and Andrews J.D. 1971. Aids for identification of bivalve larvae of Virginia. Malacologia 11: 45-119.

Chen, Y.H.. P.T. Shaw, and T.G. Wolcott. 1997. Enhancing estuarine retention of planktonic larvae by tidal currents. Estuar. Coast. Shelf. S. 45: 525-533.

Chia, F., J. Buckland-Nicks, and C.M. Young. 1984. Locomotion of marine invertebrate larvae: a review. Can. J. Zool. 62: 1205-1222.

Clancy, M. and C.E. Epifanio. 1989. Distribution of crab larvae in relation to tidal fronts in Delaware Bay, USA. Mar. Ecol. Prog. Ser. 57: 77-82.

Connell, J.H. 1985. The consequences of variation in initial settlement vs. post-settlement mortality in rocky intertidal communities. J. Exp. Mar. Biol. Ecol. 93: 11-45.

Cragg, S.M. 1980. Swimming behavior of the larvae of Pecten maximus (L.) (Bivalvia). J. Mar. Bio. Ass. U.K. 60: 551-564.

Cushing, D.H. and J.G.K. Harris. 1973. Stock and recruitment and the problem of density dependence. ICES Rapp. Proc.-Verb. 164: 143-155.

Davis, H.C. and A. Calabrese. 1964. Combined effects of temperature and salinity on development of eggs and growth of larvae of $M$. mercenaria and $C$. virginica. Fish. Bull. 63(3): 643-655.

Doall, M.H., D.K. Padilla, C.P. Lobue, C. Clapp, A.R. Webb, and J. Hornstein. 2008. Evaluating northern quahog (= hard clam, Mercenaria mercenaria L.) restoration: are transplanted clams spawning and reconditioning? J. Shellfish Res. 27(5): 1069-1080.

DeVries, M.C., R.A. Tankersley, R.B. Forward, Jr., W.W. Kirby-Smith, R.A. Luettich, Jr. 1994. Abundance of estuarine crab larvae is associated with tidal hydrologic variables. Mar. Biol. 118: 403-413. 
Dickey, T.D. 2003. Emerging ocean observations for interdisciplinary data assimilation systems. J. Mar. Syst. 40-41: 5-48.

Eckman, J.E. 1987. The role of hydrodynamics in recruitment, growth, and survival of Argopecten irradians (L.) and Anomia simplex (D’Orbingy) within eelgrass meadows. J. Exp. Mar. Biol. Ecol. 106: 165-191.

Eggleston, D.B. and D.A. Armstrong. 1995. Pre- and post-settlement determinants of estuarine Dungeness crab recruitment. Ecol. Monogr. 65(2): 193-216.

Forward, R.B., Jr. and R.A. Tankersley. 2001. Selective tidal-stream transport of marine animals. Oceanogr. Mar. Biol. Annu. Rev. 39: 305-353.

Gaines, S.D. and M.D. Bertness. 1992. Dispersal of juveniles and variable recruitment in sessile marine species. Nature 360: 579-580.

Gaines, S.D., B. Gaylord, L.R. Gerber, A. Hastings, and B.P. Kinlan. 2007. Connecting places: the ecological consequences of dispersal in the sea. Oceanography 20(3): 22-39.

Gallager, S.M., J.L. Manuel, D.A. Manning, R. O’Dor. 1996. Ontogenetic changes in the vertical distribution of giant scallop larvae, Placopecten magellanicus, in 9-m deep mesocosoms as a function of light, food and temperature stratification. Mar. Biol. 124: 679-692.

Garland, E.D. 2000. Temporal variability and vertical structure in larval abundance: the potential roles of biological and physical processes. Doctoral dissertation.

Massachusetts Institute of Technology/Woods Hole Oceanographic Institution, Woods Hole, MA, 213 pp.

Gawarkiewicz, G., S. Monismith and J. Largier. Observing larval transport processes affecting population connectivity. Oceanography 20(3): 40-53.

Geyer, W.R. 1997. Influence of wind on dynamics and flushing of shallow estuaries. Est. Coast. Shelf Sci. 44: 713-722.

Gregg, C.S. 2002. Effects of biological and physical processes on the vertical distribution and horizontal transport of bivalve larvae in an estuarine inlet. Doctoral dissertation. Rutgers University, New Brunswick, NJ, 154 pp.

Grosberg, R.K. and D.R. Levitan. 1992. For adults only? Supply-side ecology and the history of larval biology. TREE 7(4): 130-133.

Hare, M.P., S.R. Palumbi, and C.A. Butman. 2000. Single-step species identification of bivalve larvae using multiplex polymerase chain reaction. Mar. Biol. 137: 953961.

Hedgecock, D., P.H. Barber, and S. Edmands. 2007. Genetic approaches to measuring connectivity. Oceanography 20(3): 70-79.

Hendriks, I.E., L.A. van Duren, P.M.J. Herman. 2005. Image analysis techniques: a tool for the identification of bivalve larvae? J. Sea Res. 54: 151-162.

Henzler, C.M., E.A. Hoaglund, S.D. Gaines. 2010. FISH-CS - a rapid method for counting and sorting species of marine zooplankton. Mar. Ecol. Prog. Ser. 410: 111.

Herter, H. and G.L. Eckert. 2008. Transport of Dungeness crab Cancer magister megalopae into Glacier Bay, Alaska. Mar. Ecol. Prog. Ser. 372: 181-194. 
Howes, B., W.W. Kelley, J.S. Ramsey, R. Samimy, D. Schlezinger, T. Ruthven, E. Eichner. 2004. Linked Watershed-Embayment Model to Determine Critical Nitrogen Loading Thresholds for the Quashnet River, Hamblin Pond, and Jehu Pond, in the Waquoit Bay System in the Towns of Mashpee and Falmouth, Massachusetts. Massachusetts Estuaries Project, Massachusetts Department of Environmental Protection. Boston, MA.

Janzen, C.D., and K.C. Wong. 1998. On the low-frequency transport processes in a shallow coastal lagoon. Estuaries 21(4B): 754-766.

Jones, G.P., S. Planes, S.R. Thorrold. 2005. Coral reef fish larvae settle close to home. Curr. Biol. 15: 1314-1318.

Jordan, T.E. and I. Valiela. 1982. A nitrogen budget of the ribbed mussel, Geukensia demissa, and its significance in nitrogen flow in a New England salt marsh. Limnol. Oceanogr. 27(1): 75-90.

Kassner, J. and R.E. Malouf. 1982. An evaluation of "spawner transplants" as a management tool in Long Island's hard clam fishery. J. Shellfish Res. 2(2): 165 172.

Keck, R.T., D. Maurer, H. Lind. 1975. A comparative study of the hard clam gonad developmental cycle. Biol. Bull. 148: 243-258.

Kjerfva, B. and T.G. Wolaver. 1988. Sampling optimization for studies of tidal transport in estuaries. American Fisheries Society Symposium 3: 26-33.

Largier, J.L. 2003. Considerations in estimating larval dispersal distances from oceanographic data. Ecol. App. 13(1): S71-S89.

Larsen, J.B., M.E. Frischer, L.J. Rasmussen, B.W. Hansen. 2005. Single-step nested multiplex PCR to differentiate between various bivalve larvae. Mar. Biol. 146: 1119-1129.

Levin, L.A. 1986. The influence of tides on larval availability in shallow waters overlying a mudflat. Bull. Mar. Sci. 39(2): 224-233.

Lewin, R. 1986. Supply-side ecology. Science 234: 25-27.

Litaker, W., C.S. Duke, B.E. Kenney, and J. Ramus. 1987. Short-term environmental variability and phytoplankton abundance in a shallow tidal estuary. Mar. Biol. 96: 115-121.

Loosanoff, V.L., W.S. Miller, P.B. Smith. 1951. Growth and setting of larvae of Venus mercenaria in relation to temperature. J. Mar. Res. 10: 59-81.

Loosanoff, V.L. 1961. Partial metamorphosis in Anomia simplex. Science 133: 20702071.

Lutz, R. J. Goodshell, M. Castagna, S. Chapman, C. Newell, H. Hidu, R. Mann, D. Jablonski, V. Kennedy, S. Siddall, R. Goldberg, H. Beattie, C. Galmagne, A. Chestnut, and A. Partridge. 1982. Preliminary observations on the usefulness of hinge structures for identification of bivalve larvae. J. Shell. Res. 2(1): 65-70.

Ma, H. 2005. Spatial and temporal variation in surfclam (Spisula solidissima) larval supply and settlement on the new Jersey inner shelf during summer upwelling gand downwelling. Estuar. Coast Mar. Sci. 62: 41-53.

Mann, R. 1988. Distribution of bivalve larvae at a frontal system in the James River, Virginia. Mar. Ecol. Prog. Ser. 50: 29-44. 
Manuel, J.L., S.M. Gallager, C.M. Pearce, D.A. Manning, and R.K. O’Dor. 1996. Veligers from different populations of sea scallop Placopecten magellanicus have different vertical migration patterns. Mar. Ecol. Prog. Ser. 142: 147-183.

Morgan, S.G. 2001. The larval ecology of marine communities. In: Bertness, E.D., S.D. Gaines, and M.E. Hay (ed) Marine Community Ecology. Sinauer Associates, Inc., Sunderland, MA pp 159-181.

Natunewicz, C.C. and C.E. Epifanio. 2001. Spatial and temporal scales of patches of crab larvae in coastal waters. Mar. Ecol. Prog. Ser. 212: 217-222.

North, E.W., Z. Schlag, R.R. Hood, M. Li, L. Zhong, T. Gross, V.S. Kennedy. 2008. Vertical swimming behavior influences the dispersal of simulated oyster larvae in a coupled particle-tracking and hydrodynamic model of Chesapeake Bay. Mar. Ecol. Prog. Ser. 359: 99-115.

Orson, R.A. and B.L. Howes. 1992. Salt marsh development studies at Waquoit Bay, Massachusetts: influence of geomorphology on long-term plant community structure. Est. Coast. Shelf Sci. 3: 453-471.

Palmer, M.A., J.D. Allan and C.A. Butman. 1996. Dispersal as a regional process affecting the local dynamics of marine and stream benthic invertebrates. Trends Ecol. Evol. 11(8): 322-326.

Paris, C.B. and R.K. Cowen. 2004. Direct evidence of a biophysical retention mechanism for coral reef fish larvae. Limnol. Oceanogr. 49(6): 1964-1979.

Paris, C.B., R.K. Cowen, R. Claro, K.C. Lindeman. 2005. Larval transport pathways from Cuban snapper (Lutjanidae) spawning aggregations based on biophysical modeling. Mar. Ecol. Prog. Ser. 225: 299-310.

Perino, L.L., D.K. Padilla, and M.H. Doall. 2008. Testing the accuracy of morphological identification of northern quahog larvae. J. Shellfish Res. 27(5): 1081-1085.

Peterson, C.H. and H.C. Summerson. 1992. Basin-scale coherence of population dynamics of an exploited marine invertebrate, the bay scallop: implications of recruitment limitiation. Mar. Ecol. Prog. Ser. 90:257-272.

Peterson, C.H., H.C. Summerson, and J. Huber. 1995. Replenishment of hard-clam stocks using hatchery seed: combined importance of bottom type, seed size, planting season, and density. J. Shellfish Res. 14(2) 293-300.

Peterson, C.H., H.C. Summerson, R.A. Luettich, Jr. 1996. Response of bay scallops to spawner transplants: a test of recruitment limitation. Mar. Ecol. Prog. Ser. 132: 93-107.

Pineda, J. 1991. Predictable upwelling and the shoreward transport of plankton larvae by internal tidal bores. Science 53: 548-551.

Pineda, J., J.A. Hare, and S. Sponaugle. 2007. Larval transport and dispersal in the coastal ocean and consequences for population connectivity. Oceanography 20(3): 22-39.

Pringle, J.M. and P.J.S. Franks. 2001. Asymmetric mixing transport: A horizontal transport mechanism for sinking plankton and sediment in tidal flows. Limnol. Oceanogr. 46(2): 381-391. 
Raby, D., Y. Lagadeuc, J.J. Doson, M. Mingelbier. 1994. Relationship between feeding and vertical distribution of bivalve larvae in stratified and mixed waters. Mar.

Ecol. Prog. Ser. 103: 275-284.

Roegner, G.C. 2000. Transport of molluscan larvae through a shallow estuary. J. Plankton Res. 22(9): 1779-1800.

Roughgarden, J. S. Gaines, and H. Possingham. 1988. Recruitment dynamics in complex life cycles. Science 241: 1460-1466.

Scheltema, R.S. 1986. On dispersal and planktonic larvae of benthic invertebrates: an eclectic overview and summary of problems. Bull. Mar. Sci. 39(2): 290-322.

Scheltema, R.S. 1988. Initial evidence for the transport of teleplanic larvae of benthic invertebrates across the East Pacific Barrier. Biol. Bull.

Seabergh, W.C. Observations on inlet flow patterns derived from numerical and physical modeling studies. American Fisheries Society Symposium 3: 16-25.

Seliger, H.H., J.A. Goggs, R.B. Rivkin, W.H. Biggley, and K.R.H. Aspden. 1982. The transport of oyster larvae in an estuary. Mar. Biol. 71: 57-72.

Siegel, D.A., B.P. Kinlan, B. Gaylord, S.D. Gaines. 2003. Lagrangian descriptions of marine larval dispersion. Mar. Ecol. Prog. Ser. 260: 83-96.

Sponaugle, S., R.K. Cowen, A. Shanks, S.G. Morgan, J.M. Leis, J. Pineda, G.W. Boehlert, M.J. Kingsford, K.C. Lindeman, C. Grimes and J.L. Munro. 2002. Predicting self-recruitment in marine populations: biophysical correlates and mechanisms. Bull. Mar. Sci. 70(1): 341-375.

Strathmann, R.R. 1985. Feeding and nonfeeding larval development and life-history evolution in marine invertebrates. Annu. Rev. Ecol. Syst. 16: 339-361.

Thorson, G. 1950. Reproductive and larval ecology of marine bottom invertebrates. Bio. Rev. 25: 1-45.

Tiwari, S. and S.M. Gallager. 2003a. Optimizing multiscale invariants for the identification of bivalve larvae. Proceedings of the 2003 IEEE International Conference on Image Processing, Barcelona, Spain, September 14-17, 2003.

Tiwari, S. and S. Gallager. 2003b. Machine learning and multiscale methods in the identification of bivalve larvae. Proceedings of the Ninth IEEE International Conference on Computer Vision, Nice, France, October 14-17, 2003.

Tremblay, M.J. and M. Sinclair. 1990. Diel vertical migration of sea scallop larvae Placopecten magellanicus in a shallow embayment. Mar. Ecol. Prog. Ser. 67(1): $19-25$.

Todd, C.D. 1998. Larval supply and recruitment of benthic invertebrates: do larvae always disperse as much as we believe? Hydroiologia 375/376: 1-21.

Tomasky-Holmes, G. 2008. Nutrient supply, water residence time, temperature, and grazing as controls of size-fractionated phytoplankton biomass in shallow temperate estuarine ecosystems. Ph.D. thesis, Boston University, Boston, MA.

Townsend, D.W. and L.M. Cammen. 1988. Potential importance of the timing of spring plankton blooms to benthic-pelagic coupling and recruitment of juvenile demersal fishes. Biol. Oceanogr. 5: 215-229. 
Underwood, A.J. and M.J. Keough. 2001. Supply-side ecology: the nature and consequences of variations in recruitment of intertidal organisms. In: Bertness, E.D., S.D. Gaines, and M.E. Hay (ed) Marine Community Ecology. Sinauer Associates, Inc., Sunderland, MA pp 183-200.

Vadopalas, B., J.V. Bouma, C.R. Jackels, C.S. Friedman. 2006. Application of real-time PCR for simultaneous identification and quantification of larval abalone. J. Exp. Mar. Biol. Ecol. 334: 219-228.

Valiela, I., K. Foreman, M. LaMontagne, D. Hersh, J. Costa, P. Peckol, B. DeMeoAnderson, C. D’Avanzo, M. Babione, C. Sham, J. Brawley, K. Lajtha. 1992. Couplings of Watersheds and Coastal Waters: Sources and Consequences of Nutrient Enrichment in Waquoit Bay, Massachusetts. Estuaries 15(4): 443-457.

Welch, J.M., R.B. Forward, Jr., and P.A. Howd. 1999. Behavioral responses of blue crab Callinectes sapidus postlarvae to turbulence: implications for selective tidal stream transport. Mar. Ecol. Prog. Ser. 178: 135-143.

Wiseman, W.J., W.W. Schroeder, and S.P. Dinnel. 1988. Shelf-estuarine water exchanges between the Gulf of Mexico and Mobile Bay, Alabama. American Fisheries Society Symposium 3: 1-8.

Yamazaki, H., D.L. Mackas, K.L. Denman. 2002. Coupling small-scale physical processes with biology. In: Robinson, A.R., J.J. McCarthy, and B.J. Rothschild (ed) The Sea. John Wiley \& Sons, Inc., New York, NY pp 51-104. 


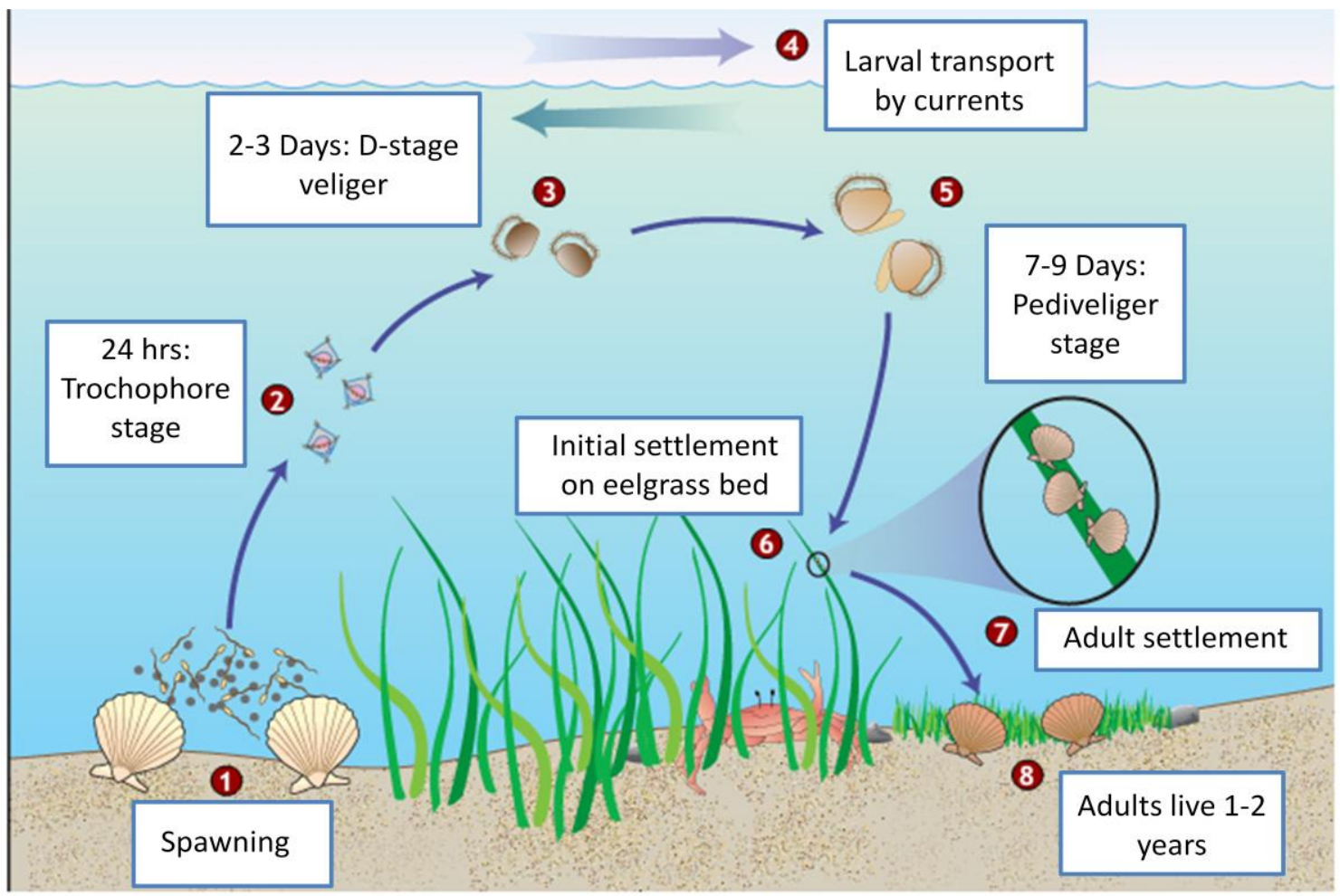

Figure 1.1 Life cycle diagram of a bivalve scallop. (1) Adults spawn by releasing gametes into the water column where they fertilize. (2) First developmental stage consists of a ciliated trochophore lasting up to 24 hours. (3) The larval shell forms, and the larva persists as a ciliated veliger for a few days. (4) During the pelagic larval period, larvae are subjected to transport and dispersal by currents. (5) By the pedi-veliger stage, the shell takes on a more rounded, umbonate form and the larva develops an appendage called a foot. (6) Settlement occurs when pedi-veligers encounter suitable substrate and metamorphose. (7) In the case of scallops, adult settlement occurs when juveniles detach from eelgrass blades. (8) Adult scallops live for a few years and reproduce the following spring/summer. (Diagram by Jack Cook, Woods Hole Oceanographic Institution) 


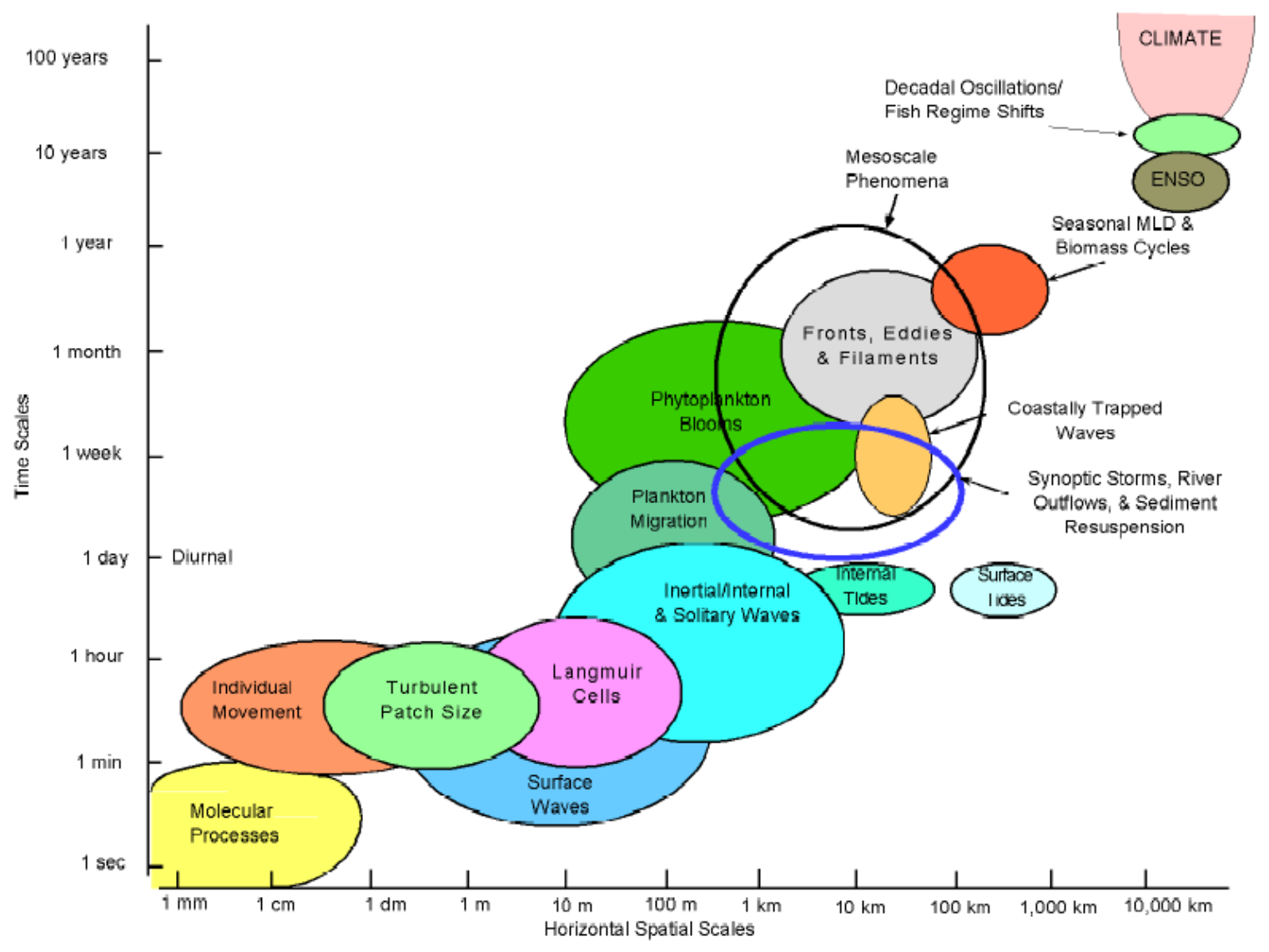

Figure 1.2 Spatial and temporal diagram of physical processes affecting biological processes. Circles represent physical processes, and the size of each circle corresponds to the space and time scales on which they act. Figure adapted from Dickey 2003. 


\section{CHAPTER 2}

Automated Image-Analysis for the Identification of Bivalve Larvae from a Cape Cod Estuary 


\begin{abstract}
Machine learning methods for identifying planktonic organisms are becoming well-established in marine science. Although similar morphologies among species make traditional image identification methods difficult for larval bivalves, species-specific shell birefringence patterns allow color and texture-based features to distinguish species. This approach uses Gabor and color angle feature-selection algorithms on polarized images of bivalve larvae, and image classifications are made using Support Vector Machine software. We adapted this method which was established on hatchery-reared larvae to identify bivalve larvae from a series of field samples from a Cape Cod estuary in 2009. This method showed up to $99 \%$ overall accuracy on four hatchery reared species. We used a multiplex-PCR method to confirm field identifications and to compare accuracies to the software classifications. Field classified larvae had lower accuracies with the identification software due to error in classifying unknown larvae and variability in larval images from the field. Our six-species field training set had the best correspondence to our manual classifications with $75 \%$ overall agreement and individual species agreements from $63-88 \%$. The biggest issue with our field identification accuracies was the large occurrence of false-positive identifications from species not represented in our training sets. This error was improved as much as $30 \%$ by adding correction methods. Overall, this approach represents a less expensive and less time-consuming alternative to molecular-based identifications that can produce sufficient results to address long-term abundance and transport-based questions on a species-specific level, a rarity in studies of bivalve larvae.
\end{abstract}




\subsection{INTRODUCTION}

The larvae of many coastal benthic invertebrates have complex life cycles that begin with a pelagic larval stage lasting from a few days to weeks. During development, larvae are passively transported by ocean currents (Thorson 1950, Scheltema 1986). Studies of invertebrate larval dispersal have been met by challenges associated with small sizes of individuals, high mortality, and patchiness over large spatial scales (Boicourt 1988, Garland 2000, Pineda et al. 2007). Particularly for bivalve larvae, it is difficult to achieve species-specific field studies because of an inability to accurately identify early stage larvae (Garland 2000, Garland and Zimmer 2002, Gregg 2002). Since larvae can exhibit species-specific behaviors in the field (Shanks and Brink 2006), one cannot accurately assess transport if species identity is unknown. This is especially important when considering populations of commercially important species, as an understanding of larval transport is necessary to address management questions concerning species productivity and decline, shellfish enhancement through seeding, and habitat restoration efforts (Gregg 2002).

Once a larval bivalve begins shell mineralization (usually 20 hours postfertilization), most species proceed to a straight-hinge (veliger) stage followed by transformation to a more rounded, umbonate (pedi-veliger) stage after several days (Chanley and Andrews 1971). It is particularly difficult to distinguish species of straighthinged larvae by morphological features alone, but as the larva develops, characteristic morphological changes can sometimes help distinguish species or genera. Photographs of cultured species are limited to those that can be raised in the laboratory and matching 
photographs to larvae from the field can often result in misidentification (Loosanoff et al. 1951). Electron-micrographs of the larva's hinge structure have historically been the standard for larval species identification (Lutz et al. 1982), but the labor required to perform these identifications is unrealistic for field studies. The pros and cons of more recent species-specific identification methods have been reviewed by Garland and Zimmer (2002) and Hendricks et al. (2005). It has been a challenge to develop a reliable and cost-effective solution for larval identification that can handle the large volume of samples required for many field studies. Current successful methods have involved multiplex PCR (Hare et al. 2000, Larsen et al. 2005) and fluorescent in situ hybridization with rRNA probes (Henzler et al. 2010), but each method has specific limitations on sample volume, specificity, and cost per sample.

Recently, advances in imaging technology have allowed for greater spatial and temporal resolution of plankton studies through optical sampling methods (Benfield et al. 2007). In-situ optical sampling instruments such as the Video Plankton Recorder (Davis et al. 1992), benchtop equipment such as FLOW-CAM (Sieracki et al. 1998), and laboratory-based scanning methods such as ZOOSCAN (Grosjean et al. 2004) have created a need for image recognition software to identify plankton based on characteristic features the computer reads from each image (Davis et al. 2004). The basic concept of computerized image processing is to create a reference set of known or manually sorted images that train the computer to recognize boundaries between each category and then use the categories made from this "training set" to assign unknown images from a sample. 
There are several requirements for image analysis of plankton. First, acquired images must be of sufficient quality to be easily recognized and handled by a computer. Second, there must be distinguishing image characteristics (or features) from each class of species or organism that the computer can recognize (i.e., shape and edge detection, texture analysis, pixel intensity). Thirdly, not every statistical classifier is optimal for analysis of a given image set, so there can be a lengthy start up time for optimizing image-processing techniques (Grosjean et al. 2004, Lou et al. 2005). Computer image analysis is not capable of discriminating images exactly as humans and is generally assumed to be less accurate than having a human expert carefully analyze microscope samples (Culverhouse et al. 2003). Overall, image identification of plankton samples must sacrifice some accuracy for the ability to handle and rapidly process large volumes of data. Concerns associated with computer speed and image handling are lessened as the technology for more powerful and faster computers becomes available.

The similar morphologies of veliger larvae make them less amenable to traditional identification methods using size features and black-and-white images (Hendriks et al. 2005), but color images of larvae under polarized light show distinct birefringence patterns (Tiwari and Gallager 2003a,b). Once a larva begins shell formation, each species uses a specific protein matrix to control the orientation of the aragonite crystals forming the shell. Mineralization continues throughout the larval phase as the shell changes shape. The orientation of the crystals creates color patterns under polarized light in combination with a full wavelength retardation filter. These colorpatterns are species-specific and can be used as features for machine identification 
(Tiwari and Gallager 2003a, b). This method can be applied to images of larvae from preserved samples as well as larvae optically sampled in the field using polarized light. In addition, since only color patterns are used as features, polarization techniques are insensitive to shell orientation, size and morphology (Tiwari and Gallager 2003a, b), eliminating many of the ambiguities involved in differentiating bivalve larvae.

Here we present an application of the polarization technology to larval bivalves from field-collected samples. Field larvae may grow at different rates and thus appear different than larvae from hatcheries and represent a larger number of species than can be featured in a reference set of larvae from monocultures. Using a reference set that doesn't accurately represent the sample composition could create misclassifications, particularly false-positives. We first compared classification data from training sets of four hatcheryreared species using shells with tissue ("raw," as seen in the field) and bleached shells not containing tissue ("clean," as used for the original classifications, see Tiwari and Gallager 2003a,b). We then optimized this method for the number of training set images to include, thus minimizing computing power and manual sorting time.

To test the ability of our method to identify field larvae, we applied a few groundtruthing methods. We employed DNA identification methods using multiplex PCR (Hare et al. 2000) and genetic database searches on a subset of control hatchery and wild field larvae. This was to ensure identification accuracy as well as compare our method to other available methods for bivalve larval identification. Then, from a set of weekly field samples taken from Waquoit Bay, MA over a six-month period, common bivalve species 
were sorted manually using keys (Chanley and Andrews 1971) and used to set up training sets based only on field larvae.

By using training sets specific for larvae from a Cape Cod estuary, we can generate species-specific data to better address questions related to larval transport, dispersal, and survival (Garland 2000). Because this method allows for training on any number of species for which one has known image sets, it can be extremely versatile. The polarization techinque is relatively inexpensive (only a computer and a polarization microscope are required) and has the potential to be used alongside a real-time optical sampling system (Gallager et al., submitted). Automated sampling capabilities complied with the polarization technique would allow for even greater spatial and temporal sampling than could be accomplished by any published larval identification method to date.

\subsection{MATERIALS AND PROCEDURES}

The approach for our image processing and sampling technique requires six key steps (Fig. 2.1a): (1) sample collection for field and hatchery reference larvae, (2) image acquisition using a polarization microscope, (3) image pre-processing to remove background image "noise", (4) image sorting to create "training sets" (reference sets of images of known species used to train the software classifier), (5) training set feature extraction and cross-validation, (6) classification of unknown images using a support vector machine (SVM). For the following sections, a reference to "computer" identifications refer to the results of the classification software, and "manual" identifications are the identifications from manually sorting images. 
2.2.1 Sample Collection. Reference larvae were spawned from two Cape Cod aquaculture facilities between 2007 and 2010 and preserved in 80\% ethanol. Larvae of four commercially important species, Argopecten irradians (bay scallop), Crassostrea virginica (eastern oyster), Mercenaria mercenaria (quahog), and Mya arenaria (softshell clam), were sampled from cultures every 1-2 days after spawning (Table 2.1). We tested classification accuracy between larval stages, as we have observed that birefringence patterns change with larval growth. As the original work using this method was performed on larvae where the tissue had been bleached from the shell (Tiwari and Gallager 2003a), a subset of larvae was soaked in a 10\% bleach solution for 24 hours followed by rinsing with distilled water to create a reference set of larvae with tissue removed.

For our field collections, plankton samples were collected from Waquoit Bay, a National Estuarine Research Reserve site, on the south shore of Cape Cod, MA. Samples were taken at four locations throughout the estuary on a weekly basis from May October 2009. Volumes of 100-200 L were collected in a $53 \mu \mathrm{m}$ screen and preserved in $4 \%$ buffered formalin. Samples were processed by counting total bivalve larvae using a dissecting microscope. A more detailed description of the field sampling protocol is described in Chapter 3.

2.2.2 Image Acquisition. All images were taken using a Moticam 10004 megapixel camera mounted on a Zeiss IM 35 compound microscope fitted with a polarization filter and full wave compensation plate to make cross-polarized images (see Fig. 2.2 for optical path setup). A $12 \mathrm{~V} 100 \mathrm{~W}$ halogen bulb was used as light source. We 
used Motic Images Plus (version 2.0; Motic China Group, Ltd.) to capture images with the color and exposure settings for the image capture window set to match the appearance of the larvae under the microscope. For the hatchery samples, 100 images of larvae were taken from each sample to total over 3000 images representing different larval stages (Table 2.1, Fig. 2.1b). For the field samples, 100 images of larvae were taken from each sample resulting in a field set of over 7,000 images. All larvae were imaged on a glass slide with coverslip in distilled water.

2.2.3 Image Pre-Processing. Before images could be run through the classification software, we had to complete pre-processing steps to segment the larva, or region of interest (ROI), from its background. All image analysis routines were run with the MATLAB software package (version R2009a; Mathworks, Inc.) and its Image Processing Toolbox (version 6.3; Mathworks, Inc.). Pre-processing was done through an automated Canny edge routine to detect the shell's edges, set them against a black background, and crop the image to the area of interest. In a few cases where this routine failed (i.e. too much background or overlapping shapes with the larvae), the preprocessing was performed using a manual ROI masking routine in MATLAB.

2.2.4 Image Sorting. We set up training sets from both the hatchery (known) and field (unknown) images for comparison. We used field identification guides of Chanley and Andrews 1971 and Loosanoff et al. 1966 for morphology and size criteria to manually sort unknown images from field samples into training sets. Molecular analysis for some of these species, as explained later, provided further verification of our identifications. We sorted all of the field images into a total of 14 different species 
categories plus an "other" category. For the six species that were most abundant, we created training sets of 250, and 400-500 images per species by randomly selecting manually classified larvae. We created a second training set containing 250 images for each of nine species. Images from the hatchery were manually sorted to ensure each training set had equal representation from all size-classes, and then images were randomly sorted into different sized training sets.

\subsubsection{Feature Extraction and Cross-Validation: Training sets. Each image}

from our training sets was run through feature extraction software and classification accuracy was evaluated by using a leave-one-out cross-validation method (LOO). Training was done with an established set of images representing the groups of interest (termed "supervised" learning). In feature extraction, the computer software calculates the specific features from an image in a mathematical context and stores each feature in an $n$-dimenstional space, where $n$ corresponds to the number of features extracted.

We used MATLAB to calculate both Gabor and color-angle features to represent the texture and color features of each polarized image. Gabor Fast-Fourier Transform data was generated from the spatial domain of Gabor wavelets from a number of scales and rotations of the original image using parameters as described in Tiwari and Gallager 2003b. Rotation and size invariant red, green, and blue Gabor features were calculated from the magnitudes of Discrete Fourier Transforms of the Gabor feature matrix. The total feature set consisted of 4 scales and 90 orientations for three RGB (Red, Green, Blue) color channels to achieve a 1080 dimensional feature space. Color edge and distribution angles were calculated from HSV (Hue, Saturation, and Value) components 
of the image as defined in Tiwari and Gallager 2003b and converted to true angles. Nine invariants of the color image matrix were included in the feature space. Extracted feature data were represented as Principal Component Analysis (PCA) scores for both the Gabor and color statistic matrices for each image. The 25 most significant eigenvectors from the PCA on the Gabor features and all the color statistics were used for the classifications.

Next, a statistical classifier (the SVM) sorted the vectorized feature data and mapped it to an $n$-dimensional space based on the number of features. For training sets, each region in this $n$-dimensional space corresponded to a different taxa based on the features, creating a boundary for future decisions. We used an SVM with a Gaussian Radial Basis Function (RBF) Kernel of $\gamma=2$ and regularization parameter $\mathrm{C}=70 . \mathrm{A}$ standard LOO cross-validation method using the SVM output was then run on every image in the training set to ensure that it was set up to classify unknown images accurately (Fukunaga and Hummels 1989). The LOO method iterates through each image in the training set, and trains the SVM classifier with every image except the current image, and uses those boundaries to make the decision to classify the left-out image. The leave-one-out method assigns an accuracy based on which training images fall into which categories and how many fall into an "unknown" category. While this is absolute for the hatchery training sets, the accuracy for the manually classified training sets varies because of human classification error, and for the purposes of this paper is reported as "agreement."

2.2.6 Classification: Unknown Images. Once the training set has been created and evaluated for accuracy, the next step is to use it to classify unknown images from the sample set. The 
process works by loading images from samples (so in the case of the field samples, the software will load the 100 images in each sample) and extracting the same Gabor texture, shape, and color features as the labeled training images.

The feature sets from each training image are then used to train the SVM classifier. We combined an SMO (Sequential Minimal Optimization) training algorithm and a DAG-SVM (Directed Acyclic Graph-Support Vector Machine) algorithm to form a multi-class neural network for a one-to-one SVM classifier. Only the most influential features from the training set vectors were used to train the classifier. The feature vectors from each unknown image are then run through the support vector machine to make a classification. Each image from the training set is also classified during this process using the support vectors created for the classifications to test the accuracy of the particular classifier.

\subsection{ASSESSMENT}

To assess the performance, accuracy, and versatility of our image analysis method, we performed three categories of assessment tests: hatchery training sets to optimize conditions for training set creation; a PCR-based method to verify identifications of field larvae and to compare identification results with our computer classifier; and a field application using a manually classified training set to identify species from a time series of larval samples. Finally, computer-classified data is compared to manually classified data for the field image set.

2.3.1 Optimizing Training Sets. We performed several iterations of training and LOO cross-validation using the hatchery training set as a model for how our method 
works under ideal conditions. This is because the larval species were known, larvae were grown under equal and ideal food and light conditions at both facilities, and the images contain equal representation of all age classes and thus morphological features of the larvae.

The original work for this method was performed on cleaned images with tissues removed (Tiwari and Gallager 2003a,b). We wanted to compare the accuracy of training sets of larvae with tissue present to cleaned images. Since larvae collected from the field originally contain tissue, by not bleaching larvae we can eliminate a pre-processing step as well as enable in-situ image collection or molecular analysis. We extracted training features from 3,256 labeled raw images and 2,993 labeled bleached images from the hatchery image sets (Table 2.1) and classified the images using the LOO method. Classification data from the LOO method is presented as a confusion matrix (Table 2.2). The overall accuracies for both raw and bleached training sets were similar and very high (99\%), with those of the raw images only being slightly lower than the bleached images. Species-specific accuracies varied from $97-99 \%$ which confirms that these four species are easily distinguished by the classifier. Thus, we determined using uncleaned shells has no effect on classification accuracy.

The second optimization procedure we performed with the hatchery data sets was to compare the LOO accuracies using different sized training sets. This was to determine the approximate number of images necessary to maximize performance and minimize computing power and sorting or acquisition time. We calculated classification accuracy from randomly selected hatchery images of all sizes sorted into groups of 100, 200, 300 
and 500 images for each species (Fig. 2.3a). Accuracies increased slightly overall and for each species as training set size increased, but even at the smallest sample size of 100 images/species, accuracies only decreased by $1-2 \%$. This suggests that this method is robust for even small numbers of images for each category, provided that the training images are classified without error (as they were for this training set).

A third element we tested was classifier performance on different age classes of larvae because each training set contains combinations of images representing different larval stages. We looked at classification accuracies for larvae that were 2, 5 and 7 days old as part of the 500 images per species training set that was evaluated using the LOO technique. Accuracies were highest for the seven day old larvae and lowest for the five day old larvae, but overall accuracies were high between 97-99\% (Fig. 2.3b). Accuracies were between $93-100 \%$ for individual species at each age group. Thus, the classifier is consistent at identifying species throughout their development regardless of shell size.

Finally, to test our classification method on "unknown" images, we trained the classifier with 250 images from each species category of the 500 image/species training set, and used the remaining images as "unknown" larvae to be classified. This method has been referred to as the holdout method (Fukunaga and Hummels 1989) and provides the most stringent estimate of classifier accuracy. The classification accuracies for these "unknown" images ranged from 96.8-100\% for each age group (Table 2.3), thus demonstrating strong performance of the classifier on known hatchery images.

2.3.2 Comparison with Molecular Method. In order to achieve higher accuracy with our manual identifications of field larvae and to compare our image- 
processing method to an independent method of larval identification, we used a multiplex PCR method targeted to identify five species of bivalves from field samples (Hare et al. 2000). Species targeted were M. mercenaria, A. irradians, M. arenaria, Mulinia lateralis (little surf clam), and Spisula solidissima (surf clam). Live (unpreserved) plankton samples were collected from Waquoit Bay on three dates in June and July 2008 and five dates from May-September 2009. Individual larvae were isolated and placed into separate wells in $1.5 \mathrm{~mL} 24$-well glass-bottom plates to culture in the laboratory. A total of 24 larvae were isolated from three sites in 2008 and four sites in 2009. Every three days larvae were fed Isochrysis galbana strain T-ISO at a concentration of $5 \times 10^{4}$ cells $/ \mathrm{mL}$ and imaged live on the polarization microscope. This resulted in a series of images for each larva depicting morphological changes over 12 days (our expected time to metamorphosis for most species). All larvae that survived were washed into $8 \mathrm{~mL}$ vials and preserved in $70 \%$ ethanol for molecular analysis.

In the molecular analysis, DNA was extracted from the ethanol-preserved larvae and used in multiplex polymerase chain reaction (PCR) assays containing five speciesspecific primer pairs mapping to the cytochrome oxidase I (CO1) gene and a universal 18S-rRNA primer pair as a positive control. Each primer pair amplified a different length DNA fragment. Specific details of primer design, larval DNA extraction and PCR assays can be found in Hare et al. (2000). Only reactions prepared from a master mix for which no amplification products appeared in the negative (no DNA) control reaction were used for comparison with images. A total of 31 larvae from 2008 and 50 larvae from 2009 were analyzed, for a combined total of 81 larvae and 355 images from each larva's 
growth period (Table 2.4). As a control for the multiplex PCR, 20 hatchery larvae of $A$. irradians, M. mercenaria, and $M$. arenaria were both amplified and imaged. These results were later used to compare true accuracies of the PCR and image analysis methods.

About half of the field PCR samples only amplified at the 18S locus, and those reactions were re-amplified with only the $18 \mathrm{~S}$ primers using the same PCR parameters from the multiplex reactions. Sequencing this 430 base-pair band provided a way to identify field larvae that were not targeted by multiplex $\mathrm{CO} 1$ primers, as it can be diagnostic for some bivalve families and genera (Bell and Grassle 1998). Successful PCR products from the $18 \mathrm{~S}$ re-amplification were purified using the QIAquick PCR Purification kit (Qiagen) and used in one-eighth format sequencing reactions in 96-well plates using Big Dye terminators (version 3, Perkin-Elmer). Samples were purified by isopropanol precipitation and sequenced bi-directionally on an ABI 3700 Capillary Sequencer. Sequences were edited in Sequencher 4.8 (Gene Codes Corporation Inc.) and compared to the GenBank universal database for species identification using BLAST searches (National Center for Biotechnology Information database). A few sequences that did not match with species located in the Cape Cod region were assumed to be from species not represented in GenBank and left out of further analysis.

To verify that our 18S DNA sequence identifications from the BLAST searches correctly corresponded to known Cape Cod species, we extracted DNA from five adult bivalve species to compare with our larval sequences. Adult DNA from the ribbed mussel Geukensia demissa, clams M. mercenaria, M. arenaria, and Spisula solidissima, and 
oyster $C$. virginica were extracted from adult muscle tissue using the QIAquick DNeasy Blood and Tissue kit (Qiagen) following manufacturers protocols. We amplified the 18S region using only the universal $18 \mathrm{~S}$ primers and same PCR parameters as previously described. We aligned the adult and larval sequences using ClustalX v. 1.83, viewed and edited them by eye using McClade 4.06 (Maddison and Maddison 2000), and trimmed our alignments to a $301 \mathrm{bp}$ region of uniformly high quality data. We used the Kimura two parameter (K2P) distance model (Kimura 1980) to calculate nucleotide sequence divergences between larval and adult sequences. We then employed a neighbor-joining analysis based on sequence divergence in MEGA4 (Tamura et al. 2007) using a bootstrap/jackknife procedure of 1000 replicates using $C$. virginica as the outgroup. We found that all larvae that were classified as G. demissa, M. mercenaria, or S. solidissima in GenBank also had 0 sequence divergences with the $18 \mathrm{~S}$ sequence obtained for these species. The other two species had $18 \mathrm{~S}$ sequences that were at least $3 \%$ divergent from the most similar larval sequences, indicating that these species were not represented among the collected larvae. Based on the sequence divergence for different bivalve families for this region of the gene (Bell and Grassle 1998), we can conclude that these identifications using the $18 \mathrm{~S}$ rRNA are accurate and any disagreement between the image and the sequence identification would thus be a result of human misclassification or error in sample preparation.

In order to estimate an error rate for the PCR multiplex method, we used 60 control larvae from the hatcheries in the assay (Table 2.5). No false positives (the case of a wrong CO1 band amplification) were reported for these assays, but $15-35 \%$ of the 
samples were false negatives (the case of an $18 \mathrm{~S}$ band, but no CO1 band when it was expected). This indicates that the multiplex method itself is not always informative for species-specific identifications based on $\mathrm{CO} 1$ results, but accurate when it is informative. No follow-up 18S data were collected for these samples. We then compared the identifications of the PCR and computer image analysis for these control larvae. We ran our larval classifier using a training set for $A$. irradians, $M$. mercenaria, and $M$. arenaria on the 60 images of larvae on which we performed PCR. Total PCR accuracies were between $65-85 \%$ (described above) compared to computer accuracies of $80-90 \%$ (Table 2.5). Combining the positive CO1 results to correct image classifications showed a 69 93\% agreement between the two methods.

Computer accuracies for these images were lower than those previously reported for the hatchery larvae probably because we used a different three-species training set of hatchery species that only comprised about 60-80 images per species. The higher number of errors observed in the PCR method are due to the many false negatives in the PCR assays. This was also seen for field samples of both $M$. mercenaria and S. solidissima. In these field samples there was no species-specific CO1 amplification, but the 18S sequencing confirmed the identification. Had we not done this extra step, it would have been classified as a false-negative. Thus, even a DNA-based classification approach can have error, which may be a result of poor quality DNA from preserved field samples (Larsen et al. 2005). Our control results indicate that errors of up to $30 \%$ could be expected when comparing unknown PCR identified larval images to image classification results as described below. 
In order to compare the unknown larvae from the field identified using PCR to the computer classification method, we created a new training set featuring species abundant in the field image set. G. demissia was added to the training set since we were able to create positive image identifications from BLAST matches to larval 18S sequences. To ensure adequate representation for the training set, we added 400 manually sorted images of $G$. demissa that were independent of the PCR images. We did not have enough representation of field-collected S. solidissima in our molecular data to include these images as a training set. Our new hybrid training set included 500 manually sorted $G$. demissa images, 250 hatchery training set images of $M$. mercenaria and M. arenaria, and 250 manually sorted and genetically verified field images of those two species. We did not classify any images based on PCR results indicating unknown or other species in order to minimize error. For G. demissa and M. arenaria, $81 \%$ and $84 \%$, respectively, of the larval images that had been verified with PCR agreed with the computer classifications (Table 2.6). These values are within the range of the errors from the control assessment with hatchery larvae. There was only 55\% agreement between molecular identified and computer classified larvae for M. mercenaria, which was lower than what was expected based on the control results. It seemed as if the PCR was amplifying a false-positive band with $G$. demissa larvae, which was later verified on adult G. demissa showing amplification of a fragment at the M. mercenaria $\mathrm{CO} 1$ size range in multiplex PCR. It may be that the M. mercenaria $\mathrm{CO} 1$ primers are not species-specific with respect to G. demissa, a non-target species never tested in the original method development (Hare et al. 2000). Overall, the molecular method enabled us to get positive 
identifications on field larvae from several species that had corresponding images throughout the larval period. This helped us reduce classification error for our manually sorted field training sets.

2.3.3 Field Application. The final assessment and proof of concept was testing classifier performance on an unknown field sample set compared with manuallyclassified training sets made from the field images. Our manual training sets consisted of species that were most common in the field samples. Of the species in our hatchery training set, only $M$. arenaria and $M$. mercenaria were present in large quantities in our field images, and A. irradians and C. virginica composed only about $2 \%$ of the total images. Initial classifications of field images using the hatchery training set only classified larvae as A. irradians or M. mercenaria. Thus, we determined the hatchery training set would not be an accurate representation of the larvae in our samples and would lead to a disproportionate amount of false positive results. We expected the classification accuracies of the manual training set to be lower than our hatchery training set because 1) these images were manually sorted and thus subject to human error and bias, 2) the quality and appearance of field-preserved larvae in images is slightly less than those from the hatcheries because of fungal and other particulate matter that sometimes clouded the image of the shell, and 3) not all growth stages would be equally represented due to the higher larval mortalities seen in field conditions.

To first test our accuracies for manual classification using known hatchery larvae, we had an inexperienced assistant sort four groups of 100 images representing random assortments of all ages of the four hatchery species. These images were then randomized 
for each group and renamed with generic filenames to make a double-blind test. Each group was then manually re-classified for the four species. Results for the human classifications produced accuracies ranging from $85-100 \%$ for each species (Table 2.7). Culverhouse et al. (2003) showed that human performance in classifying phytoplankton images can vary between $67-83 \%$, which alone could introduce substantial variability into a manually-classified training set. Sorting accuracies were highest for species like $C$. virginica that have distinct morphologies. Our calculated accuracies represent a minimum estimate for human sorting error as we only performed this test on four species.

We compared the agreements of the computer classifier on manually sorted training sets with field larvae from six and nine species and compared sizes of 500 and 250 images per species on six species. Identifications were based on the morphological and molecular criteria described previously. Any groups we could not identify with certainty were left out of the training sets, as these showed poor LOO results in initial tests. Agreement of field larvae with manual classifications was lower than the hatchery and live field sorted training sets, likely due to the error in human sorting. Sorting field images present more challenges as field samples contain mostly smaller, straight-hinged veligers. Not only are these more difficult to classify, but they could also bias the classifier by overtraining it with smaller larvae.

For the six-category training set (Table 2.8), agreements were highest for the 500 images per species training set, being above $60 \%$ for all species, with a total agreement of $74.7 \%$. This demonstrates that manually sorted images are more sensitive to training set size than our hatchery training set, with agreements improving by as much as $11 \%$ from 
250 images to 500 . The additional three species were not present in quantities greater than 250, thus this became our limit for image composition for this training set. For the nine-category training set, accuracies were lower compared to the six-category training set (Table 2.9). Total accuracy was 66\%, but accuracies below 60\% were observed for four species, including M. arenaria and M. mercenaria. By adding more species to this training set, we increased the chances for misclassification into another species category by about $10 \%$. In general, classification accuracy increases with increasing number of training images, but can decrease as the number of categories increases. This result has been demonstrated in other image processing methods (Davis et al. 2004, Grosjean et al. 2004). Increasing the number of categories in our training sets can make identifications more difficult as the decision boundaries between species categories are more likely to overlap.

We used both six and nine species training sets to classify all images from one sampling site in the middle of Waquoit Bay. We present results for two species with high classification accuracies (Anomia simplex, the jingle clam and G. demissa), and two species with lower accuracies (M. arenaria and M. mercenaria) as the number of individuals identified for each sample plotted as a time-series (Fig. 2.4). We compared our manual classification results to the classification results of the two training sets. The time-series for A. simplex and G. demissa show strong correspondence (Fig. 2.4a, b) for both training sets, capturing the trends of the time-series. For $M$. arenaria and $M$. mercenaria, correspondence was less. The nine-species training set underestimated $M$. arenaria abundance in the beginning and end of the time-series, and the six-species 
training set overestimated M. arenaria abundance (Fig. 2.4c). For M. mercenaria, the sixspecies training set overestimated its abundance for most of the time-series (Fig. 2.4d), but the nine-species training set tracked the manual time-series closely despite having a lower LOO agreement for M. mercenaria. Evaluating the graphs alone, it appeared that the six-category training set fit all species better with the exception of M. mercenaria.

Although our time-series showed agreement between our manually sorted larvae and the computer-classified larvae for the two training sets, the next step was to see how many of these images were classified as true positives (images classified correctly by both human and computer). For the six and nine category training sets (Tables 2.10, 2.11), the manually and computer classified images for each species were compared. The six-category training set had the best agreement with $74 \%$ true positives. The ninecategory training set only had about 50\% agreement between manually and computer classified images.

The largest contributions to the differences seen for the six-category training set were in the classifications for the "other" category. Only 5\% of images that were manually classified as "other" species were also classified this way by the computer. Instead, the computer classified most of these "other" species into one of the six categories, which were mostly those species with LOO agreements below $70 \%$. This was particularly true for M. mercenaria and led to an overestimation of abundance by as much as $40 \%$ (Fig. 2.4c). The nine-category field training set also showed poor correspondence between the "other" category, but many differences observed for this training set also involved misclassifications between species categories. Thus, despite 
showing a better fit to the M. mercenaria time series, the nine-category training misclassified "other" co-occurring species. Frequent misclassifications between species, such as between M. mercenaria and M. arenaria, could also be a result of human error that the computer classifications might have corrected. Attempts to morphologically identify M. mercenaria from field studies in Long Island showed a 100\% disagreement with molecularly confirmed larvae, and this was attributed to the presence of many similar species (Perino et al. 2008). As size differences between the two species was used as a main factor to make manual classifications, different growth rates in the field could hinder identifications by size criteria. Thus it is important to recognize that both methods are subject to error and agreement cannot be absolute.

2.3.4 Improving Classifier Performance. Based on the accuracies observed in our LOO results, time series plots, and true positive rates, we concluded that the sixspecies training set was the best estimate for the field image set. We can view the performance of the classifier for both training sets based on the occurrence of false positives compared to true positives if we assumed that manually classified larvae represent the true positives and negatives for each species, referred to as a receiver operating characteristic or ROC (Fawcett 2006). In ROC space, we can confirm that the six-species training set had the best classification results overall, despite having higher false positive rates.

However, the issue of overestimation and misclassification remains for some species in the six-species training set. Our manual counts are subject to error and are not representative of the perfect standard as necessary to stringently evaluate classifier 
performance. To allow for better correspondence, we explored methods to improve performance of our six category training set. Adding morphological features such as shell aspect ratio resulted in worse performance. A bootstrap method on the data also did not show better agreement for most species (Solow et al. 2001). Davis et al. 2004 found that adding an "Other" category to the training set as well as a manual correction method improved classification agreement with manually sorted images. Both of these methods greatly improved our time series correspondences (Fig. 2.6). We added 320 images of a randomly chosen subset of larvae exclusive of our target species into a new "other" category as a seventh category for the training set. Despite only a $25 \%$ classifier agreement for this category, it eliminated up to $14 \%$ of false positive classifications, decreasing this percentage by $10 \%$ for $M$. mercenaria with only a slight decrease (1-7\%) in species classification agreement.

The greatest improvement was seen by manually removing outliers from the original classification results. Since the computer software does not use size or shape as a distinguishing feature, many false-positive images have distinct morphologies from the target species and can be removed manually. This correction procedure works well because morphology (i.e. size, shape of umbo) is a much better criterion for excluding non-target species than it is for positively identifying a species (Perino et al. 2008). All larvae that were removed manually were not re-sorted into other categories. This method correspondence the greatest, by up to $25 \%$ for $M$. mercenaria, with no effect on overall classifier performance. 
The Bland-Altman method compares agreement between two methods of measurement subject to error (Bland and Altman 1986) by comparing the residuals of both estimates as a function of estimate size. We used this method to depict the relationship between the improved methods and the manual counts. Plots of residuals show the relationship between the mean of both estimates and the difference observed for each sample (Figs. 2.8 and 2.9). A perfect correspondence would be equal to zero. Mean differences between estimates were decreased from the original training set, and most samples fell within $95 \%$ confidence limits for estimates. Confidence limits were widest for $M$. arenaria for both correction methods, indicating that this species has the largest difference in estimates between the methods. G. demissa had the least improvement with both methods, although it already had a strong correspondence with the original training set (Fig. 2.6b). Correspondence with M. mercenaria was improved in both methods, but overestimations were smallest for the manually corrected method (Fig. 2.6d). Thus, we concluded that although the original six-species training set was sufficient to depict trends in larval abundance, by adding simple classification improvement methods we achieved stronger agreement of classified images with manually sorted images.

\subsection{DISCUSSION}

The goal of this work was to develop an image-processing technique using shell birefringence patterns to distinguish species of bivalve larvae into a reproducible method that can be applied to field studies. The true strength of this method lies in its ability to inexpensively handle large amounts of samples in a short amount of time and with high accuracy. This method works best when known or genetically-verified larvae are used to 
create the training sets because any error associated with human misclassification is eliminated and true classifier performance for these species ranges from 97-100\%. Our assessment tests confirmed that our classifier performs well on training sets as small as 100 images per species and is consistent at indentifying larvae of all ages and morphologies. Using training sets created from sorted field images introduces more error associated with human classification and quality of field images, but this step may be necessary to achieve the best results for field studies. We showed that a few simple correction methods can achieve results consistent with human sorting of larval images, but with less overall effort.

When compared to the accuracies of other methods of automated plankton identification, these results fall in the middle. For our hatchery training sets, our accuracies fall under the high end of image analysis capabilities (with up to $100 \%$ accuracy for the 500 images per species training sets), but for our field training sets our accuracies are lower, but still acceptable (62-88\% for the 400-500 images per species field training set). The Video Plankton Recorder group found that their plankton classification method had higher accuracies for more abundant taxa and lower accuracies for rare taxa, with an overall accuracy range of 45-91\% (Davis et al. 2004), which was later improved with a dual-classification method (Hu and Davis 2006). Plankton recognition software for the SIPPER II underwater camera was improved from $77 \%$ to 90\% by adding an active-learning approach for training a multiple-class SVM (Lou et al. 2005). The scanning approached used for the ZOOSCAN system found that accuracy was highest for a simplified approach using eight groups and a random-forest classification 
method (83.9\%), and when the training sets were grouped into 29 categories, accuracy declined to $73.4 \%$. They were able to improve total accuracy to between $80-85 \%$ after manually reclassifying "suspect" images identified by the computer (Grosjean et al. 2004). Phytoplankton are traditionally difficult to identify, but automated classification for the in-situ imaging flow cytometer, FlowCytobot, achieved between 68-99\% accuracy among 22 categories (Sosik and Olson 2007). The DiCANN machine-learning system for dinoflagellates categorized six species with accuracies ranging between $41-100 \%$ (Culverhouse et al. 2003). Our system has a more limited set of reference images available as compared to these methods, as each image had to be manually captured on the microscope. In the future, automation of this process may allow for collection of a greater number of images and the ability to further increase accuracy through active learning and error correction.

We compared our image analysis system to a multiplex PCR method. Molecular methods are commonly used to identify species for which distinguishing morphological features are absent. Because this method is based on DNA, it gave us a higher level of certainty for many of our field identifications. However, this method was more time consuming and expensive than the image analysis method which limited the number of larvae we could test. This illustrates the major drawback of PCR methods with individual larvae. Sequencing adult DNA and measuring sequence divergences confirmed our identifications of four species, but for some rarer species that are not in GenBank, false positive BLAST searches can occur. Although the PCR based method may be more accurate, it can only be readily used on small subsets of samples and still has suspected 
problems with accuracy unless results can be verified by $18 \mathrm{~S}$ sequencing. Our 7,000 field image set was only a subsample of the total field larvae collected, and performing PCR on this quantity of larvae would be daunting. Although this method was useful for confirming image identifications when sorting field larvae into training sets, it is difficult to scale to large numbers of samples.

Our proof of concept application involved a series of weekly plankton samples taken from Waquoit Bay, MA in the summer of 2009 (Chapter 3). Although these data are represented as counts from a standardized subsample of 100 individuals and are not representative of true concentrations, we can observe species-specific trends in the composition of samples. Further applications for this method could involve relating larval supply to juvenile and adult recruitment, re-visiting information from archived samples, identifying larvae for genetic analysis for gene frequency patterns, and testing transport models with information on species-specific distributions.

The polarization method can be easily adapted for use in other geographical areas, requiring only a polarization microscope with digital camera, computer with at least 2 GB of RAM, and software package for MATLAB. Many molecular-based methods require significant start-up for including a new species. Primer or antibody design both require significant knowledge, data collection, cost, and time to perform. Ideally, our imageanalysis method involves imaging a collection of hatchery reared larvae, but if this is not possible, a field-identified training set can suffice, albeit with lower classification accuracies. This method could potentially be applied to bivalve larval samples from any location where they could be imaged using polarization. Although we have not tested this 
method on bivalve larvae from areas outside of Cape Cod, the characteristics of shell mineralization for all bivalves are species-specific (Gallager et al. 1988), and thus the method should be adaptable. We have yet to analyze birefringence patterns for closely related species (i.e. the same genus), but previous comparison of the bay scallop, $A$. irradians, and sea scallop, Placopecten magellanicus showed distinctive shell birefringence patterns (Tiwari and Gallager 2003a).

Overall, we conclude that a minor sacrifice to accuracy biased by human sorting is worth the ability to handle a large amount of field samples. Automation of image collection is currently being established and will enable even larger spatial and temporal coverage. By focusing on species the computer can classify most accurately, better results and information on species-specific abundances can be estimated. Machine learning has the potential to revolutionize plankton sampling by eliminating time-consuming sample processing. Currently, few species-specific field studies of bivalve larvae exist, which limits our understanding of their larval ecology compared to other larval groups. The ability to estimate species-specific abundance from studies with large spatial and temporal coverages in relatively short time periods will greatly increase our understanding of bivalve larvae abundance, distribution and transport, and how species might be responding to climate change. This will have lasting implications in the fields of larval ecology, biological-physical processes, and shellfish restoration and management.

\subsection{COMMENTS AND RECOMMENDATIONS}

Our state-of-the-art method presents a good and cost-effective alternative for bivalve larval species identification. Our image processing technique compares well with 
other methods for bivalve larval identification and other image analysis techniques for plankton. The next step for this method is to integrate it into an automated image collection and analysis routine. The Larval Identification and Hydrographic Data Telemetry system (or LIHDAT) has been developed and implemented in two laboratory settings for analysis of bivalve larvae from plankton samples (Gallager et al. 2005, submitted). The ultimate goal of this system is to make it continuous and fieldoperational. This machine would make this method more comparable to the other automated image processing methods. In addition, it would enable us to create more accurate training sets from larger sets of field images as well as standardize identifications with known images we can run through the system.

We found two main drawbacks to our image processing method. First it is unknown how much variability is present in shell polarization patterns. Microscope settings may affect these patterns which could affect the performance of the classifier if they are not kept standard. Because our image collections spanned several months to years, we suspect that slight variations of the microscope settings over time may affect polarization patterns. Our trials showed that training sets of images cannot be used to classify images taken at different microscope settings unless those images are also represented in a training set. It is also unknown how variable polarization patterns are between and among species. Furthermore, laboratory studies of ocean acidification on larval bivalves have shown an effect on shell formation in larval scallops (D. McCorkle, pers. comm.), and as increased $\mathrm{CO}_{2}$ lowers the $\mathrm{pH}$ in coastal waters, this could affect 
shell birefringence patterns, although this has not been shown to impact aragonite crystal rotation (see Gallager et al 1988).

The second issue with this method is that training sets must accurately represent the species composition of the sample set, or many false-positive classifications will occur. Based on our results, training sets should be composed of more abundant species that together represent at least $50 \%$ of the entire sample composition. Samples that contain large numbers of different species may be difficult to use due to the reduced classifier performance on many categories. If species composition of the field samples is not known a priori, it may be difficult to set up a training set using known, hatcheryreared species. Because field larvae can be difficult to sort due to multiple species with similar morphologies, this can add more error to human classification which is then reflected in classifier performance.

Although one cannot entirely eradicate human error when manually sorting, we recommend that further applications of this method take careful examination of species composition of each sample to create a training set that accurately represents the sample. If keys or cultured individuals are not available, genetic information can provide a decent background for some species identifications. If a known training set cannot be established to accurately represent field larvae, we recommend the following protocol when creating a field-training set:

(1) Classify 1,000 randomly selected images to the most accurate number of species categories (based on genetics and key information, or preferably cultured individuals). 
(2) Evaluate which species are most abundant based on these categories (at least 50\% of the entire sample).

(3) From the rest of the images (leaving out the ones that were classified), create training sets starting at 100 images per category representing different sizes and morphologies of the species.

(4) Evaluate accuracy using these training sets to classify the manually sorted images. Compare to the manual sorted images and adjust species categories and/or number of images per category until the best agreement is reached.

(5) Once the training set it optimized, use it to classify all images from the sample set.

For our field image classifications, we found it was necessary to employ error correction techniques to achieve better correspondence with our manual counts. We recommend this if initial agreement of both methods shows many false-positives with unlabeled images, although this may increase manual-processing efforts. More sophisticated methods of dual-classification (Hu and Davis 2006) or active-learning approaches for classifiers (Lou et al. 2005) may help with misclassifications between species categories, but we did not employ these methods here. We found that our correction methods provided sufficient agreement to our manual counts when considering the error present in both methods.

This method has been applied to a field transport study of bivalve larvae on Cape Cod (Chapter 4), but it is ready to be applied to studies in other environments. Our image analysis method can be applied from both manually extracted images (as in this study) or 
from optically sampled images from LIHDAT (future studies). The only requirements for expanding this method to other environments are a polarization microscope, computer and software package, and ability to create a representative training set.

\subsection{ACKNOWLEDGEMENTS}

Field assistance for sample collection was provided by R. York, E. Bonk, C. Weidman, and M. Mingione. R. Kraus from the Aquaculture Research Corporation in Dennis, MA and H. Lind of the Eastham Shellfish Hatchery provided larvae used in this study. Molecular work was performed with the support of $\mathrm{H}$. Borchardt-Wier at Cornell University and T. Shank and W. Cho at WHOI. K. Bolles provided helpful comments on this manuscript. This project was supported by an award to S. Gallager and C. Mingione Thompson from the Estuarine Reserves Division, Office of Ocean and Coastal Resource Management, National Ocean Service, National Oceanic and Atmospheric Administration and a grant from Woods Hole Oceanographic Institution's Coastal Ocean Institute.

\subsection{LITERATURE CITED}

Benfield, M.C., P. Gorsjean, P.F. Culverhouse, Irigoien, M.E. Sieracki, A. Lopez-Urrutia, H.G. Dam, Q. Hu, C.S. Davis, A. Hansen, C.H. Pilskain, E. Riseman, H. Schultz, P.E. Utgoff, and G. Gorsky. 2007. RAPID: Research on Automated Plankton Identifcation. Oceanography 20(2): 13-26.

Bland, J.M. and D.G. Altman. 1986. Statistical methods for assessing agreement between two methods of clinical measurement. Lancet i: 307-310.

Boicurt, W.C. 1988. Recruitment dependence on planktonic transport in coastal waters. In: Rothschild, B.J. (ed.), Toward a Theory on Biological-Physical Interactions in the World Ocean. Kluwer Academic Publishers, pp. 183-202.

Chanley, P. and Andrews J.D. 1971. Aids for identification of bivalve larvae of Virginia. Malacologia 11: 45-119.

Culverhouse, P.F., R. Williams, B. Reguera, V. Herry, S. Gonzalez-Gil. 2003. Do experts make mistakes? A comparision of human and machine identification of dinoflagellates. Mar. Ecol. Prog. Ser. 247: 17-25.

Davis, C.S., S.M. Gallager, A.R. Solow. 1992. Microaggregations of oceanic plankton observed by towed video microscopy. Science 257: 230-232.

Davis, C.S., Q. Hu, S.M. Gallager, X. Tang, C.J. Ashjian. 2004. Real-time observation of taxa-specific plankton distributions: an optical sampling method. Mar. Ecol. Prog. Ser. 284: 77-96.

Fawcett, T. 2006. An introduction to ROC analysis. Patern Recogn. Lett. 27: 861-874.

Fukunaga, K., D.M. Hummels. 1989. Leave-one-out procedures for nonparametric error estimates. IEEE Trans. Pattern Anal. Machine Intelligence 11: 421-423. 
Gallager, S.M., J. P. Bidwell and A. M. Kuzirian. 1988. Strontium is required in artificial seawater for embryonic shell formation in two species of bivalve molluscs. In R. Crick, ed. Origin, history and modern aspects of biomineralization in plants and animals. Proceedings of the Fifth International Symposium on Biomineralization, Arlington, Texas. University of Chicago Press, Chicago.

Gallager, S.M., C.S. Davis, A.W. Epstein, A. Solow, R.C. Beardsley. 1996. Highresolution observations of plankton spatial distributions correlated with hydrograpy in the Great South Channel Georges Bank. Deep-Sea Res II 43: 16271664.

Gallager, S.M., S. Tiwari, R. Taylor and A. Girard. 2005. Underway sampling and identification of bivalve larvae and other plankton. Submitted to Mar. Biol.

Gallager, S.M. and S. Tiwari. 2006. Optical Method and System for Rapid Identification of Biological and Inorganic Materials Using Multiscale Texture and Color Invariants. US. Patent Application, pending.

Garland, E.D. 2000. Temporal variability and vertical structure in larval abundance: the potential roles of biological and physical processes. Doctoral Dissertation. Massachusetts Institute of Technology/Woods Hole Oceanographic Institution, Woods Hole, MA, 213 pp.

Garland, E.D. and C.A. Zimmer. 2002. Techniques for the identification of bivalve larvae. Mar. Ecol. Prog. Ser. 225: 299-310.

Gregg, C.S. 2002. Effects of biological and physical processes on the vertical distribution and horizontal transport of bivalve larvae in an estuarine inlet. Doctoral dissertation. Rutgers University, New Brunswick, NJ, 154 pp.

Grosjean, P., M. Picheral, C. Warembourg, and G. Gorsky. 2004. Enumeration, measurement, and identification of new zooplankton samples using the ZOOSCAN digital imaging system. J. Mar. Sci. 61: 518-525.

Hare, M.P., S.R. Palumbi, and C.A. Butman. 2000. Single-step species identification of bivalve larvae using multiplex polymerase chain reaction. Mar. Biol. 137: 953-961.

Hendriks, I.E., L.A. van Duren, P.M.J. Herman. 2005. Image analysis techniques: a tool for the identification of bivalve larvae? J. Sea Res. 54: 151-162.

Henzler, C.M., E.A. Hoaglund, S.D. Gaines. 2010. FISH-CS - a rapid method for counting and sorting species of marine zooplankton. Mar. Ecol. Prog. Ser. 410: 111 .

Hu, Q. and C. Davis. 2006. Accurate automatic quantification of taxa-specific plankton abundance using dual classification with correction. Mar. Ecol. Prog. Ser. 306: 5161.

Kimura, M. 1980. A simple method for estimating evolutionary rates of base substitutions through comparative studies of nucleotide sequences. J. of Mol. Evol. 16: 111-120.

Loosanoff, V.L., W.S. Miller, P.B. Smith. 1951. Growth and setting of larvae of Venus mercenaria in relation to temperature. J. Mar. Res. 10: 59-81.

Loosanoff, V.L., H.C. Davis, P.E. Chanley. 1966. Dimensions and shapes of larvae of some marine bivalve mollusks. Malacologia 4: 351-435. 
Lou, T., K. Kramer, D.B. Goldgof, L.O. Hall, S. Samson, A. Remsen, T. Hopkins. 2005. Active learning to recognize multiple types of plankton. J. Mach. Learn. Res. 6: 589-613.

Lutz, R. J. Goodshell, M. Castagna, S. Chapman, C. Newell, H. Hidu, R. Mann, D. Jablonski, V. Kennedy, S. Siddall, R. Goldberg, H. Beattie, C. Galmagne, A. Chestnut, and A. Partridge. 1982. Preliminary observations on the usefulness of hinge structures for identification of bivalve larvae. J. Shell. Res. 2(1): 65-70.

Maddison, W.P., and D.R. Maddison. 2000. MacClade. Sinauer Associates.

Perino, L.L., D.K. Padilla, and M.H. Doall. 2008. Testing the accuracy of morphological identification of northern quahog larvae. J. Shellfish Res. 27(5): 1081-1085.

Pineda, J., J.A. Hare, and S. Sponaugle. 2007. Larval transport and dispersal in the coastal ocean and consequences for population connectivity. Oceanography 20(3): 22-39.

Scheltema, R.S. 1986. On dispersal and planktonic larvae of benthic invertebrates: an eclectic overview and summary of problems. Bull. of Mar. Sci. 39(2): 290-322.

Sieracki, C.K., M.E. Sieracki, C.S. Yentsch. 1998. An imaging-in-flow system for automated analysis of marine microplankton. Mar. Ecol. Prog. Ser. 168: 285-296.

Solow, A., C. Davis, Q. Hu. 2001. Estimating the taxonomic composition of a sample when individuals are classified with error. Mar. Ecol. Prog. Ser. 216: 309-311.

Sosik, H.M. and R.J. Olson. 2007. Automated taxonomic classification of phytoplankton sampled with imaging-in-flow cytometry. Limnol. Oceanogr.: Methods 5: 204216.

Tamura K, Dudley J, Nei M \& Kumar S (2007) MEGA4: Molecular Evolutionary Genetics Analysis (MEGA) software version 4.0. Molecular Biology and Evolution 24:1596-1599.

Tiwari, S. and S.M. Gallager. 2003a. Optimizing multiscale invariants for the identification of bivalve larvae. Proceedings of the 2003 IEEE International Conference on Image Processing, Barcelona, Spain, September 14-17, 2003.

Tiwari, S. and S. Gallager. 2003b. Machine learning and multiscale methods in the identification of bivalve larvae. Proceedings of the Ninth IEEE International Conference on Computer Vision, Nice, France, October 14-17, 2003.

Thorson, G. 1950. Reproductive and larval ecology of marine bottom invertebrates. Bio. Rev. 25: 1-45. 
Table 2.1 Details of larvae collected from Cape Cod, MA hatcheries for use in creating image training sets. Information on hatchery location, age representation, dates collected, and total images is presented for each species.

\begin{tabular}{|c|c|c|c|c|}
\hline Species & Hatchery Location & Ages (days) & Dates Collected & Total Images \\
\hline Argopecten & Aquaculture Research & & & \\
\hline irradians & Corporation, Dennis, MA & $2,3,5,7,9$ & $6 / 21 / 07-6 / 29 / 07$ & 500 \\
\hline \multicolumn{5}{|l|}{ Crassostrea } \\
\hline virginica & Eastham, MA & $1-5,7,8,10$ & $5 / 21 / 07-5 / 30 / 07$ & 754 \\
\hline Mercenaria & Aquaculture Research & & & \\
\hline mercenaria & Corporation, Dennis, MA & $1-7$ & $2 / 8 / 08-2 / 14 / 08$ & 685 \\
\hline Mya arenaria & Eastham, MA & $2-14$ & $6 / 25 / 07-7 / 8 / 07$ & 1300 \\
\hline \multicolumn{5}{|l|}{ Clean Larvae } \\
\hline Species & Hatchery Location & Ages (days) & Dates Collected & Total Images \\
\hline Argopecten & Aquaculture Research & & & \\
\hline irradians & Corporation, Dennis, MA & $2,3,5,7,9$ & 6/21/07 - 6/29/07 & 499 \\
\hline \multicolumn{5}{|l|}{ Crassostrea } \\
\hline virginica & Eastham, MA & $1-5,7,8$ & $5 / 21 / 07-5 / 30 / 07$ & 699 \\
\hline Mercenaria & Aquaculture Research & & & \\
\hline mercenaria & Corporation, Dennis, MA & $1-7$ & $2 / 5 / 10-2 / 11 / 10$ & 685 \\
\hline Mya arenaria & Eastham, MA & $2,4-10,12-14$ & $6 / 25 / 07-7 / 8 / 07$ & 1095 \\
\hline
\end{tabular}


Table 2.2 Confusion matrix and classification accuracies for raw and cleaned shells using the leave-one-out (LOO) method. The confusion matrix presents known larvae in the rows and computer classified larvae in the columns. Numbers in bold are classifications that agreed with the results. Total = total hatchery larvae used in the training sets, FP (false positives) = the number of incorrectly identified larvae in the LOO method, used to compute the accuracy (percent true positive: 1-FP/Total) in the final column. Overall accuracies for the training sets are listed in the last column. $(\mathrm{AI}=A$. irradians, $\mathrm{CV}=C$. virginica, $\mathrm{MA}=M$. arenaria, $\mathrm{MM}=M$. mercenaria, $\mathrm{OT}=$ other)

\begin{tabular}{|c|c|c|c|c|c|c|c|c|c|}
\hline \multirow{6}{*}{$\begin{array}{l}\frac{0}{0} \\
\frac{1}{2} \\
\frac{1}{\sigma} \\
\frac{5}{3} \\
0 \\
\frac{\Gamma}{2}\end{array}$} & \multirow[t]{2}{*}{ Raw Larvae } & \multicolumn{4}{|c|}{ computer classified larvae } & \multirow[b]{2}{*}{ OT } & \multirow[b]{2}{*}{ Total } & \multirow[b]{2}{*}{$\mathrm{FP}$} & \multirow[b]{2}{*}{ Accuracy } \\
\hline & & $\mathrm{Al}$ & $\mathrm{CV}$ & MA & $\mathrm{MM}$ & & & & \\
\hline & $\mathrm{Al}$ & 486 & 0 & 12 & 0 & 0 & 499 & 13 & $97.39 \%$ \\
\hline & CV & 1 & 746 & 6 & 0 & 0 & 753 & 7 & $99.07 \%$ \\
\hline & MA & 3 & 7 & 1288 & 0 & 1 & 1299 & 11 & $99.15 \%$ \\
\hline & MM & 0 & 1 & 0 & 684 & 0 & 685 & 1 & $99.85 \%$ \\
\hline & & & & & & LOC & accur & & $99.01 \%$ \\
\hline
\end{tabular}

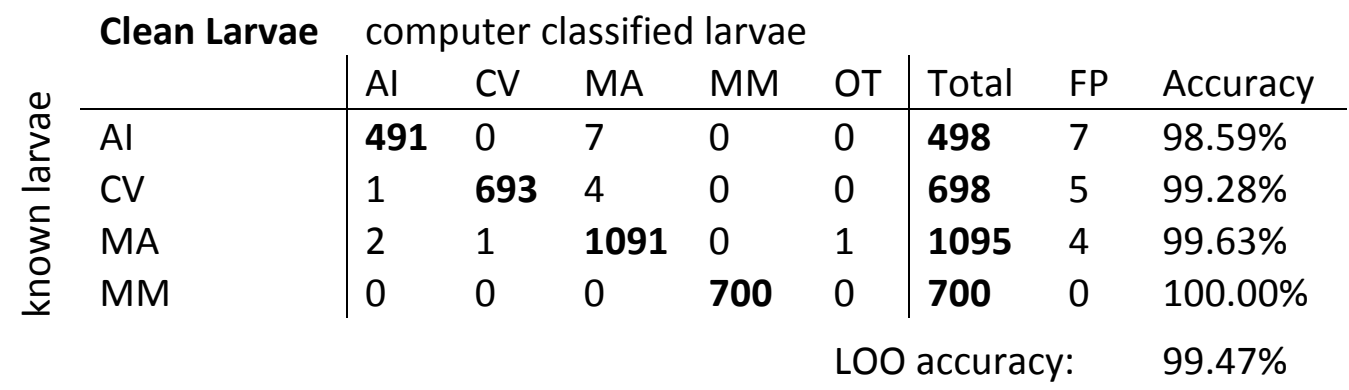


Table 2.3 Classification results for 250 images of each hatchery species. Classifier was trained with 250 independent images for each species. Total hatchery larvae sum up in the rows, computer classification results sum in the columns. See Table 2 for detailed description of confusion matrix. (FP = false positive, Accuracy $=1-\mathrm{FP} / \mathrm{Total}, \mathrm{AI}=A$. irradians, $\mathrm{CV}=C$. virginica, $\mathrm{MA}=M$. arenaria, $\mathrm{MM}=M$. mercenaria, $\mathrm{OT}=$ other)

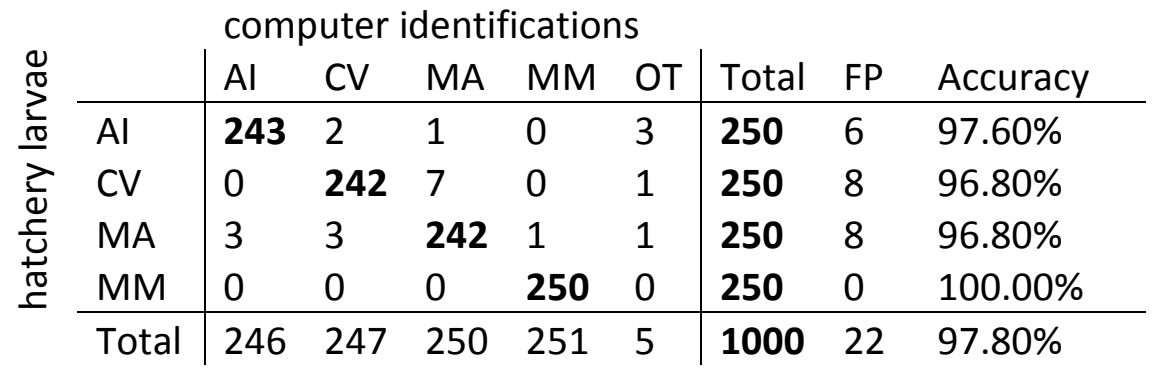

Table 2.4 Multiplex PCR and 18S sequencing identifications for larvae from live field samples of 2008 and 2009. Eighty-one larvae were used in this analysis, corresponding to 360 images. About half of the samples were re-amplified for $18 \mathrm{~S}$ sequencing. Total identified from the multiplex and sequencing are shown in the bottom rows.

\begin{tabular}{l|ll|ll|l|l|l} 
& \multicolumn{3}{|l|}{ Samples } & \multicolumn{2}{|l|}{ Images } & Samples & Images \\
\cline { 2 - 7 } & 2008 & 2009 & 2008 & 2009 & Totals & Totals \\
\cline { 2 - 7 } Guekensia demissa & 4 & 22 & 19 & 92 & 26 & 111 \\
Macoma balthica & 1 & 0 & 5 & 0 & 1 & 5 \\
Mercenaria mercenaria & 22 & 1 & 87 & 5 & 23 & 92 \\
Mya arenaria & 3 & 23 & 14 & 114 & 26 & 128 \\
Petricola pholadiformis & 0 & 1 & 0 & 5 & 1 & 5 \\
Spisula solidissima & 0 & 4 & 0 & 20 & 4 & 20 \\
\hline CO1 Multiplex & 20 & 23 & 82 & 113 & 43 & 195 \\
18S Sequencing & 11 & 27 & 43 & 122 & 38 & 165 \\
\hline Total amplified & 31 & 50 & 125 & 235 & 81 & 360
\end{tabular}


Table 2.5 Molecular and computer identification results for known hatchery larvae used to calculate error rate for the two methods. Confusion matrix is shown for known larvae identified using the multiplex PCR method and then for those same images subject to SVM classification. PCR and computer results are summed up in the columns, known results sum up in the rows, and bold numbers indicate agreement between the methods. $(\mathrm{N}=$ no information, $\mathrm{FP}=$ false positive, Accuracy $=(1-\mathrm{FP}$ or $\mathrm{N}) /$ Total, $\mathrm{AI}=A$. irradians, $\mathrm{CV}=C$. virginica, $\mathrm{MA}=M$. arenaria, $\mathrm{MM}=M$. mercenaria, $\mathrm{OT}=$ other)

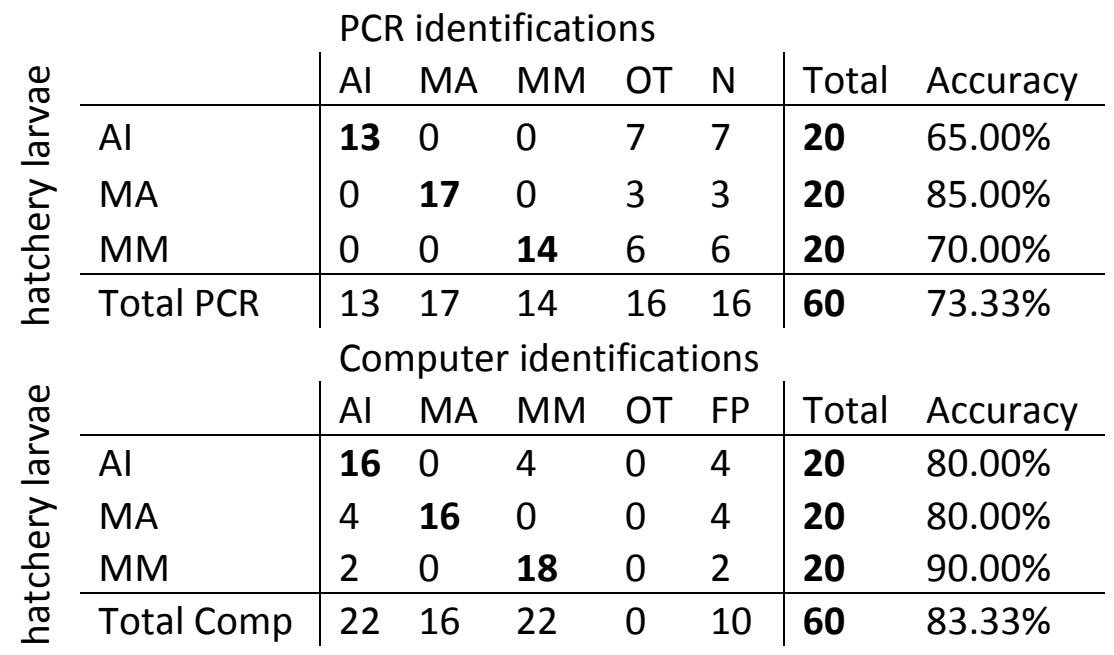

Table 2.6 Confusion matrix for the images that were positively identified using the molecular methods and then classified using the SVM. See Table 2.5 caption for description of confusion matrix. Agreement for each species was calculated by the number of image classifications that equaled the PCR identifications divided by the total number of PCR-identified images for that species category. ( $\mathrm{GD}=$ G. demissa, $\mathrm{MA}=M$. arenaria, $\mathrm{MM}=M$. mercenaria, $\mathrm{OT}=$ other)

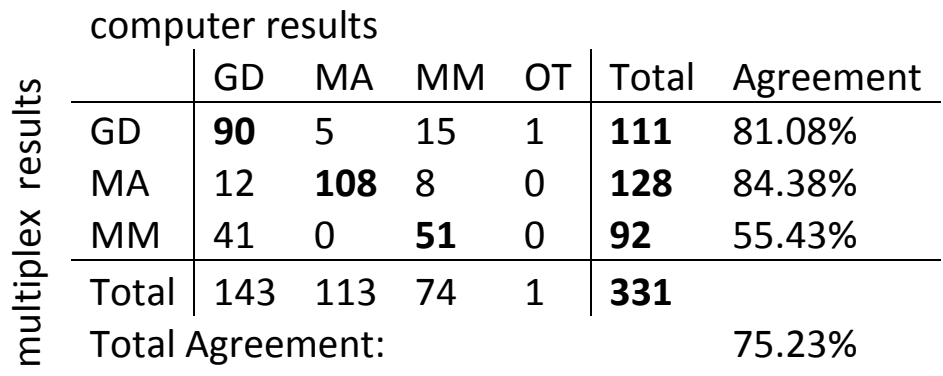


Table 2.7 Manual classification error for the four hatchery species. Table shows combined results from 4 trials of up to 100 unlabled images that were sorted from the hatchery image sets and classified manually. Total hatchery larvae sum up in the rows, total human-classified larvae sum up in the columns. (FP = false positive, Accuracy = 1$\mathrm{FP} /$ Total, $\mathrm{AI}=A$. irradians, $\mathrm{CV}=C$. virginica, $\mathrm{MA}=M$. arenaria, $\mathrm{MM}=M$. mercenaria, $\mathrm{OT}=$ other)

\begin{tabular}{|c|c|c|c|c|c|c|c|c|}
\hline & $\mathrm{Al}$ & $\mathrm{CV}$ & MA & $\mathrm{MM}$ & OT & Total & FP & Accuracy \\
\hline Al & 73 & 1 & 4 & 0 & 0 & 78 & 5 & $93.59 \%$ \\
\hline $\mathrm{CV}$ & 0 & 124 & 0 & 0 & 0 & 124 & 0 & $100.00 \%$ \\
\hline MA & 0 & 0 & 91 & 16 & 0 & 107 & 16 & $85.05 \%$ \\
\hline $\mathrm{MM}$ & 0 & 0 & 8 & 81 & 0 & 89 & 8 & $91.01 \%$ \\
\hline Total & 73 & 125 & 103 & 97 & 0 & 398 & 29 & $92.71 \%$ \\
\hline
\end{tabular}

Table 2.8 Leave-one-out cross validation accuracies for the six-species training set of manually classified field images. LOO results are shown for a six-category training set of 250 and 400-500 images per species category. The number of false images classified (FP) and the percent agreement are shown $(1-$ FP/Total $)$.

\begin{tabular}{lll|ll} 
Species & FP & \multicolumn{3}{l}{ Agreement } \\
\hline No. images/category & 250 & 500 & 250 & 500 \\
\hline Anadara ovalis & 54 & 112 & $78.40 \%$ & $73.71 \%$ \\
Anomia simplex & 44 & 58 & $82.40 \%$ & $88.40 \%$ \\
Geukensia demissa & 45 & 79 & $82.00 \%$ & $84.20 \%$ \\
Mya arenaira & 89 & 153 & $64.40 \%$ & $69.40 \%$ \\
Macoma balthica & 90 & 152 & $64.00 \%$ & $69.60 \%$ \\
Mercenaria mercenaria & 116 & 186 & $53.60 \%$ & $62.80 \%$ \\
\hline Total & 438 & 740 & $70.80 \%$ & $74.71 \%$
\end{tabular}


Table 2.9 Leave-one-out cross validation accuracies for the nine-species training set of manually classified field images. LOO results are shown for a nine-category training set of 250 images per species category. The numbers of false images classified (FP) and the percent agreement are shown $(1-$ FP/Total $)$.

\begin{tabular}{lll} 
Species & FP & Agreement \\
\hline Anadara sp. & 79 & $68.40 \%$ \\
Anomia simplex & 53 & $78.80 \%$ \\
Ensis directus* & 88 & $64.80 \%$ \\
Geukensia demissa & 59 & $76.40 \%$ \\
Mya arenaira & 111 & $55.60 \%$ \\
Macoma balthica & 104 & $58.40 \%$ \\
Mercenaria mercenaria & 117 & $53.20 \%$ \\
Spisula solidissima & 130 & $48.00 \%$ \\
Unknown A* & 33 & $86.80 \%$ \\
\hline Total & 774 & $65.60 \%$ \\
\hline
\end{tabular}

Table 2.10 Confusion matrix comparing manual and computer classifications for the 6category field training set. Results of the manually classified species are summed up in the rows, while results of the computer identifications are summed up in the columns. Bold numbers indicate agreement. PA = percent agreement or percentage of how many larvae were classified the same by both methods (true positives). Difference $=$ the percent difference between computer classified and manually classified larvae. $(\mathrm{AO}=$ Anadara sp., $\mathrm{AS}=$ Anomia simplex, $\mathrm{GD}=$ Geukensia demiss, $\mathrm{MA}=$ Mya arenaria, $\mathrm{MB}=$ Macoma balthica, $\mathrm{MM}=$ M. mercenaria, $\mathrm{OT}=$ other)

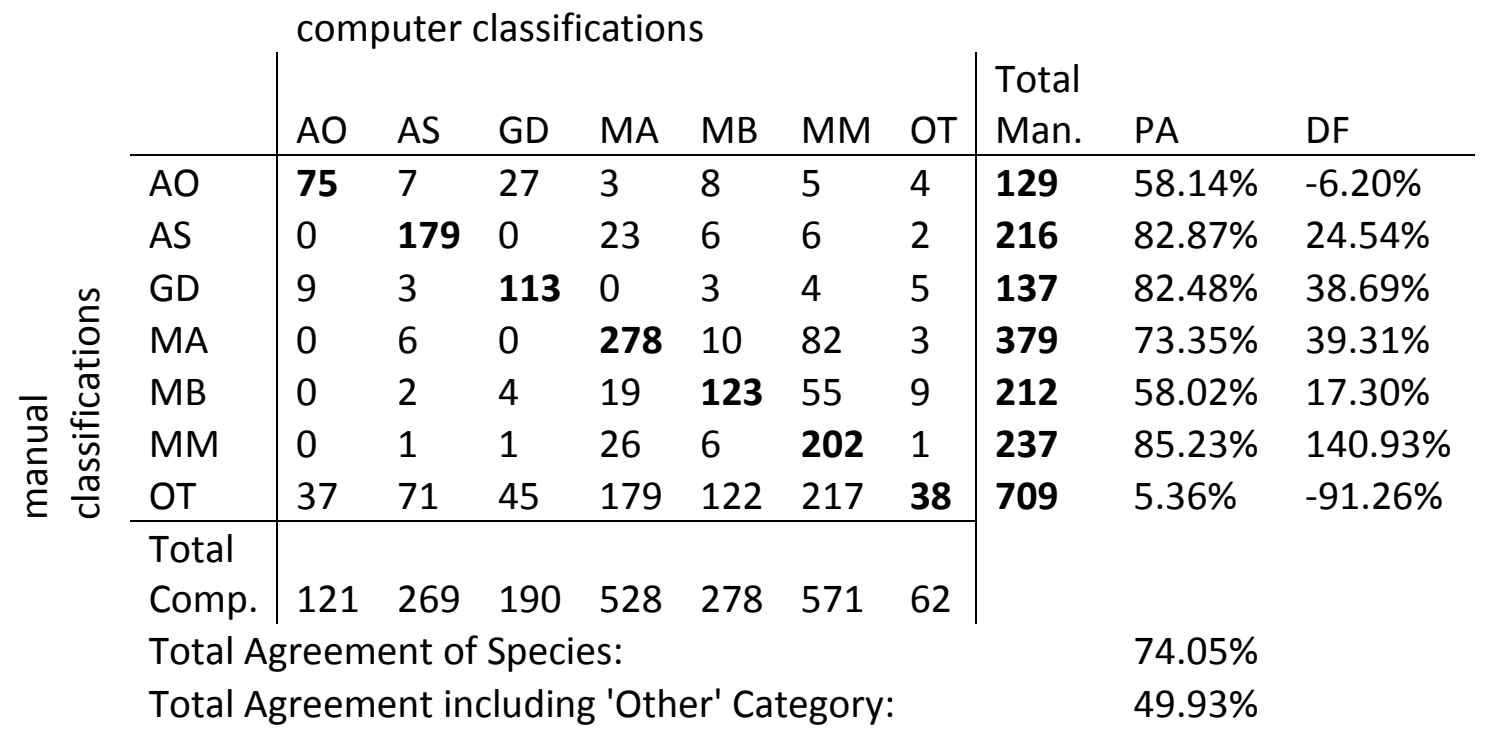


Table 2.11 Confusion matrix comparing manual and computer classifications for the 9category field training set. Description of matrix can be seen in caption to Table 2.10. PA = percent agreement or how many larvae were classified the same by both methods (true positives), $\mathrm{PD}=$ the percent difference between computer classified and manually classified larvae. $(\mathrm{AO}=$ Anadara sp., $\mathrm{AS}=A$. simplex, $\mathrm{ED}=E$. directus, $\mathrm{GD}=G$. demissa, $\mathrm{MA}=M$. arenaria, $\mathrm{MB}=M$. balthica, $\mathrm{MM}=M$. mercenaria, $\mathrm{SS}=S$. solidissima, UA = Unknown A, OT = other)

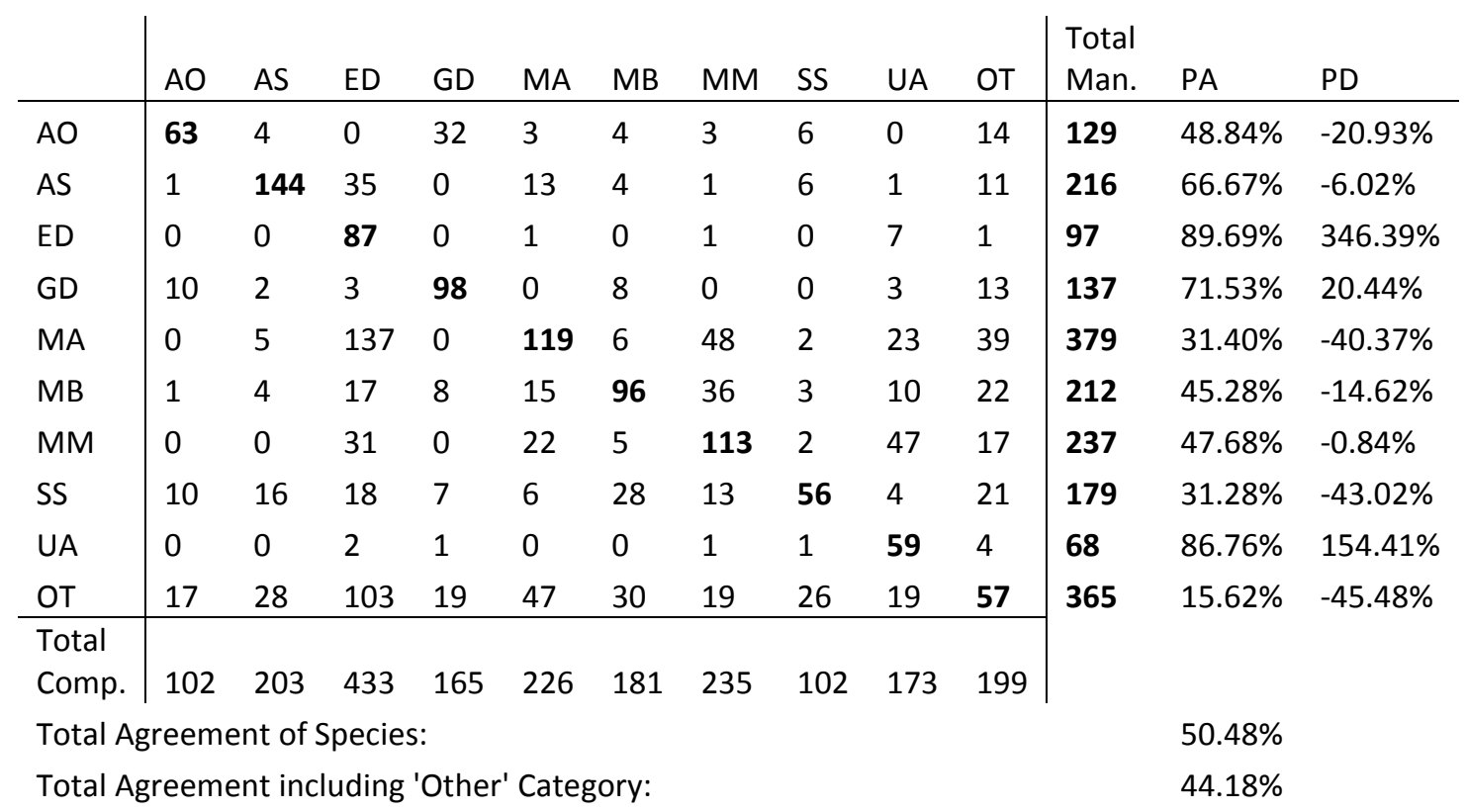


a.

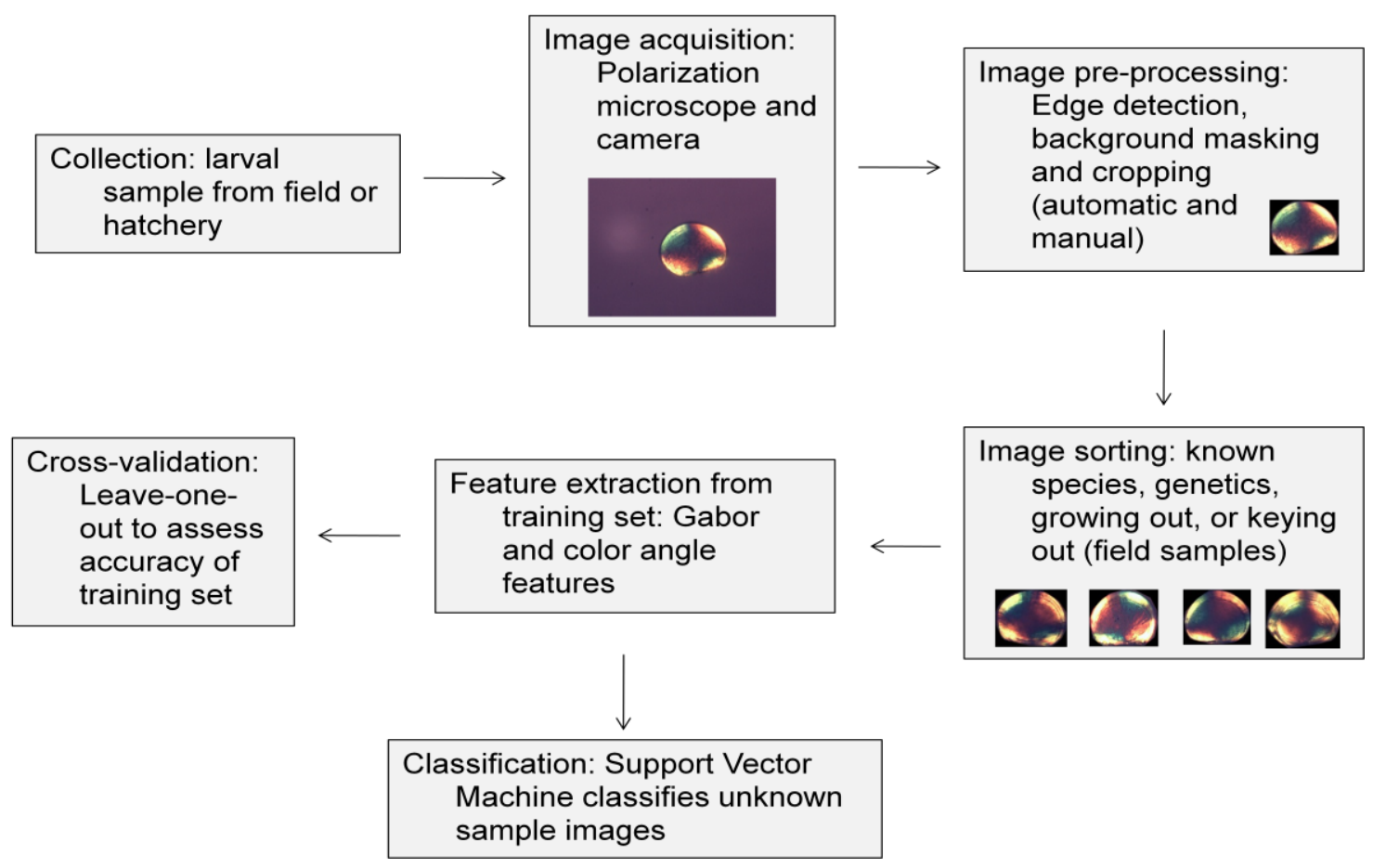

b.

\section{Argopecten irradians Crassostrea virginica Mercenaria mercenaria Mya arenaria}

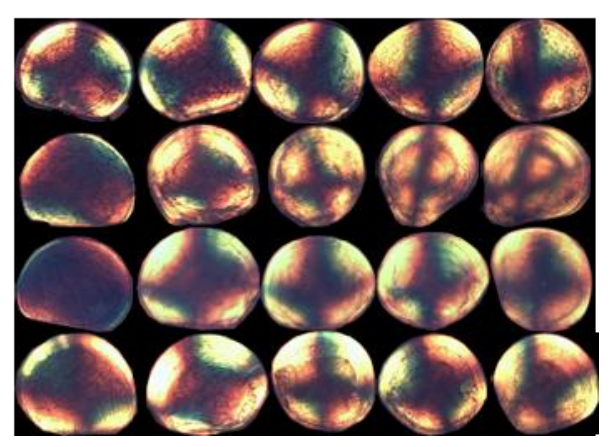

Figure 2.1 Image processing technique and training set images. (a) Diagram of image processing technique from sample collection to classification of unknown images. (b) Sample images from the hatchery training set. Polarization images of larvae from four species throughout larval development with varying color patterns. Images are not to scale. 


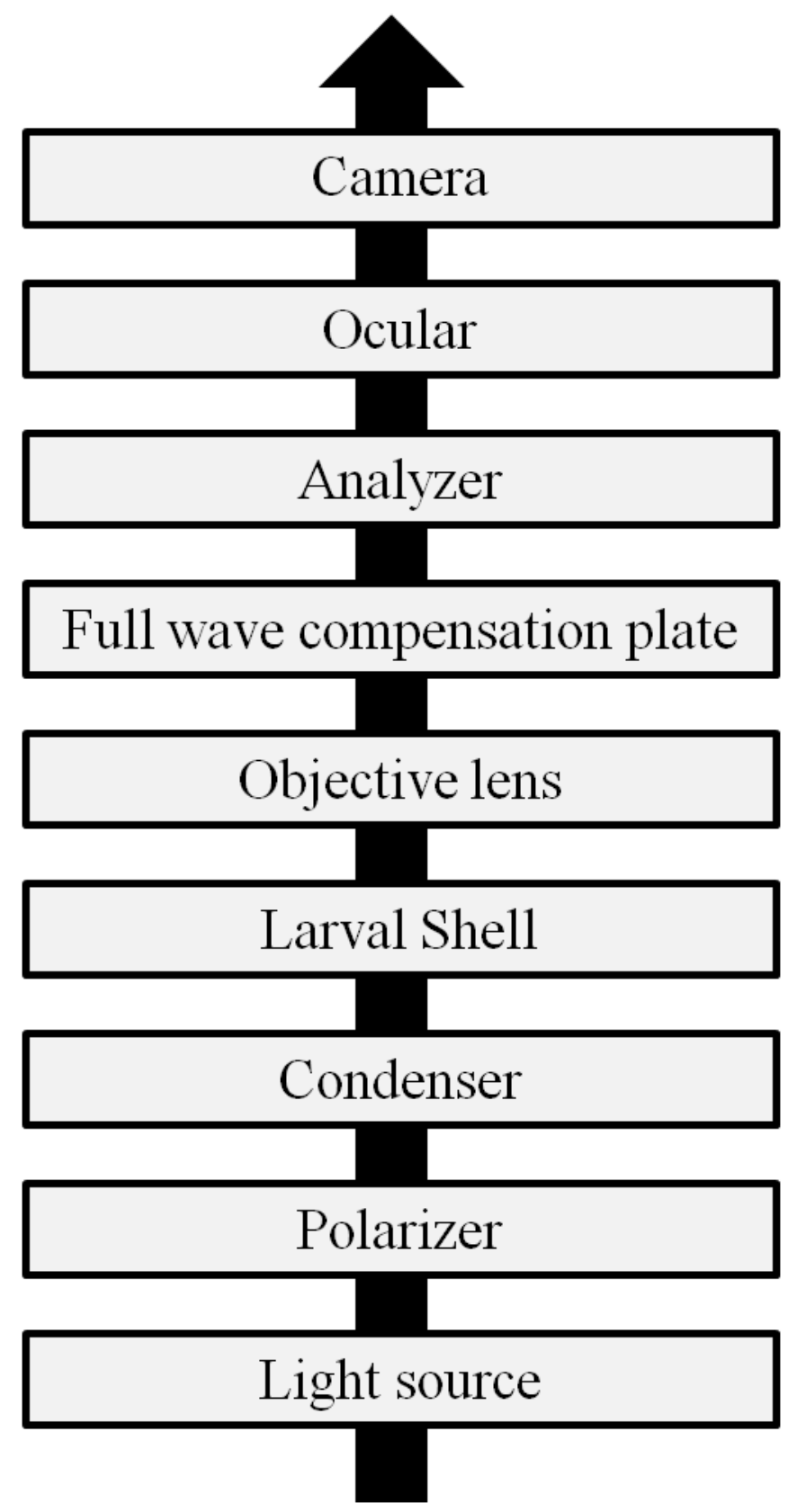

Figure 2.2 Diagram of optical path for microscope cross polarization setup for image acquisition. Black arrow represent path of light. 

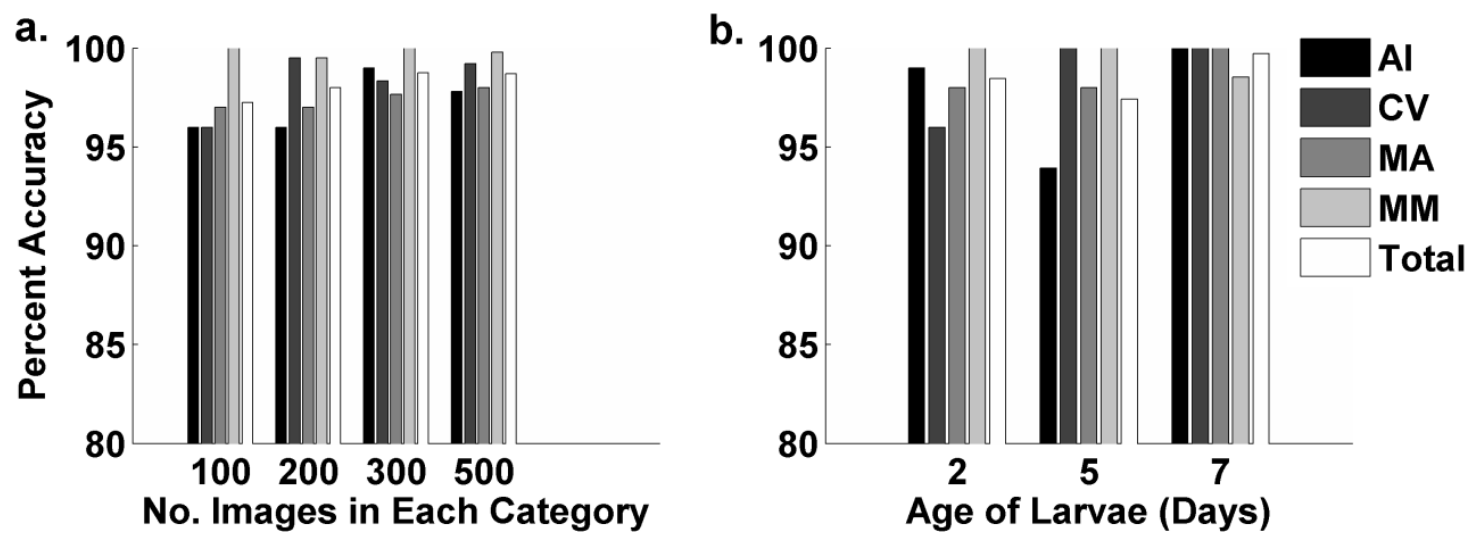

Figure 2.3 Accuracy test for hatchery training set with (a) size of species categories and (b) age of larvae. (a) Percent accuracy with varied number of images per species category for the hatchery training set as from the LOO method. (b) Accuracies from LOO crossvalidation on the 500 images/species hatchery training set of 2, 5, and 7 day old larvae. Accuracies are shown for individual species as combined for the full training set. $\mathrm{AI}=A$. irradians, $\mathrm{CV}=C$. virginica, $\mathrm{MA}=M$. arenaria, $\mathrm{MM}=M$. mercenaria 


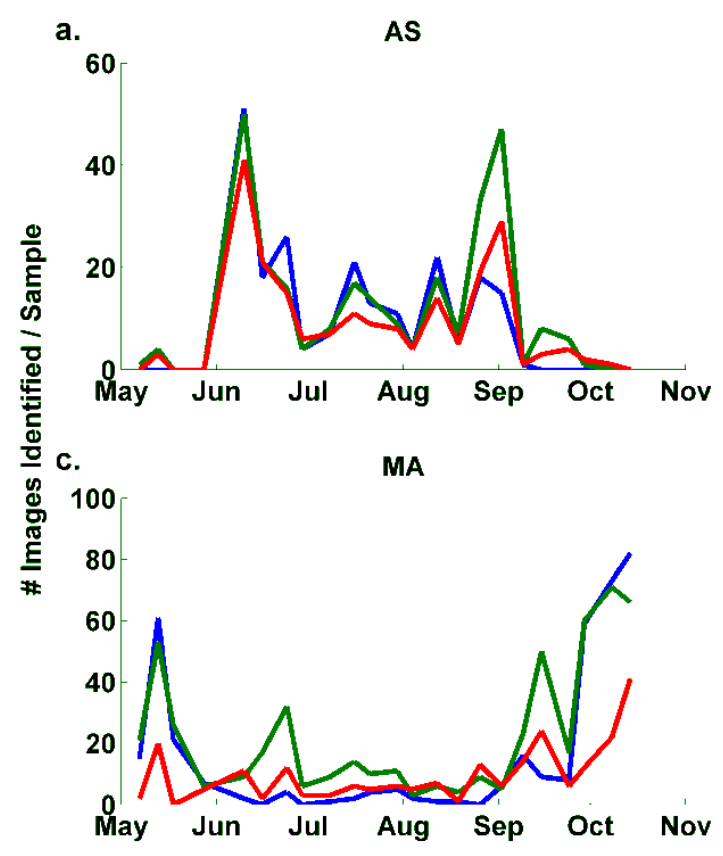

b.

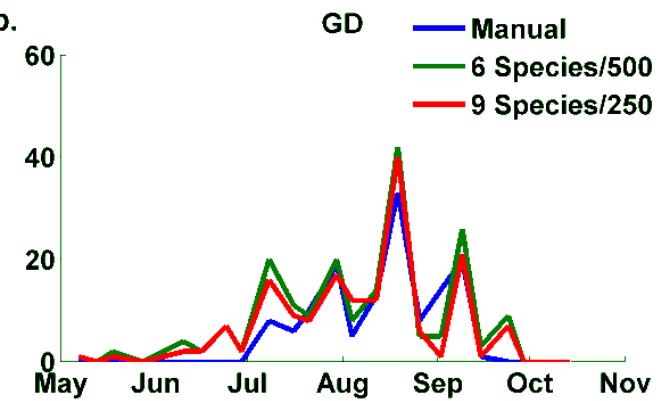

d.

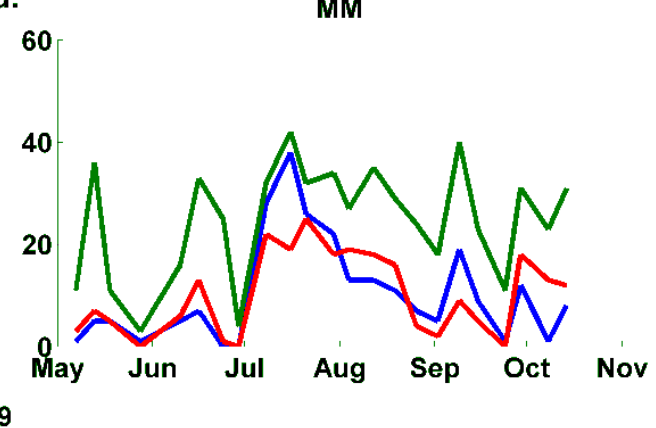

Figure 2.4 Manual sorting and computer classifier results for four species using the two field training sets. SVM classification results for two training sets (solid lines) are shown alongside manually sorted results (dashed line) for (a) Anomia simplex (AS), (b)

Geukensia demissa (GD), (c) Mya arenaria (MA) and (d) Mercenaria mercenaria (MM). The six-species training set contained 400-500 images for each species, and the ninespecies training set contained 250 images of each species. Results are shown as the number of classified images per sample of 100 larval bivalve images or less and plotted as a time series with the date the samples were taken. Samples were taken weekly from the middle of Waquoit Bay from May-October 2009. 


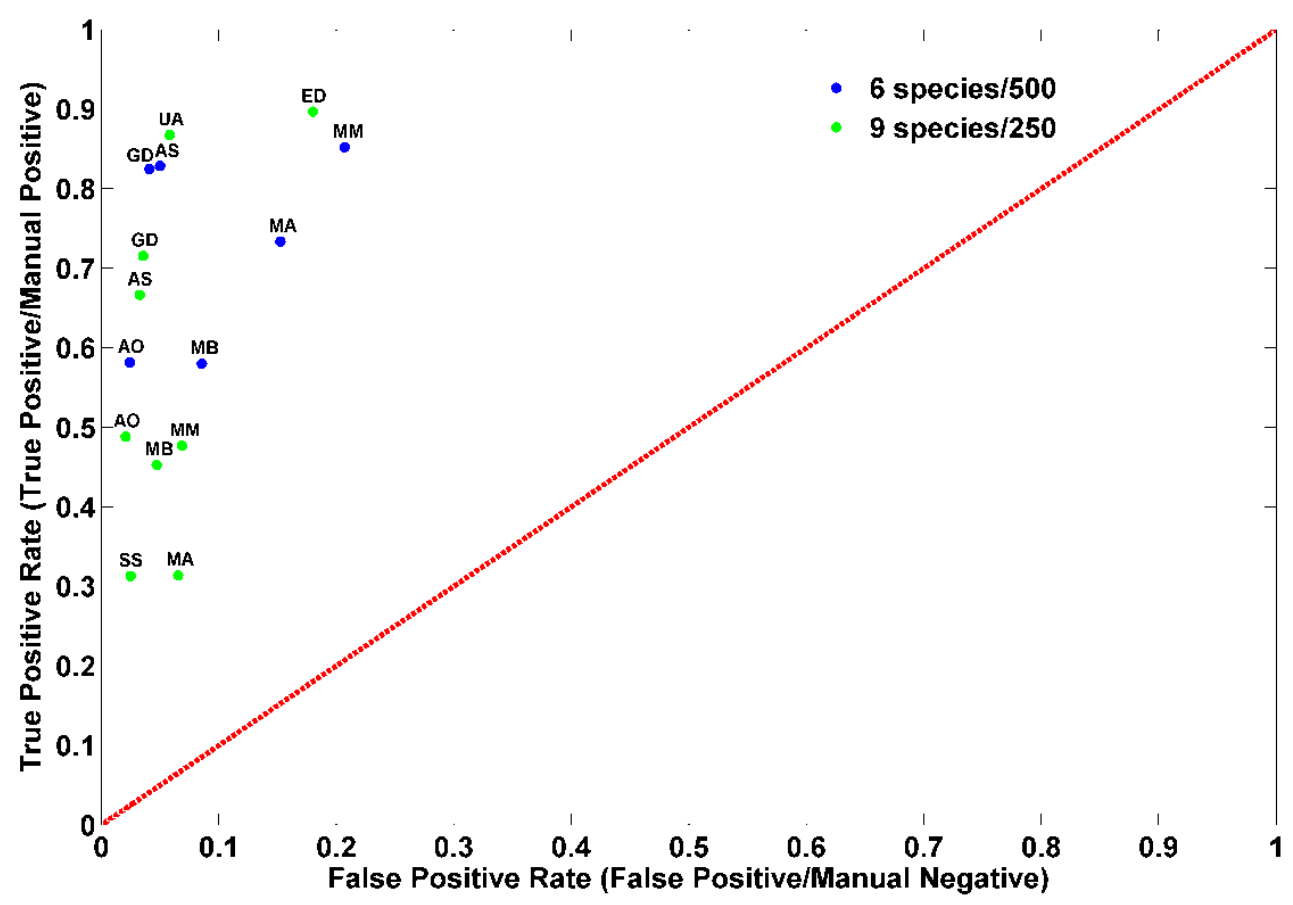

Figure 2.5 Receiver Operating Characteristic (ROC) plot for the two classifiers. False positive and true positive rate is shown for each species classified by the six-species training set (blue marker) and nine-species training set (green marker). True positive rate is defined by the total number of computer classified larvae that agreed with manual classifications (true positives) divided by the total number of manually classified larvae for that species. The false positive rate is defined by the total number of classified larvae of each species that did not agree with manual classifications divided by the total number of larvae that were not classified as that species. The dashed line shows 1:1 agreement representing a random performance of the classifier. Any point above this line represents good classification results. A perfect classifier would lie at $(0,1)$ representing $100 \%$ correct classifications and zero false positives. 


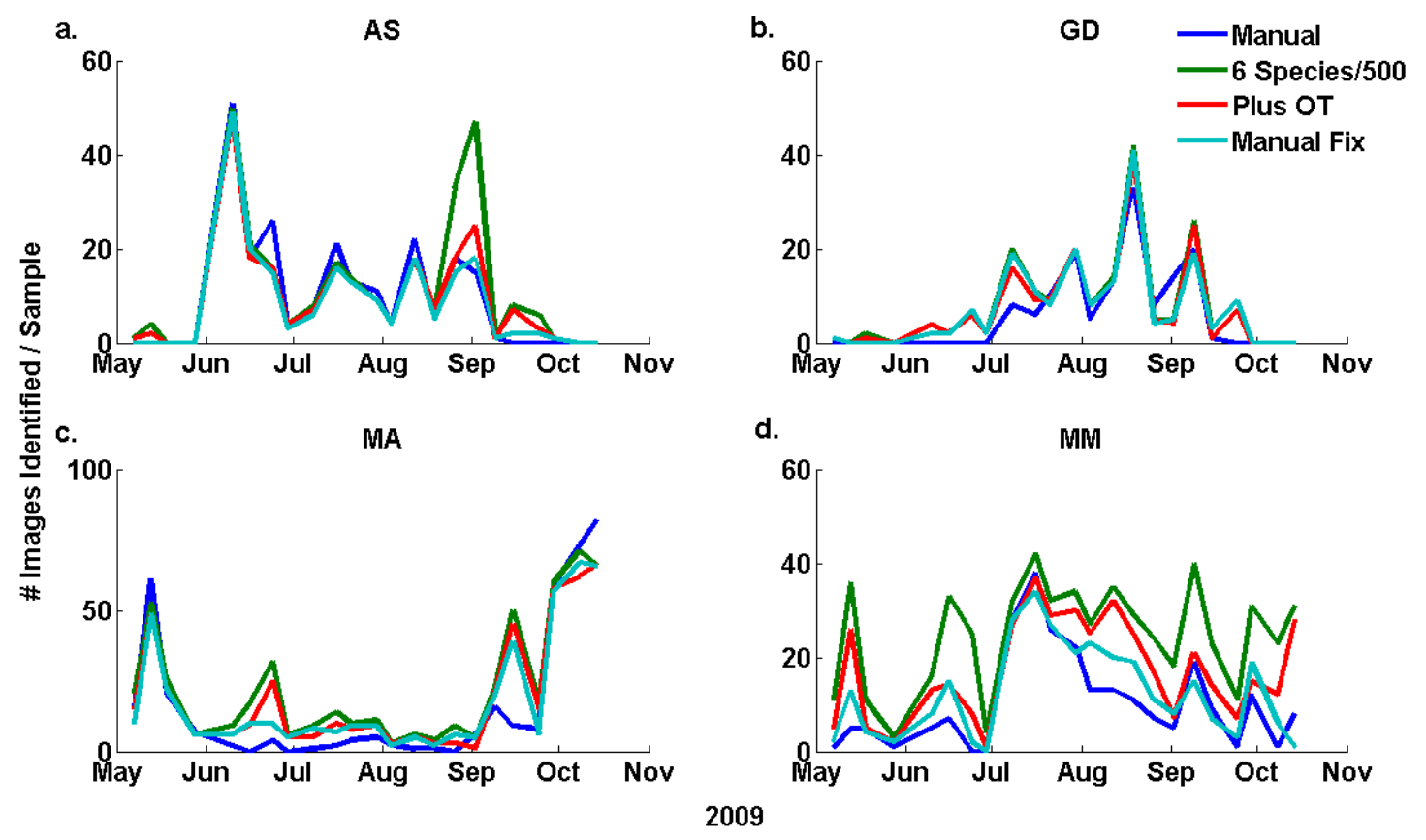

Figure 2.6 Improved classification results for the 6 species category training set. Timeseries of manually classified and computer classified larvae are shown with the results of two improvement methods. (a) Anomia simplex (AS), (b) Geukensia demissa (GD), (c) Mya arenaria (MA) and (d) Mercenaria mercenaria (MM). Results from the addition of a seventh "other" category (Plus OT) and a manual correction (Manual Fix) method are depicted for each species. Data are shown as the number of classified images per sample of 100 larval bivalve images or less plotted as a time series with sample date. 

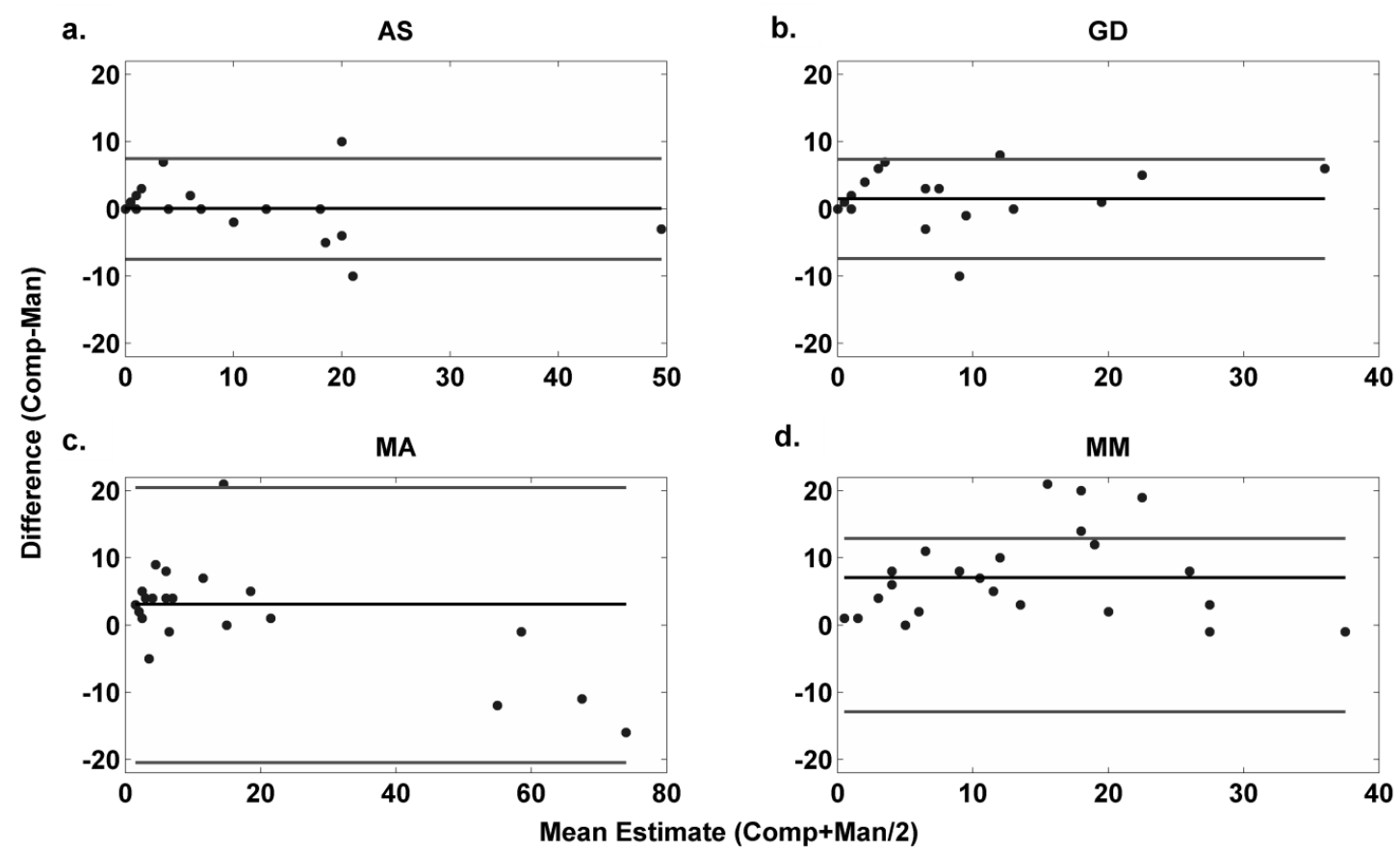

Figure 2.7 Bland-Altman plot of residuals for six-species classifier agreement after addition of a seventh "other" category. The difference between the number of computer classified and manually classified larvae of each species are plotted against the mean value of both estimates for (a) A. simplex (AS), (b) G. demissa (GD), (c) M. arenaria (MA) and (d) M. mercenaria (MM). Mean difference (dark line) and $95 \%$ confidence intervals for estimates with zero mean difference (light lines) are shown for each species. A perfect correspondence would have all points on the $y=0$ line. 

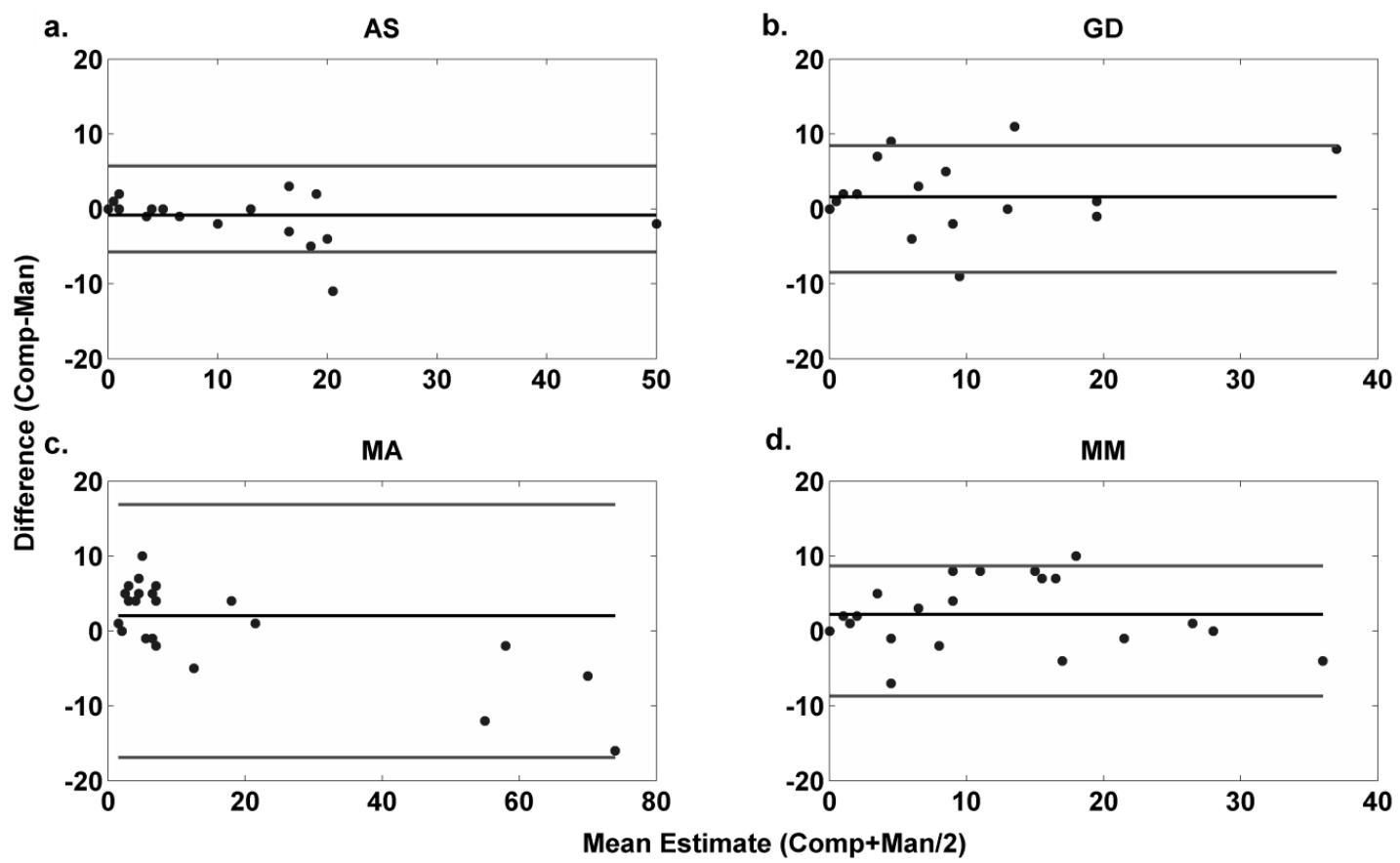

Figure 2.8 Bland-Altman plot of residuals for six-species classifier agreement with manual correction. The difference between the number of computer classified and manually classified larvae of each species are plotted against the mean value of both estimates for (a) A. simplex (AS), (b) G. demissa (GD), (c) M. arenaria (MA) and (d) $M$. mercenaria (MM). Mean difference (dark line) and 95\% confidence intervals for estimates (light lines) are shown for each species. A perfect correspondence would have all points on the $\mathrm{y}=0$ line. 


\section{CHAPTER 3}

Species-Specific Abundance and Growth of Bivalve Larvae in Relation to Biological and Physical Conditions in Waquoit Bay, $M A$ 


\begin{abstract}
Physical and biological conditions impact recruitment and adult population structure of marine invertebrates by affecting early life history processes from spawning to post-settlement. We investigated how temperature, salinity and phytoplankton influenced larval abundance and growth for three species of bivalves over two nonconsecutive years in Waquoit Bay, MA. Abundance and mean shell length of Mercenaria mercenaria (quahog), Anomia simplex (jingle clam), and Geukensia demissa (ribbed mussel) were compared between locations in the bay and with environmental conditions. Shell birefringence patterns using polarized light microscopy were used to identify species. Abundances for all three species were lower in 2007 than in 2009 and were positively correlated with temperature. Differences in abundance and size structure between bay sites were attributed to salinity tolerances and potential source locations. We used size-frequency distributions to identify larval cohorts and estimate species' growth rates for both years. Higher growth in 2009 was likely due to high temperatures and greater food availability for the peak months of July and August compared to 2007. Knowing the optimal periods and locations for larval abundance and growth can be useful for isolating species-specific patterns in larval dispersal and to aid resource managers in enhancing or restoring depleted populations.
\end{abstract}




\subsection{INTRODUCTION}

The dispersal and supply of planktonic invertebrate larvae has important consequences for benthic adult population structure (Roughgarden 1988). The strength of larval flux to a given habitat or area can vary from year to year because of environmental conditions (Thorson 1950, Shirley and Shirley 1989, Gaines and Bertness 1992). Larval supply can be influenced by many factors including the timing of larval release or spawning, local hydrographic effects, larval behavior, and quality of larvae (Scheltema 1986, Todd 1998). Particularly for areas where commercial adult populations are managed, larval supply can be a link in the relationship between reproductive output and population growth (Botsford et al. 1998).

Understanding bivalve larval supply is essential to understanding the relationship between larval abundance and the population structure at later stages. Many bivalve species are harvested commercially, and natural population stocks are typically managed by studying adult survivorship and fecundity without accounting for the larval period (Orensanz et al. 1991). When measurements of adult reproductive effort do not support their subsequent recruitment, it could be due to larval success which is rarely measured. It is difficult to study pelagic larvae because of their microscopic size, short larval period compared to the adult lifespan, high mortality, and ability to disperse long distances (Levin 2006). A need for more in-depth studies of bivalve larvae has been expressed for years (Carriker 1988, Mann 1988), but progress has lagged behind that of other invertebrate larvae because of a lack of usable techniques to identify bivalve larvae at the species level (Garland and Zimmer 2002). 
Many of the biological and physical controls on larval abundance are subject to seasonal and annual variation that can affect yearly recruitment dynamics (Botsford et al. 1994). Wind speed and direction can affect estuarine retention time (Geyer 1997), leading to fluctuations in larval import and export from an estuary (Boicurt 1988, Gaines and Bertness 1992, Belgrano et al. 1995). Adult spawning can be affected by water temperature and adult fecundity (Keck et al. 1975, Kassner and Malouf 1982), which can affect larval survival, growth and recruitment (Loosanoff et al. 1951, Davis and Calabrese 1964, Brousseau 1977, Gallager et al. 1986, Pechenikee et al. 1990, Dekshenieks et al. 1993). Areas of low salinity can be intolerable to certain species of bivalves (Loosanoff and Davis 1963). Furthermore, environmental factors such as food availability and water temperature will determine the length of larval development which can affect survival and dispersal distance (Loosanoff et al. 1951, Jorgensen 1981, Raby et al. 1994). Timing of phytoplankton blooms have been shown to affect abundances of fish (Townsend and Cammen 1988) and crab larvae (Shirley and Shirely 1989), but under estuarine conditions typical bloom patterns do not always occur (Litaker et al. 1987, Tomasky-Holmes 2008). These factors can vary spatially with certain areas being more favorable for growth or retention than others. Although it is challenging to isolate the effects of one particular environmental variable on larval abundance and growth in the field, by concentrating on a few environmental variables over a long time series we may be able to discern which factors have a greater effect on larval abundance on a seasonal and bay-wide scale. 
A majority of studies on larval bivalve growth and feeding have been performed in laboratories (e.g. Loosanoff and Davis 1963), demonstrating growth responses to temperature, salinity, and food availability (Loosanoff et al. 1951, Davis and Calabrese 1964, Gallager et al. 1986, Dekshenieks et al. 1993). Effects of these factors on larval growth rates in the field is not well documented due to challenges with larval sampling, as well as confounding factors such as advection and mortality due to predation. A few studies have attempted to follow growth of larval cohorts from estimates of their size frequency distributions (Jorgensen 1981, Chicharo and Chicaro 2001, Rigal et al. 2010), but this is most applicable for closed systems with high retention.

The purpose of our study was to investigate the biological and physical factors affecting larval abundance and growth of three species for 2007 and 2009 in Waquoit Bay, an embayment on Cape Cod, MA. Mercenaria mercenaria (quahog), is a commercially important shellfish resource for the bay and is found in open waters with sandy bottoms; Guekensia demissa (ribbed mussel) grows along the banks in marsh channels and is an important filter of nitrogen for these systems (Jordan and Valiela 1982); and Anomia simplex is a widespread fouling organism around Cape Cod often found attached to rocks and shells (Eckman 1987). We compared time-series of abundance and size of these three species of bivalve larvae from four sites in Waquoit Bay from May through mid-October (when water temperatures exceeded $15^{\circ} \mathrm{C}$ ) and applied a state-of-the-art image-analysis method using shell birefringence patterns to distinguish larval species (Twiari and Gallager 2003a,b, Chapter 2). Environmental conditions prevailing during two non-consecutive years of data collection allowed us to 
compare a warm, dry year (2007) to an initially cooler, wet year (2009). We hypothesized that better food quality in 2009 would result in more growth of larvae. We addressed the following questions: (1) Do abundance and mean larval size differ among sites and between years? (2) How does variation in environmental variables at each site and between years influence larval supply? and (3) On a bay-wide scale, how do cohorts of larvae grow with time, and how might this explain recruitment over both years? This study presents a novel effort to address species-specific questions in larval supply in Waquoit Bay and relate them to population dynamics and management issues.

\subsection{METHODS}

3.2.1 Study Site and Sampling Locations. Waquoit Bay is a $16 \mathrm{~km}^{2}$ estuary on the south shore of Cape Cod, Massachusetts. The average depth in the bay is $2.5 \mathrm{~m}$ with an average tidal range of about $0.5 \mathrm{~m}$ (Howes et al. 2004). Waquoit Bay exchanges water with outer Nantucket Sound through two inlets with a residence time of 2-3 days and is subject to occasional enhancement or reduction of exchange via wind forcing (Geyer 1997). The main freshwater input to Waquoit Bay is through groundwater, but several sub-embayments exchange water with the main bay and vary with freshwater and nutrient inputs (Howes et al. 2004). Residence times in the sub-embayments are higher than the main bay on the order of a several days to weeks (Howes et al. 2004, Tomasky-Holmes 2008). We sampled at four sites representing different areas of the bay (Fig. 3.1). The Menauhant site (MN) is the western inlet to the bay, Little River (LR) is a well-mixed sub-embayment on the eastern side, Waquoit Bay - Metoxit Point site (WB) is located in the middle of the bay proper, and the Childs River site (CR) is a sub-embayment 
upstream of the western inlet and has the lowest salinities and highest nutrient concentrations. In 2007 weekly samples were taken from 23 May - 26 October and in 2009 samples were taken weekly from 7 May - 14 October. These periods correspond to temperatures exceeding $15^{\circ} \mathrm{C}$, which favor spawning of most local bivalves. Samples collected in 2008 were inadequate for analysis for the purposes of this study.

3.2.2 Larval Sampling Procedure. On each sampling date, all four sites were sampled within 3-5 hours. Plankton samples were taken either from a small boat or a dock using a bilge pump (West Marine BilgePro 2200) attached to a hose and powered either from the boat console or a portable $12 \mathrm{~V}$ battery at $18-24 \mathrm{~L} / \mathrm{min}$. Samples were taken by slowly moving the pump through the surface to $20 \mathrm{~cm}$ above the bottom in order to get a depth-integrated sample of 100-200 L. Water was filtered through a $53 \mu$ mylon mesh PVC screen with a pre-screen of $333 \mu \mathrm{m}$ mesh. All filtered samples were immediately preserved in $4 \%$ buffered formalin.

3.2.3 Sample Processing and Larval Identification. Plankton samples were first counted in full or by volumetric sub-sampling for denser samples (to ensure at least 300 individuals were counted per sample) under a dissection microscope. Volumes were standardized to one cubic meter. One-hundred larvae were then subsampled from the total sample (or the total sample was used if it contained fewer than 100 individuals) and individually imaged using a Zeiss IM35 microscope fitted with a 4 Megapixel digital camera (Moticam 1000), polarization filter, and full wave compensation plate. Motic Images Plus (version 2.0; Motic China Group, Ltd.) was used to capture each polarized image (see Chapter 2 for details on optical setup). 
Several criteria for identification were used to ensure accuracy. Field identification guides of Chanley and Andrews (1971) and Loosanoff et al. (1966) were used for morphology and size criteria. A polarized image library of confirmed hatchery reared and molecularly identified field collected larvae was used to confirm birefringence patterns for each species. These patterns have been shown to be species-specific and can aid in larval identification (Tiwari and Gallager 2003). Based on these criteria, we sorted images into fourteen species categories. Only the larval images that were identified as $A$. simplex, G. demissa, or M. mercenaria, composing about one-third of the images, were used in further analysis as identifications of these species were molecularly confirmed.

Measurements of each larval shell were made by masking each larval image from its background and cropping it to only the region of the larval shell. An edge-detection image analysis routine in MATLAB (version R2009a; Mathworks, Inc.) was used to obtain major and minor axes in pixels, which were converted to microns by calibration with a stage micrometer.

3.2.4 Phytoplankton Counts. Alongside each larval sample, $100 \mathrm{~mL}$ of unfiltered water was sampled from the water column. Phytoplankton were identified and counted microscopically on a hemacytometer slide for each untreated sample within a few hours after collection. Subsamples of $10^{-3}$ to $10^{-1} \mathrm{ml}$ were counted depending on phytoplankton density. The larger volumes were examined by counting multiple chambers per sample.

3.2.5 Environmental Data. Measurements of temperature, salinity, pressure (depth), chlorophyll a, and other parameters were recorded in 15 minute intervals from 
moored units (YSI 6600 sonde, YSI Inc.) at each sampling location (Fig. 3.1). Three sites (MN, WB, and CR) were maintained by the Waquoit Bay National Estuarine Research Reserve's (WBNERR) seawater quality monitoring program (SWMP), and the Little River instrument was maintained by the Mashpee Shellfish Constable. Wind speed and direction were recorded from a weather station at the WBNERR facility on the north end of Waquoit Bay. Data from these instruments were averaged daily during the sampling period.

A handheld instrument (YSI 650 MDS, YSI Inc.) recorded instantaneous temperature, salinity, and occasionally dissolved oxygen at the time of plankton collection. Measurements were taken at the surface, middle, and bottom of the water column. We noted if the water column was stratified based on if salinity and temperature differed between the surface and bottom and then averaged the values for each sample.

3.2.6 Time-Series Analysis. Autocorrelation analysis on time series of each species' concentration and mean size at each site was performed to determine the scale of independence for the samples and if there was periodicity. Series means were initially subtracted from each value. Only autocorrelations at lags of 1-2 weeks were considered meaningful based on the total length of our time series (less than 20\%, Emery and Thomson 1997). To determine if larval abundance and size structure were coherent between sites, cross-correlation analyses were performed between pairs of sites for species concentrations and mean sizes. Data were lagged in both directions by weekly time steps. In the few cases of missing data points due to a lost sample or instrument failure (no more than two per series), the missing data point was interpolated using a 
quadratic spline to ensure continuity of the time series for analysis. The time scale for independent samples for each time series was determined by the time point where the autocorrelation was no longer significantly different from zero (alpha $=0.05)$. Degrees of freedom were calculated by dividing the total length of the time series by the time scale for independent realizations. Although this is a less conservative approach than using decorrelation times (the time point when the autocorrelation function crosses the $\mathrm{x}$-axis), we chose this method because the time series was only 24 points and most of the series had no autocorrelation.

We explored possible associations between larval concentrations and physical measurements of temperature, salinity and chlorophyll using the autocorrelation and cross-correlation methods described above. For these cross-correlations, the log of larval concentration was used to normalize the variance of larval time series with respect to the physical variables. We also performed simple correlation analyses on independent samples from each site for periods only when larvae were present. Temperature and salinity values were recorded simultaneously with each larval sample, and chlorophyll values from the continuous records were averaged for the tidal period when the sample was taken. All statistical tests were performed using MATLAB and SYSTAT (version 12.0; SPSS, Inc) software.

3.2.7 Cohort Analysis. In order to estimate growth rates for each species, we performed a species-specific size-class separation analysis to distinguish different cohorts of larvae based on larval shell length. This allowed us to estimate time periods of the major spawning events for each species, and to follow the growth of these spawns 
through time. Cohort analysis is often performed to assess growth in cases where individuals cannot be aged. Cohorts are determined by extracting component groups from polymodal size frequency samples, with each mode corresponding to a different cohort (Cassie 1954, Jones 1990). We define new cohorts in this study as a pool of larvae spawned between two consecutive samples. Growth rates of larvae from A. simplex, $G$. demissa, and $M$. mercenaria ranged from 2 to $5 \mu \mathrm{m}$ per day as estimated from individual laboratory cultures (methods for rearing in Chapter 2). Thus, we would expect the mean size of our different cohorts to range from about 10 to $50 \mu \mathrm{m}$ based on the amount of time between the samples (5 to 10 days) and conditions for larval growth. In some cases, more than one new cohort could be detected between samples if growth rates were fast enough to form two distinct size classes. In this analysis, we assumed all larvae were from the same population and there was no net import or export, only mortality. We pooled larvae from all of our sites for each species to cover a greater potential spawning and dispersal area and to increase the sample size.

When ten or more total larvae for a species were present for a given sampling day, we used histograms of larval sizes to estimate the number of cohorts present in the sample. This method assumes that individual sizes within a cohort follow a Gaussian distribution, and multiple cohorts can be detected using maximum likelihood criteria to split size data into specific age-groups (Bohning et al. 1992). This method represents a computerized alternative to the manual separation method using probability paper (Cassie 1951, Brousseau 1977). Each histogram was evaluated by eye to determine the number of Gaussian distributions present, and the size data were run in an expectation-maximization 
(EM) algorithm in MATLAB. The EM algorithm worked by diving the range of the shell length data into equal parts based on a specified number of size groups and used maximum-likelihood criteria to estimate Gaussian parameters (mean, standard deviation) that best fit the data (Appendix B, Fig. B.1). The appropriate number of size groups estimated from the histograms was determined by the estimated mean and standard deviation for each group as calculated from the program. We then connected cohorts through time based on mean size, standard deviation, and growth estimates mentioned above. We used this time series of age group sizes to calculate a growth rate for each cohort. Not all distributions were matched to a cohort; occasionally spawning events did not show subsequent growth. This maximum likelihood method for Gaussian separation has been applied to adult shellfish populations as a measure of recruitment (Weisberger and Grassle 2003) and has also been applied successfully to larval gastropods (Rigal et al. 2010) and bivalves (Chiracho and Chiracho 2001).

\subsection{RESULTS}

3.3.1 Environmental Data. Records from the water quality monitoring instruments from the main bay site (WB) indicate that bay conditions in 2007 were warmer and had lower chlorophyll concentrations than 2009 (Fig. 3.2a, c), with the exception of a period in late August where temperatures in 2009 surpassed those of 2007. Temperature for both years ranged between $10-26^{\circ} \mathrm{C}$. Salinities were similar between the two years, with values oscillating around 27-32 PSU, with slightly fresher bay water in 2009 (Fig. 3.2b). Data from the other three sites are shown in Appendix A. 
We grouped phytoplankton into flagellates (flagellates plus dinoflagellates) and diatoms (including centric, pennate, Chaetocerous sp., Thalassiosira sp., Skeletonema sp., and Nitzschia sp.) to represent available food sources for larvae (Fig. 3.3). Flagellates represent the background available food source for larvae in the bay, and diatoms represent a more nutritious source when available. Food was extremely low in Little River, Menauhant, and the main bay (Fig. 3.3a,b,d) for May and June in 2007. The higher chlorophyll observed in 2009 was a result of diatom blooms from August through September.

The typical summer prevalent southwest wind pattern for southern Cape Cod was observed for both years (Fig. 3.4), with average onshore wind speeds around 0.5-1 m/s. This would lead to increased freshwater buildup and stratification within the bay (Geyer 1997). In spring and fall of 2009 there were sporadic storm events changing wind speed and direction, leading to more mixing and flushing of bay water during these periods.

3.3.2 Larval Abundance and Size. Though higher concentrations of total bivalve larvae were observed in May and June 2007 compared to 2009, after July concentrations in 2008 surpassed those of 2007 (Fig. 3.5). For both years, peak abundance occurred in July and August. Correlations were performed as a way to assess the consistency, or coherence, of larval abundance and size with space and time.

There was no significant autocorrelation beyond a one week lag for either year for both the abundance and mean size time series for all species with the exception of $G$. demissa abundance at Childs River in 2009, which was correlated for three weeks. We 
subtracted degrees of freedom by two or three for the autocorrelated time series in the cross-correlations.

For A. simplex, larvae were present from June through August in 2007 and from June through September with a few individuals into October in 2009 (Fig. 3.6a,b). Higher abundances of A. simplex were observed in 2009. A. simplex was observed first in the inlet site (MN) in 2007, but in 2009 the inner bay sites, Waquoit Bay and Little River, had the highest concentrations. In 2007, cross-correlations had both Menauhant and Waquoit bay concentrations lagging behind Little River (Table 3.1), and mean sizes were all correlated for these sites. Few A. simplex were observed at Childs River. In 2009, Little River and Waquoit Bay were significantly cross-correlated for A. simplex abundance, as were Menauhant and Childs River (Table 3.2), and there was a 1-2 week lag in cross-correlations between the two sides. Time-series of mean larval size for this species showed steady growth for most sites from June through August (Fig. 3.6c,d). Size structure was coherent between all sites in 2009 with the exception of Childs River. Larvae of the ribbed mussel, G. demissa, were mostly observed July through October both years (Fig. 3.7a,b). The highest concentrations were observed in July and August both years, but 2007 was more variable. In 2007, abundances at Waquoit Bay were correlated with both Little River and Menauhant (Table 3.1), and Menauhant was correlated to Childs River. Significant one-week lags for Waquoit Bay and Little River were observed with respect to Menauhant and Childs River. In 2009, G. demissa larvae were first observed from the Menauhant inlet site, farthest from the upper marsh regions where adults are more abundant. Positive and significant correlations were observed 
between Little River, Waquoit Bay, and Menauhant and between Childs River and Waquoit Bay in 2009 (Table 3.2). Little River lagged to concentrations at Childs River by one week, and Menauhant was weakly correlated to Childs River at both positive and negative weekly lags. Mean sizes for both years stayed low (Fig. 3.7c,d), with a few peaks in 2009 early and later in the series. Only Menauhant and Childs River had correlations with sizes in 2007, and all were lagged to Little River. All mean sizes were strongly correlated in 2009 indicating strong coherence in population structure throughout the bay.

M. mercenaria larvae show a bell-shaped abundance pattern for 2007 and 2009 time series with modes in July and August (Fig. 3.8a,b). Distributions between sites were similar for both years. In 2007, abundances at Menauhant and Waquoit Bay had a significant correlation and Little River abundances lagged all other sites by 1-2 weeks (Table 3.1). All sites lagged Childs River. In 2009, Little River abundances and sizes were significantly correlated with the Menauhant and Waquoit Bay sites (Table 3.2), and Childs River lagged Little River by one week. Peaks of larger-sized individuals were prominent early on in 2009 (Fig. 3.8d), suggesting a successful early spawn. The entire size time series for both years was indicative of short, quick growth cycles. Similarly to the other species, the M. mercenaria time series at Childs River were not significant with many other sites.

3.3.3 Relationship to Environmental Factors. We compared the abundance and distributions of each species in relation to temperature and salinity by plotting larval concentration (on a log scale) as a function of temperature and salinity (Figs. 3.9; 
Temperature-Salinity-Plankton diagram or T-S-P plot; Gallager et al. 1996). Bivalve larvae were commonly found in samples taken during high temperature and salinity conditions. Temperature and salinity trends were similar for both years, though 2009 had a wider range of salinities, due to lower Childs River salinities (squares). Little River (circles) had the highest ranges of observed temperatures in 2007, and Little River and Menauhant (triangles) had the highest ranges of temperatures in 2009. Results from both years show that larval concentrations peak above $20^{\circ} \mathrm{C}$ indicating that these three species are warm-water spawners.

Cross-correlations were made between temperature, salinity and chlorophyll time series for both years accounting for autocorrelation of each time series, as well as standard correlations comparing these factors in samples only when larvae were present. Many significant correlations with samples and temperature were observed for both years (Tables 3.3 and 3.4). Cross-correlations were significant between temperature and $A$. simplex and G. demissa abundance both years with the exception of A. simplex at Childs River in 2007. M. mercenaria was less consistent with temperature correlations between sites and between years. Salinity ranges were broader for G. demissa with abundant samples through mid-salinity ranges, but $A$. simplex and M. mercenaria favored higher salinities. Few significant relationships with salinity were seen, however. There was a negative correlation with salinity time series and A. simplex time series and for $M$. mercenaria larval samples and salinity for Menauhant in 2007. We only regarded correlations with salinities at no time lags to be relevant, as the salinity time series 
oscillates predominately at a tidal frequency, much shorter than our weekly sampling interval.

There were significant relationships to chlorophyll, but these relationships were not consistent and differed whether time-series or direct correlations were made (Table 3.3 and 3.4). Waquoit Bay chlorophyll was negatively cross-correlated with G. demissa larvae at Waquoit Bay, and positively cross-correlated with A. simplex. Stronger correlations were seen with $G$. demissa samples- a negative relationship with Childs River and positive with Waquoit Bay. The only significant relationship seen in 2009 was negative between M. mercenaria and Little River time series.

3.3.4 Larval Cohorts and Growth. Our method of cohort analysis by estimation maximization and Gaussian separation was able to identify groups of cohorts for all of our species in both years. Cohorts were identified if there was evidence of growth between samples. Figs. 3.10-3.12 show the frequency of different sizes in the samples over time, and sizes of individual cohorts are plotted below.

For A. simplex, we identified four cohorts in 2007 and eight cohorts in 2009 (Fig. 3.10). In 2007, no cohorts reached the appropriate settling size (Fig. 3.10b), estimated to be around $180 \mu \mathrm{m}$ or greater in laboratory cultures (Chanely and Andrews 1971). However, in 2009, cohort growth was higher with cohorts AS5-AS7 reaching appropriate settling length in August. This period also corresponded to the period of the highest temperatures in the bay (Fig. 3.2a).

For G. demissa and M. mercenaria, settlement size occurs around $200 \mu \mathrm{m}$ (Chanley and Andrews 1971). G. demissa had only five cohorts in 2007 and three cohorts 
in 2009 (Fig. 3.11). A few cohorts reached sizes close to settlement size, but the evidence was not strong that many of these cohorts would make it to settle in the bay in either year. For M. mercenaria, we found three cohorts in 2007 that failed to reach appropriate settlement size (Fig. 3.12a,c), but in 2009 we identified eight cohorts with MM1, MM3 and MM4 likely to have settled (Fig. 3.12 b,d). Peak growth time for 2009 was in July and August, which correspond to the highest temperatures and food concentrations for both years. An early appearance of large M. mercenaria individuals appeared in early 2009, during lower temperatures and food availability. M. mercenaria were also present in May in 2007 but at concentrations that were too low to be analyzed.

We compared weekly growth rates of each cohort to growth rates of larvae reared in the laboratory. We averaged the growth rates for each cohort in 2007 (Table 3.5) and 2009 (Table 3.6). A. simplex growth rates were higher for cohorts in 2009, with growth rates on par with those observed in the laboratory. G. demissa had similar growth rates for both years, mostly lower than the laboratory growth rates. M. mercenaria had greater growth in 2009 than 2007, but both years were mostly below what was observed in the laboratory.

\subsection{DISCUSSION}

The purpose of this study was to investigate environmental factors that might have influenced observed larval abundances on a weekly scale. We were able to document two very different years in terms of biological and physical characteristics, and we suggest this had a pronounced affect on larval concentrations and growth. We used cross-correlation analyses to determine whether such characteristics had a relationship 
with larval abundance, however these results are not absolute. There could be many other mechanisms leading to the observed patterns in larval abundance and growth that were not investigated in this study, such as transport from other areas and environmental conditions and spawning rates from nearby populations. This study suggests water temperature and food availability fluctuations can lead to yearly fluctuations in larval abundance and growth. These differences can affect potential settling of adults, emphasizing the importance of recognizing larval stages in management applications. Because enhancement efforts can rely heavily on spat collection to assess recruitment, knowing when and where to place collectors would be extremely valuable to maximize returns.

\subsubsection{Relationships with Environmental Conditions. We looked at larval} abundance over two years when environmental conditions within the bay differed with respect to temperature, chlorophyll and food quality. If we use the number of cohorts as a proxy for spawning activity, spawning was less in 2007 despite higher temperatures. In 2009, bivalve larval concentrations for the Waquoit Bay site and Little River reached up to $9 \times 10^{4} / \mathrm{m}^{3}(90 / \mathrm{L})$ which are extremely high concentrations, even for an estuary. Typical reported peaks range from a few hundred to thousand bivalves per $\mathrm{m}^{3}$ (Wood and Hargis 1971, Andrews 1983, Garland 2000), suggesting that Waquoit Bay is an abundant pool of bivalve larvae when conditions are right.

Relationships between environmental conditions and individual species suggested that temperature was most influential at predicting larval abundance for each species on a temporal scale, and salinity was more important on a spatial scale. Abundances of each 
species indicated that $20^{\circ} \mathrm{C}$ and above are optimal temperatures for larval abundance, most likely due to peak spawning. Correlations with temperature were seen at all sites both years. M. mercenaria was the only species found to be consistently present below $20^{\circ} \mathrm{C}$. In contrast, salinity did not vary much temporally, but showed variations between sites. Site-specific differences in salinities highlight potential larval tolerances for each species, with $G$. demissa being most abundant during low salinity periods in Childs River, and A. simplex being the least tolerant to low salinity conditions. However, this relationship could also be explained by proximity to sources or different patterns in dispersal between species.

Negative correlations with A. simplex and G. demissa abundances and salinity at Menauhant in 2007 suggest that there could have been tidal effect on with more larvae present on outgoing tides, but this pattern could easily be causation and merits further investigation on a tidal scale (see Chapter 4). Although we did see some significant relationships to chlorophyll at Little River and Waquoit Bay, for Little River these were negative and suggest that larvae are not necessarily associated with areas of high chlorophyll. It is possible that the extremely high concentrations of larvae associated with these samples were effective at grazing the phytoplankton down to the lower levels observed, particularly for 2009. In 2007, G. demissa had a negative relationship with chlorophyll at Childs River which could be due to blooms of large dinoflagellates which created a lot of turbidity and could be a deterrent to larvae. Overall, relationships to chlorophyll were inconsistent, and other field studies of bivalve larvae have also failed to find associations with chlorophyll (Tremblay and Sinclair 1990, Raby et al. 1994). 
3.4.2 Food Quality. We compared the abundance of diatoms, a quality larval food source, and flagellates, a mediocre food source, for both years. There was very little available phytoplankton that would be suitable for larval ingestion and growth in May and June of 2007. Diatom blooms coinciding with higher temperatures in July and August 2009 could have lead to the observed higher growth for this year.

Bivalve larvae typically consume food particles in the pico- to nano- plankton size range of $0.5-12 \mu \mathrm{m}$, occasionally ingesting large particles up to $30 \mu \mathrm{m}$ if abundant (Baldwin and Newell 1995). However, it is well documented that bivalve larvae are capable of ingesting bacteria (Douillet 1993, Gallager et al. 1994, Tomaru et al. 2000), although it mostly only supplements growth on a phytoplankton-based diet (Baldwin and Newell 1991). It has been shown that larvae can grow in estuarine conditions with low natural phytoplankton abundances, although growth patterns are species-specific (Crisp et al. 1985), and diets are likely supplemented with bacteria or detritus (Fritz et al. 1984). Under ideal conditions, growth rates should be between 2-7 $\mu \mathrm{m} /$ day, but larvae can continue shell growth without food by depleting tissue for energy (Crisp et al. 1985). Growth rates for 2009 were mostly in this range, but for 2007 our growth rates were lower suggesting that low food quality may have limited growth. In Waquoit Bay, concentrations of nanoplankton are usually highest in the summer, but picoplankton are generally rare (Tomasky-Holmes 2008). Nutrients may have been limiting to growth in 2007, but the increased nutrient loading via freshwater induced by the spring rains in 2009 enabled phytoplankton to flourish and provide a stable food source for larvae. 
More predation could explain the observed low growth of larvae in 2007 if food was not limiting. Although predation may be relatively low for larvae overall, certain predators, if abundant, are capable of reducing a bivalve larval population by upwards of 80\% (Johnson and Shanks 2003). In 2007 the ctenophore Mnemiopsis leidyi was more abundant than in 2009 (C.M. Thompson, WHOI, pers. obs.) and could have reduced larval abundance through top-down control.

3.4.3 Site-Specific Abundance. Patterns in species abundances with time at different sites can allow us to make predications based on dispersal. Larval abundance at most sites was autocorrelated for a maximum of two weeks, which is on the order of water residence times and the larval development period. Comparing locations, there were significant correlations in abundance between the sites on the eastern sides of the bay (Little River and Waquoit Bay site) and the western channels (Menauhant inlet and Childs River), though these relationships were not consistent for all species or for both years. This suggests that there are both periods of limited dispersal and homogeneity throughout a spawning season for different species. Childs River often showed distinct abundance patterns from the other sites, which could be a result of its lower salinities, higher nutrients, and longer retention times (Tomasky-Holmes 2008).

All sites were separated by only 1-2 km, emphasizing the patchiness within the system. Flow dynamics through an inlet are different than flow through estuarine channels and open water. In Waquoit Bay, the inlets have the strongest flows and exchange water rapidly with the main bay. Flows through sub-embayments vary, exchanging waters over 1-3 days with the bay proper, but have much longer residence 
times within the whole bay system due to marsh storage areas (Howes et al. 2004). In addition, sporadic wind forcing from the north can disrupt stratification and lead to increased flushing of the bay (Geyer 1997), which may be responsible for occasional decreases in concentration, such as the decrease in larval concentrations in late June 2009 (Figs. 3.4b and 3.5b). Increased wind speeds in 2009 could have led to increased mixing and transport in the bay and could account for the larger presence of larvae, particularly A. simplex, upstream at Childs River.

3.4.4 Species-Specific Abundance and Growth. By studying different species, we were able to capture year-to-year differences in larval abundance and growth, which is rare for studies of bivalve larvae. Despite its commercial importance to the area, there have been few studies documenting $M$. mercenaria spawning for Cape Cod. Spawning of M. mercenaria has been documented for areas south of Long Island from June November (Loosanoff et al. 1951, Keck et al. 1975). Our study showed that $M$. mercenaria larvae were present as early as mid-May in both 2007 and 2009. As $M$. mercenaria has adapted to a wide range of conditions in its geographic range, it would not be surprising if populations off New England spawned earlier when waters initially reach $15^{\circ} \mathrm{C}$, especially in estuaries.

M. mercenaria had a coherent population structure within Waquoit Bay in 2009 as both abundance and sizes were correlated between sites indicating the population was well-dispersed and uniform throughout the bay. There was less coherence in 2007. Results indicated that Little River and Waquoit Bay could be source or spawning locations as larvae were more abundant and initially appeared there. However, it is 
possible Little River was not a large M. mercenaria source in 2007 which would explain the observed lower abundances and lags behind other sites. The highest growth for $M$. mercenaria was in August 2009 when cohorts were able to reach a setting size of $200 \mu \mathrm{m}$ (Carriker 1961). M. mercenaria cohorts later into the season did get as large, though it is possible for M. mercenaria larvae to develop at smaller sizes when conditions are not as favorable (Davis and Calabrese 1964). Reduced growth could also be attributed to cooling temperatures, predation or low dissolved oxygen. A high number of $M$. mercenaria recruits in 2010 (R.H. York, pers. obs.) can now be traced to the favorable conditions and high larval supply in mid-summer 2009.

For the jingle clam, A. simplex, different conclusions can be made. Abundance and population structure were separated between sides of the bay, and no relationships between sites were observed in 2007 when overall abundances were low. Little River was a likely source population, and early 2007 data indicated a possible source of A. simplex larvae from the inlet. There was some evidence for this species to be found in bay waters on ebbing tides, supporting an estuarine source for A. simplex. The low salinities observed in Childs River in 2007 may explain the low concentrations observed at that site compared to 2009. More upstream transport from the inlet may have caused A. simplex abundance in Childs River to be correlated with Menauhant in 2009. As the adult lifespan for A. simplex is only 1-2 years (Chanley and Andrews 1971), year-to-year differences in larval abundance would depend on the previous year's recruitment and might explain the patchiness and inconsistencies observed between years. Since our multitude of cohorts of A. simplex seems to suggest it is a pulse spawner, our data suggest these spawns may 
come from different locations. Larval periods of 3-4 weeks are typical for this species (Chanely and Andrews 1971), so retention could also be an issue.

Despite both $M$. mercenaria and A. simplex achieving growth that would lead to settlement in Waquoit Bay, G. demissa larvae showed little growth in 2009 despite maintaining a stable population in the bay. It is likely that marsh areas in the bay, and channels like Little River, were sources of larvae for G. demissa, though some larvae were found in the inlet site early on in 2009. It remains uncertain why G. demissa had reduced growth compared to the other species when all were present concurrently. Rigal et al. 2010 found that tidal efflux resulted in a lack of settlement-stage gastropod larvae in an embayment. Since $G$. demissa had the lowest growth rates in the laboratory, it is possible that a longer development time and transport processes would lead to more $G$. demissa flushed out of the bay. For instance, larvae spawned in marsh channels on an outgoing tide could be instantly flushed out of the bay and not retained as well as $M$. mercenaria larvae spawned in the middle of the bay and caught in a gyre or transported to a channel with higher retention times.

3.4.5 Cohort Analysis. In this study, we used cohorts as determined from sizefrequency distributions to estimate species-specific growth rates. Since individuals could not be aged, this method can be very subjective for determining the number of cohorts present and grouping them temporally. Sporadic wind events leading to flushing, or overall net export, would have violated our assumption of no exchange. Furthermore, our observed site-specific differences may have invalidated the assumption of bay-wide homogeneity we made to pool the samples. This assumption is investigated in Appendix 
$\mathrm{C}$ which shows that sites contain different pools of larval sizes. If there were areas with lower sizes compared to others, this may bias our growth rate calculations to underestimate growth rates for periods when larger larvae are more abundant. It is likely that the number of spawns we found were overestimated due to larvae that did not grow from a previous cohort. Also, we cannot assume that site homogeneity is consistent between years. Higher growth rates observed for A. simplex in 2009 may be the result of having higher abundances at Little River and Waqouit Bay, but growth rates remained low and comparable to 2007 for Childs River and Menauhant. Still, we argue that cohort separation is a useful tool for separating larger size groups from a distribution, and it enabled us to estimate growth rates we could not have otherwise calculated.

Here we considered larval supply in terms of estimates of larval abundance and growth rates and proposed a relationship to recruitment based on these factors alone. We did not consider larval settlement, another factor that can regulate larval recruitment. In some cases, post-settlement survival ultimately regulates juvenile and adult population structure (Roegner and Mann 1995). Furthermore, by sampling at a weekly scale, the temporal resolution in our study was not adequate to fully assess larval transport and retention at these sites, and larval export may have contributed to our observed low concentrations of larger individuals. This will be explored further in Chapter 4.

3.4.6 Summary. By performing a species-specific study using a new method to identify bivalve larvae, we were able to depict spatial and temporal trends and uncover environmental factors that may regulate larval supply for each species. We observed general patterns affecting larval abundance, such as seasonal temperature and site- 
specific salinity differences. Species-specific patterns suggested that for a commercial species like $M$. mercenaria, higher recruitment based on larval supply alone would likely be achieved in a year with high temperatures and abundant quality food. For an ecologically important species like $G$. demissa, our study suggests that recruitment was low, and that larval supply may be subsidized from other marsh areas or limited to the few individuals that get retained in high-retention areas of the bay. Because Waquoit Bay has abundant shellfish resources for both recreational and commercial fisheries and such a high abundance of larvae, a study such as ours is necessary to understand the factors regulating these valuable resources and to managing future populations and biodiversity.

\subsection{ACKNOWLEDGEMENTS}

The authors would like to thank the Waquoit Bay National Estuarine Research Reserve staff for their help and expertise with sampling, data, equipment and logistics for this study. We would especially like to thank C. Weidman, M.K. Fox, and E. Bonk. Field assistance was provided by M. Potter, A. York, C. Mingione, and M. Mingione. V. Starczak and R. Horwitz assisted with data interpretation and statistical analysis. We would also like to thank C. Swain of Edwards Boat Yard, Falmouth, MA, M. Loftus of the Menauhant Yacht Club, Falmouth, MA, and P. Ellis, Mashpee Harbormaster, Mashpee, MA for allowing access to sampling locations. This research was conducted in the National Estuarine Research Reserve System under an award to S. Gallager and C. Mingione Thompson from the Estuarine Reserves Division, Office of Ocean and Coastal Resource Management, National Ocean Service, National Oceanic and Atmospheric Administration.

\subsection{LITERATURE CITED}

Andrews, J.D. 1983. Transport of bivalve larvae in James River, Virginia. J. Shellfish Res. 3(1): 29-40.

Baldwin, B.S. and R.I.E. Newell. 1991. Omnivorous feeding by planktotrophic larvae of the eastern oyster Crassostrea virginica. Mar. Ecol. Prog. Ser. 78: 285-301.

Baldwin, B.S. and R.I.E. Newell. 1995. Relative importance of different size food particles in the natural diet of oyster larvae (Crassostrea virginica). Mar. Ecol. Prog. Ser. 120: 135-145. 
Belgrano, A., P. Legendre, J.M. Dewarumex, S. Frontier. 1995. Spatial structure and ecological variation of meroplankton on the Belgian-Dutch coast of the North Sea. Mar. Ecol. Prog. Ser. 128: 51-59.

Boicurt, W.C. 1988. Recruitment dependence on planktonic transport in coastal waters. In: Rothschild, B.J. (ed.), Toward a Theory on Biological-Physical Interactions in the World Ocean. Kluwer Academic Publishers, pp. 183-202.

Bohning, D., P. Schlattmann, and B. Lindsay. 1992. Computer-assisted analysis of mixtures (C.A.MAN): statistical algorithms. Biometrics 48: 283-303.

Botsford, L.W., C.L. Moloney, A. Hastings, J.L. Largier, T.M. Powell, K. Higgins and J.F. Quinn. 1994. The influence of spatially and temporally varying oceanographic conditions on meroplanktonic metapopulations. Deep-Sea Res. II 41: 107-145.

Botsford, L.W., S.R. Wing, and J.L. Largier. 1998. Population dynamics and management implications of larval dispersal. S. Afr. J. of Marine Sci.19: 131-142.

Brousseau, D.J. 1977. Spawning cycle, fecundity, and recruitment in a population of softshell clam, Mya arenaria, from Cape Ann, Massachusetts. Fish. Bull. 76(1): 155166.

Carriker, M.R. 1961. Interrelation of functional morphology, behavior, and autecology in early stages of the bivalves Mercenaria mercenaria. J. Elisha Mitchell Sci. Soc. 77: $168-241$.

Carriker, M.R. 1988. Bivalve larval research, in transition: a commentary. J. Shellfish Res. 7(1): 1-6.

Cassie, R.M. 1954. Some uses of probability paper in the analysis of size frequency distributions. Aust. J. Mar. Fresh. Res. 5(3): 513-522.

Chanley, P. and Andrews J.D. 1971. Aids for identification of bivalve larvae of Virginia. Malacologia 11: 45-119.

Chicharo, L. and M.A. Chicharo. 2001. Effects of environmental conditions on planktonic abundances, benthic recruitment and growth rates of the bivalve mollusc Ruditapes decussates in a Portuguese coastal lagoon. Fish. Res. 53: 235250.

Crisp, D.J., A.B. Yule and K.N. White. 1985. Feeding by oyster larvae: the functional response, energy budget and a comparison with mussel larvae. Mar. Biol. Ass. U.K. 65: 759-783.

Davis, H.C. and A. Calabrese. 1964. Combined effects of temperature and salinity on development of eggs and growth of larvae of $M$. mercenaria and $C$. virginica. Fish. Bull. 63(3): 643-655.

Dekshenieks, M.M., E.E. Hofmann, E.N. Powell. 1993. Environmental effects on the growth and development of eastern oyster, Crassostrea virginica (Gmelin, 1971), larvae: a modeling study. J. Shellfish Res. 12(2): 241-254.

Douillet, P. 1993. Bacterivory in Pacific oyster Crassostrea gigas larvae. Mar. Ecol. Prog. Ser. 98: 123-134.

Eckman, J.E. 1987. The role of hydrodynamics in recruitment, growth, and survival of Argopecten irradians (L.) and Anomia simplex (D’Orbingy) within eelgrass meadows. J. Exp. Mar. Biol. Ecol. 106: 165-191. 
Emery, W.J. and R.E. Thomson. 1997. Data Analysis Methods in Physical Oceanography. Pergamon Press, New York.

Fritz, L.W., R.A. Lutz, M.A. Foote, C.L. Van Dover, and J.W. Ewart 1984. Selective feeding and grazing rates of oyster (Crassostrea virginica) larvae on natural phytoplankton assemblages. Estuaries 7: 513-518.

Gaines, S.D. and M.D. Bertness. 1992. Dispersal of juveniles and variable recruitment in sessile marine species. Nature 360: 579-580.

Gallager, SM. R. Mann, and G. Sasaki. 1986. Lipid as an index of growth and viability in three species of bivalve larvae. Aquaculture 56: 81-103.

Gallager, S.M., J.B. Waterbury, and D.K. Stoecker. 1994. Efficient grazing and utilization of the marine cyanobacterium Synechococcus sp. by larvae of the bivalve Mercenaria mercenaria. Mar. Biol. 119: 251-259.

Gallager, S.M., C.S. Davis, A.W. Epstein, A. Solow, and R. Beardsley. 1996. High resolution observations of plankton spatial distributions correlated with hydrography in the Great South Channel, Georges Bank. Deep Sea Res. 43 (7-8): 1627-1663.

Garland, E.D. 2000. Temporal variability and vertical structure in larval abundance: the potential roles of biological and physical processes. Doctoral dissertation. Massachusetts Institute of Technology/Woods Hole Oceanographic Institution, Woods Hole, MA, 213 pp.

Garland, E.D. C.A. Zimmer. 2002. Techniques for the identification of bivalve larvae. Mar. Ecol. Prog. Ser. 225: 299-310.

Geyer, W.R. 1997. Influence of wind on dynamics and flushing of shallow estuaries. Est. Coast. Shelf Sci. 44: 713-722.

Howes, B., W.W. Kelley, J.S. Ramsey, R. Samimy, D. Schlezinger, T. Ruthven, E. Eichner. 2004. Linked Watershed-Embayment Model to Determine Critical Nitrogen Loading Thresholds for the Quashnet River, Hamblin Pond, and Jehu Pond, in the Waquoit Bay System in the Towns of Mashpee and Falmouth, Massachusetts. Massachusetts Estuaries Project, Massachusetts Department of Environmental Protection. Boston, MA.

Johnson, K.B. and A.L. Shanks. 2003. Low rates of predation on planktonic marine invertebrate larvae. Mar. Ecol. Prog. Ser. 248: 125-139.

Jones, R. 1990. Length-cohort analysis: the importance of choosing the correct growth parameters. J. Cons. Int. Explor. Mer. 46: 133-139.

Jordan, T.E. and I. Valiela. 1982. A nitrogen budget of the ribbed mussel, Geukensia demissa, and its significance in nitrogen flow in a New England salt marsh. Limnol. Oceanogr. 27(1): 75-90.

Jorgensen, C.B. 1981. Mortality, growth, and grazing impact of a cohort of bivalve larvae, Mytilus edulis L. Ophelia 20(2): 185-192.

Kassner, J. and R.E. Malouf. 1982. An evaluation of "spawner transplants" as a management tool in Long Island's hard clam fishery. J. Shellfish Res. 2(2): 165 172.

Keck, R.T., D. Maurer, H. Lind. 1975. A comparative study of the hard clam gonad developmental cycle. Biol. Bull. 148: 243-258. 
Levin, L.A. 2006. Recent progress in understanding larval dispersal: new directions and digressions. Integr. Comp. Biol. 46(3): 282-297.

Litaker, W., C.S. Duke, B.E. Kenney, and J. Ramus. 1987. Short-term environmental variability and phytoplankton abundance in a shallow tidal estuary. Mar. Biol. 96: 115-121.

Loosanoff, V.L., W.S. Miller, P.B. Smith. 1951. Growth and setting of larvae of Venus mercenaria in relation to temperature. J. Mar. Res. 10: 59-81.

Loosanoff, V.L. and H.C. Davis. 1963. Rearing of bivalve mollusks. Adv. Mar. Biol. 1: $1-136$.

Loosanoff, V.L., H.C. Davis, P.E. Chanley. 1966. Dimensions and shapes of larvae of some marine bivalve mollusks. Malacologia 4: 351-435.

Mann, R. 1988. Field studies of bivalve larvae and their recruitment to the benthos: a commentatry. J. of Shellfish Res. 7(1): 7-10.

Orensanz, J.M., A.M. Parma, O.O. Iribarne. 1991. Population dynamics and management of natural stocks. In: Shumway, S.E. (ed.) Scallops: biology, ecology, and aquaculture. Elsevier, New York, pp 625-713.

Pechenik, J.A., L.S. Eyster, J. Widdows, and B.L. Bayne. 1990. The influence of food concentration and temperature on growth and morphological differentiation of blue mussel Mytilus edulis L. larvae. J. Exp. Mar. Biol. Ecol. 136: 47-64.

Raby, D., Y. Lagadeuc, J.J. Doson, M. Mingelbier. 1994. Relationship between feeding and vertical distribution of bivalve larvae in stratified and mixed waters. Mar. Ecol. Prog. Ser. 103: 275-284.

Rigal, F., F. Viard, S. Ayata, T. Comtet. 2010. Does larval supply explain the low proliferation of the invasive gastropod Crepidula fornicata in a tidal estuary? Biol. Invasions. Pub. Online 4 Feb. 2010.

Roegner, G.C. and R. Mann. 1995. Early recruitment and growth of the America oyster Crassostrea virgininca (Bivalvia: Ostreidae) with respect to tidal zonation and season. Mar. Ecol. Prog. Ser. 117: 91-101.

Roughgarden, J., S. Gaines, and H. Possingham. 1988. Recruitment dynamics in complex life cycles. Science 241: 1460-1466.

Scheltema, R.S. 1986. On dispersal and planktonic larvae of benthic invertebrates: an eclectic overview and summary of problems. Bull. of Mar. Sci. 39(2): 290-322.

Shirley, S.M. and T.C. Shirley. 1989. Interannual variability in density, timing, and survival of Alaskan red king crab Paralithodes camtschatica larvae. Mar. Ecol. Prog. Ser. 54: 51-59.

Thorson, G. 1950. Reproductive and larval ecology of marine bottom invertebrates. Bio. Rev. 25: 1-45.

Tiwari, S. and S.M. Gallager. 2003a. Optimizing multiscale invariants for the identification of bivalve larvae. Proceedings of the 2003 IEEE International Conference on Image Processing, Barcelona, Spain, September 14-17, 2003.

Tiwari, S. and S. Gallager. 2003b. Machine learning and multiscale methods in the identification of bivalve larvae. Proceedings of the Ninth IEEE International Conference on Computer Vision, Nice, France, October 14-17, 2003. 
Todd, C.D. 1998. Larval supply and recruitment of benthic invertebrates: do larvae always disperse as much as we believe? Hydroiologia 375/376: 1-21.

Townsend, D.W. and L.M. Cammen. 1988. Potential importance of the timing of spring plankton blooms to benthic-pelagic coupling and recruitment of juvenile demersal fishes. Biol. Oceanogr. 5: 215-229.

Tomaru, Y., S. Kawabata, S. Nakano. 2000. Consumption of picoplankton by the bivalve larvae of Japanese pearl oyster Pinctada fucata martensii. Mar. Ecol. Prog. Ser. 192: 195-202.

Tomasky-Holmes, G. 2008. Nutrient supply, water residence time, temperature, and grazing as controls of size-fractionated phytoplankton biomass in shallow temperate estuarine ecosystems. Ph.D. thesis, Boston University, Boston, MA.

Tremblay, M.J., M. Sinclair. 1990. Sea scallop larvae Placopecten magellanicus on Georges Bank: vertical distribution in relation to water column stratification and food. 61: 1-15.

Weissberger, E.J. and J.P. Grassle. 2003. Settlement, first-year growth and mortality of surfclams, Spisula solidissima. Estaur. Coast. Shelf S. 56: 669-684.

Wood, L. and W.J. Hargis. 1971. Transport of bivalve larvae in a tidal estuary. IN: Crisp, D.J. (ed.) Proceedings of the Fourth European Marine Biology Symposium. Bangor, 1969. Cambridge University Press, Cambridge, pp 29-44. 
Table 3.1 Matrix of cross-correlation coefficients (r) for concentration and shell length data between sites for each species in 2007. All reported correlation coefficients were significant $(p<0.05)$ and adjusted for autocorrelation of the lowest frequency. Bold values were significant for the decorrelation time of the series. Integers represent if there was a significant lag between the sites in the columns and the rows. A positive lag means the sites in the columns lagged the sites in the rows by the factor, and a negative lag means the sites in the rows lagged behind the sites in the columns.

\begin{tabular}{|c|c|c|c|c|c|c|}
\hline & \multicolumn{2}{|l|}{ Little River } & \multicolumn{2}{|c|}{ Menauhant } & \multicolumn{2}{|c|}{ Childs River } \\
\hline & Conc. & Size & Conc. & Size & Conc. & Size \\
\hline \multicolumn{7}{|c|}{ Anomia simplex } \\
\hline \multirow[t]{3}{*}{ Menauhant } & $-2(0.727)$ & $-2(0.734)$ & & & & \\
\hline & & $-1(0.671)$ & & & & \\
\hline & & $0(0.612)$ & & & & \\
\hline Childs River & - & - & - & - & & \\
\hline \multirow[t]{4}{*}{ Waquoit Bay } & $-1(0.517)$ & $-3(0.651)$ & $-1(0.580)$ & $-1(0.633)$ & - & \\
\hline & & $-2(0.906)$ & & $0(0.692)$ & & \\
\hline & & $-1(0.781)$ & & & & \\
\hline & & $0(0.579)$ & & & & \\
\hline
\end{tabular}

\section{Geukensia demissa}

Menauhant $\quad 1(0.714) \quad-3(0.582)$

Childs River $\quad 1$ (0.508) $-1(0.681)$

$-1(0.530) \quad 0(0.651)$

$0(0.761)$

Waquoit Bay $\quad 0(0.616) \quad-1(0.626)-1(0.677)$

$0(0.727)$

Mercenaria mercenaria

Menauhant $1(0.536)$

Childs River 2 (0.662)

Waquoit Bay $1(0.731)$

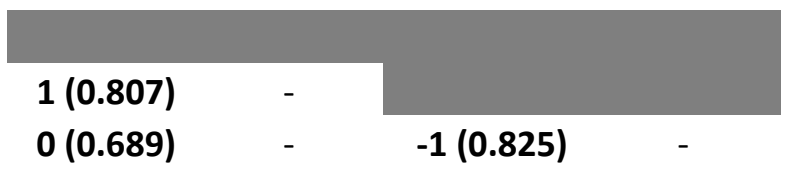


Table 3.2 Matrix of cross-correlation coefficients (r) for concentration and shell length data between sites for each species in 2009. All reported correlation coefficients were significant $(p<0.05)$ and adjusted for autocorrelation of the lowest frequency. Bold values were significant for the decorrelation time of the series. Integers represent if there was a significant lag between the sites in the columns and the rows. See Table 3.1 caption for description of lags.

\begin{tabular}{|c|c|c|c|c|c|c|}
\hline & \multicolumn{2}{|l|}{ Little River } & \multicolumn{2}{|l|}{ Menauhant } & \multicolumn{2}{|c|}{ Childs River } \\
\hline & Conc. & Size & Conc. & Size & Conc. & Size \\
\hline \multicolumn{7}{|c|}{ Anomia simplex } \\
\hline \multirow[t]{4}{*}{ Menauhant } & $-2(0.836)$ & $-1(0.645)$ & & & & \\
\hline & & $0(0.811)$ & & & & \\
\hline & & $1(0.750)$ & & & & \\
\hline & & $2(0.536)$ & & & & \\
\hline \multirow[t]{2}{*}{ Childs River } & $-2(0.826)$ & - & $0(0.658)$ & $0(0.592)$ & & \\
\hline & & & $1(0.673)$ & & & \\
\hline \multirow[t]{4}{*}{ Waquoit Bay } & $0(0.790)$ & $-1(0.669)$ & $1(0.666)$ & $-2(0.669)$ & $1(0.554)$ & - \\
\hline & & $0(0.877)$ & $2(0.839)$ & $-1(0.849)$ & $2(0.891)$ & \\
\hline & & $1(0.627)$ & & $0(0.875)$ & & \\
\hline & & & & $1(0.726)$ & & \\
\hline
\end{tabular}

\section{Geukensia demissa}

\begin{tabular}{|c|c|c|c|c|c|c|}
\hline \multirow[t]{2}{*}{ Menauhant } & $-1(0.788)$ & $0(0.588)$ & & & & \\
\hline & $0(0.751)$ & $1(0.607)$ & & & & \\
\hline \multirow[t]{2}{*}{ Childs River } & $1(0.560)$ & $0(0.672)$ & $-1(0.469)$ & $0(0.711)$ & & \\
\hline & & $1(0.714)$ & $1(0.449)$ & $1(0.544)$ & & \\
\hline \multirow[t]{4}{*}{ Waquoit Bay } & $-1(0.728)$ & $0(0.661)$ & $0(0.737)$ & $-1(0.574)$ & $-2(0.615)$ & $0(0.713)$ \\
\hline & $0(0.943)$ & 1 (0.639) & $1(0.798)$ & $0(0.795)$ & $0(0.575)$ & $1(0.689)$ \\
\hline & $1(0.598)$ & $2(0.679)$ & & $1(0.810)$ & & \\
\hline & & & & $2(0.610)$ & & \\
\hline
\end{tabular}

Mercenaria mercenaria

$\begin{array}{lrrrrr}\text { Menauhant } & -2(0.666) & 0(0.518) & & & \\ & -1(0.794) & 1(0.488) & & \\ & 0(0.714) & & & - \\ \text { Childs River } & -1(0.628) & - & - & - & - \\ \text { Waquoit Bay } & -1(0.608) & 0(0.791) & 1(0.866) & -1(0.413) & - \\ & 0(0.764) & & 2(0.847) & 0(0.557) & \\ & 1(0.848) & & & \end{array}$


Table 3.3 Significant Pearson correlation coefficients (r) from cross-correlations of larval concentrations to temperature, salinity and chlorophyll time series for each species in 2007. Correlations were performed between full time series as well as independent samples only when larvae were present. All reported correlations were significant at $\mathrm{p}<$ 0.05 . Numbers in front of cross-correlations represent the lag of the larval time series with respect to the physical series (i.e., a lag of -1 would mean larval concentration lagged the physical time series by one week). No correlations were significant when accounting for full decorrelation time of each time series.

\begin{tabular}{|c|c|c|c|c|c|c|}
\hline & \multicolumn{2}{|c|}{ Anomia simplex } & \multicolumn{2}{|c|}{ Geukenisa demissa } & \multicolumn{2}{|c|}{ Mercenaria mercenaria } \\
\hline & Time-series & Samples & Time-series & Samples & Time-series & Samples \\
\hline \multicolumn{7}{|l|}{ Temperature } \\
\hline \multirow[t]{3}{*}{ Little River } & $0(0.575)$ & & $0(0.764)$ & & $-1(0.477)$ & \\
\hline & & & $1(0.600)$ & & $0(0.575)$ & \\
\hline & & & $2(0.602)$ & & & \\
\hline Menauhant & $0(0.717)$ & 0.832 & $0(0.647)$ & & $0(0.621)$ & 0.655 \\
\hline Childs River & & & $0(0.782)$ & 0.645 & & \\
\hline \multirow[t]{2}{*}{ Waquoit Bay } & $-1(0.633)$ & & $-1(0.584)$ & 0.661 & & \\
\hline & $0(0.645)$ & & $0(0.774)$ & & & \\
\hline \multicolumn{7}{|l|}{ Salinity } \\
\hline Menauhant & $0(-0.615)$ & & & & & -0.537 \\
\hline \multicolumn{7}{|l|}{ Chlorophyll } \\
\hline Childs River & $0(0.470)$ & & & -0.691 & & \\
\hline Waquoit Bay & & & $0(-0.444)$ & 0.859 & & \\
\hline
\end{tabular}


Table 3.4 Significant Pearson correlation coefficients (r) from cross-correlations of larval concentrations to temperature and chlorophyll for each species in 2009. No significant correlations were observed with salinity. Correlations were performed between full time series as well as independent samples only when larvae were present. All reported correlations were significant at $p<0.05$. See table 3.3 for description of lags. Time-series were adjusted for autocorrelation of the lowest frequency for both timeseries. Bold values indicate significant correlations accounting for full decorrelation time.

\begin{tabular}{|c|c|c|c|c|c|c|}
\hline & \multicolumn{2}{|c|}{ Anomia simplex } & \multicolumn{2}{|c|}{ Geukenisa demissa } & \multicolumn{2}{|c|}{ Mercenaria mercenaria } \\
\hline & Time-series & Samples & Time-series & Samples & Time-series & Samples \\
\hline \multicolumn{7}{|l|}{ Temperature } \\
\hline \multirow[t]{5}{*}{ Little River } & $0(0.663)$ & 0.581 & $-2(0.540)$ & 0.738 & & 0.616 \\
\hline & & & $-1(0.720)$ & & & \\
\hline & & & $0(0.831)$ & & & \\
\hline & & & $1(0.792)$ & & & \\
\hline & & & $2(0.617)$ & & & \\
\hline \multirow[t]{5}{*}{ Menauhant } & $0(0.605)$ & & $-1(0.733)$ & 0.749 & $0(0.601)$ & 0.719 \\
\hline & $1(0.641)$ & & $0(0.832)$ & & $1(0.617)$ & \\
\hline & $2(0.681)$ & & $1(0.800)$ & & & \\
\hline & $3(0.688)$ & & $2(0.640)$ & & & \\
\hline & $4(0.633)$ & & & & & \\
\hline \multirow[t]{5}{*}{ Childs River } & $0(0.551)$ & 0.665 & $-2(0.565)$ & & $-3(0.554)$ & 0.745 \\
\hline & & & $-1(0.740)$ & & $-2(0.544)$ & \\
\hline & & & $0(0.846)$ & & $-1(0.567)$ & \\
\hline & & & $1(0.765)$ & & $0(0.653)$ & \\
\hline & & & $2(0.614)$ & & $1(0.540)$ & \\
\hline \multirow[t]{5}{*}{ Waquoit Bay } & $0(0.684)$ & & $-2(0.576)$ & & $0(0.607)$ & 0.703 \\
\hline & $1(0.714)$ & & $-1(0.725)$ & & $1(0.592)$ & \\
\hline & $2(0.726)$ & & $0(0.844)$ & & & \\
\hline & $3(0.690)$ & & $1(0.826)$ & & & \\
\hline & & & $2(0.728)$ & & & \\
\hline \multicolumn{7}{|l|}{ Chlorophyll } \\
\hline Little River & & & & & $1(-0.663)$ & -0.728 \\
\hline \multirow[t]{2}{*}{ Childs River } & & & & & $-2(-0.436)$ & \\
\hline & & & & & $-1(-0.511)$ & \\
\hline
\end{tabular}


Table 3.5 Mean growth rate (GR) and period present for all cohorts of each species in 2007. Lab growth rates were averaged for individuals that were grown under constant and ideal food and temperature conditions in the laboratory. $\mathrm{SD}=$ standard deviation; $\mathrm{AS}=$ Anomia simplex $; \mathrm{GD}=$ Guekensia demiss $; \mathrm{MM}=$ Mercenaria mercenaria

\begin{tabular}{l|l|l|l} 
Cohort & Dates & $\begin{array}{l}\text { Mean GR } \pm \\
\text { SD }\left(\mu \mathbf{m ~ d}^{-1}\right)\end{array}$ & $\begin{array}{l}\text { Mean Lab GR } \\
\pm \text { SD }\left(\mu \mathrm{m} \mathrm{d}^{-1}\right)\end{array}$ \\
\hline AS1 & 23 Jun - 27 Jun & 0.56 & $3.85 \pm 2.68$ \\
AS2 & 11 Jul - 2 Aug & $2.01 \pm 0.79$ & \\
AS3 & 25 Jul - 7 Aug & $4.81 \pm 1.75$ & \\
AS4 & 2 Aug - 7 Aug & 5.44 & \\
\hline GD1 & 27 Jun - 11 Jul & $1.82 \pm 0.07$ & $2.71 \pm 2.38$ \\
GD2 & 5 Jul - 18 Jul & $1.53 \pm 0.21$ & \\
GD3 & 11 Jul - 2 Aug & $0.91 \pm 0.52$ & \\
GD4 & 2 Aug - 7 Aug & 3.47 & \\
GD5 & 14 Aug - 28 Aug & $2.52 \pm 3.44$ & \\
\hline MM1 & 7 Aug - 22 Aug & $1.42 \pm 1.32$ & $4.83 \pm 2.80$ \\
MM2 & 22 Aug - 28 Aug & 5.12 & \\
MM3 & 28 Aug - 4 Sep & 0.88 &
\end{tabular}


Table 3.6 Mean growth rate (GR) and period present for all cohorts of each species in 2009. Lab growth rates were averaged for individuals that were grown under constant and ideal food and temperature conditions in the laboratory. $\mathrm{SD}=$ standard deviation; $\mathrm{AS}=$ Anomia simplex $; \mathrm{GD}=$ Guekensia demiss $; \mathrm{MM}=$ Mercenaria mercenaria

\begin{tabular}{l|l|l|l} 
Cohort & Dates & $\begin{array}{l}\text { Mean GR } \\
\text { SD }\left(\mu \mathbf{m ~ d}^{-1}\right)\end{array}$ & $\begin{array}{l}\text { Mean Lab GR } \\
\pm \text { SD }\left(\mu \mathbf{m ~ d}^{-1}\right)\end{array}$ \\
\hline AS1 & 16 Jun - 24 Jun & 2.37 & $3.85 \pm 2.68$ \\
AS2 & 29 Jun - 16 Jul & $4.60 \pm 1.2$ & \\
AS3 & 8 Jul - 21 Jul & $4.15 \pm 0.80$ & \\
AS4 & 16 Jul - 30 Jul & $4.95 \pm 2.62$ & \\
AS5 & 21 Jul - 4 Aug & $11.54 \pm 13.33$ & \\
AS6 & 30 Jul - 19 Aug & $5.46 \pm 2.38$ & \\
AS7 & 4 Aug - 26 Aug & $5.53 \pm 5.95$ & \\
AS8 & 19 Aug - 2 Sep & $2.14 \pm 1.18$ & \\
\hline GD1 & 8 Jul - 16 Jul & 1.42 & $2.71 \pm 2.38$ \\
GD2 & 12 Aug - 19 Aug & 2.75 & \\
GD3 & 19 Aug - 15 Sep & $1.48 \pm 0.51$ & \\
\hline MM1 & 7 May - 13 May & 6.00 & $4.83 \pm 2.80$ \\
MM2 & 8 Jul - 16 Jul & 1.96 & \\
MM3 & 16 Jul - 4 Aug & $3.47 \pm 1.29$ & \\
MM4 & 30 Jul - 19 Aug & $2.60 \pm 1.54$ & \\
MM5 & 12 Aug - 26 Aug & $2.84 \pm 3.37$ & \\
MM6 & 26 Aug - 2 Sep & 4.46 & \\
MM7 & 2 Sep - 15 Sep & $2.36 \pm 1.30$ & \\
MM8 & 15 Sep - 29 Sep & $1.46 \pm 0.37$ & \\
& & &
\end{tabular}




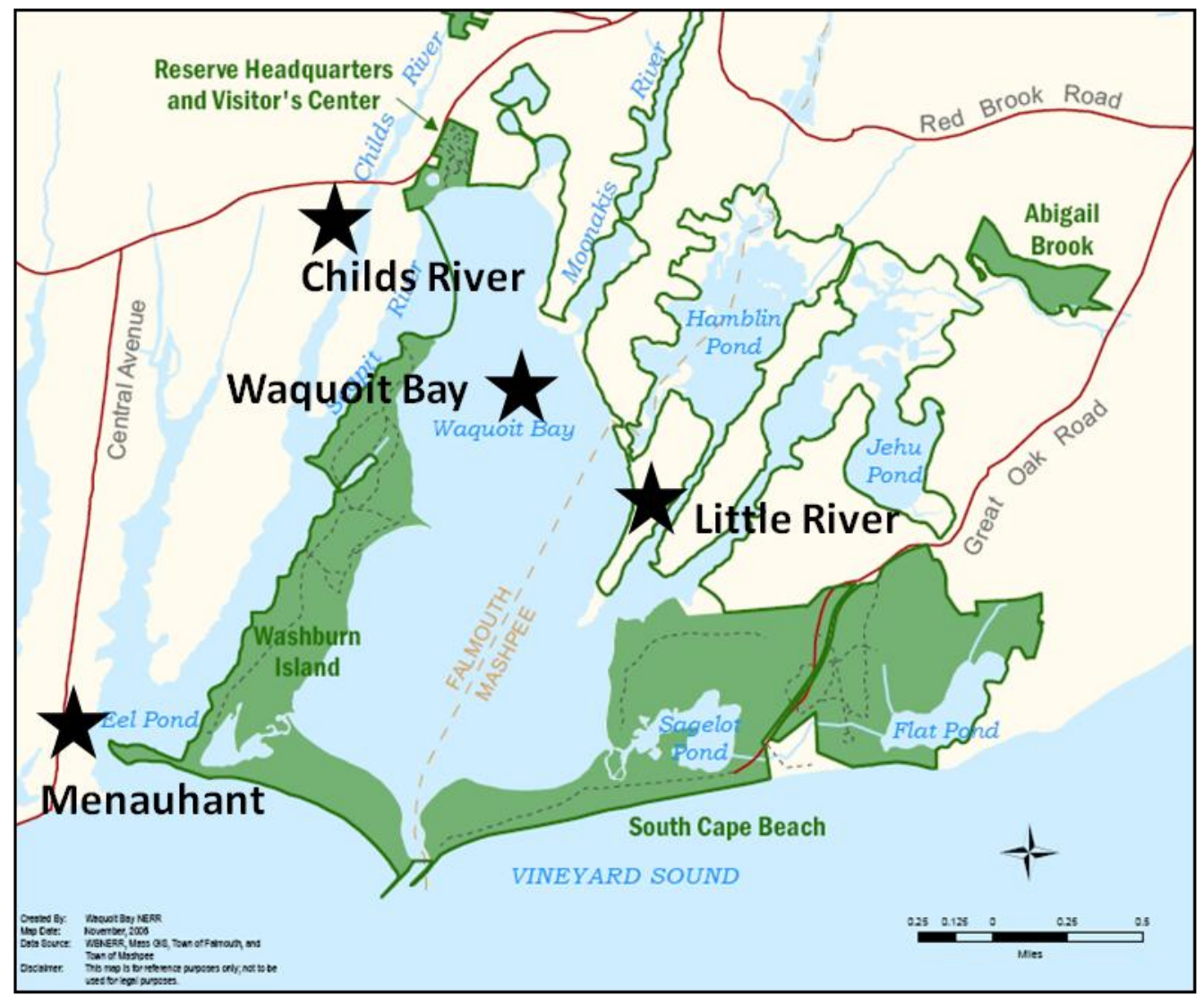

Figure 3.1 Reserve boundary map of Waquoit Bay showing the four larval sampling sites (stars). Figure courtesy of the Waquoit Bay National Estuarine Research Reserve. 


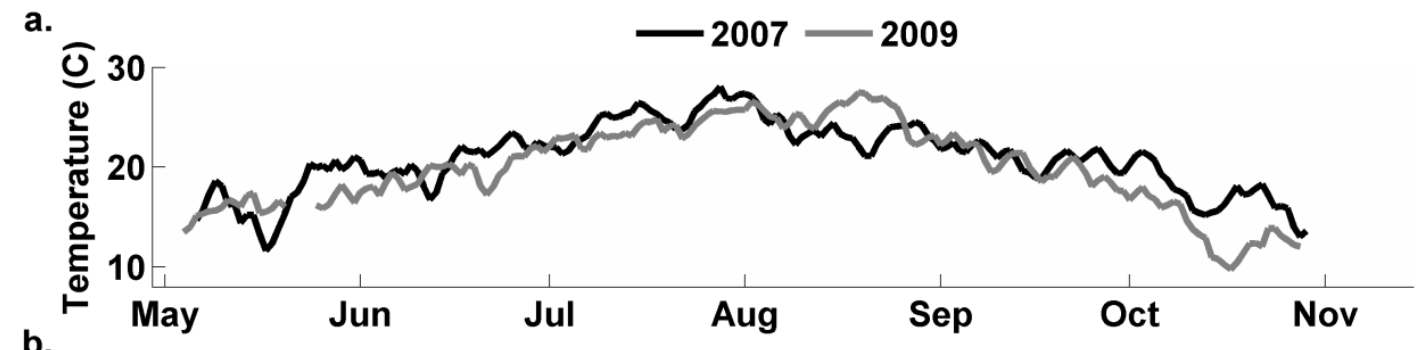

b.

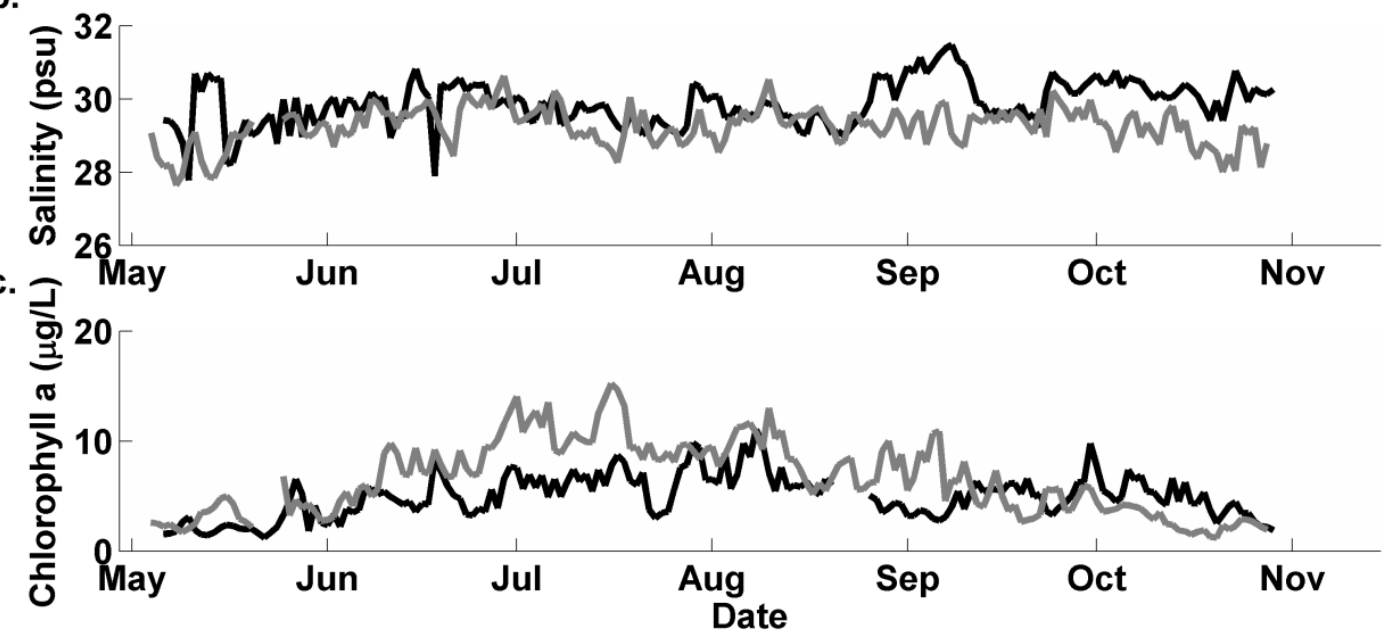

Figure 3.2 Daily averaged (a) temperature (b) salinity and (c) chlorophyll a for Waquoit Bay - Metoxit Point. Water temperature and cholorphyll a readings were averaged daily from moored loggers for the sampling periods of May through October in 2007 and 2009. 

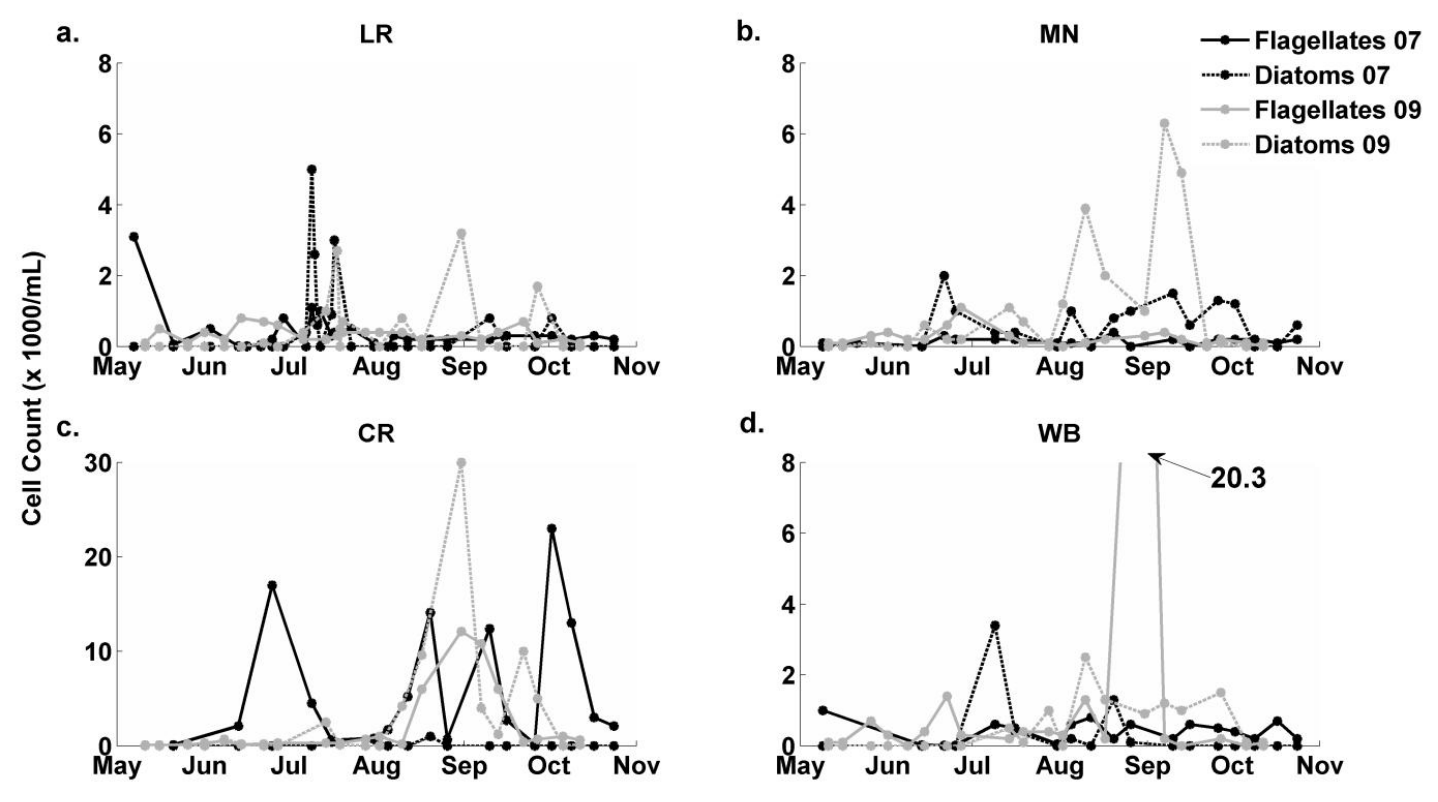

Figure 3.3 Phytoplankton counts for all sites in 2007 (black) and 2009 (gray). Total counts of flagellates (solid line) and diatoms (dashed lines) from water samples on each sampling date are plotted for each site. Flagellates included counts for flagellates and dinoflagellates and diatoms consisted of centric, pennate, Chaetoceros sp., Skeletonema sp., Thalassiora sp., and Nitzchia sp. Note the different axis scale for (c) and outlier value for (d). Site abbreviations: LR = Little River; CR = Childs River; MN = Menauhant; WB $=$ Waquoit Bay - Metoxit Point. 


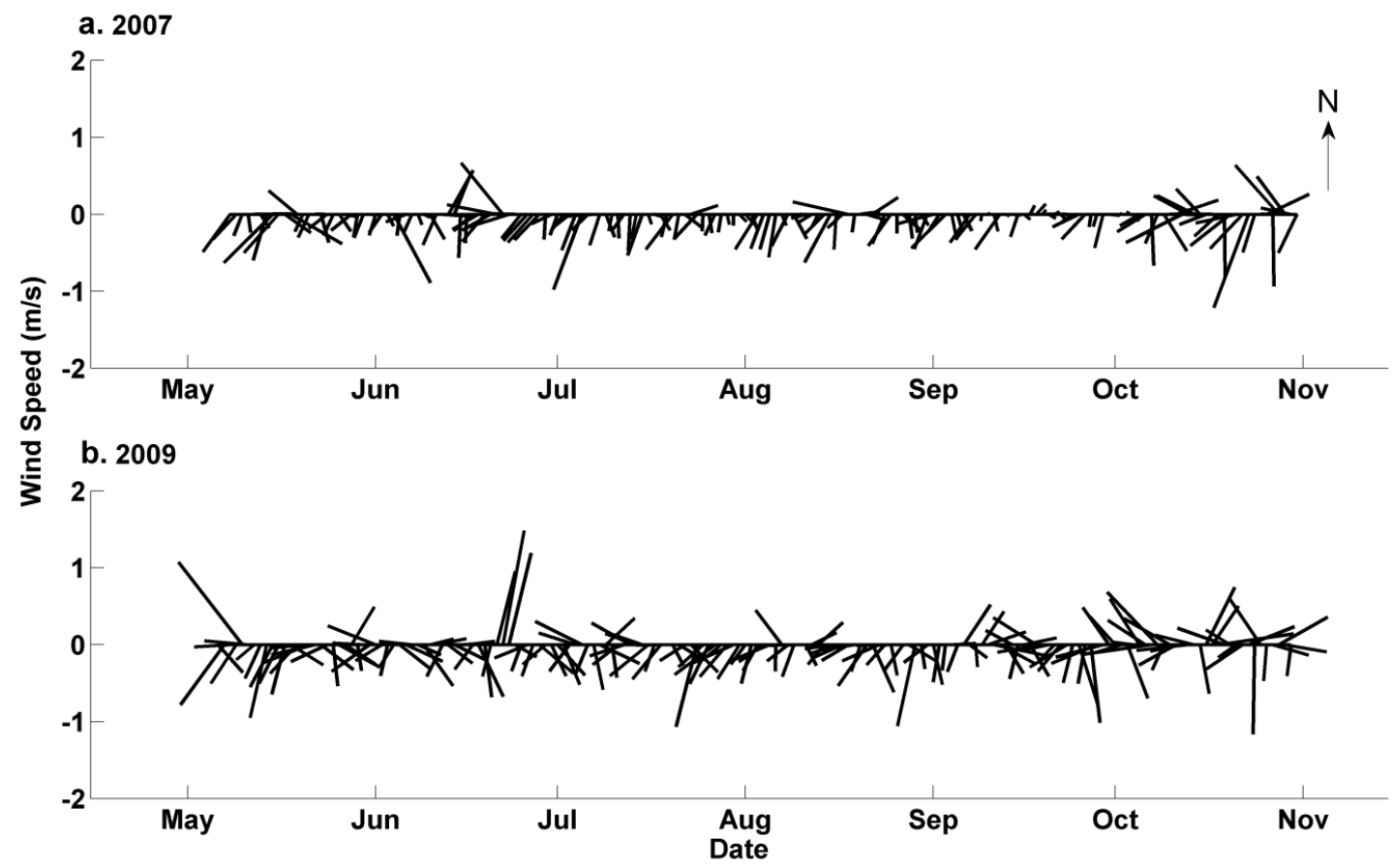

Figure 3.4 Time-series of wind vectors for Waquoit Bay for (a) 2007 and (b) 2009. Wind speed $(\mathrm{m} / \mathrm{s})$ and direction were averaged daily from May through October for both years. The weather station was located at the north tip of the bay at the Waquoit Bay National Estuarine Research Reserve. 


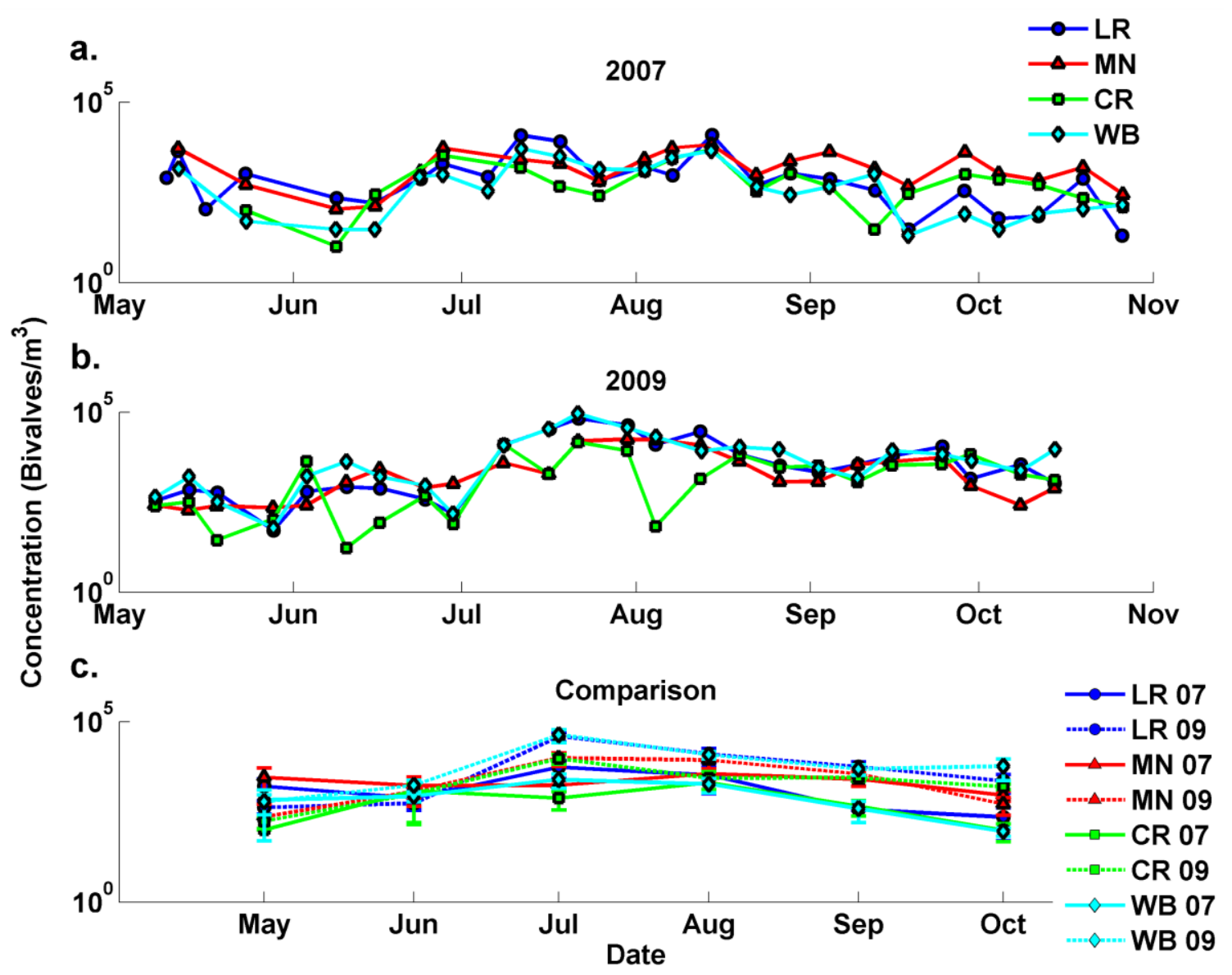

Figure 3.5 Total bivalve larvae for all sites in 2007 and 2009. (a,b) Concentrations of larvae (bivalves $/ \mathrm{m}^{3}$ ) are shown from counts of 100L samples taken weekly during from May - October from each site in 2007 and 2009. (c) Monthly mean and standard errors for all larvae in 2007 (solid lines) and 2009 (dashed lines) for comparison.

Concentrations are shown on a log scale to capture the high variability during this period. $\mathrm{LR}=$ Little River; $\mathrm{CR}=$ Childs River; $\mathrm{MN}=$ Menauhant; $\mathrm{WB}=$ Waquoit Bay - Metoxit Point 

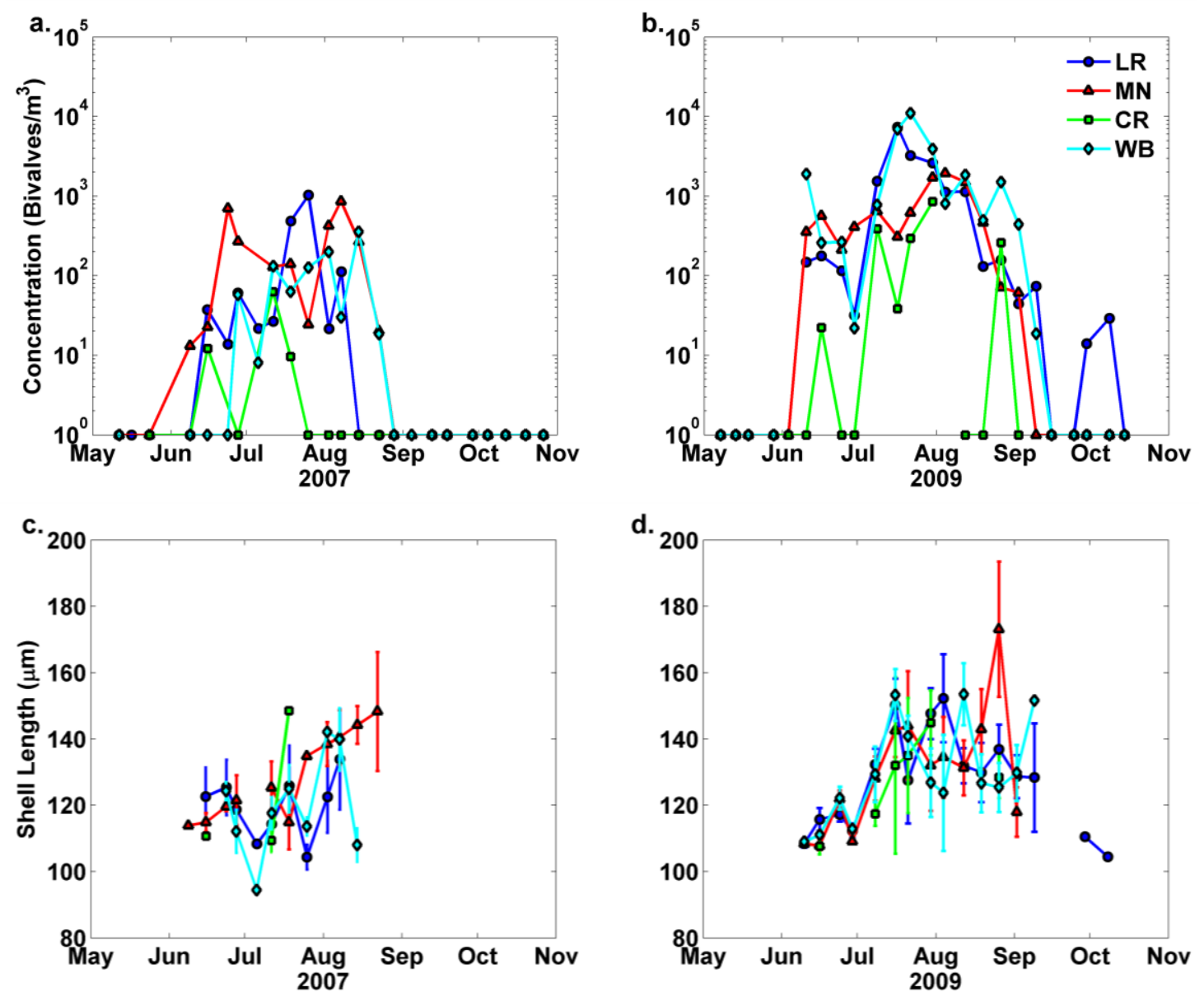

Figure 3.6 Time series of (a-b) concentration and (c-d) mean size of Anomia simplex larvae from the four sampling sites in 2007 (a-c) and 2009 (b-d). (a-b) Concentration (bivalves $/ \mathrm{m}^{3}$ ) was calculated from percentage of A. simplex larvae in each subsample multiplied by total bivalve concentration and plotted on a log scale. (c-d) Mean size was estimated from the shell length of each $A$. simplex image. Error bars are standard errors. Site abbreviations: LR = Little River; CR = Childs River; $\mathrm{MN}=$ Menauhant; WB = Waquoit Bay - Metoxit Point. 

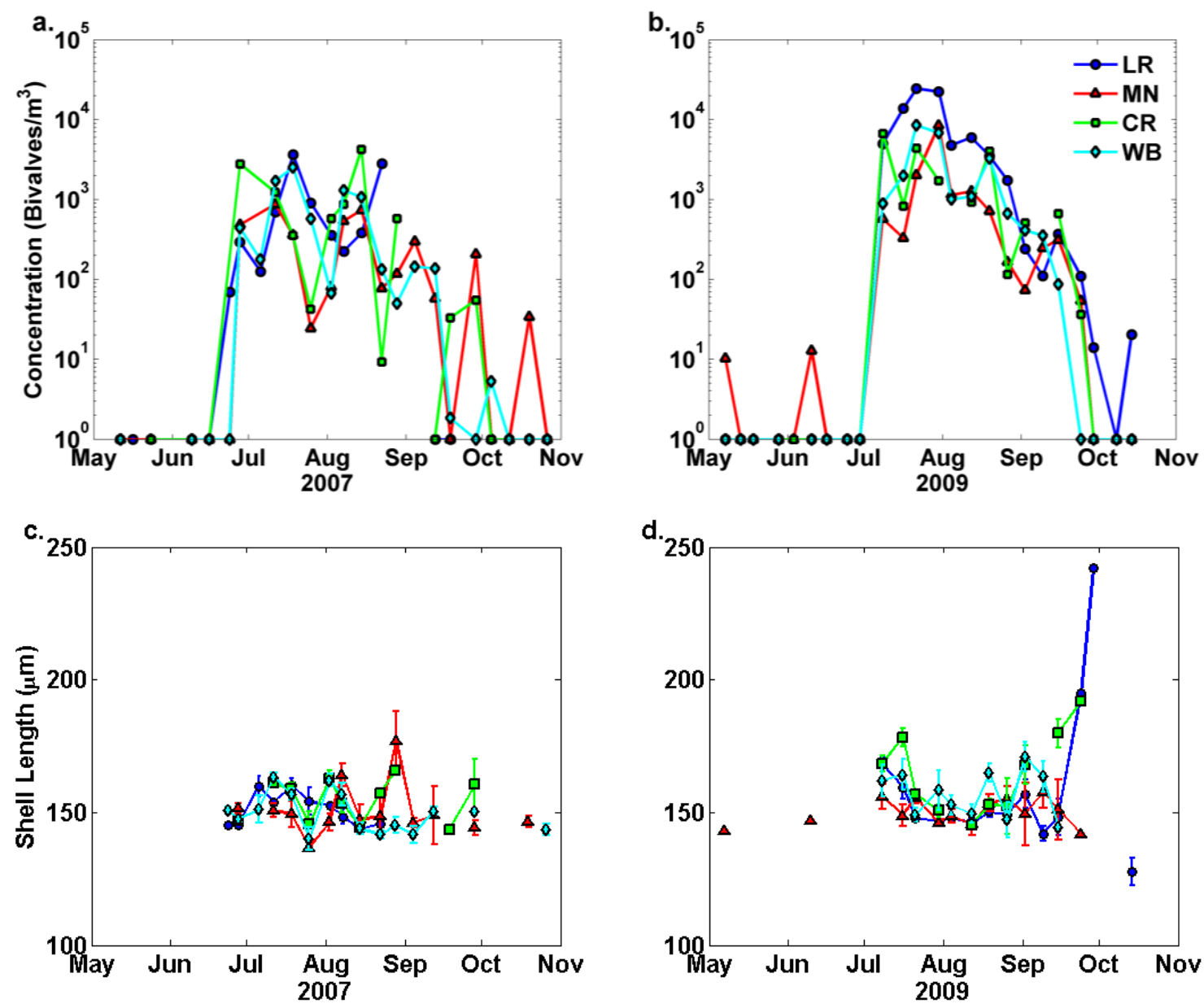

Figure 3.7 Time series of (a-b) concentration and (c-d) mean size of Geukensia demissa larvae from the four sampling sites in 2007 (a-c) and 2009 (b-d). (a-b) Concentration (bivalves $/ \mathrm{m}^{3}$ ) was calculated from percentage of $G$. demissa larvae in each subsample multiplied by total bivalve concentration and plotted on a log scale. (c-d) Mean size was estimated from the shell length of each $G$. demissa image. Error bars are standard errors. Site abbreviations: LR = Little River; $\mathrm{CR}=$ Childs River; $\mathrm{MN}=$ Menauhant; $\mathrm{WB}=$ Waquoit Bay - Metoxit Point. 

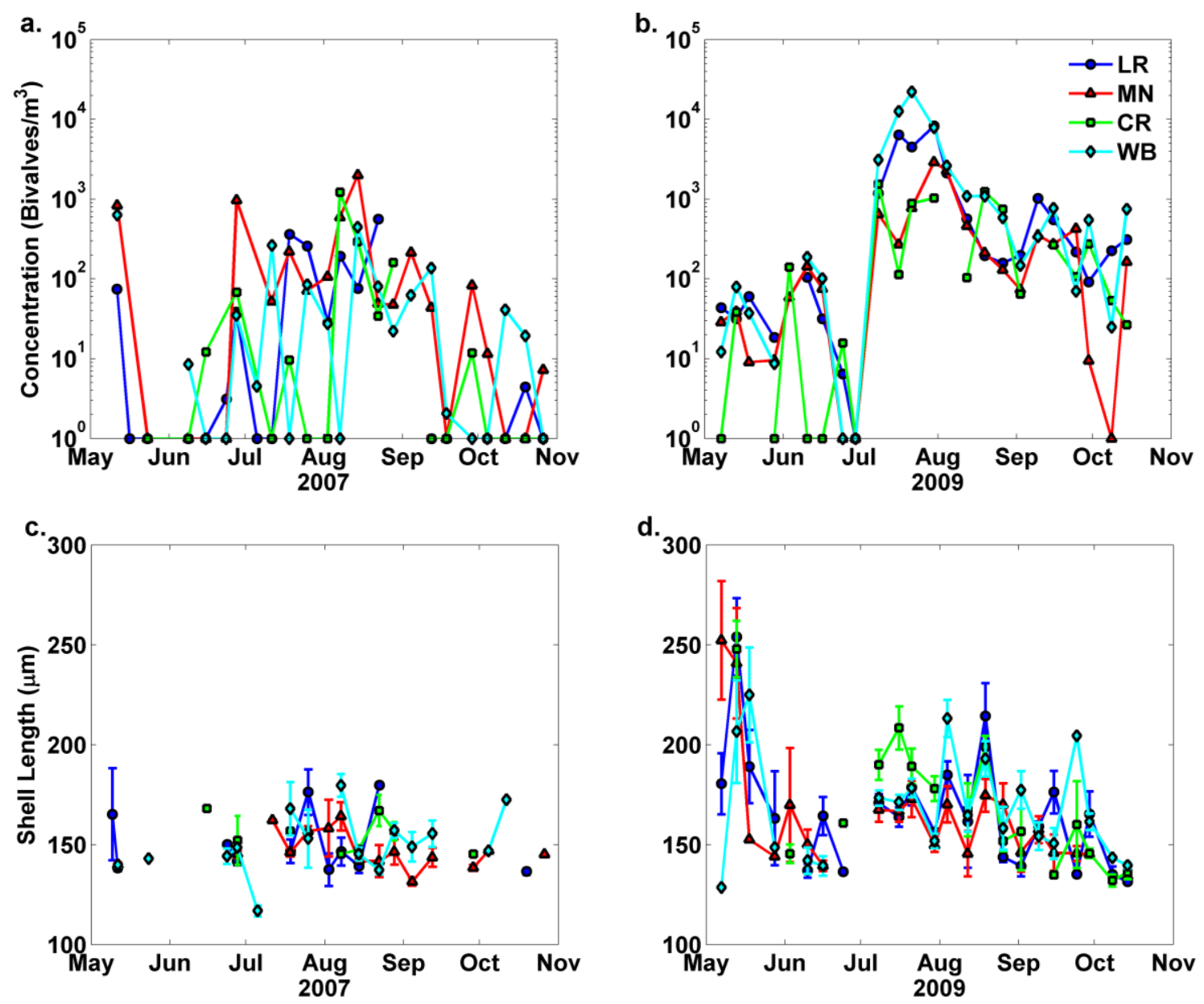

Figure 3.8 Time series of (a-b) concentration and (c-d) mean size of Mercenaria mercenaria larvae from the four sampling sites in 2007 (a-c) and 2009 (b-d). (a-b) Concentration (bivalves $/ \mathrm{m}^{3}$ ) was calculated from percentage of M. mercenaria larvae in each subsample multiplied by total bivalve concentration and plotted on a log scale. (c-d) Mean size was estimated from the shell length of each $M$. mercenaria image. Error bars are standard errors. Site abbreviations: $\mathrm{LR}=$ Little River; $\mathrm{CR}=$ Childs River; $\mathrm{MN}=$ Menauhant; WB = Waquoit Bay - Metoxit Point. 


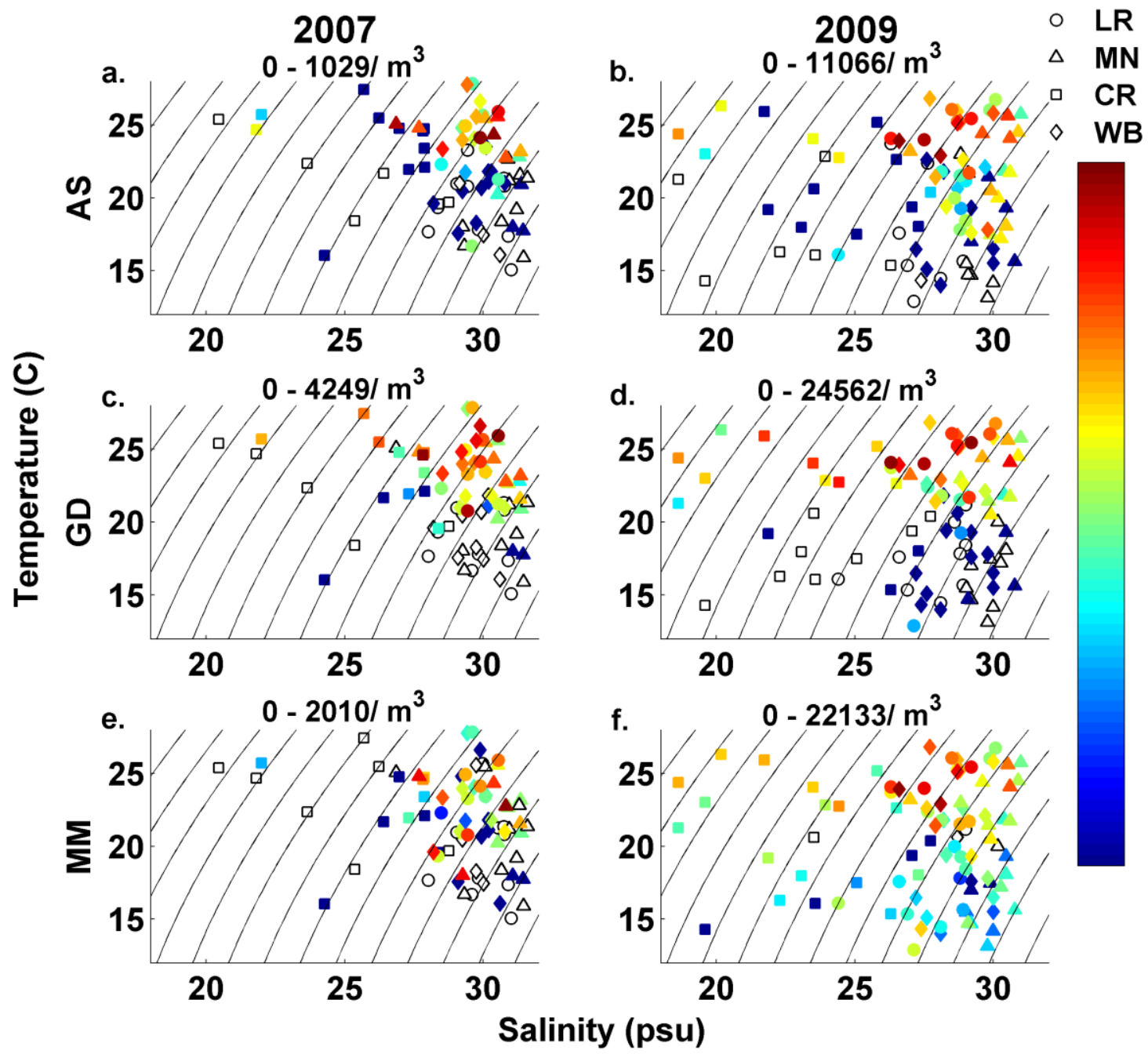

Figure 3.9 Temperature-salinity-plankton plots of three species of bivalve larvae at all four sites in 2007 (a,c,e) and 2009 (b,d,f). The location of each data point represents the temperature and salinity as recorded during each sample. The color of each point represents the concentration of each species as determined from the percentage observed in each subsample and total concentration. Numbers at the top of each figure are the range of concentrations for each species that correspond to the colorbar. Concentrations are on a log scale. Each site is depicted with its own symbol. Unfilled symbols represent zero larvae. Black lines represent constant density at one sigma-t unit. Species abbreviations: $\mathrm{AS}=A$. simplex; $\mathrm{GD}=G$. demissa; $\mathrm{MM}=M$. mercenaria . Site abbreviations: $\mathrm{LR}=$ Little River; $\mathrm{CR}=$ Childs River; $\mathrm{MN}=$ Menauhant; $\mathrm{WB}=$ Waquoit Bay - Metoxit Point. 

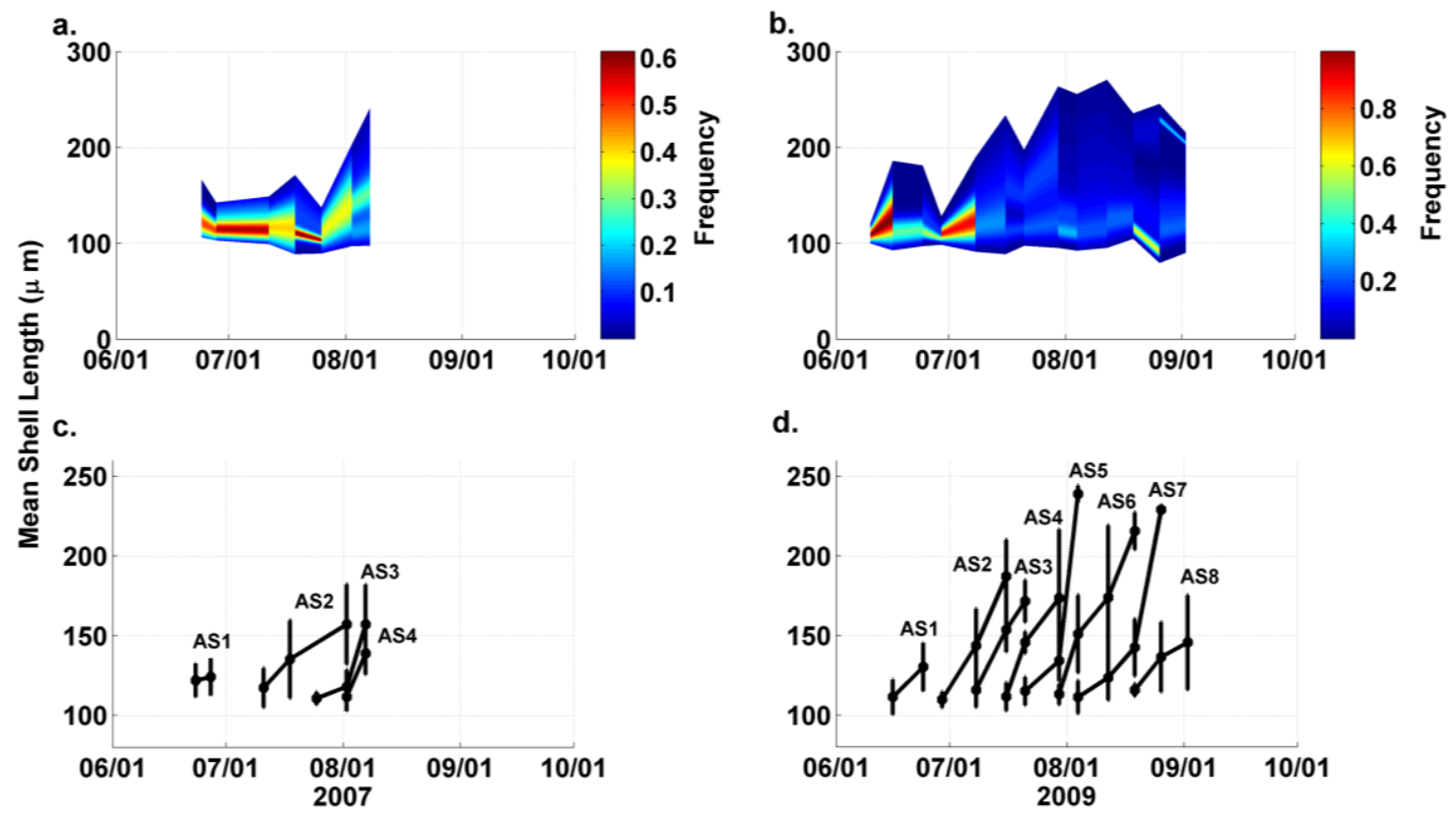

d.

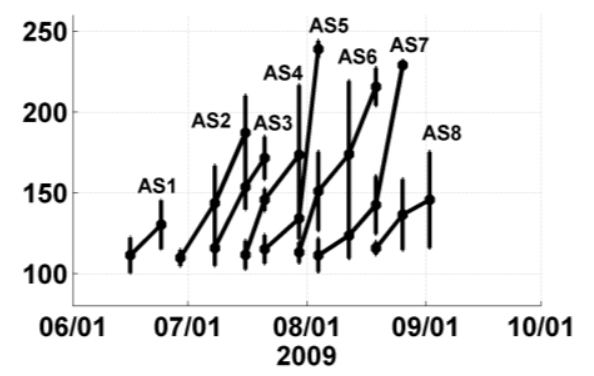

Figure 3.10 Cohort graphs for Anomia simplex. (a-b) Frequency distributions of larvae sizes as interpolated from probability density functions (pdfs) for larvae pooled from all sites in (a) 2007 and (b) 2009. Colored bands represent frequency of different size classes. (c-d) Time series of mean cohort sizes as identified from Gaussian separation of the pdfs are shown for (c) 2007 and (d) 2009. Error bars represent standard deviations of the estimates. 

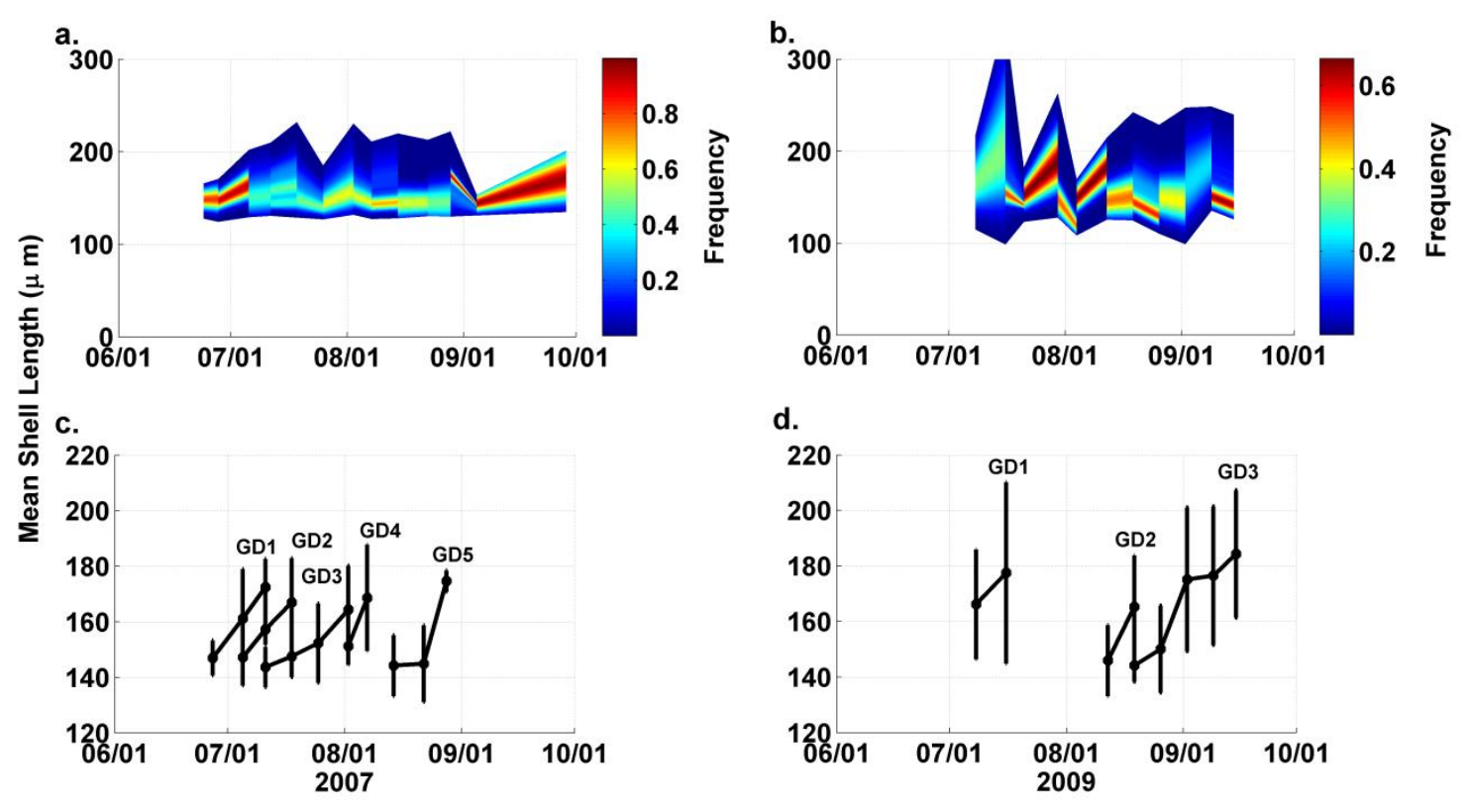

d.

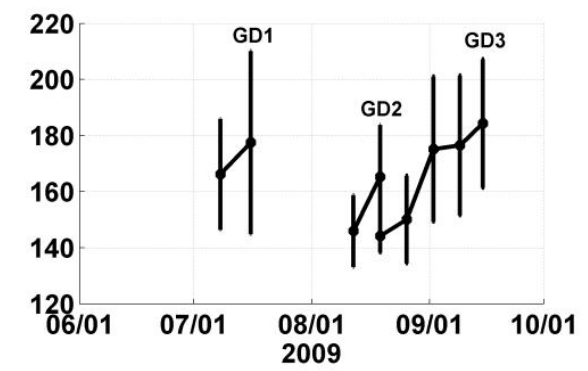

Figure 3.11 Cohort graphs for Geukensia demissa. (a-b) Frequency distributions of larvae sizes as interpolated from probability density functions (pdfs) for larvae pooled from all sites in (a) 2007 and (b) 2009. Colored bands represent frequency of different size classes. (c-d) Time series of mean cohort sizes as identified from Gaussian separation of the pdfs are shown for (c) 2007 and (d) 2009. Error bars represent standard deviations of the estimates. 

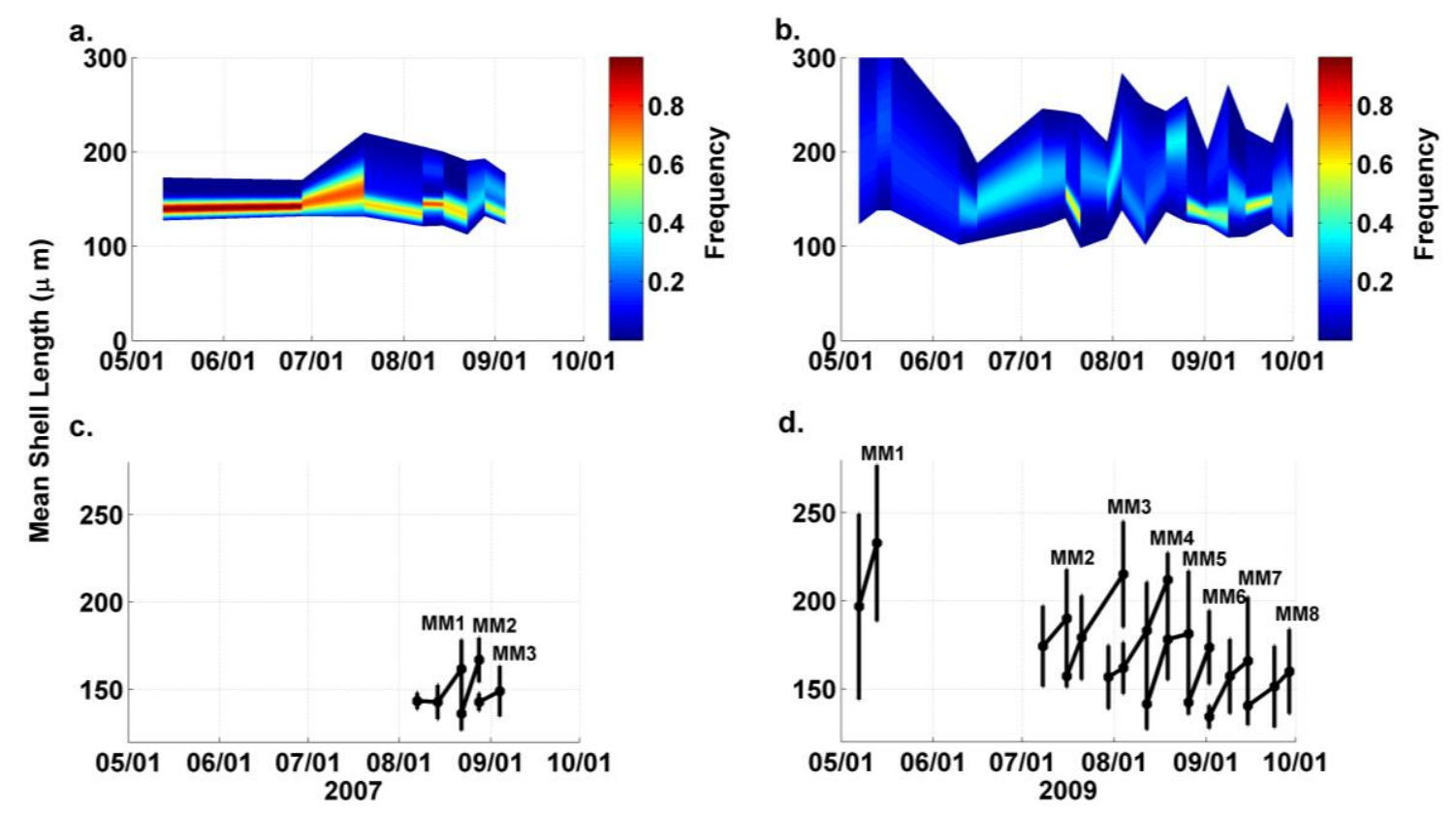

d.

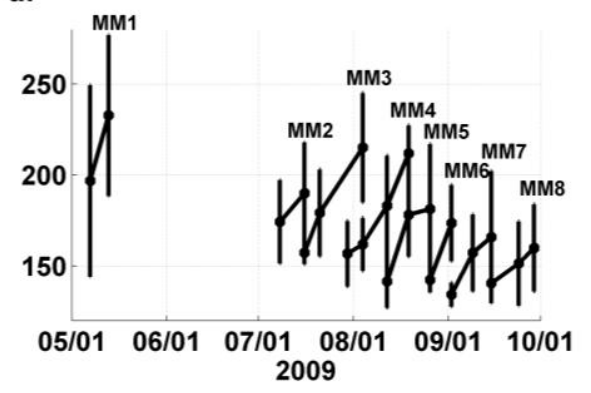

Figure 3.12 Cohort graphs for Mercenaria merecenaria. (a-b) Frequency distributions of larvae sizes as interpolated from probability density functions (pdfs) for larvae pooled from all sites in (a) 2007 and (b) 2009. Colored bands represent frequency of different size classes. (c-d) Time series of mean cohort sizes as identified from Gaussian separation of the pdfs are shown for (c) 2007 and (d) 2009. Error bars represent standard deviations of the estimates. 


\section{CHAPTER 4}

Flux and Vertical Distribution of Three Species of Bivalve Larvae During Transport Through an Estuarine System 


\begin{abstract}
It is challenging to study bivalve larval supply in estuarine systems due to complex estuarine environments, the difficulty of achieving adequate spatial and temporal coverage to assess patchiness, and obstacles with methods of larval identification. We studied flux and vertical distribution of bivalve larvae in Waquoit Bay, MA to assess biological and physical factors that were most influential to larval transport. By using both integrated and high-frequency sampling methods we captured variability in larval supply for three bivalve species on spring and neap tides around a two-week period in the height of the spawning season. We found that flux of larvae through an estuarine channel was greater on ebb tides when temperature and salinity showed a semidiurnal signal. Flux through an inlet indicated Waquoit Bay often exports large pulses of larvae, but is equally capable of importing larvae from outside areas. The magnitude of flux varied between species due to timing of pulses with tidal strength. Larvae did not show any clear vertical distribution patterns that would lead to retention within the estuary. Larvae appeared well-mixed with respect to depth in a site with higher flows and vertical mixing. Low salinities appeared to influence larval distribution in the surface at the stratified site. We also concluded that the strength of tidal flow may affect the ability of larvae to regulate vertical position, with strong flows inhibiting upward swimming at the well-mixed site, but facilitating mixing and reducing salinity structure at the stratified site enabling larvae to swim to the surface. Each species showed different patterns of vertical distribution and flux. This type of information is essential for understanding factors that regulating larval supply in estuarine systems.
\end{abstract}




\subsection{INTRODUCTION}

The transport of marine larvae is a key process regulating the supply and recruitment of benthic invertebrate populations. It has been well established that species with pelagic larval stages rely on the supply, or flux, of larvae to adult habitats in order for population persistence and dispersal over wide spatial ranges (Scheltema 1986, Roughgarden et al. 1988, Palmer et al. 1996, Largier 2003). However, recent progress in larval ecology has shown that larvae may not always disperse as much as expected based on passive drifter studies (Arnold et al. 2005), and that local self-recruitment is possible and common for many species (Todd 1998, Levin 2006). Estuaries provide discrete environments with physical and biological characteristics distinct from coastal waters. For invertebrate species indigenous to estuaries, self-recruitment is often necessary to sustain adult populations. Physical retention mechanisms coupled with larval behavior enable self-recruitment in estuaries (Sponaugle et al. 2002, Swearer et al. 2002).

Physical processes regulating water flows provide a link between larval and juvenile or adult populations. Where and when a larva ultimately settles depends on interactions between hydrodynamics, larval developmental period, and behavior. In estuarine systems, exchange of larvae can occur with tidal advection, but non-tidal events such as gravitational and density-driven currents, wind forcing, and strength of river discharge can influence the flux of larvae at various frequencies (Janzen and Wong 1998, Wiseman et al. 1988). Estuarine residence time is important for determining how likely larvae are to stay within the system (Sponaugle et al. 2002). Not all areas in an estuary have uniform retention times. Smaller-scale dispersion as a result of vertical mixing can 
lead to dispersal to areas of higher retention (Alldredge and Hamner 1980). Tidal asymmetries can also result in net flux in or out of a system (Chant et al. 2000, Chant and Stoner 2001), and larval swimming behavior, if operating at appropriate frequencies, can further enhance retention (Chen et al. 1997 for example). This has been shown convincingly in studies of estuarine brachyurans (e.g. Epifanio et al 1984, DeVries et al. 1994, Dibacco et al. 2001).

For bivalve larvae, it remains uncertain as to whether they are passively distributed or capable of actively maintaining a vertical position in the water column to affect transport. Wood and Hargis (1971) found bivalve larval were transported differently than passive coal particles. In laboratory studies in still water, bivalve larvae have shown swimming responses to gravity (Bayne 1964), light (Gallager et al. 1996), pressure (Cragg 1980, Mann and Wolf 1983), salinity and temperature (Feeny 1983, Mann et al. 1991, Hidu and Haskin 1978), and flow (Jonsson et al. 1991). In field studies, responses have varied and are dependent on the environment and species being studied. However, general patterns have been observed. Smaller bivalve larvae show positive geotaxis and swim to the surface, while larger larvae are generally found towards the bottom (negative geotaxis- Andrews 1983, Baker and Mann 2003). Low salinity avoidance has been shown (Carriker 1951, Mann 1988) and there is some evidence of diel vertical migration (Raby et al. 1994, Rawlinson et al. 2004). As bivalve larvae are weak swimmers, their capabilities of being able to actively regulate depth are strongly dependent on current strength and mixing. In areas of higher flow and turbulence, larval 
distributions are more likely to be well mixed as larvae are unable to overcome vertical mixing (Roegner 2000, Tremblay and Sinclair 1990).

It is difficult to study larval transport due to the large number of observations necessary to understand physical transport processes and the scales on which they act (Dickey 2003). Estuarine environments facilitate larval transport studies by providing geographically constrained environments often with variable conditions useful for comparisons in larval studies (Boicourt 1988). Yet since many estuarine environments are unique, it is difficult to generalize distribution patterns. Larval patchiness necessitates high-frequency observations over the time scale of interest in order to see patterns in distribution, and often tradeoffs must be made between sampling effort and sample error (Kjerfva and Wolaver 1988). Automated analysis and continuous monitoring are ideal solutions to increase sampling effort and decrease sample processing time (Carriker 1988, Garland 2000). Integrating samples can provide better estimates of flux as they are more likely to capture patchiness and pulses (Gaines and Bertness 1993), but may not be able to fully resolve transport direction (Pineda et al. 2010). Discrete samples are necessary to describe particular behavioral responses that might vary over time.

The greatest limitation to bivalve larval research is the inability to accurately identify species, especially individuals of the smallest stages. Many field studies are restricted to species that can be easily identified (i.e. oysters) or to late stage larvae (i.e. Andrews 1983, Baker and Mann 2003). However, species-specific patterns are crucial for understanding larval transport. Studies of brachyuran crab larvae have demonstrated species-specific differences on various scales (Epifanio et al. 1988, DeVries et al. 1994, 
Steppe and Epifanio 2006). Species-specific patterns in bivalve vertical distribution have been observed in upwelling systems (Shanks and Brink 2005, Ma et al. 2006), but little has been documented in estuarine systems where larval concentrations and species richness are high. Baker (2003) showed species-specific vertical distributions with two species of oyster larvae, and model results of North et al. (2008) suggest that speciesspecific vertical distributions can influence population dynamics for two oyster species.

In this study, we investigated larval transport in an estuarine system on Cape Cod, MA and combined state-of-the-art methods for sampling and sample processing. By estimating larval flux at two sites, we were able to determine the net supply of larvae to the estuary as well as determine net flux through a sub-embayment to a shellfish habitat area for a two-week period. By using an automated and integrated sampling method over consecutive semidiurnal tidal cycles, we investigated whether larvae showed increased abundance on a flood or ebb event, and if increased concentrations were associated with water mass features such as temperature and salinity, or tidal features such as tidal amplitude. Previous sampling studies at the inlet to Waquoit Bay showed a tendency for larvae to be found in high concentrations on high amplitude, outgoing tides (C.M. Thompson, WHOI, unpub. data). By evaluating flux of larvae over a spring and neap period we were also able to determine how flow patterns at each site contributed to net flux in or out of a system. Here we hypothesized that if there was a local source of larvae in the main bay, we would see a net efflux of larvae from Waquoit Bay, but a net influx of larvae to the upper marsh due to high retention times and storage capacities of upper marsh areas (Howes et al. 2004). 
We also studied larval transport on a shorter time scale by comparing larval vertical position in a well-mixed and stratified site for three tidal periods on a spring and neap tide by taking discrete hourly samples. Based on results of previous hourly sampling studies (CM Thompson, WHOI, unpub. data), we tested two main hypotheses. First, in a shallow, well-mixed channel, larvae would also appear well-mixed, but in a stratified environment, freshwater avoidance would cause larvae to concentrate in the pycnocline (Carriker 1951). Second, periods of reduced turbulence caused by low velocity would enable larvae to swim to the surface at the well-mixed site. In this study, we defined larval behavior as any distribution that might differ from what might be observed under random mixing. Furthermore, water mass associations were noted by relationships of larvae to salinity or temperature and tidal direction.

A state-of-the-art image identification method was employed to identify three species of bivalve larvae using shell birefringence patterns. We expected to see behaviors associations with tides specific to species and potential sources. We studied three species of bivalves with different habitat requirements: Mercenaria mercenaria, or quahog, is an important shellfish resource for the bay and is found in open waters with sandy bottoms; larvae from this species would be most abundant in the main bay. Guekensia demissa, or the ribbed mussel, is a prevalent species in tidal flats and grows along the banks in marsh channels and successful larvae would be retained in the upper bay. Anomia simplex is a widespread fouling organism prevalent in both estuarine and coastal environments around Cape Cod and thus would not need to remain in Waquoit Bay. Demonstrating speciesspecific larval transport patterns is important for understanding scales of dispersal and 
population connectivity for individual species, which can be useful for conservation and management efforts.

\subsection{METHODS}

4.2.1 Study Site. Waquoit Bay National Estuarine Research Reserve (WBNERR) is a shallow $16 \mathrm{~km}^{2}$ embayment on the south shore of Cape Cod, Massachusetts (Fig. 4.1). Water is tidally exchanged with Nantucket Sound through two inlets with a residence time of 2-3 days. Wind forcing during summer months is predominantly South/South-West and can enhance exchange on incoming tides (Geyer 1997). Within the bay, several sub-embayments exchange water with the main bay, and these estuaries vary in salinity and nutrient concentrations based on the level of groundwater input and urbanization (Valiela et al. 1992, Howes et al. 2004).

We chose three sites within Waquoit Bay to perform the field studies. For the tidal flux study, we sampled at the western inlet (Menauhant site, Fig 4.1) and the Little River sub-embayment (Little River, Fig. 4.1). The Menauhant (MN) site is characterized by high currents and has the deepest channel in the bay (up to $6 \mathrm{~m}$ ). In contrast, Little River (LR) has lower currents and is shallower (up to $2 \mathrm{~m}$ ). Little River exchanges water between the bay proper and Hamblin Pond. Average residence time between Hamblin Pond and the bay is estimated at 1.7 days and around 22 days between Hamblin Pond and the entire Waquoit Bay system (Howes et al. 2004). Little River and Hamblin Pond are important shellfish habitats.

The third site, Childs River (CR), was sampled only in the vertical distribution study. Childs River has a similar depth range to Little River, but has weaker currents, 
higher nutrients, and few shellfish beds. Freshwater input from the upper estuary stratifies Childs River in the upper .3-.5 meters. Water residence time for this sub-estuary is around 3-7 days with Waquoit Bay and around 130 days for the entire system (Howes et al. 2004, Tomasky-Holmes 2008).

4.2.2 Environmental Data. Depth, salinity, and temperature measurements were recorded in 15 minute intervals from moored units (YSI 6600 sonde, YSI Inc.) in the middle of the watercolumn at each sampling location. The WBNERR seawater quality monitoring program maintained the instruments at Menauhant and Childs River, and the Little River instrument was maintained by the Town of Mashpee Shellfish Constable. Wind speed and direction was recorded from a weather station at the WBNERR headquarters (Fig. 4.1).

To measure current velocity, we used SeaHorse Tilt current meters (V. Sheremet, URI) that consisted of a 0.5 or $1 \mathrm{~m}$ one-inch PVC pipe attached to a lead base by rubber tubing. When moored in the channel, the current meter would tilt in the direction of the current and a data logger attached to the top of the PVC pipe would record the angle. The angle of tilt was then transformed into a velocity measurement integrated over the length of the pipe corresponding to the velocity at the bottom meter to 0.5 meter. Current readings were calibrated with still water deployments and with acoustic current meters. Only along channel velocities were significant, with flood tide velocities recorded as positive. Velocities were logged every 7.5 minutes.

4.2.3 Flux Study. We calculated larval flux at our two sites using an automated sampling system programmed to pump continuous water samples during each flood and 
ebb tide event. The study was carried out from 16 July 2009 to 31 July 2009 to encompass the variability in tidal flow that occurs between summer neap and spring tides for an $\mathrm{M}_{\mathrm{sf}}$ lunar solar period (14 days).

Our automated sampling system consisted of four valves programmed to sample over each tidal event. A relay board wired to a computer was programmed to open and close each valve based on a tidal program corresponding to tidal height at Waquoit Bay (Massachusetts Marine Trades Association, www.boatma.com). The program was set to close each valve for an hour starting thirty minutes before slack tide to eliminate sampling residual water from a previous tide. A submersible pump (PondMaster Model 2, $250 \mathrm{gal} / \mathrm{hr}$ ) was connected to the valve system with plastic tubing. A PVC pre-filter screen of of $333 \mu \mathrm{m}$ mesh and a collection screen of $53 \mu \mathrm{m}$ mesh were placed beneath each valve. Each sample would result from about four hours of pumping at a flow rate of 1-2 L/min. Four samples were collected daily and preserved in $4 \%$ buffered formalin. At Little River, the pump was placed off of a floating dock about $20 \mathrm{~cm}$ below the surface, and samples were pumped to the valve system on shore, a distance of about 15 meters. The current meter was located directly beneath the pump. At the Menauhant site, the pump was placed off a dock about a meter away from the sampling system, but located slightly west of the main channel area. Our current meter was placed in an area of greater flow just east of the channel midpoint. For our flux calculations, we assumed uniform larval concentrations and velocity along and across the channel.

In order to calculate a relative flux of larvae for each tidal event, we first had to calculate the volume of water that passed through a cross-section of the water column. To 
calculate channel area, across-channel transects were made and depth measurements were taken every meter across the Little River channel and every two meters across the narrowest part of the Menauhant channel at a high and low tide. These measurements allowed us to interpolate channel area for a given tidal height. We calculated a water volume flux $\left(Q \mathrm{~m}^{3} / \mathrm{s}\right)$ by integrating over the tidal period:

$$
Q=\int V x A d t
$$

Where $V$ is current velocity $(\mathrm{m} / \mathrm{s})$ and is the channel area $\left(\mathrm{m}^{2}\right)$ as interpolated from depth readings at the beginning and end of each interval. To calculate larval flux ( $N$, we then multiplied the concentration of larvae in each sample, $C$ (\# larvae $\left./ \mathrm{m}^{3}\right)$ by $Q$ :

$$
N=C \times Q
$$

an estimate of the total number of larvae that passed through each channel for a tidal sampling period. By summing over consecutive tidal periods we were able to estimate net larval flux for each site.

4.2.4 Vertical Distribution Study. High-frequency sampling was performed over a spring and a neap tide period during the tidal study. Over a 36 hour period, samples were taken every two hours from the Little River and Childs River sites. The spring tide samples were taken from 6:00 on 22 July 2009 to 16:00 on 23 July 2009. The neap tide samples were taken from 6:00 on 28 July 2009 to 16:00 on 29 July 2009 .

For each sample, $100 \mathrm{~L}$ were taken from $25 \mathrm{~cm}$ below the surface of the water column, $20 \mathrm{~cm}$ above the bottom, and at the midpoint of the water column at each site. Temperature and salinity were recorded for each depth by a handheld instrument (YSI 650 MDS, YSI Inc.). Samples were taken from a dock at both sites using a bilge pump 
(West Marine BilgePro 2200) attached to a hose and powered from a portable $12 \mathrm{~V}$ battery at $20 \mathrm{~L} / \mathrm{min}$. Water flowed into a $53 \mu \mathrm{m}$ PVC screen with a $333 \mu \mathrm{m}$ filter. All samples were preserved immediately in a $4 \%$ buffered formalin solution.

4.2.5 Sample Processing and Larval Identification. Plankton samples from both studies were first enumerated using a dissecting microscope. For dense samples, volumetric subsampling was used to count at least 300 bivalves per sample. All volumes were standardized to one cubic meter. Subsamples of 100 individuals were then imaged on a Zeiss IM35 microscope fitted with a 4 Megapixel digital camera (Moticam 1000), polarization filter, and full wave-retardation plate (Chapter 2). If the sample was less than 100 larval bivalves, the full sample was imaged.

After all images were acquired, we used an image analysis routine to distinguish species of larval bivalves (Chapter 2). First, all images were cropped from their original background which was masked to be all black. Next, we chose 10 random samples (1000 images) from each study to be manually sorted into species categories. Criteria for manually identifying larvae consisted of morphological, size, and color/texture criteria as based on an image library of field collected larvae confirmed using molecular techniques. From the four species of bivalves that represented the majority in the samples, we created image "training sets" by sorting the leftover images into categories of 200-300 images of each species. For both studies, these species were Anomia simplex, Geukensia demissia, Macoma balthica, and Mercenaria mercenaria. Comparing the automated and manual methods, the tidal flux study had $84 \%$ overall agreement for training set classification, and the vertical distribution study had $86 \%$ agreement. As a test for image processing 
agreement for the entire image set, we compared the automated classification results to the manually sorted larvae on the independent 1000 image sets (Fig. 4.2). For these classifications, we added an 'other' category of unlabeled species to reduce false-positive classifications (see Chapter 2).

4.2.6 Data Analysis. For the time series of larval concentrations and semidiurnal averaged values of temperature, salinity, wind, and velocity (absolute value), we first performed autocorrelation analysis to determine if there was periodicity in the series and coherence between consecutive samples. We removed the mean from each sample before performing autocorrelations. Periodicity was determined by significant autocorrelations at each lag (one lag = one tidal event, or period between a slack high or low, approximately 0.25 days). To calculate the relevant time scale for coherence between samples, we estimated the decorrelation time as the time when the autocorrelation function crosses zero (Emery and Thomson 1997). Cross-correlation analyses were performed on time series accounting for autocorrelation. As there were gaps in many of the larval time series, cross-correlations were performed for the longest period of consecutive samples (from 11-21 samples).

A two-way analysis of variance (ANOVA) was performed to test the effect of tidal direction and amplitude on larval concentration in the flux samples. Amplitude time series was divided into even intervals and performed ANOVAs for the first and second halves of the time series. Because the larval data were heteroscedastic, we used logtransformed concentrations to equalize the variances. ANOVAs were performed separately for each site and species. 
To compare larval concentrations with depth and tide for the vertical distribution study, we ran a two-way ANOVA on log-transformed larval data for each sampling period. Each sampling depth was a factor, and tide was determined by the direction and strength of the average velocity over the hourly sampling period divided into ebb, flood or slack periods. Since previous sampling studies have suggested that larvae can show different distributions on slack tides (C. Thompson, WHOI, unpub. data), slack periods were included based on the time point that had the weakest average velocity between an incoming and outgoing tide. Tukey-Kramer post-hoc multiple comparison tests were used to compare significant depths and tides.

We also compared larval time series in the vertical distribution study to temperature, salinity, and average velocity. These were done by correlation analyses as described above for the tidal flux study. Since these time series were much shorter, full series were used and missing samples were interpolated by quadratic smoothing up to two times per 18 sample series. As these time series were relatively short, to evaluate significance of cross-correlations we calculated degrees of freedom based on the point when autocorrelations were no longer significant $($ alpha $=0.05)$ rather than true decorrelation times. Although being less conservative, this method allowed us to test more relationships since our analysis was performed for only three full tidal cycles (sometimes less due to missing samples). All statistics were performed using MATLAB (version R2009a; Mathworks, Inc.) and SYSTAT (version 12.0; SPSS, Inc) software. 


\subsection{RESULTS}

4.3.1 Physical setting. Physical data time series demonstrated unique characteristics for Little River and Menauhant, specifically with respect to salinity and velocity. Mean temperature and salinity for Little River was slightly higher and lower, respectively, than at Menauhant, reflecting the relative coastal and estuarine influences, respectively, at both sites (Table 4.1). Temperature increased throughout the time series at both sites (Figs. 4.3b and 4.4b). Temperature series followed a daily cycle with occasional tidal fluctuations. Salinities at Little River varied 2-3 PSU during a tidal event, while at Menauhant salinities remained mostly constant only decreasing briefly at low tides. After 24 July, salinity at Menauhant increased about one unit and stayed high for the rest of the sampling period. This salinity jump did not occur at Little River, although tidal fluctuations became smaller.

For both sites, the difference between semidiurnal tides at the spring period was greater than overall spring-neap differences (Figs $4.3 \mathrm{c}$ and $4.4 \mathrm{c}$ ). Velocities at Little River were highest on incoming tides, although a weakening often occurred about twothirds into the floods (Fig. 4.5a). At Menauhant, velocities were on average twice as high as Little River (Table 4.1) and more uniform with only a slight weakening on the flood tides (Fig. 4.5b). For a period after 28 July, it was evident that the current velocity readings had reversed direction, probably due to movement of the instrument, so these data were corrected for proper tidal direction. At Little River, chlorophyll changed from being semidiurnally periodic to daily cycles after a slight decrease after 22 July (Fig. 4.3d). Chlorophyll at Menauhant was very spiked and marked by periods when data were 
not plotted due to sensor fouling (Fig. 4.4d). Semidiurnal averaged wind throughout the period was mostly in the south-west direction, with a south-east change on 20-21 July and a storm event producing strong winds on 24 July.

4.3.2 Flux Study: Tidal and Water Mass Patterns. Larval concentrations were higher at Little River by an average of one order of magnitude compared to Menauhant throughout the sampling period (Table 4.1, Fig. 4.3a and 4.4a). At both sites, concentrations were an order of magnitude higher at the beginning of the sampling period. A few periods of missing samples for the Menauhant series were due to instrument failure. At both sites, some species data is missing due to larvae being unsuitable for imaging. G. demissa was most abundant at Little River and M. mercenaria was most abundant at Menauhant. A. simplex concentrations were low at both sites.

We were only able to perform autocorrelations on the full time series of total larvae from Little River and a period of 21 consecutive samples at Menauhant (Table 4.1). Because of the observed differences in water properties between the first and second half of the series, we also split the time series and performed autocorrelations for each half. The truncated time series of larval concentrations at Menauhant did not show any significant periodicity and was decorrelated after 1.25 days. Although the full time series of temperature was decorrelated after three days, the time series for the first seven days was decorrelated after one day, on the same order as the larval series. For Little River, larval samples showed semidurnal periodicity in the full series, but autocorrelations of the first and second half of the time series had different periodicities (Fig. 4.6). Significant autocorrelations for the first half (Fig. 4.6b) were observed at both 0.5 and 1 
days corresponding to both the $\mathrm{M}_{2}$ and $\mathrm{K}_{1}$ tidal periods and the decorrelation time of temperature for this series which was 0.5 days (Table 4.1, half-series). Larvae for the second half were coherent for about 1.5 days (Fig. 4.6c), also on the same decorrelation time scale as temperature (two days), indicating a possible relationship of larvae to temperature or water mass as well.

We performed a two-way ANOVA to test the effects of tidal features on larval concentrations (Fig. 4.7). Since we observed different patterns between larval concentrations between the two weeks, separate ANOVAs were performed on data before and after 24 July. Significant differences were only observed for total larvae at Little River for the first week, with greater concentrations on ebb than flood tides $(\mathrm{F}=8.53$, df $=1, \mathrm{p}=0.007)$ and low amplitudes $(\mathrm{F}=4.11, \mathrm{df}=2, \mathrm{p}=0.23)$. No significant trends were observed for the second week. Although increased concentrations were seen on ebb tides for the second week at Menauhant, these results were not significant.

We investigated relationships with water mass, as defined by temperature and salinity, further by using temperature-salinity-plankton (TSP) plots for each species. The TSP diagram for Little River (Fig. 4.8, first column) shows clustered points with temperature and salinity between four degrees and 1.5 PSU, with most larval concentrations centered in the middle within one sigma-t unit. This was most prominent for A. simplex and G. demissa for the first half (Fig. 4.8c, circles). Temperature and salinities for second half of the period (triangles) had a wider temperature but more narrow salinity range, and larvae were more abundant at higher salinities and temperatures for this portion. A significant correlation with salinity was weak and 
observed for total larvae only $(r=-0.297, \mathrm{df}=51, \mathrm{p}<0.05)$. The TSP plot for Menauhant (Fig. 4.8, second column) reveals a more significant separation of water masses. The saltier water in the later time series (triangles) was constrained by a constant density. Samples from this period contained lower concentrations of larvae than the first half of the series, and more larvae were observed with increasing temperature. There was no relationship with water mass properties for the first week (circles). A negative relationship with salinity was significant for all larvae in cross-correlations and was greatest for total larvae $(\mathrm{r}=-0.521, \mathrm{df}=55, \mathrm{p}<0.001)$ and $M$. mercenaria $(\mathrm{r}=-0.428, \mathrm{df}$ $=44, \mathrm{p}<0.005)$.

No significant correlations with wind speed or absolute value of current velocity were observed for larvae at either site. However, cross-correlations indicated negative relationships with wind and larval concentration at a lag of one tidal event (data not shown). This was significant for M. mercenaria at Little River (for an 11 sample series) and for all larvae at Menauhant (for the 21 sample series). This means that a high wind event could lead to lower larval concentrations. However, these correlations were weak and did not account for the decorrelation time scale of the larval series.

4.3.3 Flux study: Flux Patterns. Water volume and larval flux calculations showed more water volume flux on incoming tides for Little River, but the highest larval fluxes occurred on outgoing tides (Fig. 4.9). This was true for all species, but most dramatic for M. mercenaria (Fig. 4.9d), where larval export pulses were highest on tides with high ebbing volume fluxes. For G. demissa at Little River, larval concentrations were highest on ebb tides, but high export was not synchronous with high concentrations 
(Figs. 4.9c, 4.3a). Greater fluxes were observed in the beginning of the time series during spring tides. The water volume flux at Menauhant was more similar between ebb and flood tides, and high fluxes were observed in both directions for all species.

Since there were no consecutive time series for all larvae, a 48-h period of consecutive samples was chosen for a spring and a neap tide period to calculate a net flux of water volume and larvae. Total water volume fluxes were positive for both sites for each period (Table 4.2). Larval fluxes followed the direction of net water mass flux for neap tides at Little River and spring tides at Menauhant. There were no species-specific differences in flux direction.

4.3.4 Vertical Distribution: Depth and Tide Effects. Sampling periods for the vertical distribution study are highlighted in Fig. 4.3. For the Little River spring period, the peaks in larval abundance occurred during the first flood event and at the end of flood tides (Fig. 4.10). These pulses were not likely influenced by daylight, as no similar peak occurred the following day. Although the highest concentrations were at the surface, we found no significant difference between depths, but A. simplex and G. demissa showed significant relationships with tidal phase (Table 4.3). A. simplex concentrations were greater on ebbing tides, while $G$. demissa larvae significantly peaked at slack periods. Total larvae, G. demissa and M. mercenaria had high concentrations falling within a density range marked by lower temperature and salinity (Fig. 4.11a). Both of these species were negatively correlated to salinity for up to two hours at mid and bottom depths (Table 4.4). A. simplex showed higher abundance with increased salinity (Fig. 4.11a). This was significant for middle and bottom depths, where A. simplex larvae 
lagged salinity increases by two hours (Table 4.4). No significant relationships were found at the surface or with temperature.

For the Little River neap sampling period, the only significant correlation was between A. simplex larvae and bottom salinity (Table 4.4). This period had smaller amplitude tides with lower ranges of high temperatures and salinities (Fig. 4.3). The greatest pulse of larvae occurred on the last flood tide (Fig. 4.12), with M. mercenaria and G. demissa showing similar patterns, and A. simplex being lowest in abundance on flooding tides. G. demissa concentrations peaked in the surface and middle depths on low tides. Although cross-correlations were not significant, TSP plots indicated that $M$. mercenaria and G. demissa were highest in abundance in less dense, warmer water, corresponding to midday and parts of ebb tides (Fig. 4.11b).

For the Childs River series, our stratified site, markedly different relationships were seen with depth. For both spring and neap tides, there were significant effects of depth on concentration (Table 4.3). For the spring series, larval abundance at the surface and mid depths was significantly greater than the bottom. G. demissa and M. mercenaria had significantly greater concentrations on flood tides, while A. simplex had low concentrations throughout (Fig. 4.13). TSP plots reflect these relationships showing increased concentrations at mid-salinities, as the bottom samples had the highest salinities but lowest larval concentrations (Fig. 4.11c). Total surface larvae were significantly correlated with salinity. Relationships with incoming tides were reflected in the negative relationships seen with temperature and salinity at lags of 2-6 hours for G. demissa and M. mercenaria (Table 2.4). 
For the Childs River neap series, concentrations in the middle sampling depth were significantly higher than both surface and bottom (Table 4.3). Larval concentration at mid-depth was correlated to higher temperatures (Table 4.4, Fig. 4.11d). In this series, salinities were lower at the surface and larval abundance at the surface was low for all species (Fig. 4.14). Like the spring period, concentrations of G. demissa larvae were greatest on incoming tides. Highest concentrations once again fell in the middle of the TSP plots (Fig. 4.11d). G. demissa and A. simplex had a significant and negative relationship to salinity at four hour lags, once again suggesting a slight tidal effect.

4.3.5 Vertical Distribution: Flow. Larval concentrations were also compared with tidal velocity (Table 4.4). Many of the significant correlations were oppositely correlated at lags of zero and six hours indicating tidal periodicities. This was most apparent for bottom concentrations of A. simplex at the Little River spring period and for all larvae with the exception of M. mercenaria at the Childs River neap period. Direct comparisons between larval concentration and tidal velocity indicated that larval pulses frequently corresponded to either high flooding or low velocity events (Fig. 4.15). Often the highest velocities had lower concentrations resulting in outliers that would have affected the correlation analyses. Periods when larvae were greater in the surface or the middle compared to the bottom could be seen at Little River for low to mid flow, particularly for M. mercenaria (spring and neap) and G. demissa (neap, Fig. 4.15 a,b). For Childs River, greater concentrations in middle and surface seemed to be associated with higher velocities (Fig. 4.15c,d). For the neap period, this only applied to the middle and was associated with high flood velocities. 


\subsection{DISCUSSION}

For both the tidal flux study and the higher frequency vertical distribution study, bivalve larval concentrations highlighted the extensive variability that exists in planktonic larval populations, even on scales of a few hours. These pulses in larval abundance and larval transport potential are ultimately what may lead to recruitment variability within a spawning season. We chose the two week sampling period for this study to cover a period when larval concentrations were highest and to capture the variability that exists between spring and neap tides. Changes in water mass properties, likely brought about by a storm event on 24 July, resulted in increased mixing and flushing of estuarine water and could significantly affect the ability of larvae to respond to temperature and salinity.

4.4.1 Flux Study: Tidal and Water Mass Patterns. For the tidal flux study, we expected to see larvae being exported at Menauhant and imported to Little River. At Little River, all three species showed increased concentrations on ebb tides for the first half of the series, refuting this hypothesis. We did not see any patterns with concentration and tidal direction at Menauhant. Although we did see a significant effect of low amplitudes on total bivalve concentrations, this was only observed in Little River for the first week. A closer look at tidal and water mass properties may explain these results.

Although similar tidal heights were observed between the two sites, temperature and salinity properties for Menauhant had a more coastal signature with only short pulses at the end of the tides indicative of estuarine water. Little River had semidiurnal oscillations with temperature and salinity, although the channel was well-mixed vertically. Time-series analyses showed that larval concentrations had similar 
periodicities to temperature which suggests some relationship to water masses. At Little River, pulses of both $G$. demissa and M. mercenaria, possibly spawns, appeared on separate ebb tides and oscillated with a semidiurnal frequency. Initial pulses of larvae at Menauhant occurred a few hours after Little River, and were composed of a mixture of species, with $M$. mercenaria most abundant. These peaks did not show a systematic semidiurnal tidal signal with respect to concentrations, but rather appeared every 3-4 tides. If the estuarine water signal only appeared at the very end of an ebb tide at Menauhant, it is possible our automated, integrated samples did not fully sample this water mass on ebb tides. The change to warmer, saltier water that occurred after the storm event was associated with lower concentrations of larvae. This could have been a result of mixing and flushing of the bay, reflected by the lack of a semidiurnal water mass signal for this time period. This pattern was also seen at Little River, except $M$. mercenaria regained a semidiurnal periodicity on ebb tides by the end of the sampling period when temperature and salinity resumed semidiurnal fluctuations.

4.4.2 Flux Study: Flux Patterns. Although net water volume flux was incoming at both sites, larvae did not always follow the direction of water mass transport. This could be a result of patchiness between water masses or larval behavior that prevented us from sampling larvae at the surface. Higher concentrations on ebb tides explain the observed export at Little River for the spring period despite net import of water. For the neap period, concentrations had less of a tidal periodicity and larval flux followed water volume flux. For Menauhant, increased larval patchiness around the spring tide did not lead to different transport from water volume flux. Relative fluxes for the neap period at 
Menauhant suggest associations with ebb tides, but this was not evident from the concentration data. Since we had to assume uniform conditions across a channel to make these calculations, these fluxes are highly biased to a given area of the channel and are only intended to give a snapshot of conditions and are not absolute.

Timing of larval pulses to strength of tidal events can result in unexpected fluxes based on concentration data alone and help can explain discrepancies between the direction of larval flux and water volume exchange. The first pulse of $G$. demissa larvae at Little River was mostly exported within a few days. However, this pulse coincided with a smaller amplitude tide resulting in less export than might be expected given the high concentrations at that time. In contrast, more $M$. mercenaria larvae were exported on the subsequent larger event when concentrations and water volume flux were both high. By spawning on the previous tide, the potential for G. demissa export was reduced. In a study of invertebrate larval flux within an estuary, Christy and Stancyk (1982) found that larval populations can remain aggregated in water masses that maintain integrity over several tidal cycles. Although this is likely what was observed at Little River, the concentration of larvae observed is not always a good estimate for relative larval flux if the strengths of consecutive tides are unequal. This mechanism of tidal "setup" has also been used to explain increased retention in periods of smaller ebbs following a large flood tide (Roegner 2000). Tidal asymmetries have been shown to affect transport in other estuaries with low freshwater flow (DiBacco et al. 2001), and tidal circulation may limit or direct dispersal based on the properties of a given estuary (Scheltema 1986, Sponaugle et al. 2002). 
Overall, we saw a net export of larvae from Little River and net import at Menauhant based on relative fluxes. This does not support our initial hypotheses, but instead suggests that Little River/Hamblin Pond are sources of larvae to the main bay, and Menauhant receives inputs from a coastal pool. Previous studies of bivalve larvae found larvae to be concentrated on flooding tides (Wood and Hargis 1971, Andrews 1983, Roegner 2000, Gregg 2002, Baker and Mann 2003). The mechanism suggested for this was that a nearshore pool of larvae supplements larvae that are rapidly exported from bay sources (Roegner 2000). Our results may support this mechanism, with the subestuaries contributing significantly to the bay pool which is rapidly exported when conditions are right. However, larvae exported from Little River could be transported elsewhere in the bay and not necessarily subjected to immediate export from the system.

Our results suggest that patterns in the flux study were a result of both biological (spawning times, larval origins) and physical factors (tidal strength, water mass flux). Spawning events can increase larval concentrations as much as two orders of magnitude over only a few hours (Seliger et al. 1982), and the specific tide at which a spawn may appear could have a large effect on its export. In fact, many decapod crustacean species can time their spawning to a given tidal event (Christy and Stancyk 1982). Semidiurnal variations in temperature and salinity could enhance the ability of larvae to be retained if they responded by changing vertical distributions to reduce export. The only significant relationships seen with tidal direction and amplitude were for total larvae. Patterns of total larvae reflect the patterns of the dominant species at the time, and individual species may show different patterns based on their local concentrations and behaviors. 
4.4.3 Vertical Distribution: Depth and Tide Effects. The vertical distribution study enabled investigation of larval concentrations within a semidiurnal tidal event that could not be resolved from the integrative flux samples. Although we saw patterns that might suggest a behavioral response, these patterns were not consistent for all tidal events or between sample periods. Many of the larval time-series contained gaps or outliers that made correlative relationships difficult to uncover. We present these results as speculative, noting that the differences observed between species are likely to result in differential transport.

At Little River, uniform larval concentrations with depth were typical of shallow, well-mixed estuaries (DeVries et al. 1994). However, during certain periods, mainly daytime, larvae would peak at the surface around slack tides. If this is a behavioral response, this would (1) facilitate surface swimming due to less turbulent mixing, (2) enable feeding on phytoplankton at the surface, and (3) reduce export due to minimal flow. Pedi-veliger G. demissa larvae have shown surface-seeking behavior, but this has not been documented for smaller larvae (Baker and Mann 2003).

Semidiurnal fluctuations with salinity resulted in larval abundances that indicated relationships with water masses. Salinities at Little River increased at the end of high flood tides, indicating the first part of the flood contains returning ebb water (Chant et al. 2000). Increases of $A$. simplex larvae with salinity in the middle and bottom occasionally occurred without a corresponding peak in the surface, indicating a behavioral mechanism to retain larvae before an ebb event. For $G$. demissa and $M$. mercenaria, concentrations of larvae indicated the opposite relationship with salinity, and this would suggest that more 
larvae are associated with estuarine water on outgoing tides and do not necessarily return. No relationships with temperature or salinity and G. demissa or M. mercenaria abundances were seen for the neap tidal period, likely because of the narrower ranges of temperature and salinity observed for this time period.

At Childs River, larval distributions were strongly related to depth. Although we had expected to see larvae aggregated at intermediate depths due to the stratification (Carriker 1951m Deksheieks et al. 1996), larvae were abundant at the surface when the pycnocline may have been weak enough to facilitate larval swimming. Mann et al. 1991 found that bivalve larvae can swim through a halocline of up to $5 \%$, but at our site the halocline was as much as $15 \%$, and G. demissa was observed above a halocline of $10 \%$. Despite having higher salinities, concentrations in the bottom of Childs River were very low. In areas of reduced velocity like that of Childs River, larvae can more consistently maintain a surface-seeking distribution. There can be unfavorable conditions at depth in estuaries that may force larvae to constantly swim upwards (Andrews 1983). Factors we did not sample (such as dissolved oxygen) may have been limiting at this depth, or all flow and larval transport occurs in the middle depth.

There was also a relationship with larval concentration and tide at Childs River. Both G. demissa and M. mercenaria showed increased concentrations with flood tides, indicating a sink for larvae. Upstream of our sampling site, Childs River becomes fresher and its muddy benthos is an unsuitable habitat for all of our target species. Despite being successfully transported and retained here, settlement is unlikely. Species that do successfully settle in Childs River, such as M. arenaria, were not spawning when we had 
sampled. If M. arenaria is transported in a similar fashion as G. demissa and $M$. mercenaria, then this might explain its distribution in the upper estuary.

4.4.4 Vertical Distribution: Flow. For Little River, there were periods when larvae were higher at the surface than other depths. Although this suggests larval behavior, there was weak evidence that larvae were using temperature or salinity as cues for swimming. Instead, flow might have contributed to these observed patterns, although we were unable to measure flow at the exact depth and time samples were taken, so it had to be averaged for a tidal period. For periods of low flow in Little River, larvae often appeared higher in the surface and middle compared to the bottom. This would indicate that surface swimming behavior may be inhibited by the higher turbulence observed with high flows in Little River, supporting our hypothesis. Although there were no consistent patterns with flow direction, larvae may have to be more responsive to velocity and turbulence when semidiurnal signals with temperature and salinity uniform; this supports the observation that concentrations were related to incoming velocities for the neap period.

A DVM study of various larval groups only found significant migration with bivalve larvae in calm conditions (Rawlinson et al. 2004), and our sampling location at Childs River was in a lower-flow area outside the main channel where the current measurements were taken. Larvae at this site demonstrated significant responses to velocity, particularly in the middle sampling depth during the neap period when larval concentrations peaked on periods of high incoming flow. This was also observed for larval concentrations in the surface, particularly for the spring period. Thus, for Little 
River, high flows may inhibit surface swimming due to increased vertical mixing, but at a stratified site like Childs River flows that increase mixing and reduce stratification could alternately enable larvae to swim to the surface.

4.4.3 Comparing Studies. By performing the vertical distribution sampling study synchronously with the tidal flux study, we could compare net flux for each period at Little River (Table 4.5). Overall concentrations for each integrated sample followed the same trends we saw in the hourly samples. However, the net flux was different than what might have been expected from concentration data alone. For the spring period, larval concentrations of $G$. demissa and $M$. mercenaria were higher on outgoing tides, yet there were net imports of $G$. demissa following water volume flux. For the neap period, net imports were seen for all species but $M$. mercenaria. Because velocity at Little River is stronger on flood tides, this may compensate for increased concentrations on ebb tides resulting in upstream transport and retention in marsh areas. Because our integrated sampler was turned off during slack tides, the flux data do not account for slack periods when larvae were most concentrated in the surface. This should not affect the flux calculations drastically as these larvae would have little to no net transport at slack tides.

There are a few caveats to this sampling study that should be noted. Although the best sampling method for investigating tidal transport has been shown to be sampling hourly from one station in the middle of the channel (Kjerfva and Wolaver 1988), spatial variation in flow rates across a channel could become important if concentrations are directly related to flow (Gaines and Bertness 1993). Both Menauhant and Little River have shown different flow structures in areas across a channel. If larval concentrations 
vary across the channel, then flux may not be uniform across an inlet. Furthermore, our current measurements only estimated a water velocity for the last $0.5-1$ meter of the bottom. A short study using an ADCP in Little River showed that velocity does vary with depth, more noticeably on outgoing tides (data not shown). Thus, a species like $A$. simplex showing increased concentration at depth at the beginning of an ebb tide would show reduced outward transport with this behavior.

Recent studies have emphasized the importance of integrative sampling in larval transport and distribution studies (Gaines and Bertness 1993, Dudas et al. 2009, Pineda et al. 2010). Integrative and discrete samples are not always correlated, yet our two studies showed agreement with general trends. Since estuarine systems are so variable, larvae that disperse between estuaries and coastal waters must be adaptable to the variety of conditions experienced. Conditions within sites in Waquoit Bay were unique enough to distribute larvae differently. It is not likely that there is a one particular element or behavioral pattern all bivalve larvae exhibit. Our data suggest that a variety of factors can influence larval distribution and transport, most importantly the timing of larval release, stratification, and local hydrodynamics. We did not observe the suggested pattern for retention of larval bivalves at either site- when larvae swim to the surface at flood tides, and sink on ebb tides (Epifanio et al. 1984, Gregg 2002). If larvae are capable of exhibiting this behavior, Childs River may be too stratified at times, and Little River and Menahuant may be too turbulent. This type of behavior may be more important in deeper waters with lower flows (Roegner 2000). The residual water mass flux after a series of tidal events at our sites indicated that it was sufficient to retain larvae. 
This study demonstrated that species-specific patterns can be observed with tidal fluxes and that vertical distributions and are important to account for when estimating larval dispersal and transport. Recruitment depends on the ability for competent larvae to be retained in the estuary and settle. Baker and Mann (2003) noted that late-stage larvae do not display the same patterns as their younger counterparts and should be removed from behavior studies. Since late-stage larvae were rare in our samples, we did not assume their presence would be significant. Appendix D investigates transport and behavioral potential for larvae greater than $200 \mu \mathrm{m}$ that we would determine as competent to settle. We can conclude that these larvae are often less abundant in the surface than the middle or bottom, and they can have flux in opposite directions than smaller larvae. This points out that larval flux may not be the best indicator of larval supply if larval supply refers to competent larva (Pineda et al. 2010). However, knowing general patterns of larval flux is important for estimating retention.

\subsection{ACKNOWLEDGEMENTS}

The intensive nature of this field study required the help of many gracious volunteers. We would like to thank A. York, M. White, Z. Balmuth-Loris, S. Perkins, J. Gyory, C. Petrik, L. Hamady, H. Moeller and A. Heithoff for sampling assistance. R. York provided necessary assistance for installing our system at Little River. J. Karutz helped build the automated integrated samplers, and V. Sheremet provided the current meters. We would like to thank the personnel at Menauhant Yacht Club and Edwards Boat Yard in Falmouth, MA for allowing us space to perform these studies, especially M. Loftus and C. Swain. This research was conducted within the National Estuarine Research Reserve System and the instrument data used in this study was given by $\mathrm{C}$. Weidman, M.K. Fox and E. Bonk. Funding was provided by an award to S. Gallager and C. Mingione Thompson from the Estuarine Reserves Division, Office of Ocean and Coastal Resource Management, National Ocean Service, National Oceanic and Atmospheric Administration. 


\subsection{LITERATURE CITED}

Alldredge, A.L. and W.M. Hamner. 1980. Recurring aggregation of zooplankton by a tidal current. Est. Coast. Mar. Sci. 10: 31-37.

Andrews, J.D. 1983. Transport of bivalve larvae in James River, Virginia. J. Shellfish Res. 3(1): 29-40.

Arnold, W.S., G.L. Hitchcock, M.E. Frischer, R. Wanninkhof, Y.P. Sheng. 2005. Dispersal of an introduced larval cohort in a coastal lagoon. Limnol. Oceanogr. 50(2): 587-597.

Baker, P. and R. Mann. 2003. Late stage bivalve larvae in a well-mixed estuary are not inert particles. Estuaries 26(4A): 837-845.

Baker, P. 2003. Two species of oyster larvae show different depth distributions in a shallow, well-mixed estuary. J. Shell. Res. 22(3): 733-736.

Bayne, B.L. 1964. The responses of the larvae of Mytilus edulis L. to light and gravity. Okios 15: 162-174.

Benfield, M.C., P. Gorsjean, P.F. Culverhouse, Irigoien, M.E. Sieracki, A. Lopez-Urrutia, H.G. Dam, Q. Hu, C.S. Davis, A. Hansen, C.H. Pilskain, E. Riseman, H. Schultz, P.E. Utgoff, and G. Gorsky. 2007. RAPID: Research on Automated Plankton Identifcation. Oceanography 20(2): 13-26.

Boicurt, W.C. 1988. Recruitment dependence on planktonic transport in coastal waters. In: Rothschild, B.J. (ed.), Toward a Theory on Biological-Physical Interactions in the World Ocean. Kluwer Academic Publishers, pp. 183-202.

Carriker, M.R. 1951. Ecological observations on the distribution of oyster larvae in New Jersey estuaries. Ecological Monographs 21(1): 19-38.

Carriker, M.R. 1988. Bivalve larval research, in transition: a commentary. J. Shellfish Res. 7(1): 1-6.

Chant, R.J., M.C. Curran, K.W. Able, and S.M. Glenn. 2000. Delivery of winter flounder (Pseudopleuronectes americanus) larvae to settlement habitats in coves near tidal inlets. Est. Coast. Shelf Sci. 51: 529-541.

Chant, R.J. and A.W. Stoner. 2001. Particle trapping in a stratified flood-dominated estuary. J. Mar. Res. 59: 29-51.

Chen, Y.H.. P.T. Shaw, and T.G. Wolcott. 1997. Enhancing estuarine retention of planktonic larvae by tidal currents. Estuar. Coast. Shelf. S. 45: 525-533.

Christy, J.H. and S.E. Stancyk. 1982. Timing of larval production and flux of invertebrate larvae in a well-mixed estuary. In: Kennedy, V. (ed.) Estuarine comparisons. Academic Press, New York, pp 489-503.

Cragg, S.M. 1980. Swimming behavior of the larvae of Pecten maximus (L.) (Bivalvia). J. Mar. Bio. Ass. U.K. 60: 551-564.

Dekshenieks, M.M., E.E. Hofmann, J.M. Klinck, E.N. Powell. 1996. Modeling the vertical distribution of oyster larvae in response to environmental conditions. Mar. Ecol. Prog. Ser. 136: 97-110. 
DeVries, M.C., R.A. Tankersley, R.B. Forward, Jr., W.W. Kirby-Smith, R.A. Luettich, Jr. 1994. Abundance of estuarine crab larvae is associated with tidal hydrologic variables. Mar. Biol. 118: 403-413.

DiBacco, C., D. Sutton, and L. McConnico. 2001. Vertical migration behavior and horizontal distribution of brachyuran larvae in a low-inflow estuary: implications for bay-ocean exchange. Mar. Ecol. Prog. Ser. 217: 191-206.

Dickey, T.D. 2003. Emerging ocean observations for interdisciplinary data assimilation systems. J. Mar. Syst. 40-41: 5-48.

Emery, W.J. and R.E. Thomson. 1997. Data Analysis Methods in Physical Oceanography. Pergamon Press, New York.

Epifanio, C.E., C.C. Valenti and A.E. Pembroke. 1984. Dispersal and recruitment of blue crab larvae in Delaware Bay, USA. Est. Coast. Shelf Sci. 18: 1-12.

Epifanio, C.E., K.T. Little, P.M. Rowe. 1988. Dispersal and recruitment of fiddler crab larvae in the Delaware River estuary. Mar. Ecol. Prog. Ser. 43: 181-188.

Feeny, C.F. 1983. Effects of salinity on the vertical distribution of the larvae of Crassostrea virginica (Gmelin) and Ostrea equestris (Say). Abstracts, National Shellfisheries Association Annual Meeting, June 6-9 1983.

Gaines, S.D. and M. Bertness. 1993. The dynamics of juvenile dispersal: why field ecologists must integrate. Ecology 74(8): 2430-2435.

Gallager, S.M., J.L. Manuel, D.A. Manning, R. O’Dor. 1996. Ontogenetic changes in the vertical distribution of giant scallop larvae, Placopecten magellanicus, in 9-m deep mesocosoms as a function of light, food and temperature stratification. Mar. Biol. 124: 679-692.

Garland, E.D. 2000. Temporal variability and vertical structure in larval abundance: the potential roles of biological and physical processes. Doctoral dissertation. Massachusetts Institute of Technology/Woods Hole Oceanographic Institution, Woods Hole, MA, 213 pp.

Garland, E.D. C.A. Zimmer. 2002. Techniques for the identification of bivalve larvae. Mar. Ecol. Prog. Ser. 225: 299-310.

Geyer, W.R. 1997. Influence of wind on dynamics and flushing of shallow estuaries. Est. Coast. Shelf Sci. 44: 713-722.

Gregg, C.S. 2002. Effects of biological and physical processes on the vertical distribution and horizontal transport of bivalve larvae in an estuarine inlet. Doctoral dissertation. Rutgers University, New Brunswick, NJ, 154 pp.

Hidu, H. and H.H. Haskin. 1978. Swimming speeds of oyster larvae Crassostrea virginica in different salinities and temperatures. Estuaries 1(4): 252-255.

Howes, B., W.W. Kelley, J.S. Ramsey, R. Samimy, D. Schlezinger, T. Ruthven, E. Eichner. 2004. Linked Watershed-Embayment Model to Determine Critical Nitrogen Loading Thresholds for the Quashnet River, Hamblin Pond, and Jehu Pond, in the Waquoit Bay System in the Towns of Mashpee and Falmouth, Massachusetts. Massachusetts Estuaries Project, Massachusetts Department of Environmental Protection. Boston, MA.

Janzen, C.D., and K.C. Wong. 1998. On the low-frequency transport processes in a shallow coastal lagoon. Estuaries 21(4B): 754-766. 
Jonsson, P.R., Andre, C. and M. Lindegarth. 1991. Swimming behavior of marine bivalve larvae in a flume boundary-layer flow: evidence for near-bottom confinement. Mar. Ecol. Prog. Ser. 79: 67-76.

Kjerfva, B. and T.G. Wolaver. 1988. Sampling optimization for studies of tidal transport in estuaries. American Fisheries Society Symposium 3: 26-33.

Largier, J.L. 2003. Considerations in estimating larval dispersal distances from oceanographic data. Ecol. App. 13(1): S71-S89.

Levin, L.A. 2006. Recent progress in understanding larval dispersal: new directions and digressions. Integr. Comp. Biol. 46(3): 282-297.

Ma, H., J.P. Grassle, R.J. Chant. 2006. Vertical distribution of bivalve larvae along a cross-shelf transect during summer upwelling and downwelling. Mar. Biol. 149: 1123-1138.

Mann, R., and C.C. Wolf. 1983. Swimming behaviour of larvae of the ocean quahog Arctica islandica in response to pressure and temperature. Mar. Ecol. Prog. Ser. 13: 211-218.

Mann, R. 1988. Distribution of bivalve larvae at a frontal system in the James River, Virginia. Mar. Ecol. Prog. Ser. 50: 29-44.

Mann, R., B.M. Campos, M.W. Luckenbach. 1991. Swimming rate and responses of larvae of three mactrid bivalves to salinity discontinuities. Mar. Ecol. Prog. Ser. 68: 257-269.

North, E.W., Z. Schlag, R.R. Hood, M. Li, L. Zhong, T. Gross, V.S. Kennedy. 2008. Vertical swimming behavior influences the dispersal of simulated oyster larvae in a coupled particle-tracking and hydrodynamic model of Chesapeake Bay. Mar. Ecol. Prog. Ser. 359: 99-115.

Palmer, M.A., J. D. Allan, and C.A. Butman. 1996. Dispersal as a regional process affecting the local dynamics of marine and stream benthic invertebrates. TREE 11(8): 322-326.

Pineda, J., F. Porri, V. Starczak, and J. Blythe. 2010. Causes of decoupling between larval supply and settlement and consequences for understanding recruitment and population connectivity. J. Exp. Mar. Biol. Ecol. 392: 9-21.

Raby, D., Y. Lagadeuc, J.J. Doson, M. Mingelbier. 1994. Relationship between feeding and vertical distribution of bivalve larvae in stratified and mixed waters. Mar. Ecol. Prog. Ser. 103: 275-284.

Rawlinson, K.A., J. Davenport, and D.K.A. Barnes. 2004. Vertical migration strategies with respect to advection and stratification in a semi-enclosed lough: a comparison of mero- and holozooplankton. Mar. Biol. 144: 935-946.

Roughgarden, J. S. Gaines, and H. Possingham. 1988. Recruitment dynamics in complex life cycles. Science 241: 1460-1466.

Roegner, G.C. 2000. Transport of molluscan larvae through a shallow estuary. J. Plankton Res. 22(9): 1779-1800.

Scheltema, R.S. 1986. On dispersal and planktonic larvae of benthic invertebrates: an eclectic overview and summary of problems. Bull. of Mar. Sci. 39(2): 290-322.

Seliger, H.H., J.A. Goggs, R.B. Rivkin, W.H. Biggley, and K.R.H. Aspden. 1982. The transport of oyster larvae in an estuary. Mar. Biol. 71: 57-72. 
Shanks, A.L. and L. Brink. 2005. Upwelling, downwelling, and cross-shelf transport of bivalve larvae: test of a hypothesis. Mar. Ecol. Prog. Ser. 302: 1-12.

Sponaugle, S., R.K. Cowen, A. Shanks, S.G. Morgan, J.M. Leis, J. Pineda, G.W. Boehlert, M.J. Kingsford, K.C. Lindeman, C. Grimes and J.L. Munro. 2002. Predicting self-recruitment in marine populations: biophysical correlates and mechanisms. Bull. Mar. Sci. 70(1): 341-375.

Steppe, C.N., C.E. Epifanio. 2006. Synoptic distribution of crab larvae near the mouth of Delaware Bay: Influence of nearshore hydrographic regimes. Estuar. Coast. Shelf. S. 70: 654-662.

Swearer, S.E., J.S. Shima, M.E. Hellberg, S.R. Thrrold, G.P. Jones, D.R. Robertson, S.G. Morgan, K.A. Selkoe, G.M. Ruiz, and R.R. Warner. 2002. Evidence of selfrecruitment in demersal marine populations. Bull. Mar. Sci. 70(1): 251-271.

Tremblay, M.J. and M. Sinclair. 1990. Diel vertical migration of sea scallop larvae Placopecten magellanicus in a shallow embayment. Mar. Ecol. Prog. Ser. 67(1): 19-25.

Todd, C.D. 1998. Larval supply and recruitment of benthic invertebrates: do larvae always disperse as much as we believe? Hydroiologia 375/376: 1-21.

Valiela, I., K. Foreman, M. LaMontagne, D. Hersh, J. Costa, P. Peckol, B. DeMeoAnderson, C. D’Avanzo, M. Babione, C. Sham, J. Brawley, K. Lajtha. 1992Couplings of Watersheds and Coastal Waters: Sources and Consequences of Nutrient Enrichment in Waquoit Bay, Massachusetts. Estuaries 15(4): 443-457.

Wiseman, W.J., W.W. Schroeder, and S.P. Dinnel. 1988. Shelf-estuarine water exchanges between the Gulf of Mexico and Mobile Bay, Alabama. American Fisheries Society Symposium 3: 1-8.

Wood, L. and W.J. Hargis. 1971. Transport of bivalve larvae in a tidal estuary. IN: Crisp, D.J. (ed.) Proceedings of the Fourth European Marine Biology Symposium. Bangor, 1969. Cambridge University Press, Cambridge, pp 29-44. 
Table 4.1 Properties of bivalve larval and physical time series. Mean values for total bivalve larval time series at Little River (LR) and Menauhant (MN) are shown along with mean temperature, salinity, wind speed, and tidal velocity for each tidal period and are shown separately for each week. Standard deviations for bivalve concentrations were similar to the means and are not shown. Only one wind time series was used. Periodicity and decorrelation times (DT) from each series' autocorrelations are shown. Periodicities represent when the autocorrelation was significant $($ alpha $=0.05)$ at a given time lag. Decorrelation times represent the period of sample coherence based on how long the time series was correlated. A minus sign (-) indicates a negative correlation at that given timescale. Due to gaps in the Menauhant time series, only a 21-sample series was used + .

\begin{tabular}{|c|c|c|c|c|c|c|}
\hline \multirow[b]{2}{*}{ Full Series } & \multicolumn{2}{|c|}{ Mean (std) } & \multicolumn{2}{|c|}{ Periodicity (d) } & \multicolumn{2}{|c|}{ DT (d) } \\
\hline & LR & $\mathrm{MN}$ & LR & $\mathrm{MN}$ & LR & $\mathrm{MN}$ \\
\hline \multicolumn{6}{|l|}{$\left(\right.$ larvae $\left./ \mathrm{m}^{3}\right)$} & $1.25+$ \\
\hline $\begin{array}{l}\text { Temperature } \\
\text { (C) }\end{array}$ & $24.4(1.2)$ & $23.2(0.7)$ & $0.25-1$ & 0.25 & 2.25 & 3 \\
\hline $\begin{array}{l}\text { Salinity } \\
\text { (PSU) }\end{array}$ & $28.6(0.2)$ & $30.0(0.7)$ & $0.25,1$ & $0.25-1$ & 1.25 & 3.25 \\
\hline $\begin{array}{l}\text { Wind } \\
(\mathrm{m} / \mathrm{s})\end{array}$ & \multicolumn{2}{|c|}{$1.6(0.8)$} & \multicolumn{2}{|c|}{$0.25,2.25$} & \multicolumn{2}{|c|}{0.5} \\
\hline \multirow[t]{2}{*}{$\begin{array}{l}\text { Velocity } \\
(\mathrm{m} / \mathrm{s})\end{array}$} & $22.4(7.8)$ & $55.7(17.4)$ & $0.5(-), 1,2$ & $0.5(-)$ & 0.25 & 0.5 \\
\hline & \multicolumn{2}{|c|}{ Mean (std) } & \multicolumn{2}{|c|}{ Periodicity (d) } & \multicolumn{2}{|c|}{$\mathrm{DT}(\mathrm{d})$} \\
\hline Half-Series & Wk1 & Wk2 & Wk1 & Wk2 & Wk1 & Wk2 \\
\hline \multicolumn{7}{|l|}{ Little River } \\
\hline $\begin{array}{l}\text { Bivalves } \\
\text { (larvae/m³) }\end{array}$ & $4.62 E+04$ & $1.39 \mathrm{E}+04$ & 0.5 & $0.25,0.5$ & 0.5 & 1.5 \\
\hline $\begin{array}{l}\text { Temperature } \\
\text { (C) }\end{array}$ & $24.2(0.9)$ & $24.7(1.2)$ & 0.25 & 0.25 & 0.5 & 2 \\
\hline $\begin{array}{l}\text { Salinity } \\
\text { (PSU) }\end{array}$ & $28.5(0.4)$ & $28.6(0.2)$ & $0.25,1$ & 0.25 & 1.25 & 0.5 \\
\hline \multicolumn{7}{|l|}{ Menauhant } \\
\hline $\begin{array}{l}\text { Temperature } \\
\text { (C) }\end{array}$ & $22.9(0.6)$ & $23.6(0.7)$ & 0.25 & 0.25 & 1 & 1.75 \\
\hline $\begin{array}{l}\text { Salinity } \\
\text { (PSU) }\end{array}$ & $29.5(0.5)$ & $30.6(0.1)$ & $0.25,0.5$ & 0.25 & 2.5 & 1.25 \\
\hline & † perform & trunct & ata series $(5.2$ & & & \\
\hline
\end{tabular}


Table 4.2 Flux calculations of water volume $\left(\mathrm{x}_{10}^{4} \mathrm{~m}^{3}\right)$ and larvae (x 10 $10^{9}$ larvae) for spring and neap 48 hour periods. Water volume flux for each tidal sampling period was compared to the total of larvae transported for four consecutive tidal periods. Positive fluxes are indicated in bold.

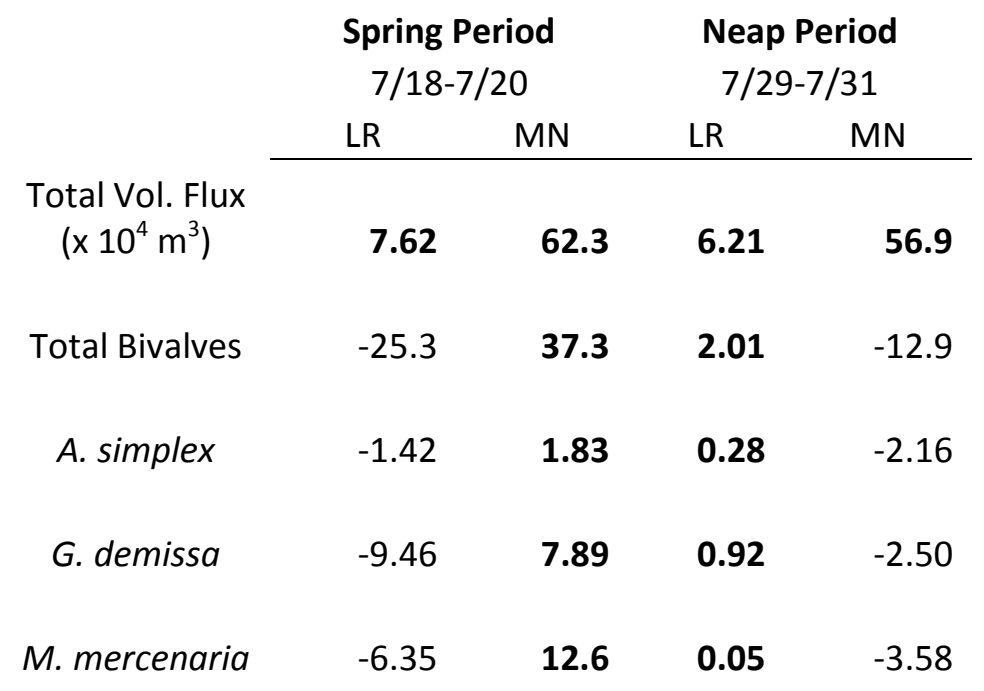


Table 4.3 ANOVA tables of the effects of depth and tide on larval concentrations.

Results from a two-way ANOVA on log-transformed data are shown for each sampling period. Depth was defined by samples at surface, middle, and bottom. Tide was

determined by the strength and direction of current velocity during each sample resulting in three treatments of ebb, flood, and slack. Only surface and middle values were used for each species in the Childs River neap series. Significant relationships (alpha <0.05) are shown in bold. $\mathrm{DF}=$ degrees of freedom; TOT = total larvae; $\mathrm{AS}=$ A. simplex; $\mathrm{GD}=G$. demissa, $\mathrm{MM}=$ M. mercenaria

\begin{tabular}{llccc|rrr} 
& & \multicolumn{3}{c}{ Little River } & \multicolumn{3}{c}{ Childs River } \\
\hline SPRING & Source & DF & F & P & DF & F & \multicolumn{1}{c}{ P } \\
\hline TOT & Depth & 2 & 1.72 & 0.193 & $\mathbf{2}$ & $\mathbf{9 . 9 4}$ & $\mathbf{0 . 0 0 0 4}$ \\
& Tide & 2 & 0.85 & 0.435 & 2 & 2.16 & 0.1307 \\
& Depth*Tide & 4 & 0.30 & 0.877 & 4 & 0.83 & 0.5152 \\
AS & Depth & 2 & 1.53 & 0.229 & $\mathbf{2}$ & $\mathbf{5 . 2 4}$ & $\mathbf{0 . 0 1 2}$ \\
& Tide & $\mathbf{2}$ & $\mathbf{6 . 0 0}$ & $\mathbf{0 . 0 0 6}$ & 2 & 0.12 & 0.875 \\
& Depth*Tide & 4 & 0.65 & 0.634 & 4 & 0.65 & 0.632 \\
GD & Depth & 2 & 0.13 & 0.875 & $\mathbf{2}$ & $\mathbf{1 0 . 6 2}$ & $\mathbf{0 . 0 0 0 4}$ \\
& Tide & $\mathbf{2}$ & $\mathbf{3 . 5 7}$ & $\mathbf{0 . 0 3 9}$ & $\mathbf{2}$ & $\mathbf{4 . 4 0}$ & $\mathbf{0 . 0 2 4}$ \\
& Depth*Tide & 4 & 0.02 & 0.999 & 4 & 1.46 & 0.242 \\
MM & Depth & 2 & 0.76 & 0.476 & $\mathbf{2}$ & $\mathbf{6 . 6 0}$ & $\mathbf{0 . 0 0 5}$ \\
& Tide & 2 & 1.25 & 0.300 & $\mathbf{2}$ & $\mathbf{4 . 3 5}$ & $\mathbf{0 . 0 2 3}$ \\
& Depth*Tide & 4 & 0.34 & 0.85 & 4 & 1.95 & 0.131 \\
\hline NEAP & Source & DF & $\mathrm{F}$ & $\mathrm{P}$ & $\mathrm{DF}$ & $\mathrm{F}$ & $\mathrm{P}$ \\
\hline TOT & Depth & $\mathbf{2}$ & 0.72 & 0.49 & $\mathbf{2}$ & $\mathbf{1 6 . 2 7}$ & $\mathbf{0}$ \\
& Tide & $\mathbf{2}$ & 0.94 & 0.397 & 2 & 1.66 & 0.204 \\
& Depth*Tide & 4 & 0.05 & 0.999 & $\mathbf{4}$ & $\mathbf{3 . 3 8}$ & $\mathbf{0 . 0 1 8}$ \\
AS & Depth & $\mathbf{2}$ & 1.21 & 0.310 & $\mathbf{1}$ & $\mathbf{5 . 5 5}$ & $\mathbf{0 . 0 2 5}$ \\
& Tide & $\mathbf{2}$ & 1.16 & 0.323 & 1 & 0.46 & 0.501 \\
& Depth*Tide & 4 & 0.15 & 0.963 & 3 & 1.40 & 0.263 \\
GD & Depth & $\mathbf{2}$ & 0.46 & 0.636 & $\mathbf{1}$ & $\mathbf{1 4 . 6}$ & $\mathbf{0 . 0 0 6}$ \\
& Tide & $\mathbf{2}$ & 1.50 & 0.235 & $\mathbf{1}$ & $\mathbf{5 . 4 4}$ & $\mathbf{0 . 0 2 7}$ \\
& Depth*Tide & 4 & 0.33 & 0.859 & $\mathbf{3}$ & $\mathbf{3 . 6 1}$ & $\mathbf{0 . 0 2 5}$ \\
MM & Depth & $\mathbf{2}$ & 0.38 & 0.683 & $\mathbf{1}$ & $\mathbf{1 9 . 3 5}$ & $\mathbf{0 . 0 0 0 1}$ \\
& Tide & $\mathbf{2}$ & 1.59 & 0.217 & 1 & 1.69 & 0.204 \\
& Depth*Tide & 4 & 0.24 & 0.915 & $\mathbf{3}$ & 1.57 & 0.219
\end{tabular}


Table 4.4 Cross-correlations between larval concentration and temperature, salinity and velocity for the vertical distribution study. Periods of significant cross-correlations are indicated by the hourly time lag with respect to the physical variable (for instance, $a+2$ lag to salinity means the larval concentrations led salinity by two hours). Pearson's correlation coefficient, $r$, is given in parentheses next to each lag. $\mathrm{LR}=$ Little River, $\mathrm{CR}=$ Childs River

\begin{tabular}{|c|c|c|c|c|c|c|}
\hline \multirow[b]{2}{*}{ LR Spring } & \multicolumn{3}{|c|}{ Total Bivalves } & \multicolumn{3}{|c|}{ Anomia simplex } \\
\hline & Surface & Middle & Bottom & Surface & Middle & Bottom \\
\hline \multirow[t]{2}{*}{ Salinity } & & $0(-0.676)$ & $0(-0.676)$ & & $-2(0.552)$ & $-2(0.667)$ \\
\hline & & $+2(-0.624)$ & $+2(-0.624)$ & & & $0(0.538)$ \\
\hline \multirow[t]{4}{*}{ Velocity } & & & & $+2(0.556)$ & & $-6(0.621)$ \\
\hline & & & & & & $-4(0.533)$ \\
\hline & & & & & & $0(-0.590)$ \\
\hline & & & & & & $+2(0.668)$ \\
\hline \multicolumn{7}{|l|}{ LR Neap } \\
\hline Salinity & & & & & & $0(0.579)$ \\
\hline \multicolumn{7}{|l|}{ CR Spring } \\
\hline \multicolumn{7}{|l|}{ Temperature } \\
\hline \multirow[t]{2}{*}{ Salinity } & $0(0.585)$ & & & $2(0.773)$ & & \\
\hline & $+2(0.586)$ & & & & & \\
\hline \multirow[t]{2}{*}{ Velocity } & $-2(0.652)$ & $2(0.652)$ & & & & \\
\hline & $+4(-0.585)$ & $6(-0.610)$ & & & & \\
\hline \multicolumn{7}{|l|}{ CR Neap } \\
\hline Temperature & & $-4(-0.502)$ & & $-2(0.548)$ & $0(0.611)$ & \\
\hline Salinity & & $-4(-0.542)$ & & & $-4(-0.542)$ & \\
\hline Velocity & & $-6(-0.519)$ & & & $-6(-0.528)$ & \\
\hline & & $0(0.621)$ & & & $0(0.548)$ & \\
\hline & & $+6(-0.581)$ & & & & \\
\hline
\end{tabular}




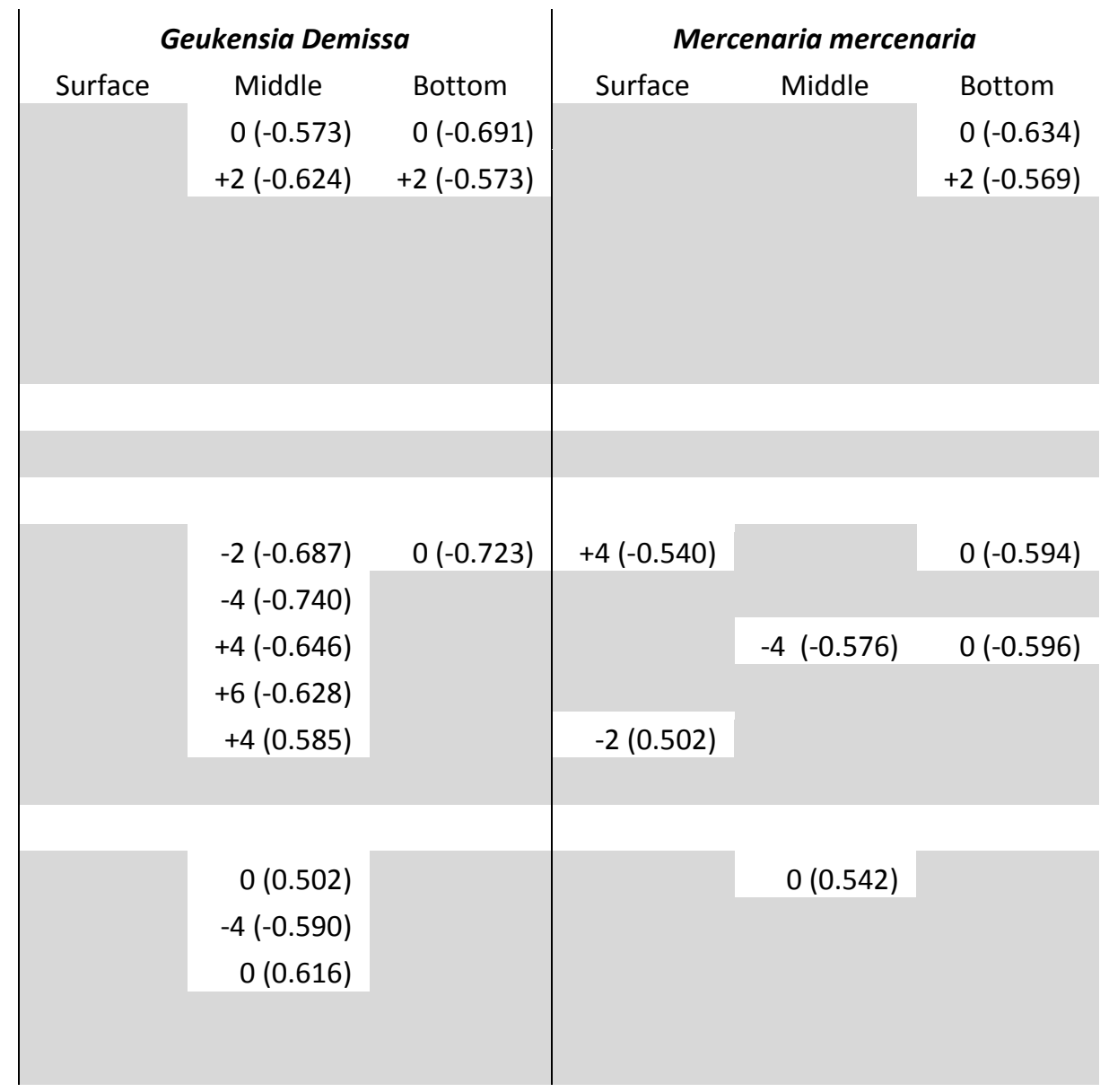


Table 4.5 Flux calculations for each tidal period for the Little River spring and neap tide sampling events. Water volume flux $\left(\times 10^{5} \mathrm{~m}^{3}\right)$ and number of larvae $\left(\mathrm{x} 10^{8}\right)$ are shown for each of three tidal pairs. Total water volume flux and flux of all larvae are summed in the second to last column. The last column contains sums for specified tidal pairs because of missing samples. $\mathrm{F}=$ flood, $\mathrm{E}=\mathrm{ebb}, \mathrm{AS}=$ A. simplex, $\mathrm{GD}=$ G. demiss $a, \mathrm{MM}=M$.

mercenaria.

$\begin{array}{llllllllr}\begin{array}{l}\text { Spring } \\ \text { Water }\end{array} & \text { F1 } & \text { E1 } & \text { F2 } & \text { E2 } & \text { F3 } & \text { E3 } & \text { Total } & 1 \text { and 3 } \\ \text { Volume } & \mathbf{1 . 0 5} & -0.69 & \mathbf{2 . 5 8} & -1.79 & \mathbf{1 . 5 2} & -0.85 & \mathbf{1 . 8 2} & \mathbf{1 . 0 4} \\ \text { Total } & \mathbf{1 9 . 1} & -15.6 & \mathbf{3 2 . 3} & -15.0 & \mathbf{5 . 2 1} & -8.44 & \mathbf{1 7 . 6} & \mathbf{0 . 2 4} \\ \text { AS } & \mathbf{0 . 7 6} & -0.63 & \mathrm{n} / \mathrm{a} & -2.39 & \mathbf{0 . 7 8} & -1.10 & & -0.18 \\ \text { GD } & \mathbf{9 . 1 8} & -4.54 & \mathrm{n} / \mathrm{a} & -4.34 & \mathbf{1 . 7 7} & -1.77 & & \mathbf{4 . 6 4} \\ \text { MM } & \mathbf{0 . 7 6} & -1.56 & \mathrm{n} / \mathrm{a} & -2.24 & \mathbf{0 . 8 9} & -1.52 & & -1.43 \\ & & & & & & & & \\ \text { Neap } & \text { E1 } & \mathrm{F} 1 & \mathrm{E} 2 & \mathrm{~F} 2 & \mathrm{E} 3 & \mathrm{~F} 3 & \text { Total } & \text { 2 and 3 } \\ \text { Water } & & & & & & & & \\ \text { Volume } & -0.60 & \mathbf{1 . 4 1} & -1.18 & \mathbf{0 . 6 3} & -0.47 & \mathbf{1 . 4 4} & \mathbf{1 . 2 4} & \mathbf{0 . 4 2} \\ \text { Total } & -0.10 & \mathbf{1 5 . 1} & -21.7 & \mathbf{1 1 . 1} & -10.8 & \mathbf{3 3 . 4} & \mathbf{2 7 . 0} & \mathbf{1 1 . 9} \\ \text { AS } & \mathrm{n} / \mathrm{a} & \mathbf{1 . 8 2} & -1.08 & \mathbf{1 . 0 0} & -0.97 & \mathbf{4 . 6 7} & & \mathbf{3 . 6 1} \\ \text { GD } & \mathrm{n} / \mathrm{a} & \mathbf{6 . 5 1} & -6.72 & \mathbf{4 . 7 6} & -2.49 & \mathbf{8 . 6 8} & & \mathbf{4 . 2 2} \\ \text { MM } & \text { n/a } & \mathbf{1 . 2 1} & -\mathbf{7 . 5 9} & \mathbf{1 . 6 6} & -3.67 & \mathbf{7 . 3 4} & & -\mathbf{2 . 2 7}\end{array}$




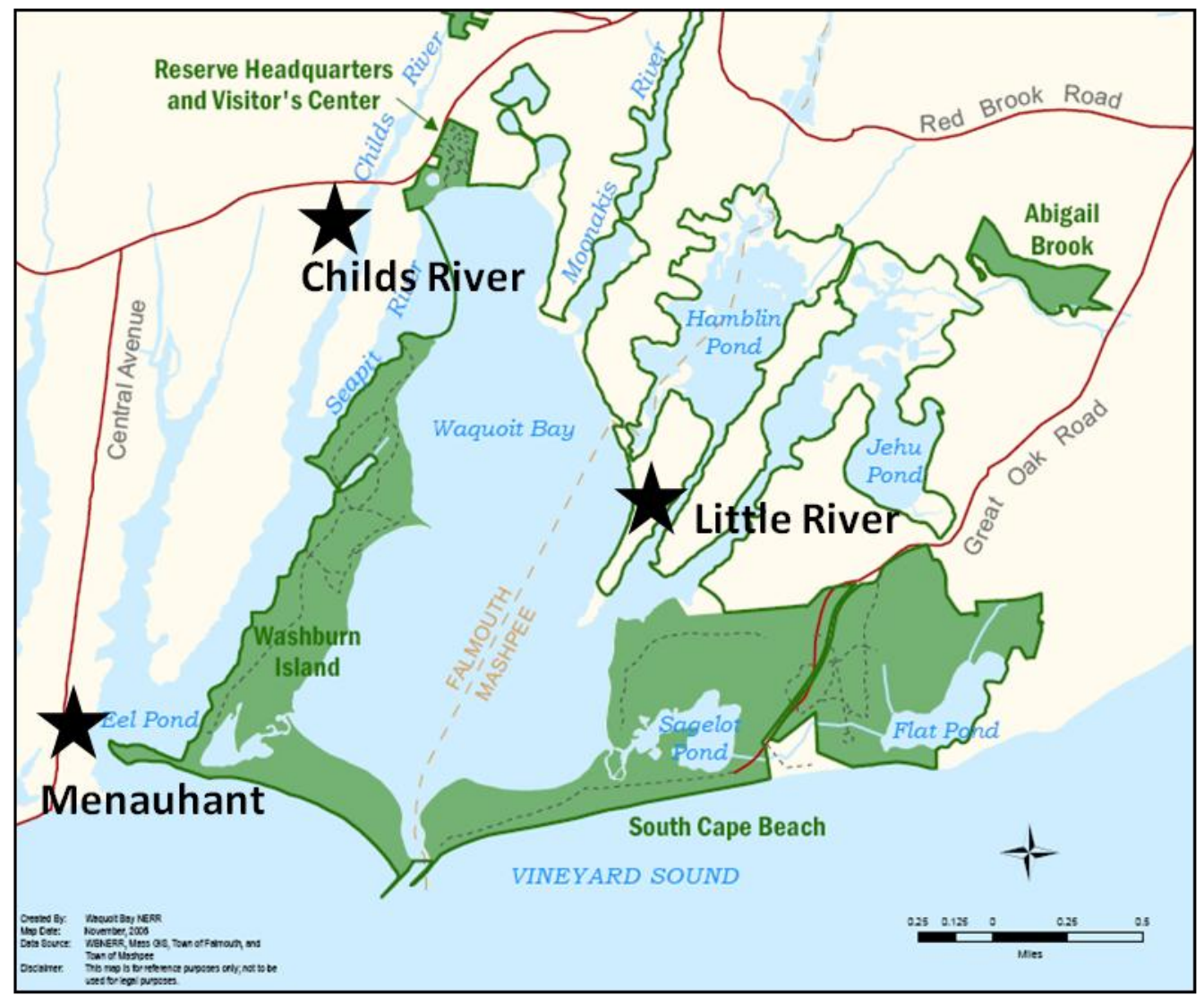

Figure 4.1 Reserve boundary map of Waquoit Bay showing sampling locations for flux and vertical distribution study. Stars depict each site. Menauhant and Little River were sites of the tidal flux study, and Childs River and Little River were sites of the vertical distribution study. Figure courtesy of the Waquoit Bay National Estuarine Research Reserve. 


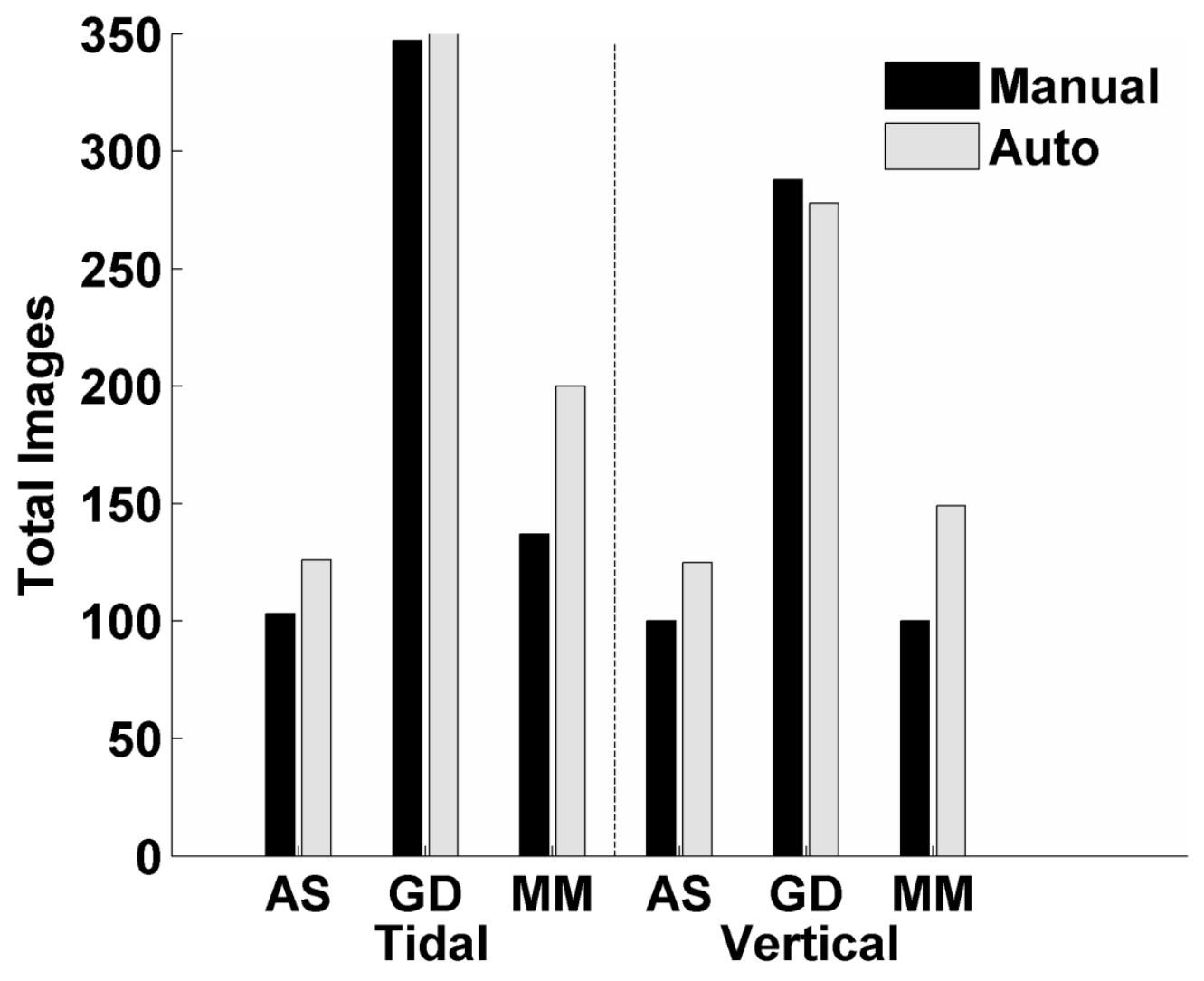

Figure 4.2 Classification comparisons by the manual and automated methods. Total images classified manually (black bars) and with the automated software (gray bars) are shown for our three species of interest for the tidal and vertical distribution studies.

Classified larvae were summed from 10 random samples (1000 images) we used to test each training set. 


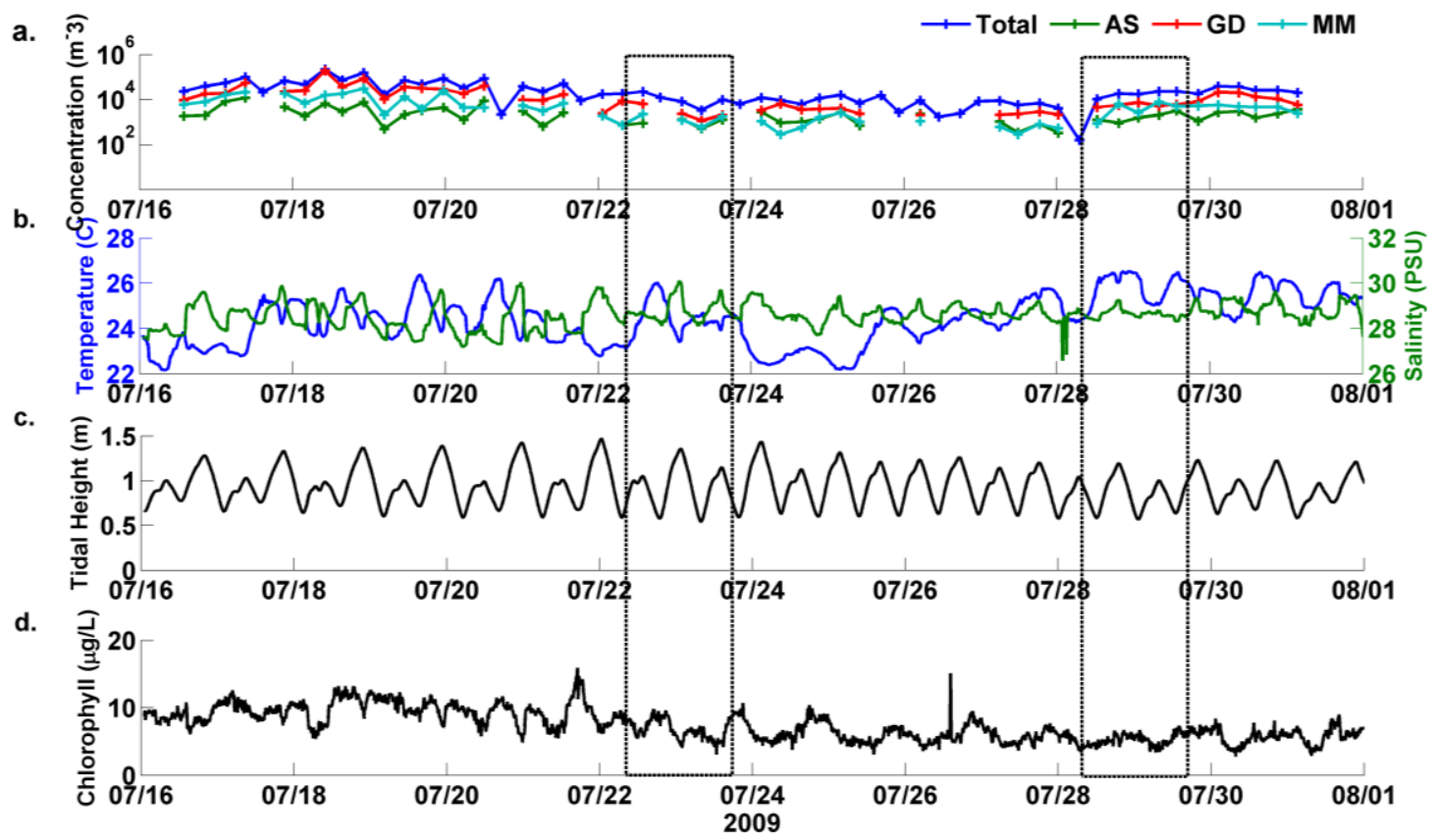

Figure 4.3 (a) Bivalve larval concentrations, (b) temperature/salinity, (c) depth, and (d) chlorophyll for Little River during study period. (a) Total bivalve larvae and concentrations of the three species were calculated based on the total water volume pumped for each sample and the percentage species composition from each imaged subsample. Concentrations are plotted on a log scale. (b-c) Physical data were measured in 15 minute intervals. Dashed boxes indicate sampling period for high-frequency spring (first box) and neap (second box) tide sampling. Total = total bivalve larvae; $\mathrm{AS}=A$. simplex, $\mathrm{GD}=$ G. demissa, $\mathrm{MM}=\mathrm{M}$. mercenaria . 

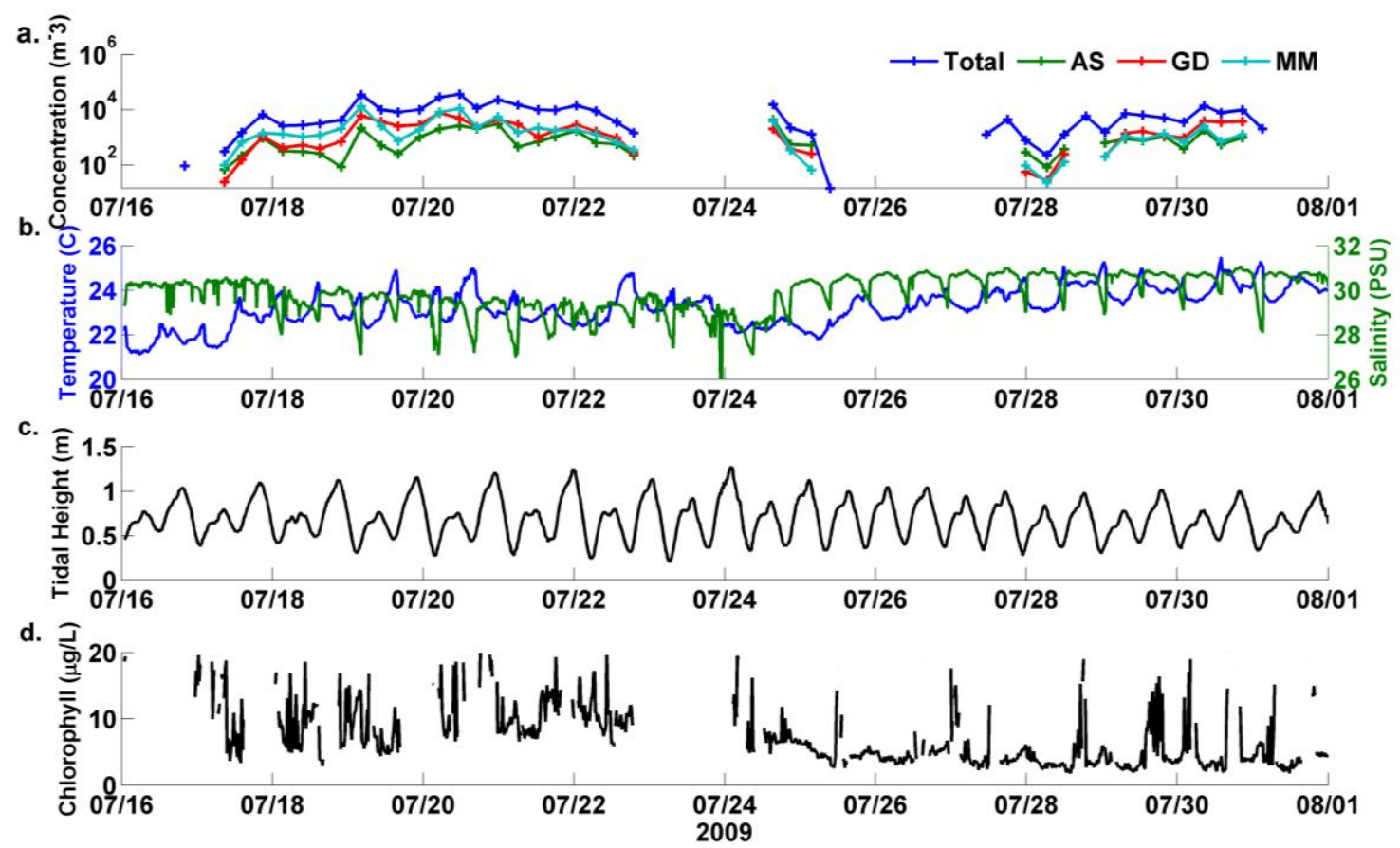

Figure 4.4 (a) Bivalve larvae, (b) temperature/salinity, (c) depth, and (d) chlorophyll for Menauhant during study period. (a) Total bivalve larvae and concentrations of the three species were calculated based on the total water volume pumped for each sample and the percentage species composition from each imaged subsample. Concentrations are plotted on a log scale. (b-c) Physical data were measured in 15 minute intervals. Missing data for chlorophyll time series indicate periods when sensor was fouled. Total = total bivalve larvae; $\mathrm{AS}=$ A. simplex, $\mathrm{GD}=$ G. demissa, $\mathrm{MM}=\mathrm{M}$. mercenaria . 
a.

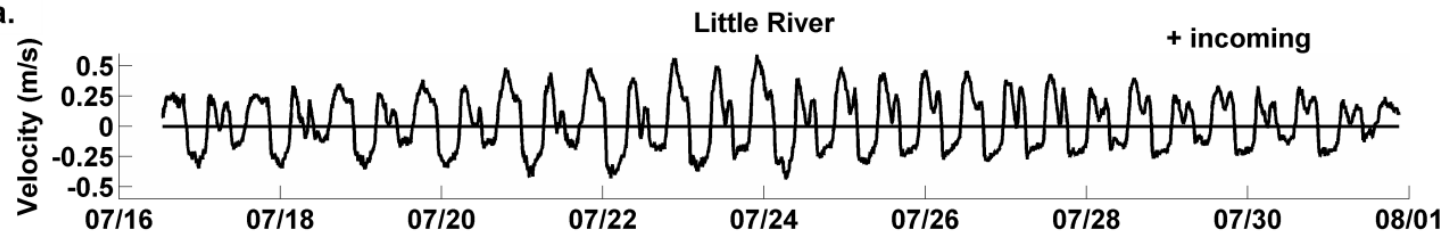

b.
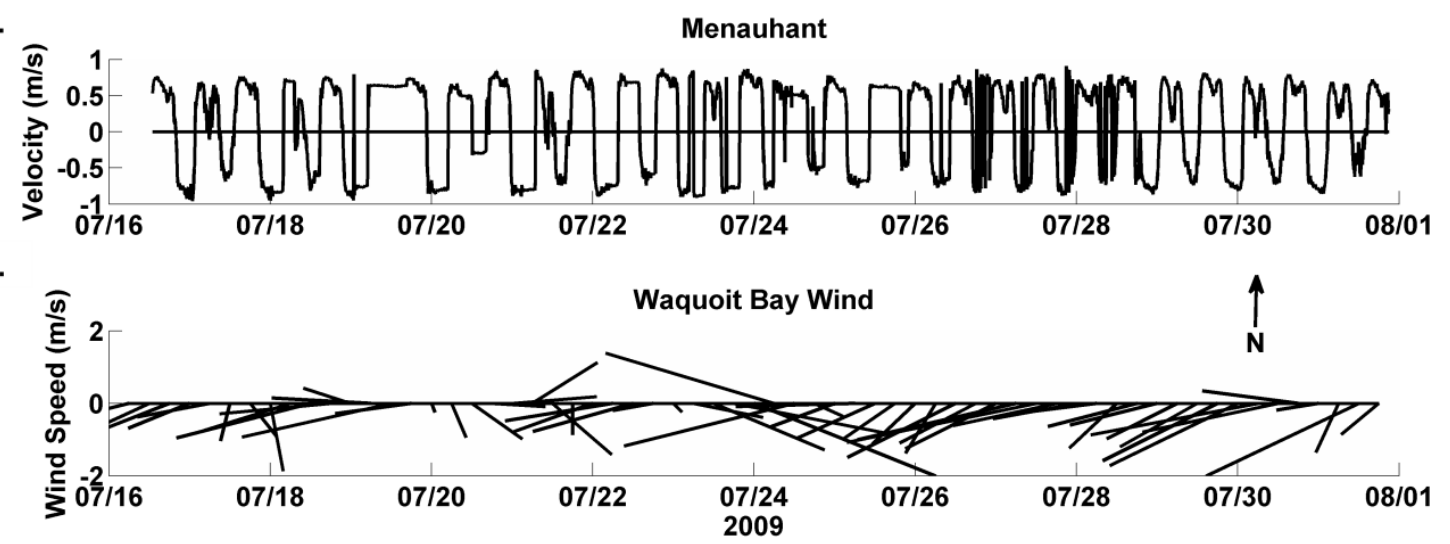

Figure 4.5 Velocity (a-b) and wind (c) for Little River and Menauhant for the two-week study period. Velocities were measured in 7.5 minute intervals with positive velocities corresponding to the incoming tide. Wind data was recorded as the maximum wind speed in 15 minute intervals from a weather station at the north point of the bay and averaged for each tidal period. 


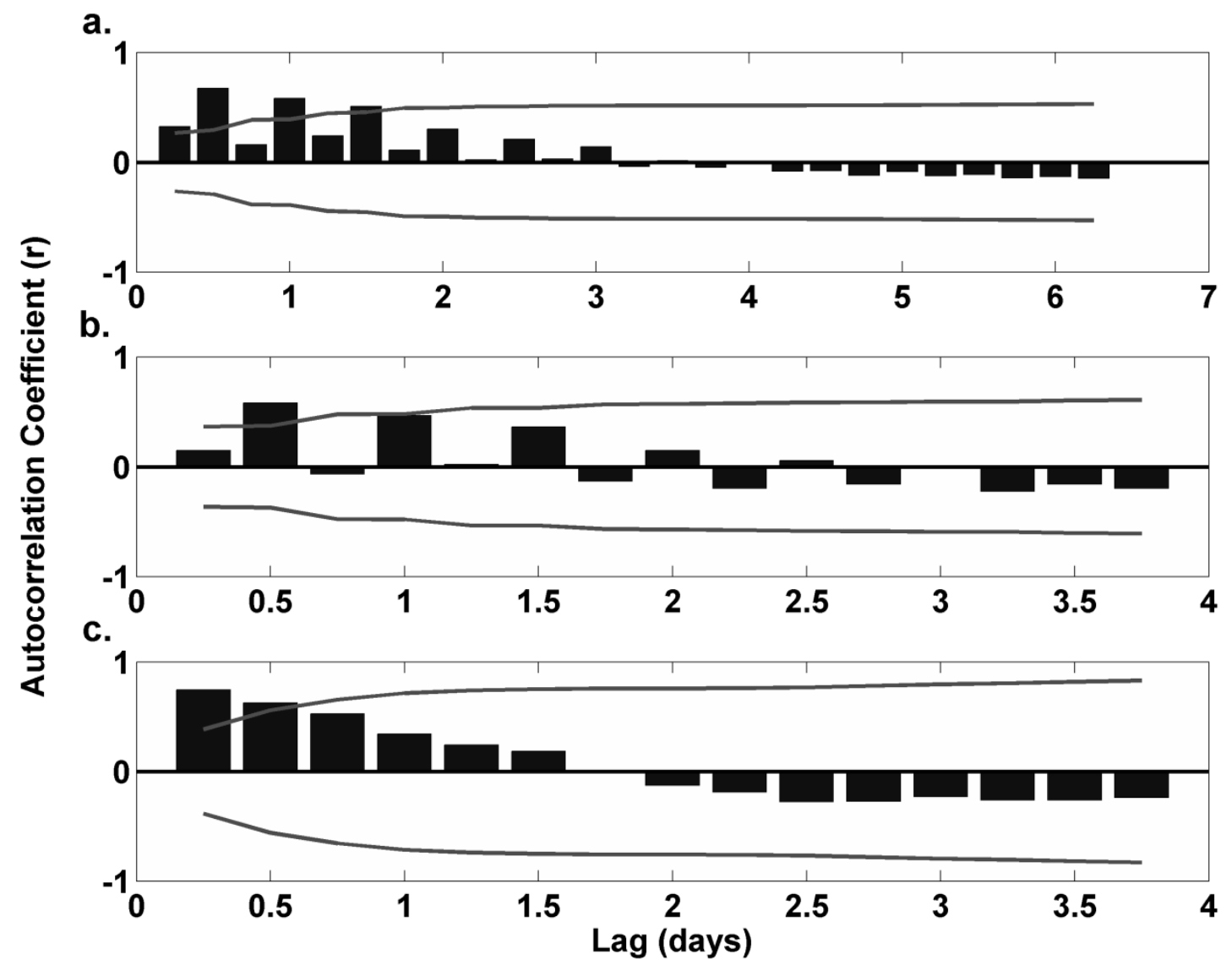

Figure 4.6 Autocorrelation functions for total bivalves at Little River. Autocorrelation shown for (a) 25 time step lags for the full larval time series, (b) 15 lags from 16-24 Jul 2009, and (c) 15 lags from 24-31 Jul 2009. The length of each bar represents the size of the correlation at each lag, equal to one tidal event (approximately 0.25 days). Red lines represent $95 \%$ confidence intervals. The decorrelation time is indicated by the time point where the function crosses the $\mathrm{x}$-axis. 

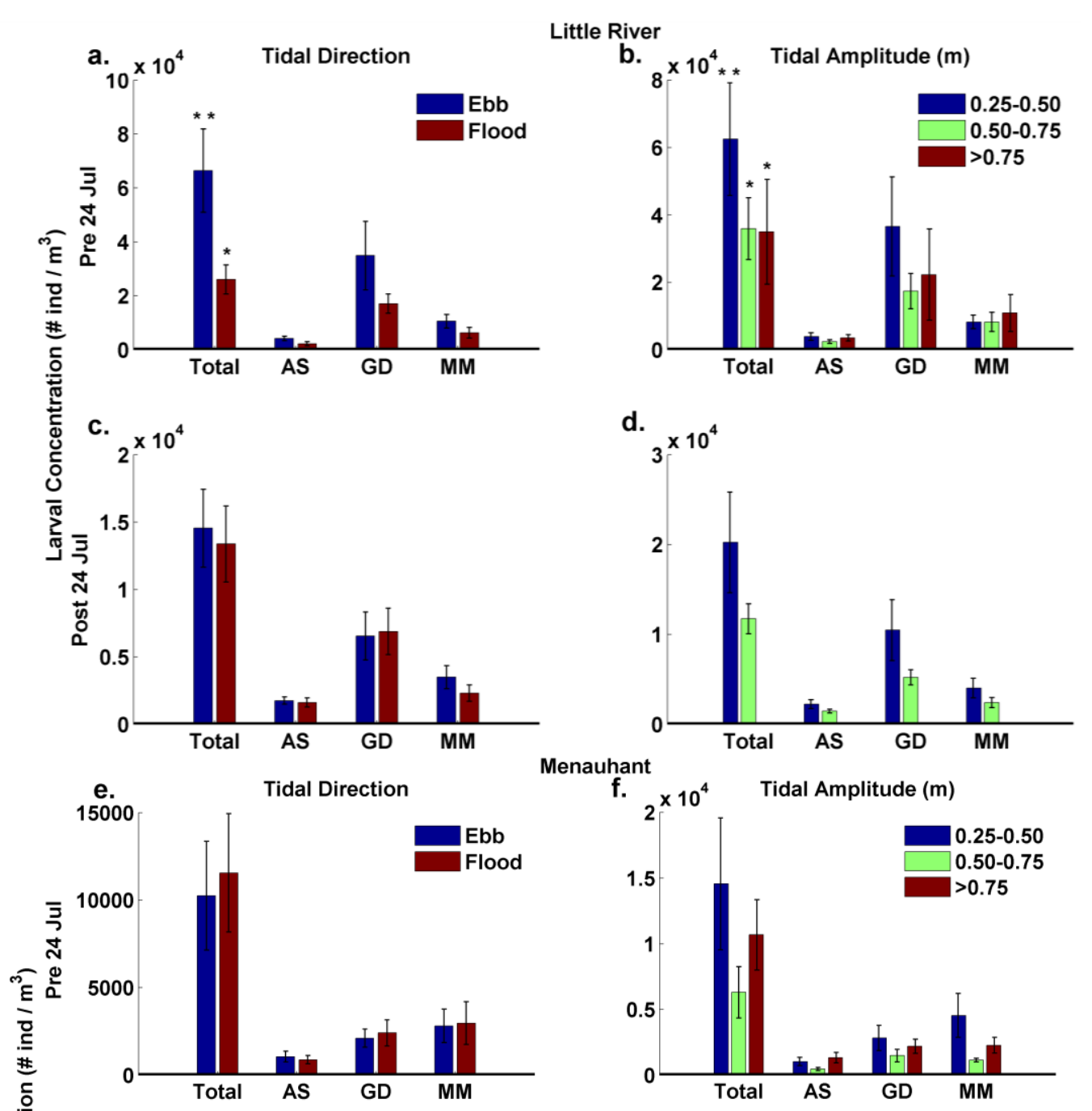

d.

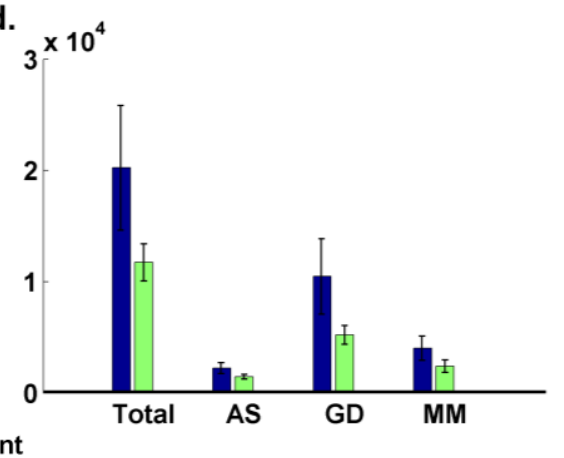

Menauhant
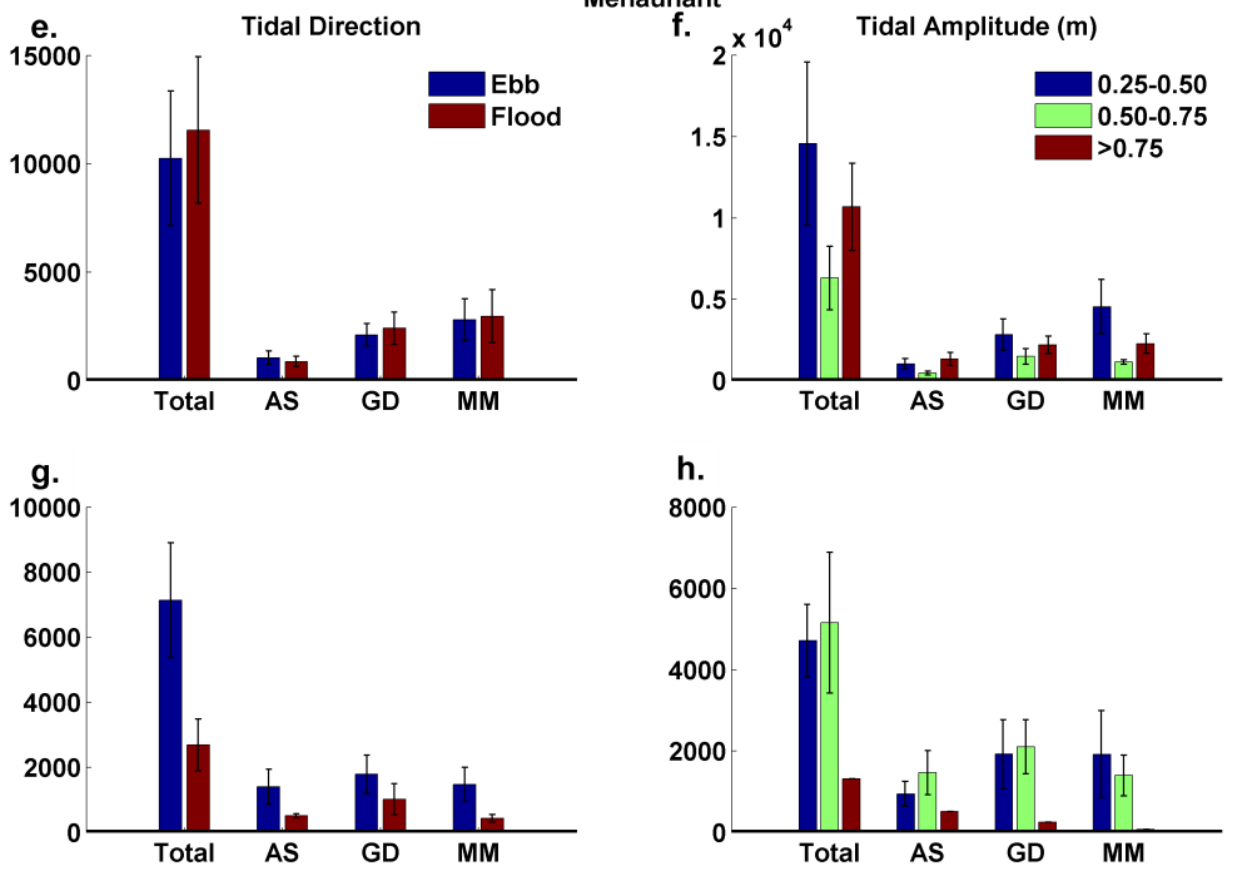

Figure 4.7 Relationships of larvae at Little River (a-d) and Menauhant (e-h) to tidal features. Mean concentration and standard error of total larvae and for all three species grouped by tidal direction (first column) and tidal amplitude (second column) are shown for both weeks of the time series. Significant groups are marked by asterisks $(*)$. Total = total bivalve larvae; $\mathrm{AS}=$ A. simplex, $\mathrm{GD}=$ G. demissa, $\mathrm{MM}=\mathrm{M}$. mercenaria . 


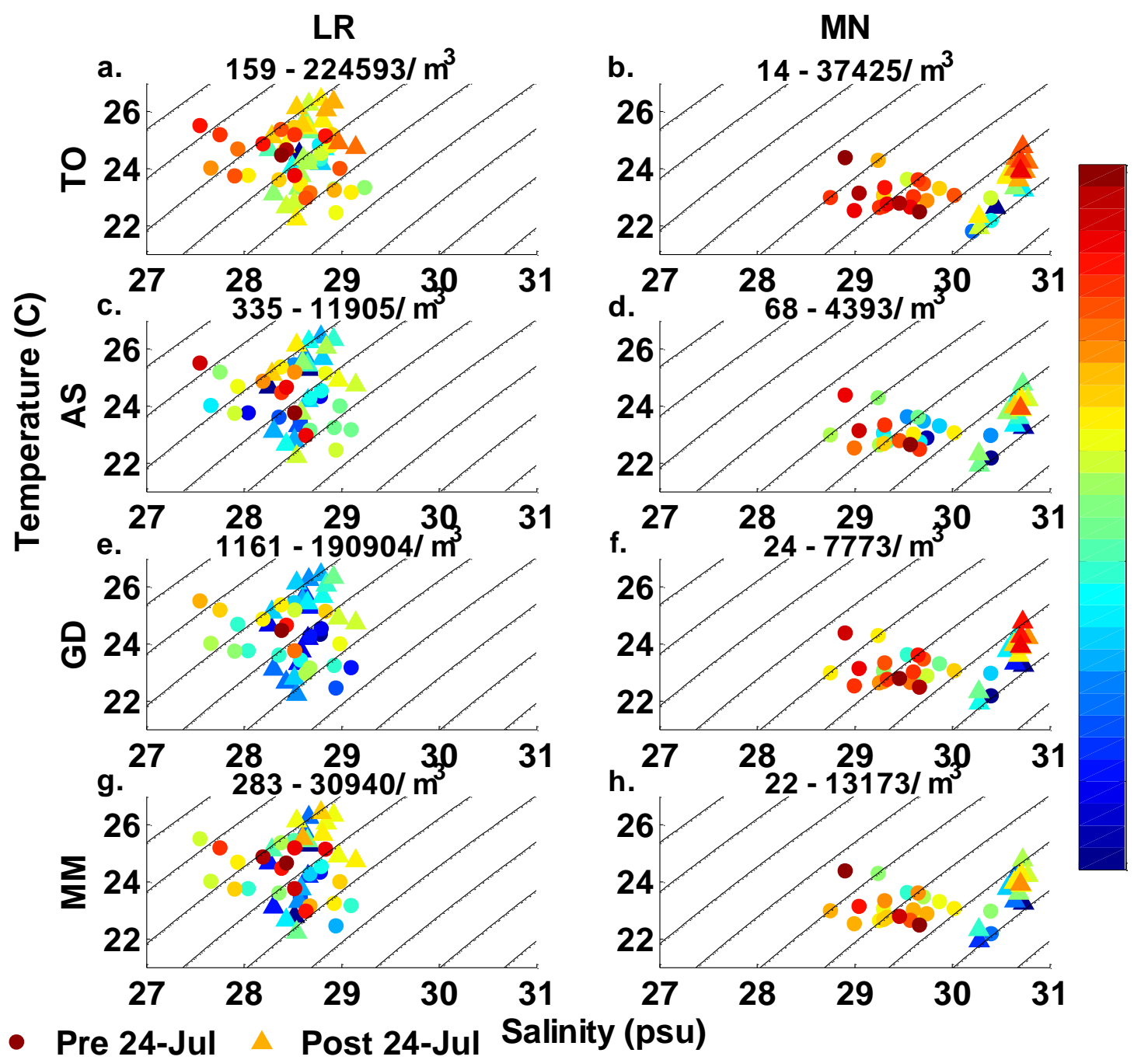

Figure 4.8 Temperature-Salinity-Plankton (TSP) plot for total bivalve larvae and larvae of three species for Little River (LR) and Menauhant (MN). Larval concentration is plotted as a function of temperature and salinity for (a,b) Total larvae (TO), (c,d) $A$. simplex (AS), (e,f) G. demissa (GD) and (h,i) M. mercenaria (MM). Circular symbols represent concentrations prior to 24 July; triangle symbols represent conditions after 24 July. Larval concentrations are scaled to the range of the data shown above each plot on a log scale, corresponding to the side color bar. Black lines represent lines of constant density at 0.5 sigma-t units. 


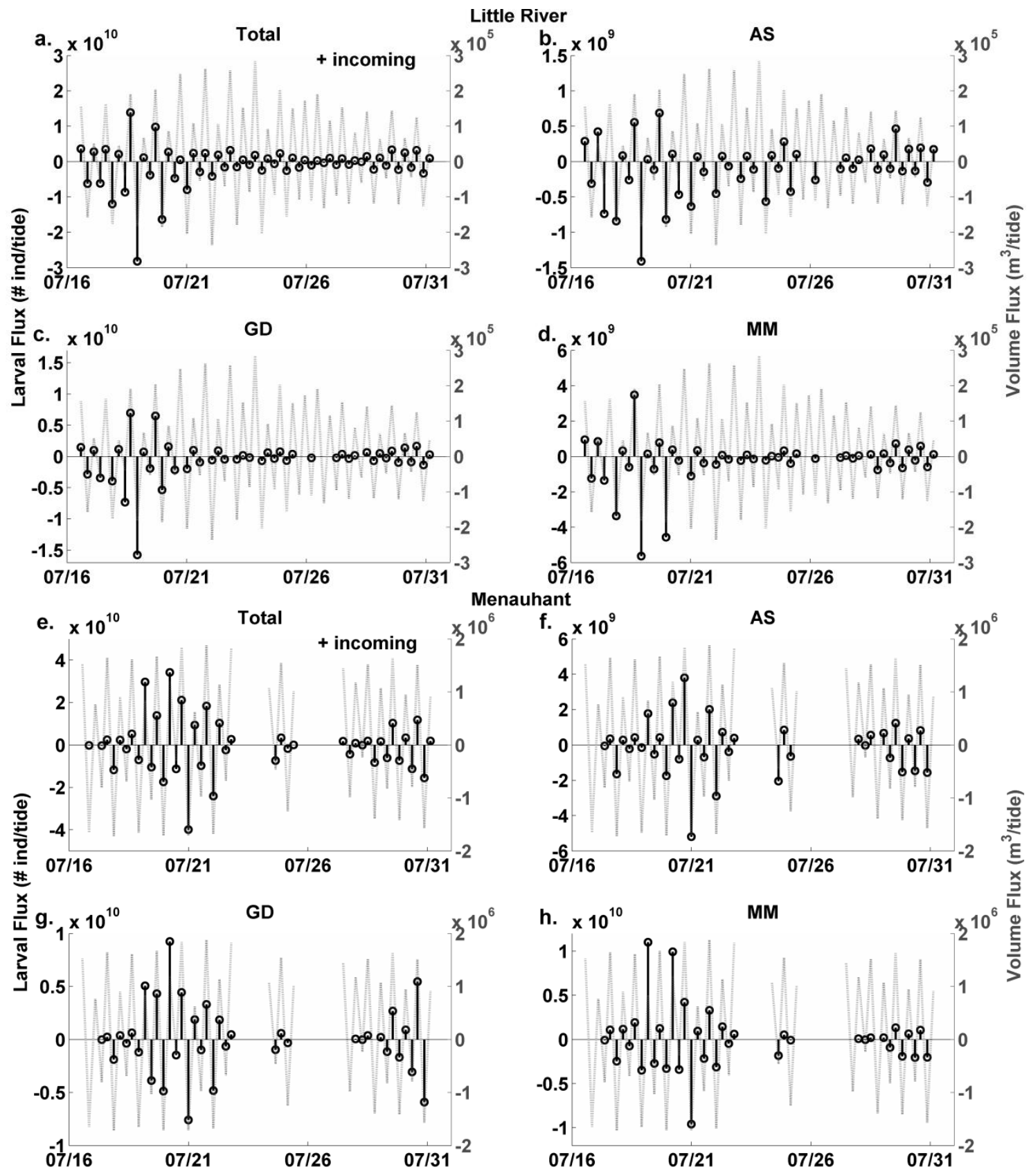

Figure 4.9 Relative flux of larvae and water volume for all species for 16-31 July 2009. Larval flux was calculated as the number of larvae transported in or out of the estuary during a tidal event for a channel cross-section of Little River (a-d) and Menauhant (e-h). Volume flux is total volume flux for each tidal sampling period. Positive fluxes indicate transport into the estuary on flood (incoming) tides. (a,e) Total = total bivalves, (b,f) AS = Anomia simplex,$(\mathrm{c}, \mathrm{g}) \mathrm{GD}=$ Geukensia demissa,$(\mathrm{d}, \mathrm{h}) \mathrm{MM}=$ Mercenaria mercenaria . 


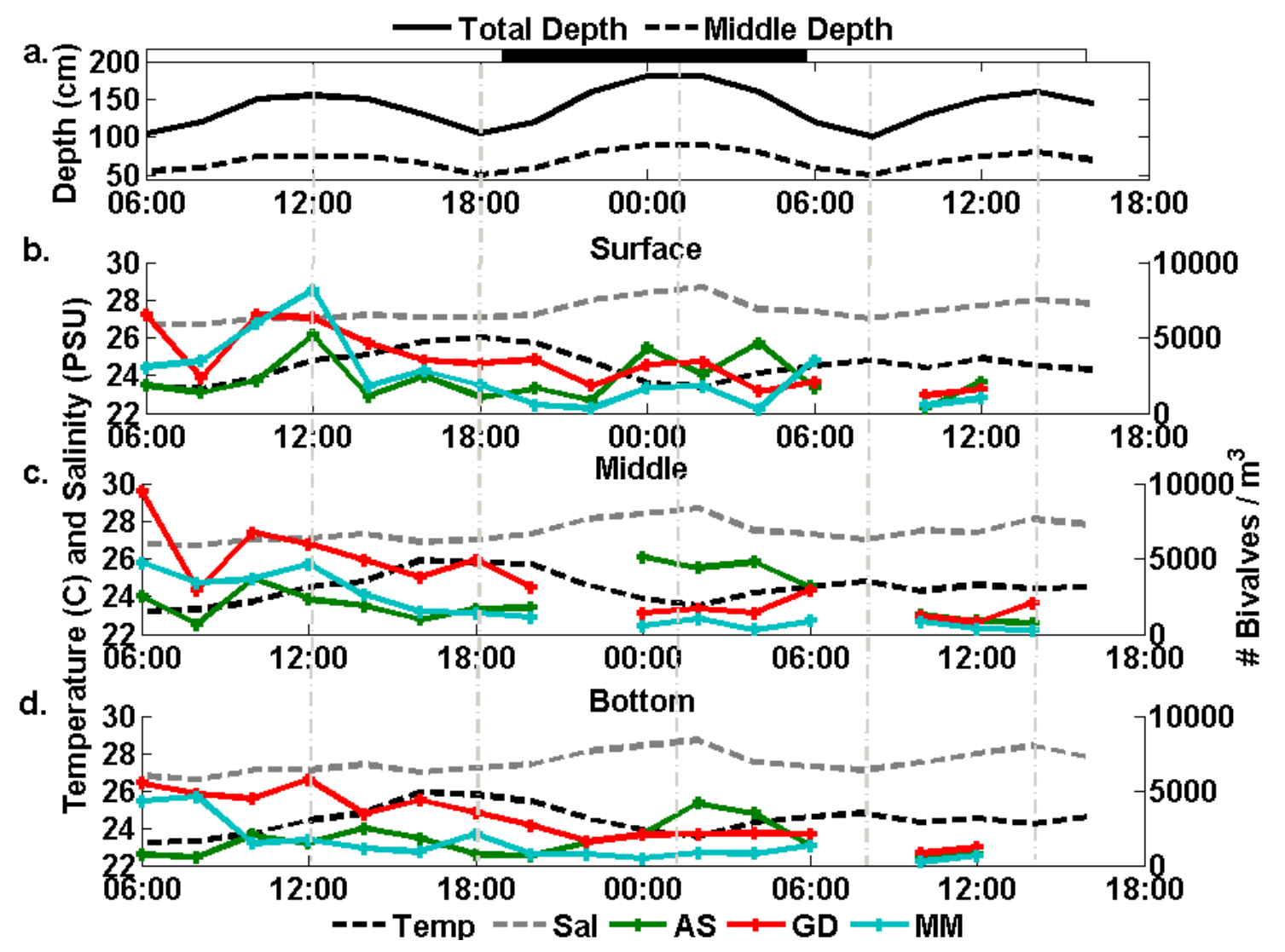

Figure 4.10 Larval concentrations with temperature, salinity, and depth for Little River spring sampling period (22-23 July 2009). (a) Total water column depth (solid line) and middle sample depth (dashed line) over the period. Photoperiod is indicated by boxes on the top axis. Surface samples were taken $25 \mathrm{~cm}$ below the surface and bottom samples were taken $20 \mathrm{~cm}$ above the bottom. (b-d) Concentration of each species for surface, middle, and bottom (right axis - solid lines) are plotted with temperature and salinity (left axes - dashed lines) for each strata. Gaps are due to missing or unimaged samples. Tidal periods are marked by vertical gray lines. Temp = temperature; $\mathrm{Sal}=$ salinity; $\mathrm{AS}=A$. simplex; $\mathrm{GD}=G$. demissa $; \mathrm{MM}=$ M. mercenaria 

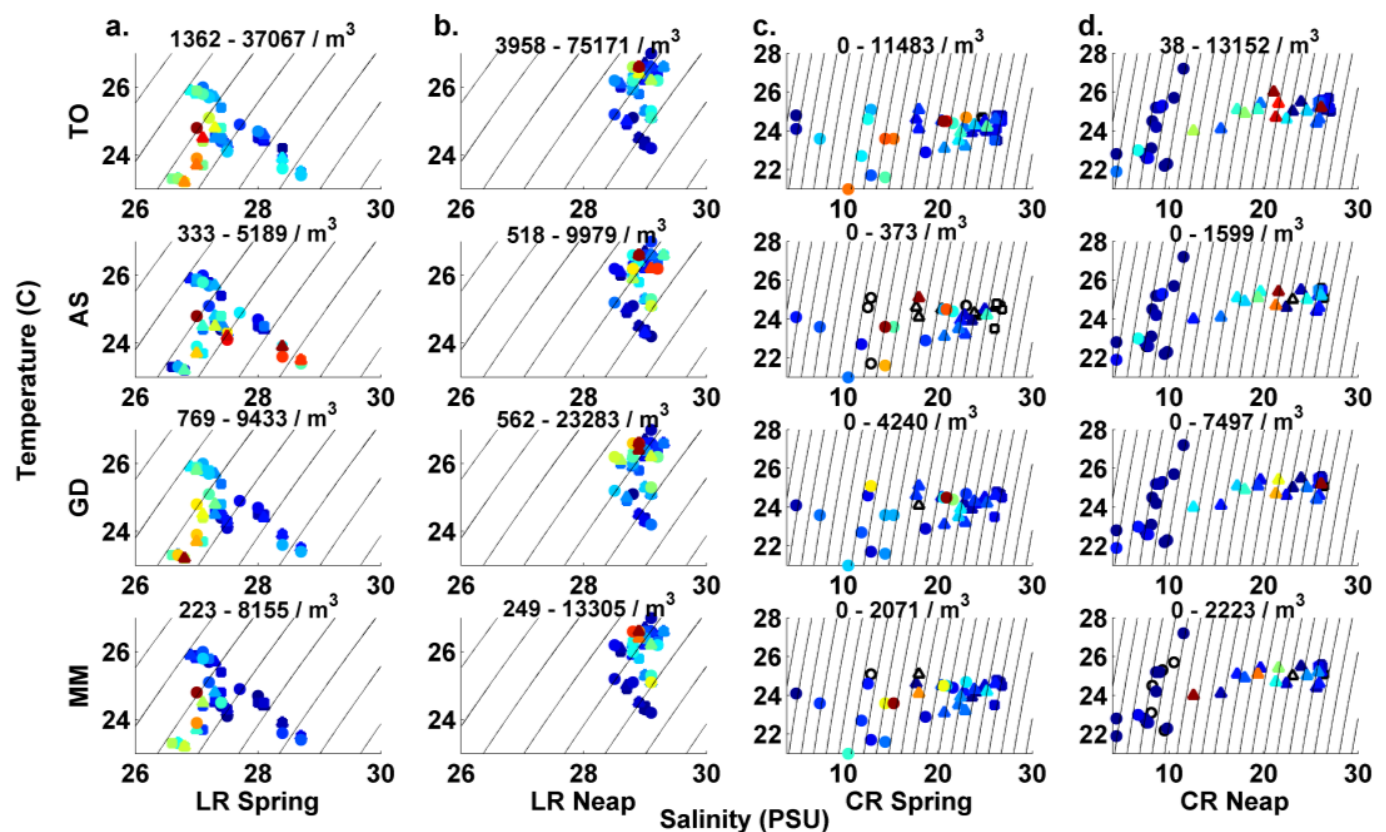

- $\mathbf{S}$

$\Delta \mathbf{M}$

- B
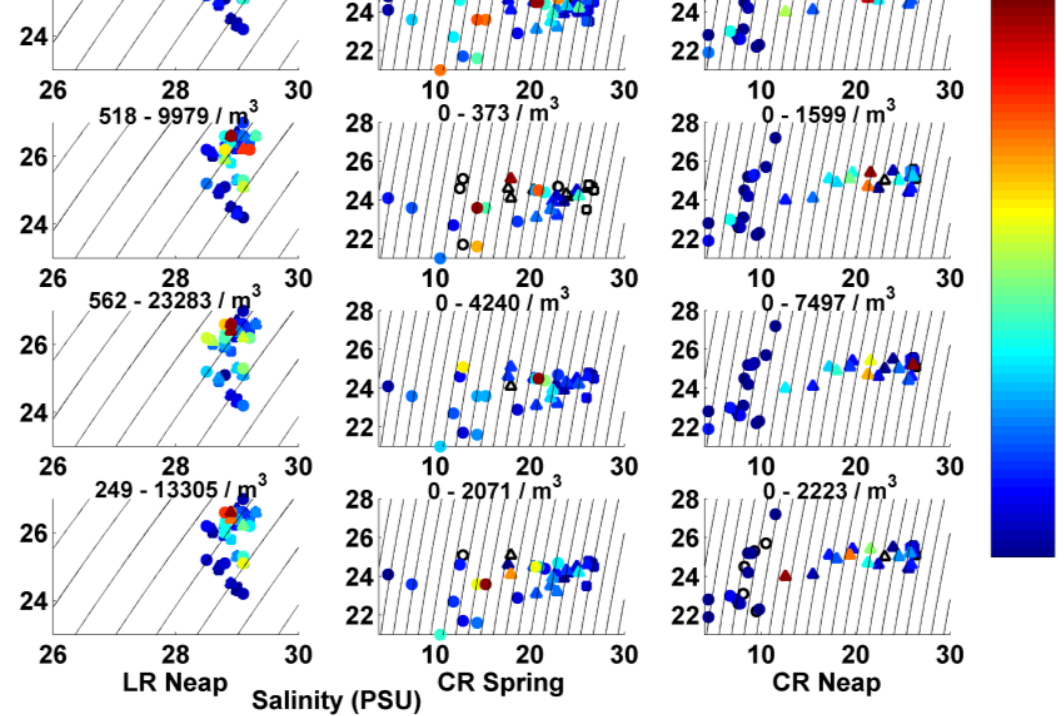

Figure 4.11 Temperature-Salinity-Plankton (TSP) plot for total bivalve larvae and larvae of three species for each vertical distribution study. Each column contains plots from a different sampling event: (a) Little River spring (22-23 Jul 2009), (b) Little River neap (28-29 Jul 2009), (c) Childs River spring (22-23 Jul 2009) and (d) Childs River neap (28$29 \mathrm{Jul}$ 2009). Larval concentration is plotted as a function of temperature and salinity for Total larvae (TO - first row), A. simplex (AS - second row), G. demissa (GD - third row) and M. mercenaria (MM - fourth row). Each symbol corresponds to the surface (circle), middle (triangle) or bottom (square) depths. Empty symbols represent zero larvae for that sample. Relative larval concentrations are scaled to the range of the data shown above each plot and correspond to the side color bar. Black lines represent lines of constant density at 0.5 sigma-t units for Little River and 1 sigma-t unit for Childs River. LR = Little River; $\mathrm{CR}=$ Childs River. 


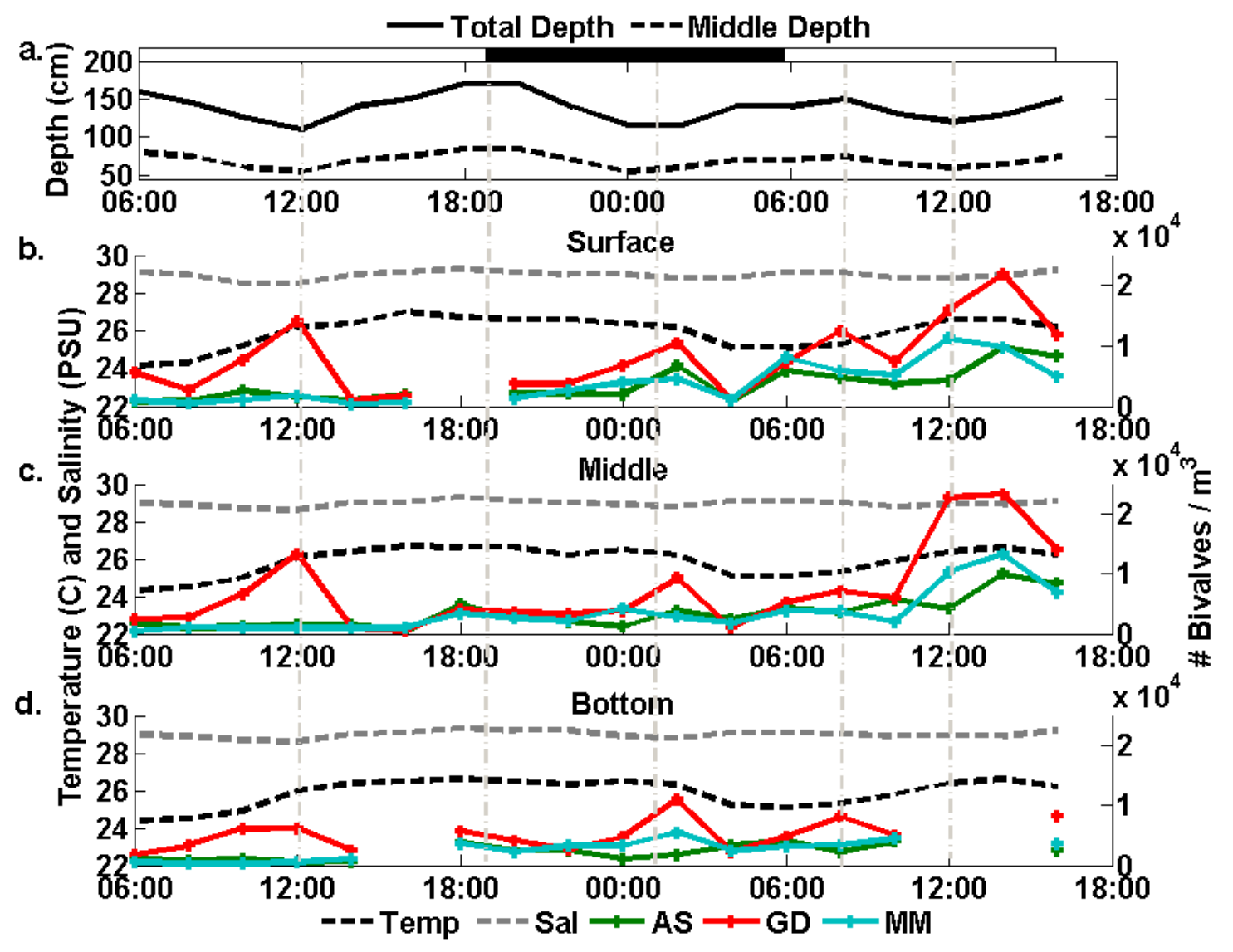

Figure 4.12 Larval concentrations with temperature, salinity, and depth for Little River neap sampling period (28-29 July 2009). (a) Total water column depth (solid line) and middle sample depth (dashed line) over the period. (b-c) Concentration of each species for surface, middle, and bottom (right axis - solid lines) are plotted with temperature and salinity (left axes - dashed lines) for each strata. See Fig. 4.10 legend for further figure explanation. $\mathrm{Temp}=$ temperature $; \mathrm{Sal}=$ salinity $; \mathrm{TO}=$ total bivalves; $\mathrm{AS}=$ A. simplex; $\mathrm{GD}=G$. demiss $; \mathrm{MM}=$ M. mercenaria 


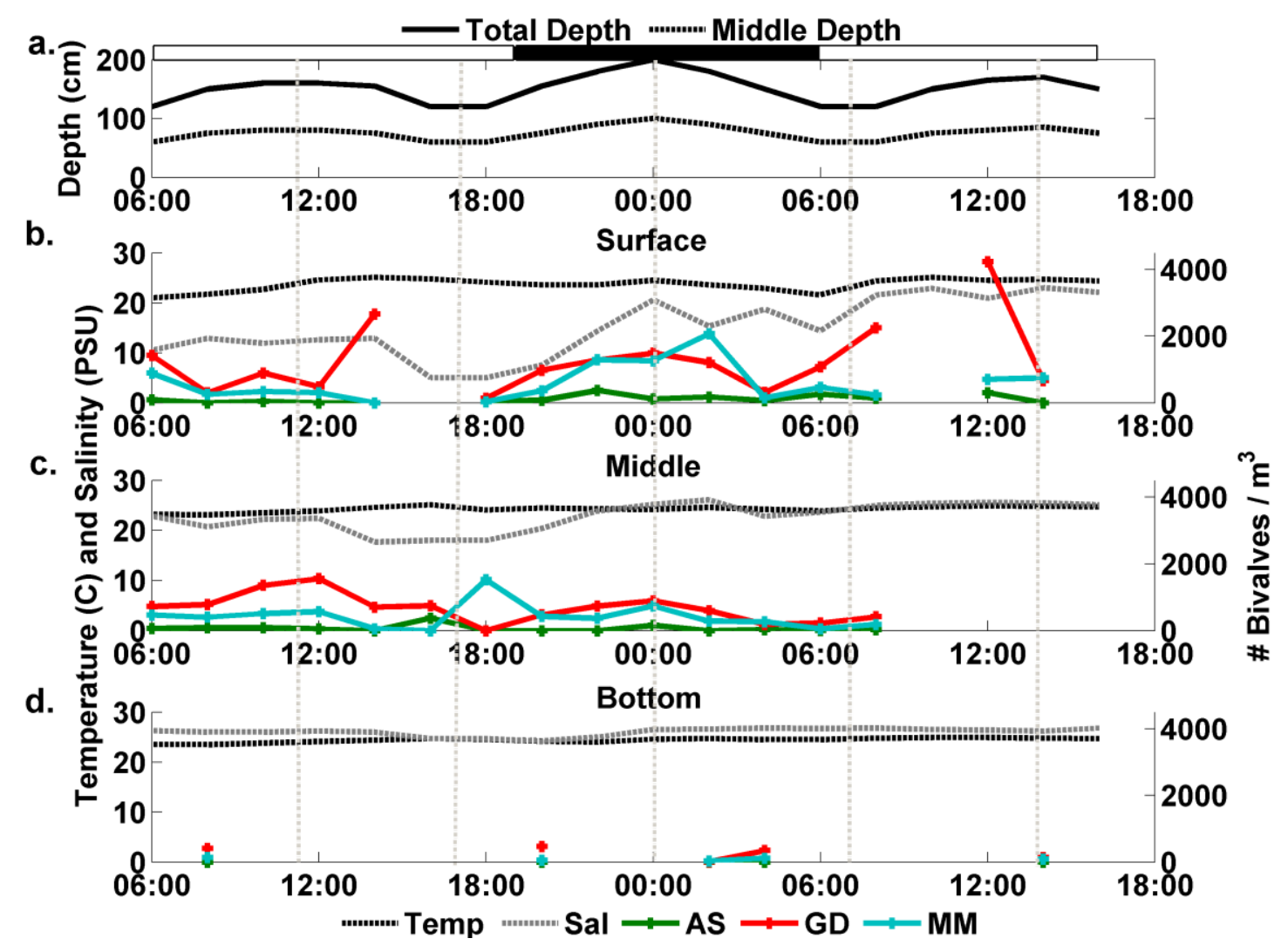

Figure 4.13 Larval concentrations with temperature, salinity, and depth for Childs River spring sampling period (22-23 July 2009). (a) Total water column depth (solid line) and middle sample depth (dashed line) over the period. (b-c) Concentration of each species for surface, middle, and bottom (right axis - solid lines) are plotted with temperature and salinity (left axes - dashed lines) for each strata. See Fig. 4.10 legend for further figure explanation. Temp = temperature; Sal = salinity; $\mathrm{AS}=\mathrm{A}$. simplex; GD = G. demissa; $\mathrm{MM}=\mathrm{M}$. mercenaria 


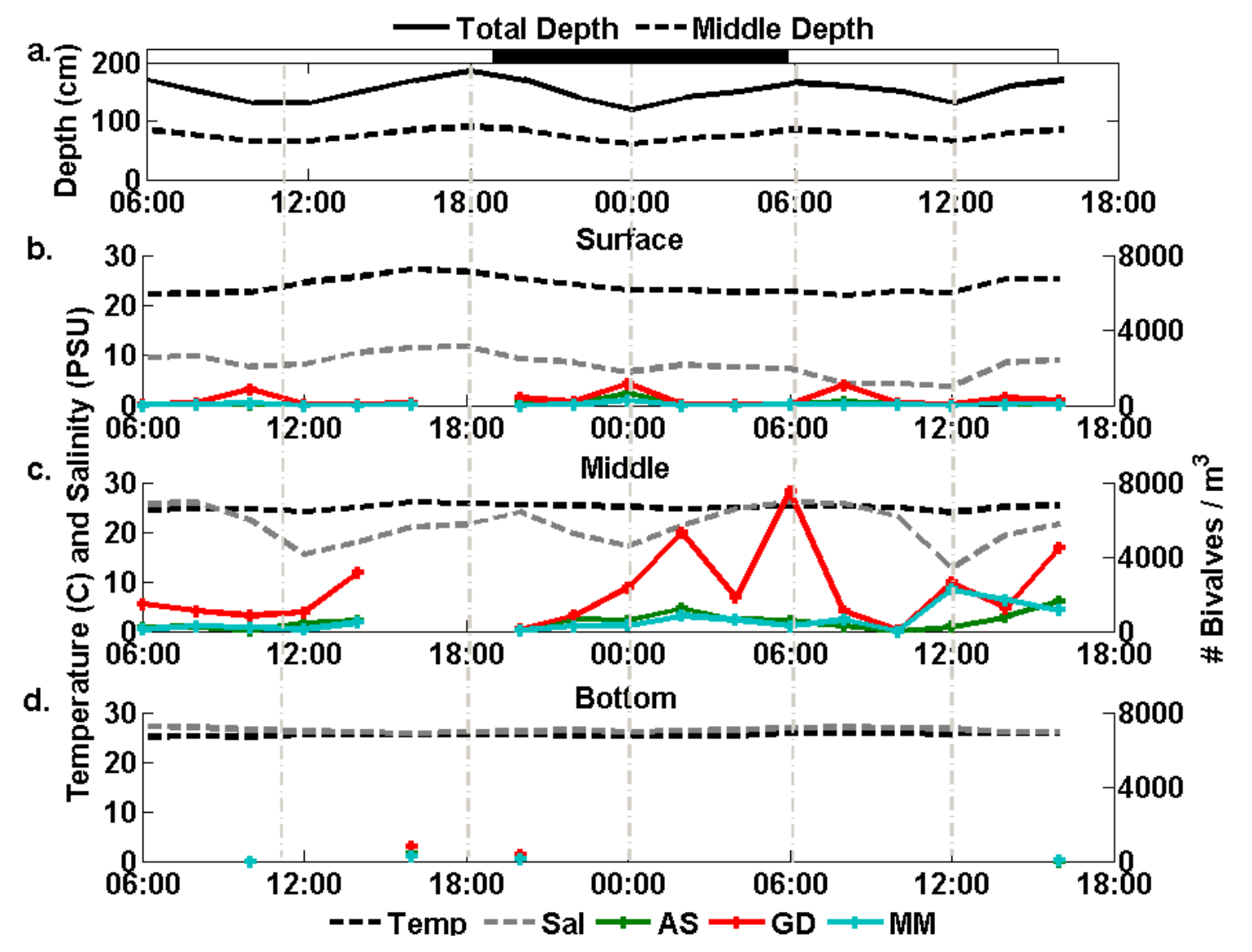

Figure 4.14 Larval concentrations with temperature, salinity, and depth for Childs River neap sampling period (28-29 July 2009). (a) Total water column depth (solid line) and middle sample depth (dashed line) over the period. Surface samples were at $25 \mathrm{~cm}$ and bottom samples were taken $20 \mathrm{~cm}$ above the bottom. (b-c) Concentration of each species for surface, middle, and bottom (right axis - solid lines) are plotted with temperature and salinity (left axes - dashed lines) for each strata. See Fig. 4.10 legend for further figure explanation. Temp = temperature; $\mathrm{Sal}=$ salinity; $\mathrm{AS}=\mathrm{A}$. simplex; $\mathrm{GD}=\mathrm{G}$. demissa; $\mathrm{MM}=\mathrm{M}$. mercenaria 


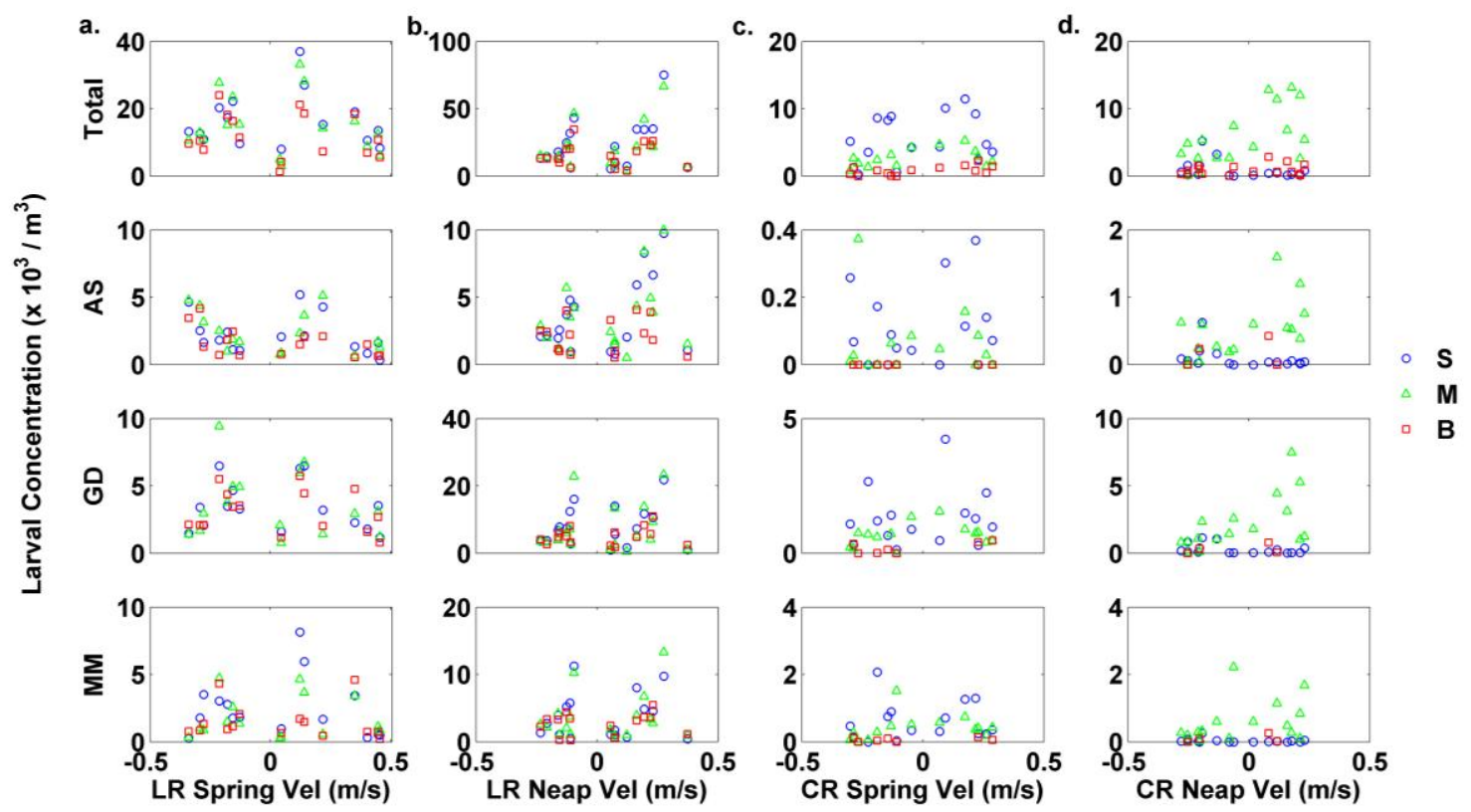

4.15 Larval concentration in relation to average tidal velocity for all four sampling periods. Larval concentration for total larvae and for each species is plotted against hourly averaged velocity for each hour the sample was taken. Positive velocities represent flood periods. Symbols correspond to surface $(\mathrm{S}=$ circle $)$, middle $(\mathrm{M}=$ triangle) or bottom ( $\mathrm{B}=$ square) samples. Columns contain plots for each species for each sampling period: (a) Little River (LR) spring period (22-23 Jul 2009); (b) Little River neap period (28-29 Jul 2009); (c) Childs River (CR) spring period (28-29 Jul 2009); (d) Childs River neap period (28-29 Jul 2009). Total = total bivalves; AS = A. simplex; GD $=$ G. demiss $;$, MM = M. mercenaria. 


\section{CHAPTER 5}

A Summary of Bivalve Larval Transport Patterns in Waquoit Bay 
This dissertation research brings forth and challenges important concepts related to larval transport and retention in estuarine systems. In this chapter, the processes that influenced spatial and temporal trends in larval abundance are discussed, and mechanisms of transport for each species are described. In light of the results from this research, I discuss the importance of species-specific studies in larval transport, the role of active and passive transport, and the usability of the birefringence classification method. Finally, I speculate on the importance of this research for the field of larval ecology and suggest future studies that can incorporate results from this research or the method for larval identification.

\subsection{SPATIAL AND TEMPORAL VARIABILITY IN BIVALVE LARVAE}

By sampling for larvae on weekly, tidal, and hourly scales we were able to isolate the processes that are most influential to larval abundance and distribution on each scale. We sampled weekly for six months during two years and found that overall bivalve larval concentrations were highest during periods of high temperatures. With many species having a threshold temperature of $15-20^{\circ} \mathrm{C}$ to initiate spawning, abundance of larvae is highly dependent on bay warming during these months. When comparing abundances between 2007 and 2009, higher concentrations in 2009 were likely due to increased food availability for both adults and larvae and stronger winds leading to increased mixing throughout the time period. Results also showed that larvae are not uniformly distributed throughout the bay. The highest concentrations of larvae were observed at the sites in the middle of the bay, and the lowest concentrations were observed in the most upstream site with the lowest salinities. These distributions are likely a function of proximity to source 
populations within the bay and loss of larvae during upstream transport. Not all species followed the same distribution patterns, suggesting that vertical behavior or salinity tolerances might influence dispersal.

By sampling on a tidal scale over fourteen days, we investigated if tidal amplitude had an effect on larval concentration and flux. Although the highest fluxes of larvae were observed on the largest tides, this was not always synchronous with periods of high larval abundance, which likely reflected spawning. Instead, larval concentrations seemed to track with water mass characteristics which changed halfway through the sampling period following a storm. During the first week, larval concentrations at a subinlet had a strong semidiurnal signal associated with ebb tides. However, during the second week most of the estuarine water had been flushed by a storm, resulting in higher salinities, a decreased tidal signal with water masses, and lower concentrations of larvae that remained coherent for one or two days. An external larval pool may be intermittently important in subsidizing larval supply in the bay, but no consistent patterns between higher fluxes on flood or ebb tides were apparent at the inlet.

Finally, the vertical distribution sampling on an hourly scale illustrated that larval concentrations with depth are sensitive to local velocity and salinity conditions. Markedly different distributions with depth between the two sampling sites indicated that transport patterns were not uniform throughout the bay, and this may explain some of the observed site-specific differences from Chapter 3. There were no significant behaviors with tidal phase observed, but larval concentrations varied tenfold both temporally and vertically. Whether concentrations peaked on ebb or flood tides were likely due to sources within 
water masses. Each of the three species studied showed slightly different responses to local conditions. These results and the implications for species-specific transport are summarized in the following section.

\subsection{SPECIES-SPECIFIC TRANSPORT MECHANISMS}

5.2.1 Anomia simplex (Jingle Clam). Anomia simplex showed the most

variability in its distribution between years and among sites. Our weekly data showed that A. simplex can spawn when temperatures reach $15^{\circ} \mathrm{C}$, but it most abundant in temperatures over $20^{\circ} \mathrm{C}$ and prefers salinities greater than 25 PSU. In 2009, A. simplex was more abundant than in 2007, with concentrations and growth slightly higher and appearing earlier at the eastern sites. This observation was consistent with the flux study at Little River and Menauhant. A. simplex was often associated with ebbing tides at both Little River and Menauhant indicating sources in estuarine waters within the bay. The high abundance of docks and rocky outcrops along the channels in the bay as well as localized areas of eelgrass may provide more habitat for $A$. simplex compared to the coastline outside the bay.

A. simplex was mostly exported during the flux study, with some periods of net import. The cohort analysis showed that A. simplex was capable of reaching settling size in Waquoit Bay in 2009, particularly at the eastern sites. The vertical distribution study indicated that $A$. simplex is capable of behaviors that could enhance retention. There was a positive relationship between $A$. simplex concentrations and salinity at the bottom. As salinity increases at the end of a flood tide, sinking $A$. simplex larvae would avoid being transported out of the channel. Concentrations of $A$. simplex were well-mixed on ebb 
tides, and highest in the surface and middle on flood tides, increasing their transport ability and chances for upstream retention. Despite large fluxes on ebb tides, if sufficient numbers remain on the bottom the larvae would be transported less and possibly retained. The supply of larger larvae during the flux study was sporadic. The largest sizes of $A$. simplex in our weekly study were observed in August after the flux and vertical distribution studies were performed. The few A. simplex pedi-veligers present during this period explain the observed low fluxes. During periods when larvae are more abundant, by sinking on ebb tides and swimming up on flood tides they would likely be retained.

5.2.1 Guekensia desmissa (Ribbed Mussel). Geukensia demissa was widely distributed in Waquoit Bay and had the most coherent larval population and size structure of the three species. It had the widest salinity tolerances, being continually abundant in Childs River, but abundances were mostly restricted to temperatures above $20^{\circ} \mathrm{C}$. However, despite its abundance and wide distribution, cohort growth remained low. Only three cohorts were observed in 2009, with only the last cohort achieving a growth rate on par with laboratory estimates. With the other species readily reaching settlement size in the day, it was hypothesized that G. demissa larvae were not retained in Waquoit Bay.

The flux study addressed this problem of retention. On the second day of the study there was a spawning event on an outgoing tide in Little River marked by high concentrations of straight-hinged G. demissa. The timing of this event with a lowamplitude ebb tide reduced the potential for export. G. demissa concentrations oscillated for about two days before the patch dissipated. Large exports of G. demissa were also observed at Menauhant during this period, but they followed similar trends for other 
species indicating mixing of the spawn with other species. This event alone suggests that larvae spawned within the bay oscillate with the tides and are exported over a few days, which is less than the development time. The greatest flux of large larvae that might have originated from this spawn occurred three days later. A few isolated import events may supplement some of this loss, and these results suggest that larvae may grow faster than could be observed from weekly samples, although larval duration has not been adequately studied (see Ch. 1). After this mass spawning, flux of G. demissa was more uniform between the tides perhaps allowing for more retention to occur.

G. demissa demonstrated behaviors in the vertical distribution study that could lead to retention. G. demissa larvae showed significant surface-seeking behaviors during slack periods at Little River. During the spring tide period this behavior occurred at the end of flood tides when salinity was highest, and larval concentrations at the middle and bottom were significantly lower. During the neap period, this surface-seeking behavior occurred after both flood and ebb. If $G$. demissa larvae respond to high salinity by increasing upward swimming, salinity was higher and did not vary enough during the neap periods to provide a tidal cue. There could be a combination of both salinity and velocity necessary to trigger upward swimming, or simply that lower velocities are required to enable larvae to overcome turbulent mixing to reach the surface. At Childs River, $G$. demissa were readily found in the surface on both flood and ebb spring tides and presence at the surface seemed to be associated with higher velocities. During the neap period, salinities were much lower in the surface and G. demissa concentrations were associated with high-velocity incoming tides. These results suggest that $G$. demissa 
larvae may constantly swim to the surface, which would be most easily performed during slack periods. Tidal signals with salinity may enable this behavior to enhance retention, but these signals may not always be different enough to elicit a response, and in the case of Childs River, may transport them to an unsuitable habitat. In general, surface swimming on slack tides would decrease net import or export given that surface flows are lowest during these periods.

In conclusion, G. demissa could show retention behavior if surface swimming was timed to incoming tides, although this was not always observed. Retention was observed based on tidal flux during the distribution study at Little River. If the only source for large G. demissa is through local retention of bay populations, as suggested by the low import of G. demissa pedi-veligers observed at the inlet, then it may be difficult to maintain the local population. Despite high concentrations and possible retention of younger larvae, growth and settlement of $G$. demissa either occurs quickly making pediveligers are hard to sample, or pressures such as starvation or predation contributed to the lower abundance of larger larvae.

\subsubsection{Mercenaria mercenaria (Quahog). Mercenaria mercenaria was found} throughout the sampling season suggesting that early and late spawning of this species can occur. Concentrations were correlated between all sites except Childs River. The greatest concentrations were found in July and August where temperatures were highest. In 2009, growth of M. mercenaria was marked by high concentrations of larger larvae appearing every two weeks and successful cohort survival in July and August. The 
weekly data suggest that $M$. mercenaria are abundant in the bay, grow rapidly, and most likely are retained to settle.

Results from the flux and vertical distribution study, however, did not support this result. Although concentrations were associated with ebb tide and had bay water origins, this species had the highest overall export. M. mercenaria had the highest concentrations of large larvae, but they were also mostly exported. M. mercenaria did not show clear retention behavior in the vertical distribution study. Like G. demissa, peaks of $M$. mercenaria occurred in the surface around slack tide periods. Still, there was no evidence of a tidal periodicity to this response, although slightly more larvae were sometimes observed on flood tides. However, this conflicts with the net outgoing flux observed for M. mercenaria this period that differed from the flux direction of the other two species. Concentrations of $M$. mercenaria were not as high in the surface as $G$. demissa, and net export observed may result in reduced flood tide transport and reduced transport during slack periods. Since we did observe some import for M. mercenaria, it cannot be assumed that all M. mercenaria are exported. Furthermore, larvae exported from Little River would be transported to the main bay, an ideal sandy bottom substrate with large densities of quahogs, and possibly retained there.

\subsection{GENERAL CONCLUSIONS}

5.3.1 Total Bivalves vs. Species-Specific Trends. This thesis is a pioneer study investigating larval supply to an embayment on three temporal scales for multiple species. Total larvae were included in many of the analyses in order to compare patterns which were generally observed for all larvae to those that were species-specific. In some 
cases, relationships were only significant for total bivalves. This was mostly for purely physical processes, such as the significant relationship between larval concentrations and tidal direction and amplitude for the first part of the flux study at Little River. When looking at individual species, significant relationships were found with water mass properties and tidal velocities, particularly at higher frequencies.

Each species behaved differently with respect to salinity and flow. This enabled speculations related to individual species' transport and retention, which was expected to differ based on observed distributions and growth rates. Isolating periods of spawning and following cohorts was only possible with a species-specific analysis. Although all three species showed the most growth in late July and August, the timing of spawning events was different for each species, and overall distribution depended on source locations and tolerances of individual species.

5.3.2 Passive vs. Active Transport. Although some field studies of bivalve larvae have discounted behavior and argued for passive dispersal, the results from this thesis suggest that larvae are not always passive. The comparison between Little River and Childs River supports this conclusion. The shell makes a larva negatively buoyant, so any presence in the surface or middle is either a result of mixing or swimming. In an area of low mixing like Childs River, passive larvae would accumulate below the picnocline at Childs River. However, larvae were most abundant at the surface and the middle in Childs River and rarely found at the bottom. Therefore, if given the ability to maintain an upward swimming velocity, larvae will congregate at the surface (such as during slack periods at Little River). The ability for a larva to maintain this behavior, or respond to 
cues that might initiate this behavior on a tidal frequency, depends on local salinities and velocities. However, the high velocities observed through most of the channels in Waquoit Bay frequently prevent this from occurring, and the majority of larval transport was based on water mass flux. If a vertical distribution study were performed in a tidally influenced area away from high channel flows, such as the middle of the bay, one might observe more significant behavioral responses.

\subsubsection{Larval Supply to Waquoit Bay. Larval supply to Waquoit Bay is} sensitive to timing. On a yearly scale, the timing of temperature increases leading to spawning, the availability of food during the season, and the effects of wind mixing enhancing transport can affect larval supply. Slower increases in temperature in 2009 led to mass spawning in July, rapid growth due to available food, and stronger winds creating mixing. On a weekly scale, transport processes were reflected in water mass properties as a whole. Storms can cause mixing, reduce transport, and decrease stratification. After a storm, the tidal signal in temperature and salinity decreased, leading to more even flux. With patterns of transport varying from week to week, it is possible that the patterns of decreased retention of $M$. mercenaria could change as water column properties regained a tidal signal.

5.3.4 Image Processing as a Tool for Identification. Using shell birefringence patterns to identify species presents a promising solution to the problem of bivalve larval identification. This work had to overcome a few obstacles before it could be applied, so it is our hope that these solutions can be transferred to future studies. For instance, we were unable to investigate all species of interest. Less abundant species, such as the bay 
scallop, Argopecten irradians, resulted in many false-positive misclassifications when used in a training set. Furthermore, our hatchery set did not adequately represent the composition of species in our field samples, and it resulted in many false classifications when used as a training set. I adapted the study by focusing on species that were abundant during the study period to solve this problem. It remains to be tested whether a known hatchery training set can accurately identify larvae from field samples if microscope settings are kept constant. This would be the ultimate test for accuracy and usability of this method.

5.3.5 Cumulative Error. It should be recognized that there are many sources of error inherent in these data sets that propagated from sample collection through to data analysis. In the course of this study, care was taken to avoid as much error as possible, yet some sources of error cannot be avoided. Cumulative error can be difficult to measure given its many sources, but here I speculate on the sources of error in this work, and how it may affect the results and conclusions.

Each plankton sample was expected to represent the concentration of larvae at a given place and time. There is error that exists from variability in sampling conditions, accuracy of sample collection methods, and consistency in methods. Ritual calibration methods were employed to reduce or control for some of these errors, however unplanned and sometimes unknown changes can occur. One way of addressing field sampling error is to take replicate samples in order to calculate a standard error for each sample. However, this method can double or triple the number or samples taken each period and ultimately may limit the length of sampling possible. For this study, I decided that 
temporal replication was suitable for analysis, although it does not take into account standard error for a given sample. On one occasion two samples were taken consecutively, and the percent difference in the counts was less than $10 \%$.

Similarly, error exists in sample processing, where one must assume that the counts accurately reflect the number in the sample (Kuthuhn 1958). For this study, one person performed the initial bivalve counts which limited the variability between persons. If a sample had to be split to facilitate counting, care was taken to ensure an appropriate number of larvae and subsamples were counted. The rate-limiting step for sample processing was imaging individual larvae. For each sample over 100 larvae, 100 larvae were imaged. In the samples with highest concentration, the subsample represented as little as $0.5 \%$ of the entire sample. This could lead to underestimates of abundant species as well as overestimates of rarer species contained in the subsample. However, in these cases the subsamples were often dominated by a few abundant species. By focusing on these species for our analysis, I avoided the issues associated with rare species that may be absent from a subsample but present in the full sample.

Finally, there is error in our image processing method. This was discussed extensively in Chapter 2, but in Chapters 3 and 4 care was taken to ensure the least amount of error propagated through the analyses. In Chapter 3, images were manually identified and thus only human error was present. In Chapter 4, human error in training set formation as well as computer software error was present. Figure 4.2 shows the agreements between manual and automatically classified larvae. The largest error was a disagreement of 50 larvae. However, these numbers summed from a total of 1000 larvae, 
or 10 samples, corresponding to a per sample difference of approximately five larvae per sample, or $5 \%$ of the subsample. Figure 5.1 shows the total error that could result from different levels of disagreements between manual and computer identifications. This potential error is lowest in cases of low disagreement or high species abundance. Thus, it is important to focus on species with high proportions in the samples in order to minimize cumulative error. For this study, focus species had at least $10 \%$ abundance in the manually sorted samples. At a 5\% error rate, this would result in a 50\% error as a highend estimate for a given sample. Such sporadic errors could explain the difficulties in interpreting data from species like $M$. mercenaria with low agreements. Employing the manual correction technique could solve some of these problems.

Although it may be unrealistic to put a number on sampling error, the tests with the image processing method helped estimate the error associated with the identification methods. There is still work to be done to minimize this error, and automation of this process could reduce or enable some estimation of the counting error as well. For many of the studies in this thesis, a $30 \%$ error would not drastically change the overall conclusions. From an ecological standpoint, presence and absence of species, patchiness, and patterns reflected in order of magnitude differences between samples would not be greatly affected by these errors. Comparative plots showed similar trends with time (Fig. 2.6) despite disagreements. In this study we also had to make many assumptions in our analyses, such as uniform flow across a channel that could have resulted in significant deviations from reality. Perhaps there would have been more significant statistical relationships or clear patterns with tide, depth and flow if some of these errors were 
minimized. But given that this work is a first step in providing a high-resolution study at the species level, many of these conclusions are important even if the size of the error bars is unknown. This thesis was intended to provide a series of snapshots of larval distributions on various spatial and temporal scale, and these results are not absolute. Future applications will hopefully improve this method to get closer to the best methods for field studies of bivalve larvae.

\subsection{FUTURE DIRECTIONS}

Although this study addressed many questions specific to transport of bivalves in Waquoit Bay, it still left aspects of dispersal unanswered. Modeling growth and resulting transport of individual species in Waquoit Bay and between Nantucket Sound could explain if some of the transport processes hypothesized for larvae in this study result in observed trends with retention abilities, coherence with water masses, and transport into upper regions of Waquoit Bay. A model for Waquoit Bay would require a vertical grid separation of at least half a meter, preferably $25 \mathrm{~cm}$. This would be necessary as larvae can exhibit orders of magnitude differences in vertical distribution at this scale.

The relationship of larval supply to settlement was also left unexplored. Fisheries data from 2010 showed increased abundance of first-year quahogs compared with previous years, which could have been a result of the 2009 observations in this study (R. York, Town of Mashpee Shellfish Constable, pers. comm.). This relationship is significant for fisheries because it relates larval supply to recruitment. However, the influence of post-settlement processes should not be discounted, as there could be other factors such as benthic predation and competition that may affect recruitment. 
This study suggests that Waquoit Bay is a source of larvae of these three species. However, to explain the proliferation of $M$. mercenaria despite overwhelming evidence for export, it may be necessary to assume inputs from other sources. By identifying species from larval samples, it could be possible to look at genetic signatures that could link to source populations. Until now, the only usable method for larval origins has been through trace-element fingerprinting of juveniles (DiBacco and Levin 2000, Becker et al. 2005) that has led to debatable results (Strasser et al. 2007). Microsatellites are emerging as one method of tracing larval origins (Helberg et al. 2002) that could be promising when combined with a method for larval identification, although there are still issues with molecular methods as seen in Chapter 2.

This thesis illustrates the potential to include bivalve larvae in studies of larval transport, dispersal, and settlement. Bivalves are important components of marine ecosystems and more importantly provide fisheries revenue to many regions. Many of these natural fisheries are troubled for a variety of reasons discussed previously, and an ability to follow larvae after enhancement or restoration efforts would greatly aid these efforts. The ability to determine the success rate of spawner transplants, pilot studies to investigate the best times and locations for spat collection, or flux calculations of larvae in areas of eelgrass decline are some of the many applications of this research to shellfish ecology and management. For Waquoit Bay, this thesis addresses some of the most important aspects of larval transport that could be used to explain settlement patterns, choose locations for seeding, and determine future studies. 


\subsection{LITERATURE CITED}

Becker, B.J., F.J. Fodrie, P.A. McMillan and L.A. Levin. 2005. Spatial and temporal variation in trace elemental fingerprints of mytilid mussel shells: a precursor to invertebrate larval tracking. Limnol. Oceanogr. 50(1): 48-61.

DiBacco, C. and L.A. Levin. 2000. Development and application of elemental fingerprinting to track the dispersal of marine invertebrate larvae. Limnol. Oceanogr. 45(4): 871-880.

Helberg, M.E., R.S. Burton, J.E. Neigel, and S.R. Palumbi. 2002. Genetic assessment of connectivity among marine populations. Bull. Mar. Sci. 70(1): 273-290.

Kuthuhn, J.H. 1958. Notes on the precision of numerical and volumetric plankton estimates from small-sample concentrates. Limnol. Oceanogr. 3(1): 69-83.

Strasser, C.A., S.R. Thorrold, V.R. Starczak, and L.S. Mullineaux. 2007. Laser ablation ICP-MS analysis of larval shell in softshell clams (Mya arenaria) poses challenges for natural tag studies. Limnol. Oceanogr. Methods 5: 241-249. 


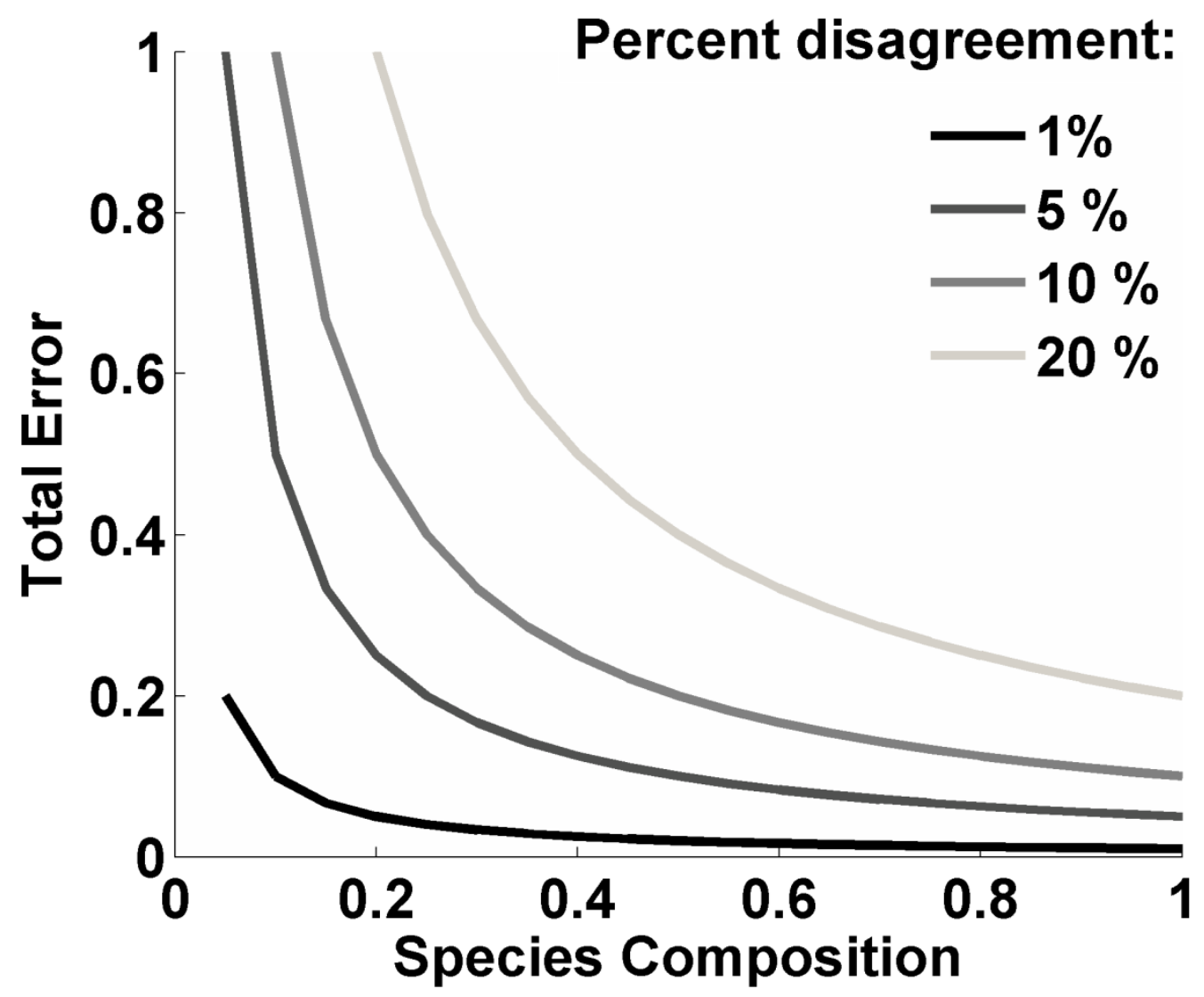

Figure 5.1 Sample estimation error as a function of species composition. The relationship between total estimation error (y-axis) and percentage species composition (x-axis) is shown for four levels of disagreement between manual and computer counts. The relationship is a negative exponential that can be expressed as $\mathrm{E}=\mathrm{D} / \mathrm{C}$ where $\mathrm{E}$ is total error, $\mathrm{D}$ is the disagreement, and $\mathrm{C}$ is proportion species composition in the sample. 


\section{APPENDIX A: Supplemental Environmental Data}

a.

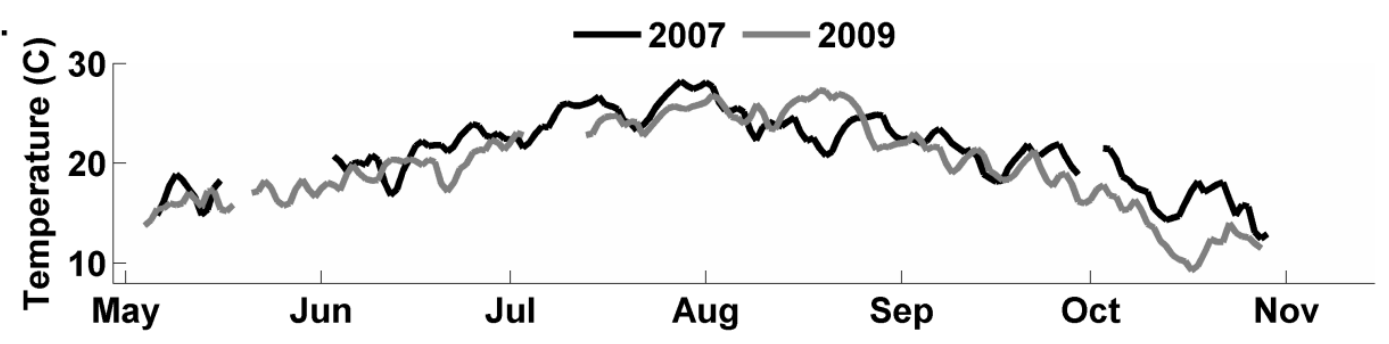

b.

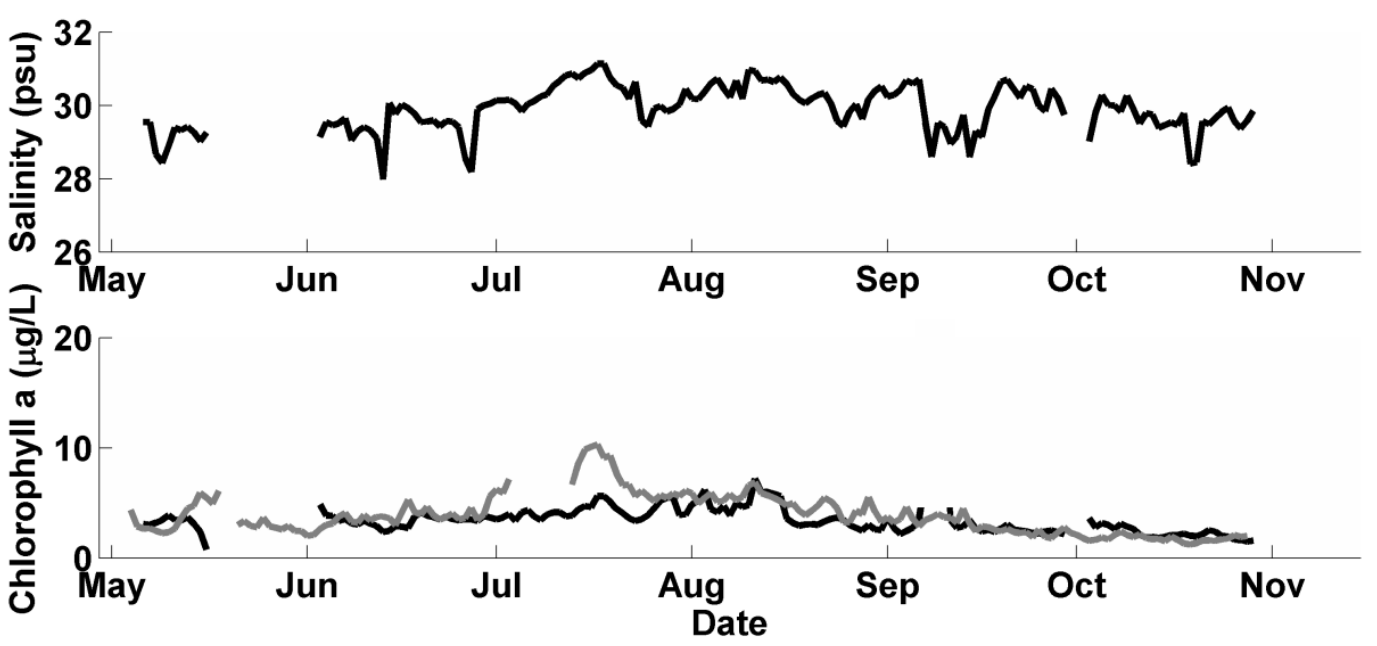

Figure A.1 Daily averaged (a) temperature, (b) salinity and (c) chlorophyll a for Little River. Water temperature and cholorphyll a readings were averaged daily from moored loggers for the sampling periods of May through November in 2007 and 2009. A salinity probe failure in 2009 prevented the use of these data for comparison purposes. 


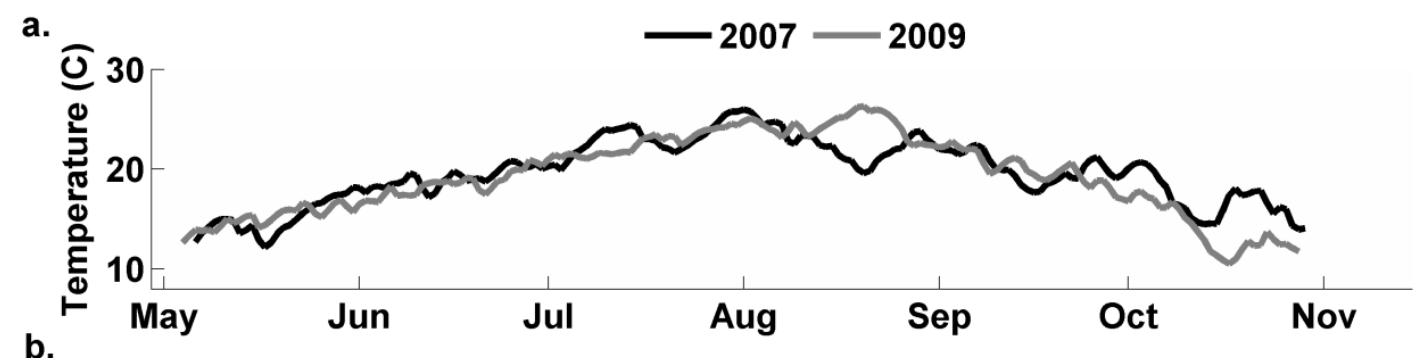

b.

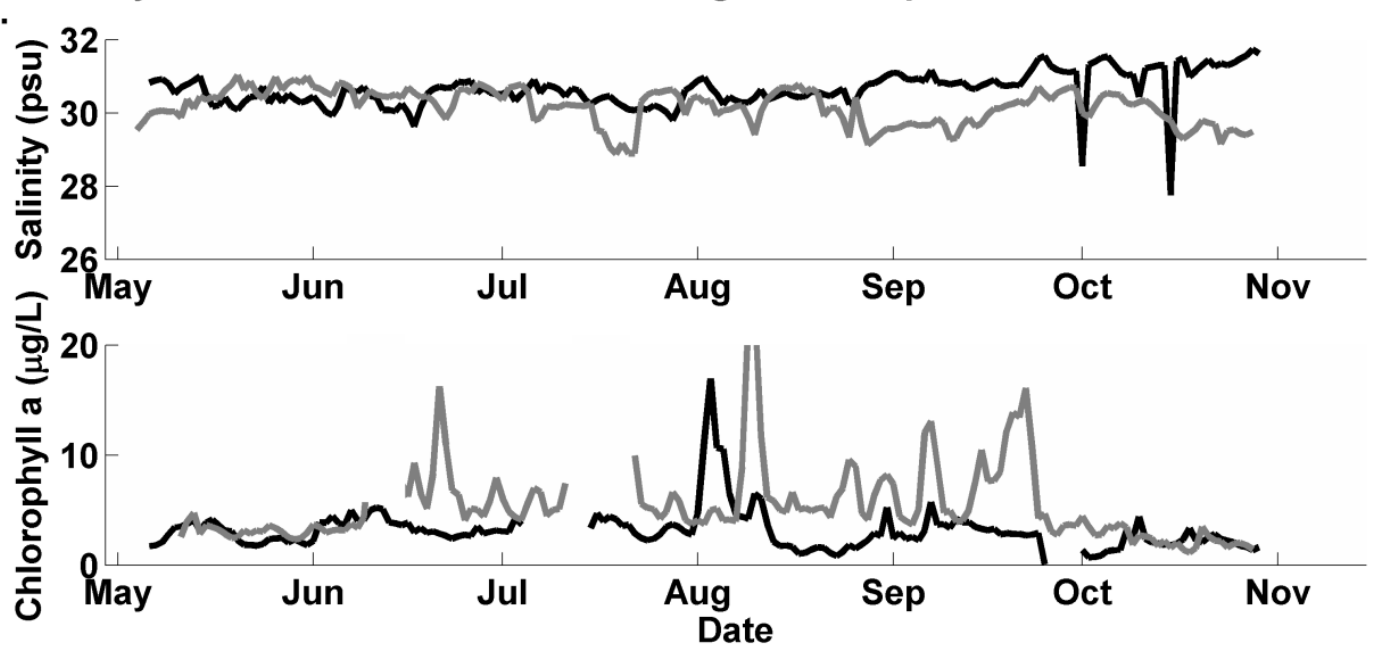

Figure A.2 Daily averaged (a) temperature, (b) salinity and (c) chlorophyll a for Menauhant. Water temperature and cholorphyll a readings were averaged daily from moored loggers for the sampling periods of May through November in 2007 and 2009. 


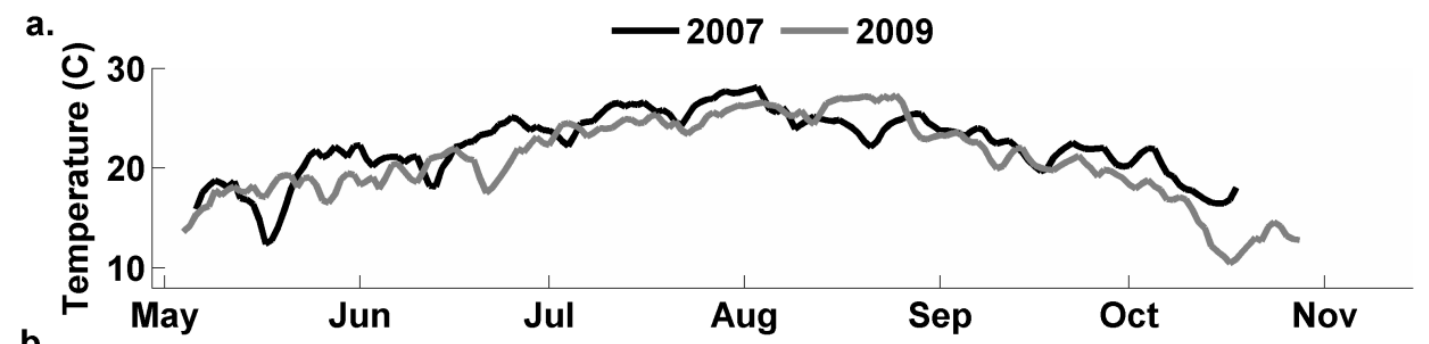

b.

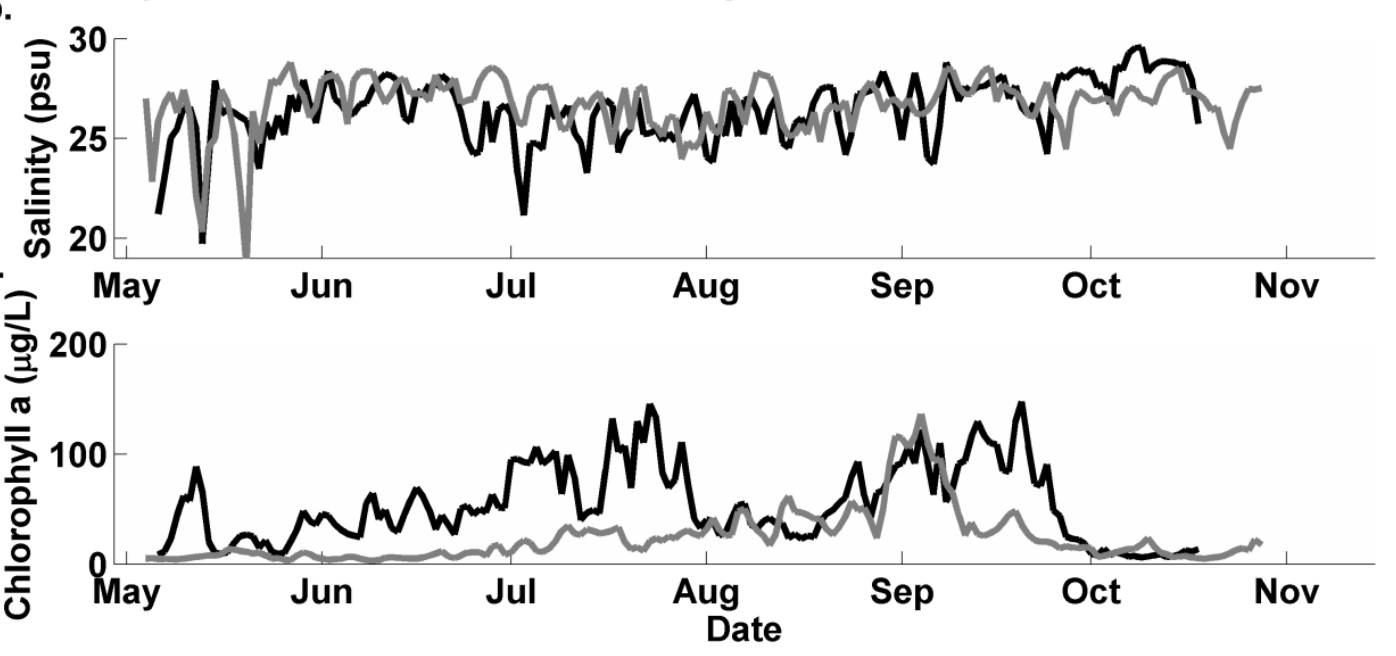

Figure A.3 Daily averaged (a) temperature, (b) salinity and (c) chlorophyll a for Childs River. Water temperature and cholorphyll a readings were averaged daily from moored loggers for the sampling periods of May through November in 2007 and 2009. 


\section{APPENDIX B: Gaussian Separation Method Example}

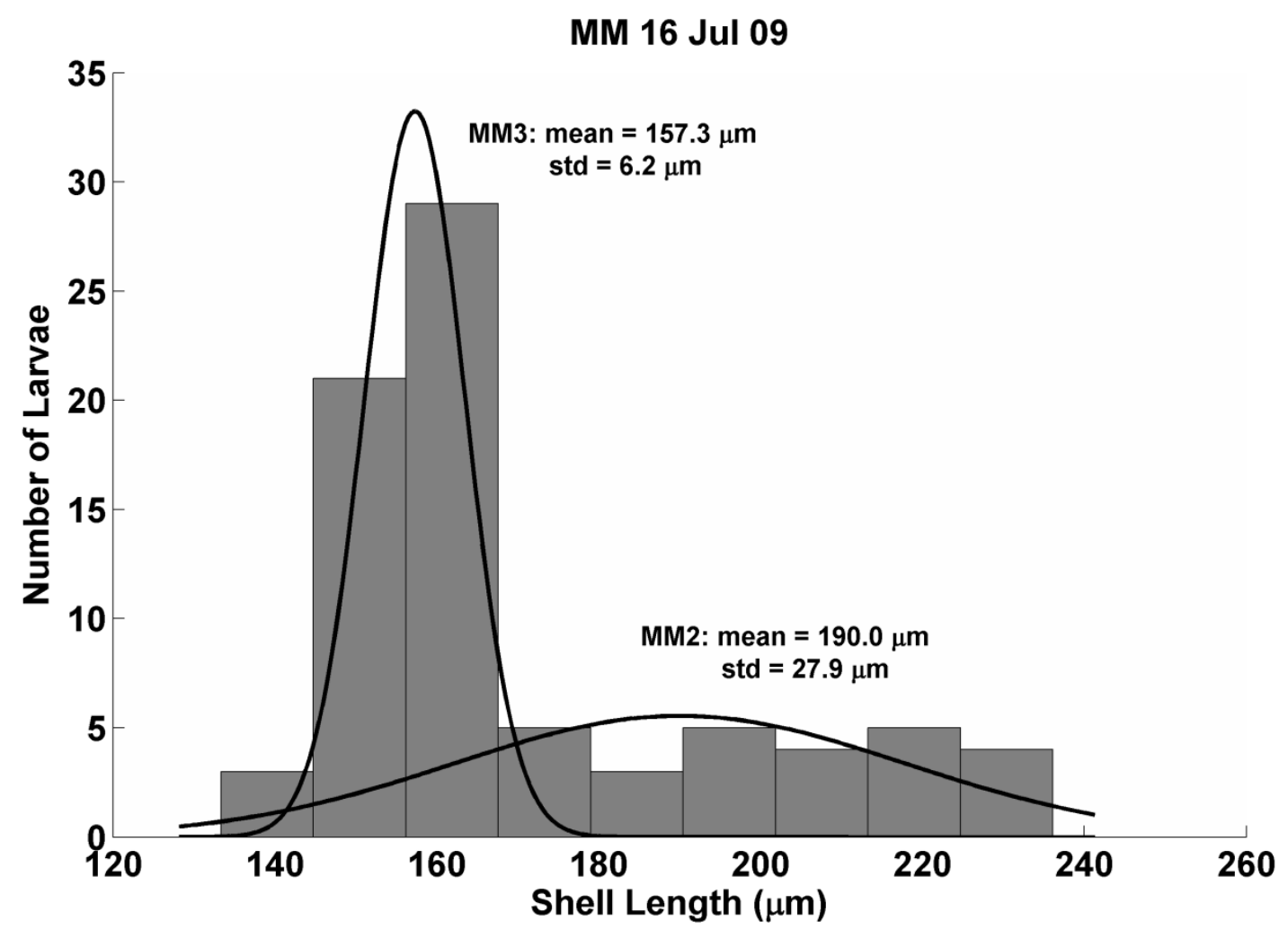

Figure B.1 Example of Gaussian-separation method for determining larval cohorts. A histogram of larval sizes is shown for Mercenaria mercenaria larvae from all samples on 16 July 2009. It was determined a priori from the histogram that this sample contained two normally distribution populations. The two Gaussian curves represent the maximumlikelihood results from the estimation-maximization function for two Gaussian curves. The mean and standard deviation are printed for each resulting cohort. $\mathrm{MM}=M$. mercenaria 


\section{APPENDIX C: Testing Assumption of Homogeneity Between Sites}

\section{C.1 INTRODUCTION AND METHODS}

When performing the cohort analysis for Chapter 3, it was necessary to pool data from all four sites to maximize the number of larvae used to make the Gaussian separation. By doing this, we assumed that abundance and size distributions are homogenous between sites. However, results from Chapter 3 (Tables 3.1 and 3.2) suggest that this may not be the case. This can be particularly problematic if larvae at different sites experience different growth rates and may bias the overall cohort size distributions. We investigated the relationships between the sites in forming cohort distributions for Anomia simplex and Mercenaria mercenaria in 2009. A. simplex showed correspondence between abundance and size distribution between Little River and Waquoit Bay-Metoxit Point and between Childs River and Menuhant. M. mercenaria showed correspondence at all sites except Childs River.

By pooling the larvae into two groups of two sites for A. simplex and one group of three sites for $M$. mercenaria, we hoped to sample sizes large enough to produce sufficient Gaussian estimation. We followed the same methods for Gaussian separation using the EM algorithm and criteria as described in Chapter 3. These new pools of larvae were expected to contain similar populations, and results were compared to the original cohort estimations for all sites in Chapter 3 (Figures 3.11 and 3.13).

\section{C.2 RESULTS AND DISCUSSION}

Combining data from two site groups produced slightly different cohorts for $A$. simplex than for all of the sites together. Six cohorts were observed for each grouping, 
but only two of them were synchronous (Fig. C.1). In the pooled data, eight cohorts were observed (Fig. 3.11b, d). By pooling all of the sites we were able to see more cohorts, but it is likely that some of these results corresponded to size classes or spawns from different sites. Comparing the two site groups, Little River and Waquoit Bay had the highest growth rates (Table C.1), but Childs River and Menauhant had more persistent cohorts with more large larvae present in later months. Since pooling two sites made for smaller sample sizes when performing Gaussian separation, observing three component groups for a sample distribution was less common than when all sites were combined. This resulted in cohorts spanning a shorter time-span, most notable for the Little River and Waquoit Bay samples.

For the M. mercenaria cohort results, combining data from three out of four sites resulted in similar cohort distributions as seen for all four sites (Figs. C.2 and 3.13b, d). The only marked contrast was that for these samples, two cohorts were observed in May, where only one was observed when all sites were combined. This, however, is more likely a consequence of low sample sizes rather than mixing sites. For these samples, distributions were split from samples between 10-15 larvae. At such low sample sizes, fitting proper distributions is difficult, and by simply removing one or two larvae by removing a site could dramatically change the size distributions. Cohorts for the peak abundance months corresponded with cohorts from all of the sites, and estimated mean growth rates were similar (Tables C.2 and 3.6).

These results show that combining samples to estimate component distributions for cohort separation can sometimes produce misleading results. Results for A. simplex 
showed that when we combined all sites, we were linking cohorts from size groups present at different sites. In 2007, few sites showed correspondence with each other (Table 3.1). Thus, size groups for these samples may be even more segregated between sites. However, it could be argued that larval transport capabilities enable populations to readily mix between sites in Waquoit Bay, and it could be plausible that a population spawned at one site could appear a week later at different site. By pooling larvae from multiple sites we also increase the odds of including larvae from cohorts that have dispersed, eliminating possible error that could result from export at a given site.

There is no way of accurately estimating cohorts of bivalve larvae from this sample set. In order to accurately assign cohorts, larval origins would have to be known, and this is not currently possible with bivalves from this area. We presented this method to demonstrate the type of data that can be gathered using a species-specific analysis. Although our groups may be subject to site-specific variation, overall, this cohort analysis provided a way to look at size structure and growth for three species of bivalves in Waquoit Bay. Simply by observing when groups of older larvae appear and connecting those with potential spawns can provide valuable information for larval ecological studies and species management. 
Table C.1 Mean growth rate (GR) and period present for Anomia simplex cohorts from grouped sites. Mean growth rate and standard deviation are reported for six cohorts for Little River/Waquoit Bay combined sites (LR/WB), and six for Childs River/Menauhant combined sites (CR/MN).

\begin{tabular}{|l|l|l} 
Cohort & Dates & $\begin{array}{l}\text { Mean GR } \\
\text { SD }\left(\mu \mathrm{m} \mathrm{d}^{-1}\right)\end{array}$ \\
\hline LR/WB & & \\
AS1 & 16 Jun - 24 Jun & 2.09 \\
AS2 & 8 Jul - 16 Jul & 6.78 \\
AS3 & 16 Jul - 21 Jul & 8.82 \\
AS4 & 21 Jul - 12 Aug & $3.30 \pm 1.13$ \\
AS5 & 4 Aug - 26 Aug & $3.85 \pm 4.50$ \\
AS6 & 26 Aug - 2 Sep & 2.39 \\
\hline CR/MN & & \\
AS1 & 16 Jun - 24 Jun & 2.92 \\
AS2 & 29 Jun - 8 Jul & 3.94 \\
AS3 & 8 Jul - 30 Jul & $3.85 \pm 4.03$ \\
AS4 & 16 Jul - 4 Aug & $3.39 \pm 2.50$ \\
AS5 & 4 Aug - 26 Aug & $5.37 \pm 3.05$ \\
AS6 & 19 Aug - 26 Aug & 3.94
\end{tabular}

Table C.2 Mean growth rate (GR) and period present for Mercenaria mercenaria cohorts from grouped sites. Mean growth rate and standard deviation are reported for nine cohorts for combined Little River, Menauhant, and Waquoit Bay sites (LR/MN/WB).

\begin{tabular}{|l|l|l} 
Cohort & Dates & $\begin{array}{l}\text { Mean GR } \\
\text { SD }\left(\mu \mathrm{m} \mathrm{d}^{-1}\right)\end{array}$ \\
\hline LR/MN/WB & & \\
MM1 & 7 May - 13 May & 11.64 \\
MM2 & 13 May - 18 May & 8.43 \\
MM3 & 8 Jul - 16 Jul & 1.53 \\
MM4 & 16 Jul - 4 Aug & $3.38 \pm 1.01$ \\
MM5 & 30 Jul - 19 Aug & $2.99 \pm 1.92$ \\
MM6 & 12 Aug - 26 Aug & $3.41 \pm 0.79$ \\
MM7 & 26 Aug - 2 Sep & 4.01 \\
MM8 & 2 Sep - 9 Sep & $2.70 \pm 0.85$ \\
MM9 & 15 Sep - 29 Sep & $1.16 \pm 0.94$
\end{tabular}



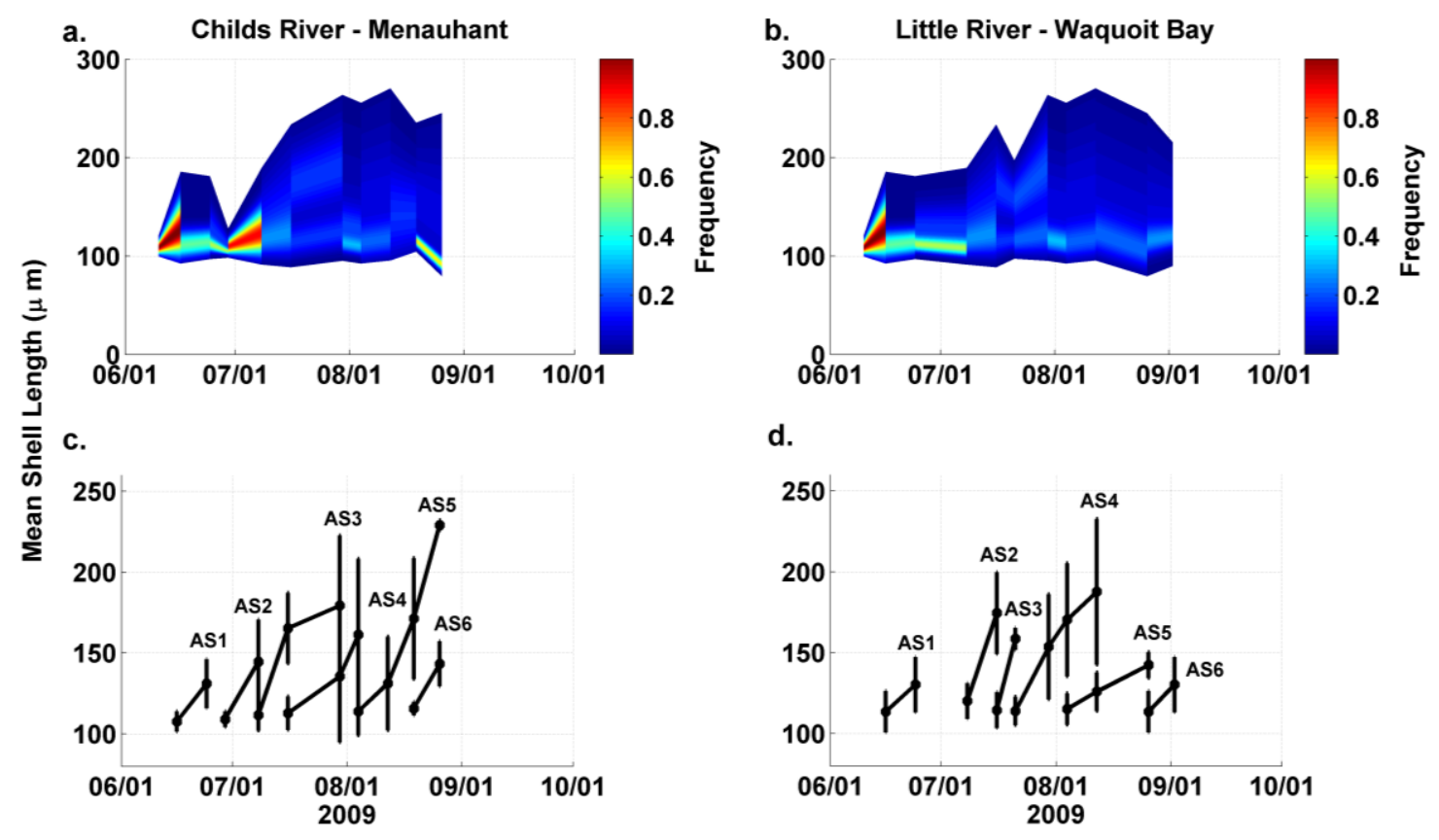

d.

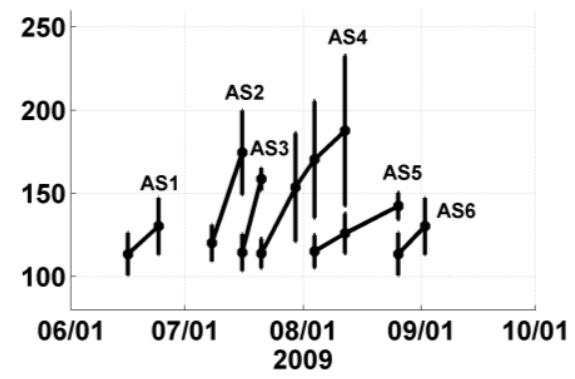

Figure C.1 Cohort graphs for Anomia simplex grouped by sites. (a-b) Frequency distributions of larval sites for (a) Childs River and Menauhant and (b) Little River and Waquoit Bay. Probability density functions (pdfs) were only made when 10 or more larvae were present after pooling the two sets of sites. (c-d) Mean size and standard deviations are shown for identified cohorts at each group of sites. 

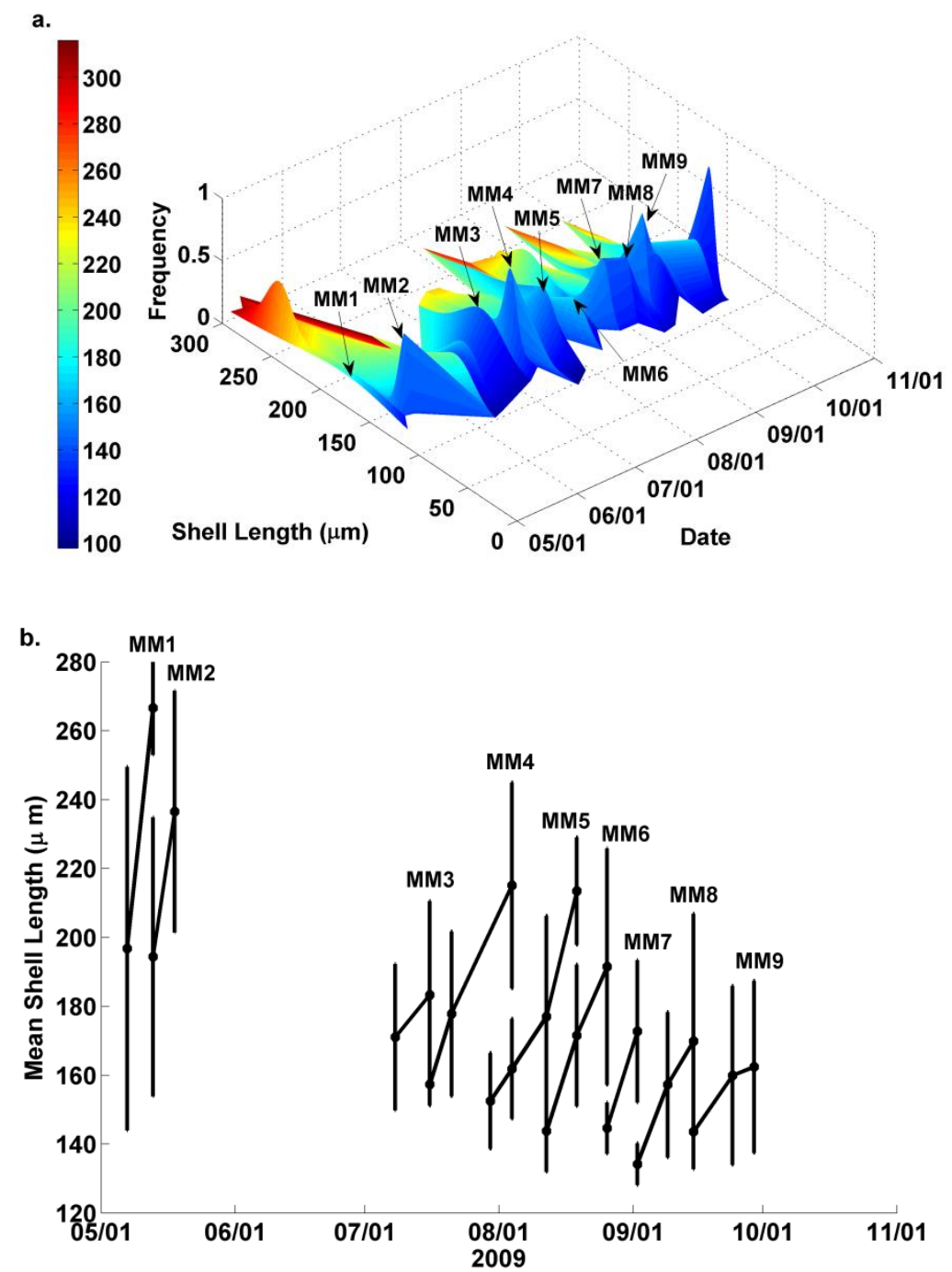

Figure C.2 Probability density functions (pdfs) and cohort size plot for Mercenaria mercenaria combined for Little River, Menauhant, and Waquoit Bay for 2009. Pdfs were only made from total counts of 10 or more individuals of $M$. mercenaria represented after pooling the three sites. Spawning peaks of identified cohorts are marked. 


\section{APPENDIX D: Flux and Vertical Distribution of Competent Larvae in Waquoit Bay}

\section{D.1 INTRODUCTION AND METHODS}

As a bivalve larva proceeds through ontogenetic changes during its pelagic larval phase, it becomes focused on finding a suitable habitat for settlement. A larger, harder shell and development of a foot allows a pedi-veliger larva to spend more time searching out suitable substrate for settlement and metamorphosis. This bottom-oriented behavior is a result of both increased difficulty of swimming with a heavier shell as well as pressure to settle (Chia et al. 1984). However, larvae are still pelagic at this point, being transported with currents and feeding on phytoplankton. Due to these different life cycle characteristics, it has been both proposed and demonstrated that competent larvae have different dispersal patterns than younger veligers (Baker and Mann 2003). Furthermore, studying flux and behavior of competent larvae provide a more realistic estimate of potential recruitment to an estuarine site as these are the individuals most likely to settle out during their tenure in the estuary.

For our species studied, this stage usually occurs when the larva reaches about $200 \mu \mathrm{m}$ (Arnold et al. 2005, Chapter 1). By employing an edge-detection algorithm on the larval images (see Chapter 3 methods), we were able to calculate larval shell length for each image. We estimated competent larvae composed about $3 \%$ of the total samples and were thus unlikely to affect the behavioral patterns observed in Chapter 4. For these larvae, we hypothesized that velocity would be the most important physical factor regulating pedi-veliger transport and distribution due to the negative geotaxis observed for these larvae. More turbulence from faster currents would cause resuspension of some 
larvae in sediments, but slower currents would enable these larvae to more easily reach the surface to feed or be transported. By performing separate analysis on these individuals we hoped to determine if larger larvae were either bottom-distributed or showed patterns that might lead to retention. We performed the same statistical tests in Chapter 4 (ANOVA and cross-correlation) to assess the significance of these patterns. We calculated flux of competent larvae for the same spring and neap events as in Chapter 4 to estimate potential settlement for each species and investigated whether there were certain tidal periods more likely to transport larger larvae.

\section{D.2 RESULTS AND DISCUSSION}

D.2.1 Vertical Distribution and Relationships to Velocity. In general, our results showed some evidence for bottom distribution of pedi-veliger larvae, but nothing consistent between tidal cycles and sampling periods. There were many cases where concentrations of large larvae differed from results of all larvae, and larger larvae were more abundant in the middle or bottom depths compared to the surface. However, in many cases pedi-veligers were also found in high concentrations at the surface.

For total larvae, a relationship with depth or velocity might suggest that these behaviors are consistent for all species. There were many surface peaks of pedi-veliger larvae in the Little River spring series which was consistent with all larvae (Fig. D.1a, Fig. 4.11), but in the Little River neap period there appeared to be increases of larvae at the bottom associated with incoming velocities, although concentrations were uniformly high at the surface and bottom. At Childs River, presence of larger larvae was erratic and didn't follow the trends of being transported on incoming tides as seen for all sizes, 
although there were significant effects of depth with neap tide concentrations (Table D.1). Instead, larger larvae seemed to occur at the end of spring flood events (Fig. D.1b) and appeared to be associated with high velocities on the neap tides (Fig. D.1d).

For Anomia simplex larvae, we saw stronger evidence for bottom seeking behavior. As smaller larvae had often peaked in the surface, larger larvae peaked in the middle or bottom depths (Fig. D.2). Larvae were still found in the surface when overall concentrations were high, perhaps due to higher velocities (Fig. D.2a,c). At Childs River, large A. simplex larvae were rare and only found on three tidal events (Fig. D.2b,d). For two of these events, A. simplex were associated with incoming tides at mid-depths.

Geukensia demissa larvae showed pulsed peaks of larvae at 2-4 hour intervals at Little River (Fig. D.3a,c). For the neap period, this seemed to be associated with periods of lower velocity. A significant correlation between surface G. demissa concentration and incoming velocity appeared at a two hour lag (data not shown), indicating larvae might be sensing higher velocity and surfacing when it lowers. For the spring period, this trend was observed with one exception during the first outgoing tide (Fig. D.3a). At Childs River, G. demissa were most abundant on the outgoing tides (Fig. D.3b,d), with the exception of a big pulse on the second neap flood (Fig. D.3d). Since all G. demissa larvae were significantly more abundant on flood versus ebb tides (Table 4.3), more pedi-veliger larvae found on ebb tides could indicate an avoidance of an unsuitable habitat.

Most of the larger larvae were classified as Mercenaria mercenaria. At Childs River, there was a significant effect of depth on pedi-veliger larvae for both periods (Table D.1), and concentrations seemed to be associated with incoming tides and 
velocities (Figs. D.4b,d). Most of the general trends observed for M. mercenaria pediveligers were not drastically different from those of all larvae. For Little River spring tides, concentrations peaked in the bottom on outgoing tides, but many were also abundant in the surface (Fig. D.4a). During the neap tides, larger M. mercenaria were found on the bottom during incoming tides and showed a slight but unsignificant trend with velocity (Fig. D.4c). This suggests that there are periods when M. mercenaria larvae may concentrate at the bottom, but are more likely associated with velocity rather than tidal direction. Carriker (1961) noted late-stage M. mercenaria to be associated with the bottom, however our data shows they may be associated with the bottom on some periodicity but also readily found at the surface.

The low presence of large larvae in our samples made statistical patterns difficult to interpret. At Childs River, we saw high correlation coefficients to velocity with pediveliger larvae of all species in the bottom, but these were only from 5-6 samples (data not shown). However, if high velocities may cause competent larvae to sink as they do for gastropod larvae (Fuchs et al. 2004), this might not be random. We included large larvae grouped for all species in these results because it gave us more samples to evaluate, but no clear patterns emerged. Species-specific patterns seem to be present for larvae at this stage. Previous studies have found pediveliger G. demissa in the surface compared to the bottom, although we occasionally saw high concentrations of all species at the surface (Baker and Mann 2003). Our data do suggest larvae are often more abundant at lower depths than at the surface, and it is likely that high velocities may enable more of these larvae to be resuspended and found in surface samples. However, 
our data were unclear in suggesting transport patterns as it seems there is a mix of both active and passive behaviors.

D.2.2 Flux and Transport. This study also demonstrated that presence of pediveliger larvae is erratic and not always consistent with patterns observed for total larvae. Our flux data for total, A. simplex, and M. mercenaria larvae at Little River showed pulses of pedi-veliger flux at 5-6 day intervals. This could reflect development time of different cohorts with either settlement or net export decreasing concentrations inbetween (Figs. D.5a,b,d). Flux of larvae of all sizes did not show these patterns (Fig. 4.10 a-d). G. demissa did not show this pattern, perhaps being complicated by the large pulse observed around 18 Jul (Fig. 4.6a). Export of larger G. demissa larvae, perhaps resulting from this spawn, may be seen in the 21 Jul peak (Fig. D.5c).

Fluxes of all sizes for each species generally followed the same patterns of water volume transport (Table 4.2), but for pedi-veligers we saw more species-specific patterns and trends that differed from those of total larvae. There was a net import of large larvae during the spring period at Little River (Table D.2) while there was a large net export of smaller larvae. Most of the larvae present during this period were likely small, but the stronger flood tides at Little River may have encouraged import of pedi-veliger larvae. So despite a net export of smaller larvae for this period, it may have overall been a favorable situation for settlement. No significant relationships were found between tidal features and pedi-veliger larvae at Little River (Fig. D.6a-b), however there is a slight trend of more pedi-veliger larvae being observed on low-amplitude tides at Little River. One 
mechanism to explain this would be if larger larvae sink in response to higher turbulence, their concentration at the surface, where our pump was located, would be lower.

Large larvae at Menauhant had more irregular patterns than Little River, showing sporadic pulses of export or import events followed by longer periods of low concentrations. For these pulses, mostly export was observed (Fig. D.5d-f). With the high flux of currents through the inlet at Menauhant, it is less likely to observe coherent cohorts and export events are likely from pulses of patches created by physical features. There was no difference between concentrations between ebb and flood events or tidal strength (Fig. D.6c-d). Summed tidal fluxes at Menauhant for the spring and neap period clarify some trends for the pooled sizes. A large efflux of large G. demissa larvae occurred despite a net influx of all G. demissa larvae for the spring period. For the neap period, A. simplex and G. demissa had were transported separate directions, with net incoming water volume flux. Flux for M. mercenaria pedi-veligers was large, and often had different flux directions than total $M$. mercenaria larvae. For the neap period, $15 \%$ of M. mercenaria exported were pedi-veligers. Thus recruitment potential for bivalve larvae transported through the Menauhant inlet seems to vary between extreme export of bay larvae to smaller periods of net import of larvae from other sources.

\section{3 SUMMARY}

This analysis emphasizes the importance of not only evaluating species-specific data, but also separating size-classes to determine patterns of larval transport. Our results for the vertical distribution study showed that pedi-veliger larvae can exhibit bottomoriented distributions that are more characteristic of having a larger shell and seeking 
settlement substrate. However, these patterns were not consistent between species, between sites, nor between times. It is likely that the strong tidal currents found at Little River and the stratified conditions at Childs River may prevent large larvae from exhibiting consistent patterns. Perhaps had this study been performed in a more stable, but tidally influenced area such as the middle of the bay, we would be able to observe clear trends.

The tidal flux data emphasized that pedi-veliger larvae have different trends than total larvae, and thus estimates of tidal flux for total larvae may not be accurate estimates of potential settlement or recruitment. Species-specific trends that did not follow water volume transport were most evident for pedi-veliger larvae. This suggests that these larvae are not only more patchy but also capable of maintaining distributions separate from passive transport.

\section{D.4 LITERATURE CITED}

Arnold, W.S., G.L. Hitchcock, M.E. Frischer, R. Wanninkhof, Y.P. Sheng. 2005. Dispersal of an introduced larval cohort in a coastal lagoon. Limnol. Oceanogr. 50(2): 587-597.

Baker, P. and R. Mann. 2003. Late stage bivalve larvae in a well-mixed estuary are not inert particles. Estuaries 26(4A): 837-845.

Carriker, M.R. 1961. Interrelation of functional morphology, behavior, and autecology in early stages of the bivalves Mercenaria mercenaria. J. Elisha Mitchell Sci. Soc. 77: $168-241$.

Chia, F., J. Buckland-Nicks, and C.M. Young. 1984. Locomotion of marine invertebrate larvae: a review. Can. J. Zool. 62: 1205-1222.

Fuchs, H.L., L.S. Mullineaux, and A.R. Solow. 2004. Sinking behavior of gastropod larvae (Ilyanassa obsoleta) in turbulence. Limnol. Oceanogr. 49(6): 1937-1948. 
Table D.1 ANOVA tables testing the effects of depth and tide on pedi-veliger larval concentrations. Results from a two-way ANOVA on log-transformed data are shown for each sampling period. Surface, middle and bottom concentrations were tested for all periods except Childs River when not enough bottom samples were represented for all species. Significant relationships (alpha $<0.05)$ are shown in bold. DF $=$ degrees of freedom; $\mathrm{TOT}=$ total larvae; $\mathrm{AS}=$ A. simplex $; \mathrm{GD}=G$. demissa, $\mathrm{MM}=M$. mercenaria

\begin{tabular}{llrrr|rrr} 
& & \multicolumn{3}{c|}{ Little River } & \multicolumn{3}{c}{ Childs River } \\
\hline SPRING & Source & DF & F & P & DF & F & P \\
\hline TOT & Depth & 2 & 1.66 & 0.103 & 1 & 0.01 & 0.905 \\
& Tide & 2 & 0.02 & 0.985 & 1 & 1.84 & 0.187 \\
& Depth*Tide & 4 & 0.42 & 0.790 & 3 & 0.24 & 0.867 \\
AS & Depth & 2 & 0.2 & 0.819 & 1 & 1.03 & 0.320 \\
& Tide & 2 & 2.49 & 0.097 & 1 & 0.76 & 0.390 \\
& Depth*Tide & 4 & 0.93 & 0.458 & 3 & 0.83 & 0.491 \\
GD & Depth & 2 & 0.35 & 0.711 & 1 & 1.44 & 0.242 \\
& Tide & 2 & 0.72 & 0.495 & 1 & 0.20 & 0.660 \\
& Depth*Tide & 4 & 1.08 & 0.379 & 3 & 0.90 & 0.453 \\
MM & Depth & 2 & 0.11 & 0.899 & $\mathbf{2}$ & $\mathbf{9 . 1 4}$ & $\mathbf{0 . 0 0 1}$ \\
& Tide & 2 & 2.31 & 0.112 & 2 & 0.49 & 0.614 \\
& Depth*Tide & 4 & 0.64 & 0.640 & 4 & 0.63 & 0.643 \\
\hline NEAP & Source & DF & F & P & DF & F & P \\
\hline TOT & Depth & 2 & 0.50 & 0.613 & $\mathbf{2}$ & $\mathbf{1 2 . 7 2}$ & $\mathbf{0 . 0 0 1}$ \\
& Tide & 2 & 1.30 & 0.284 & 2 & 0.58 & 0.454 \\
& Depth*Tide & 4 & 0.18 & 0.946 & 4 & 0.52 & 0.670 \\
AS & Depth & 2 & 0.35 & 0.710 & 1 & 1.15 & 0.292 \\
& Tide & 2 & 1.26 & 0.296 & 1 & 0.09 & 0.767 \\
& Depth*Tide & 4 & 0.63 & 0.648 & 3 & 1.14 & 0.349 \\
GD & Depth & 2 & 0.08 & 0.919 & 1 & 2.90 & 0.099 \\
& Tide & 2 & 0.26 & 0.772 & 1 & 0.09 & 0.768 \\
& Depth*Tide & 4 & 0.24 & 0.916 & 3 & 0.07 & 0.978 \\
& Depth & 2 & 0.55 & 0.581 & $\mathbf{2}$ & $\mathbf{4 . 7 5}$ & $\mathbf{0 . 0 1 3}$ \\
& Tide & 2 & 0.91 & 0.410 & 2 & 1.50 & 0.234 \\
& Depth*Tide & 4 & 0.96 & 0.438 & 4 & 0.9 & 0.470
\end{tabular}


Table D.2 Net flux of pedi-veliger larvae $\left(x 10^{7}\right)$ for spring and neap 48 hour periods. Summary of data calculations given in Table 4.2. Positive fluxes are indicated in bold. $\mathrm{LR}=$ Little River; MN = Menauhant.

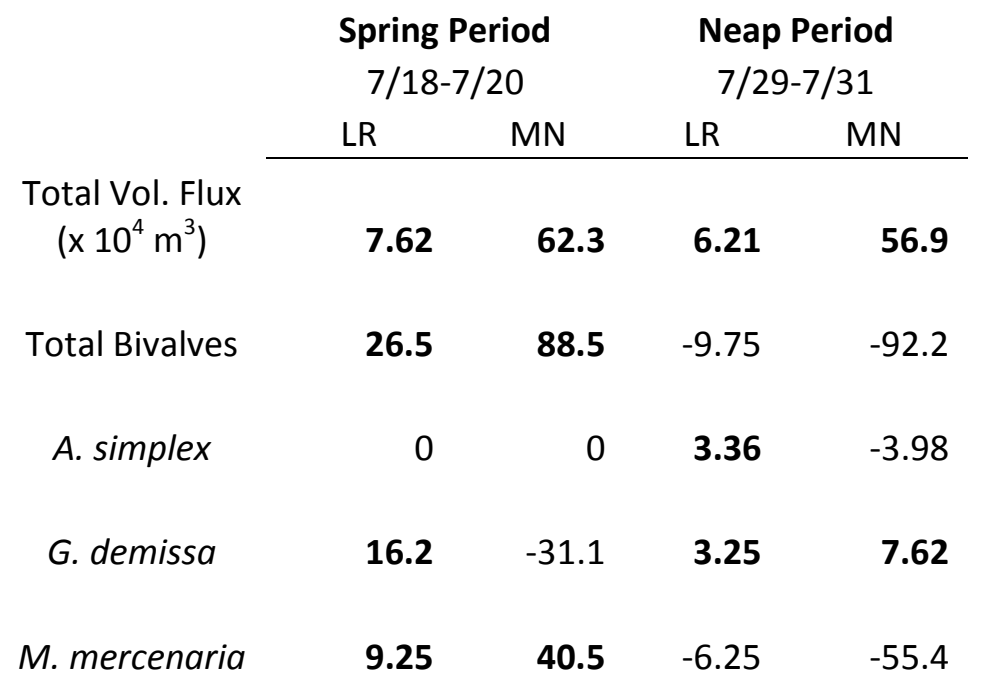




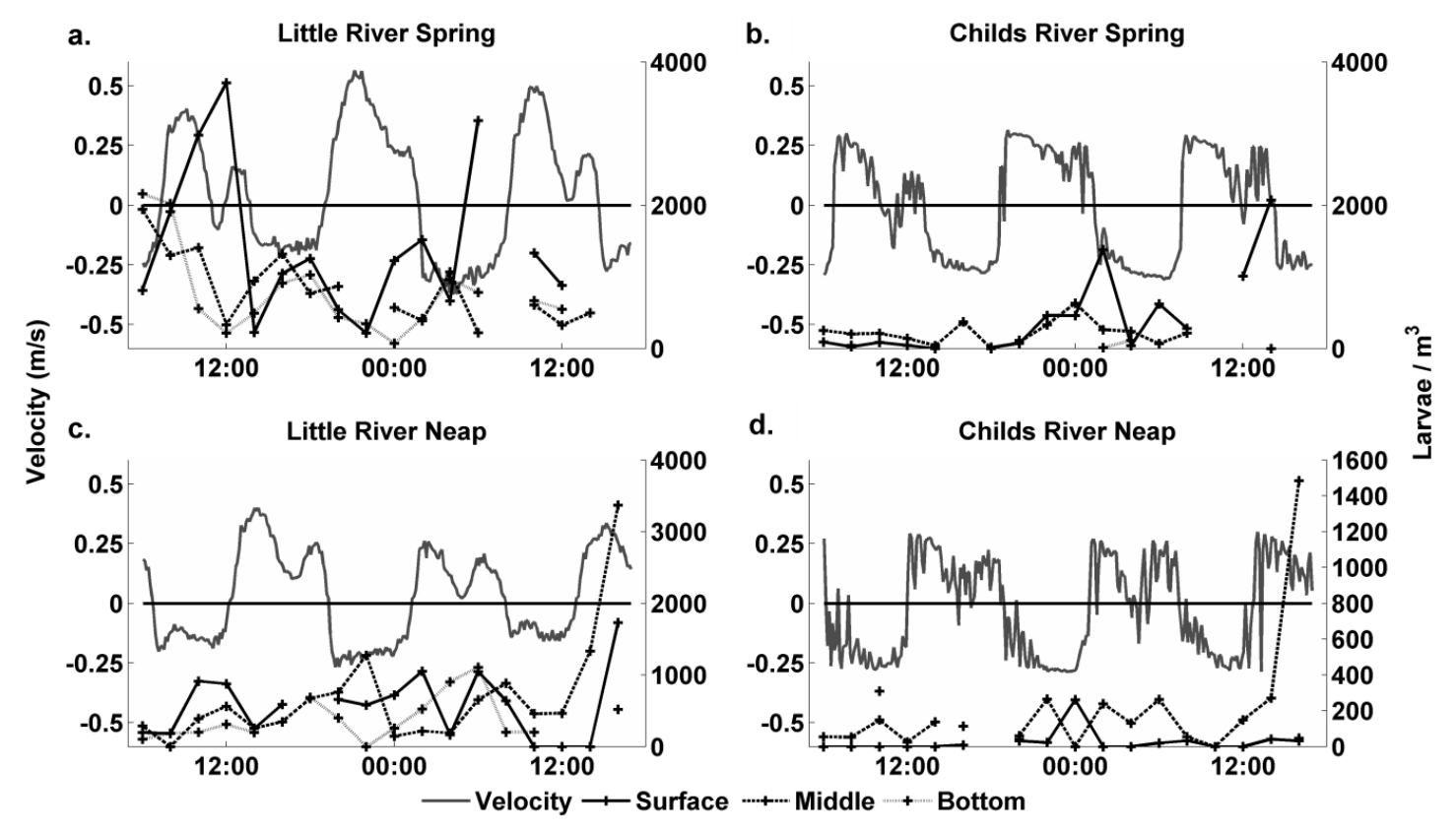

Figure D.1 Competent larval concentration and velocity time series for all pedi-veliger larvae during vertical distribution study. Concentration of larvae as estimated from measured larval images at surface, middle, and bottom depths is shown for (a) Little River spring tide (22-23 Jul 2009), (b) Little River neap tide (28-29 Jul 2009), (c) Childs River spring tide (22-23 Jul 2009) and (d) Childs River neap tide (28-29 Jul 2009). Velocity measurements were recorded from current meters at $0.5 \mathrm{~m}$ above the bottom every 7.5 minutes. Positive velocity corresponds to incoming tides. Solid black line represents zero velocity. 

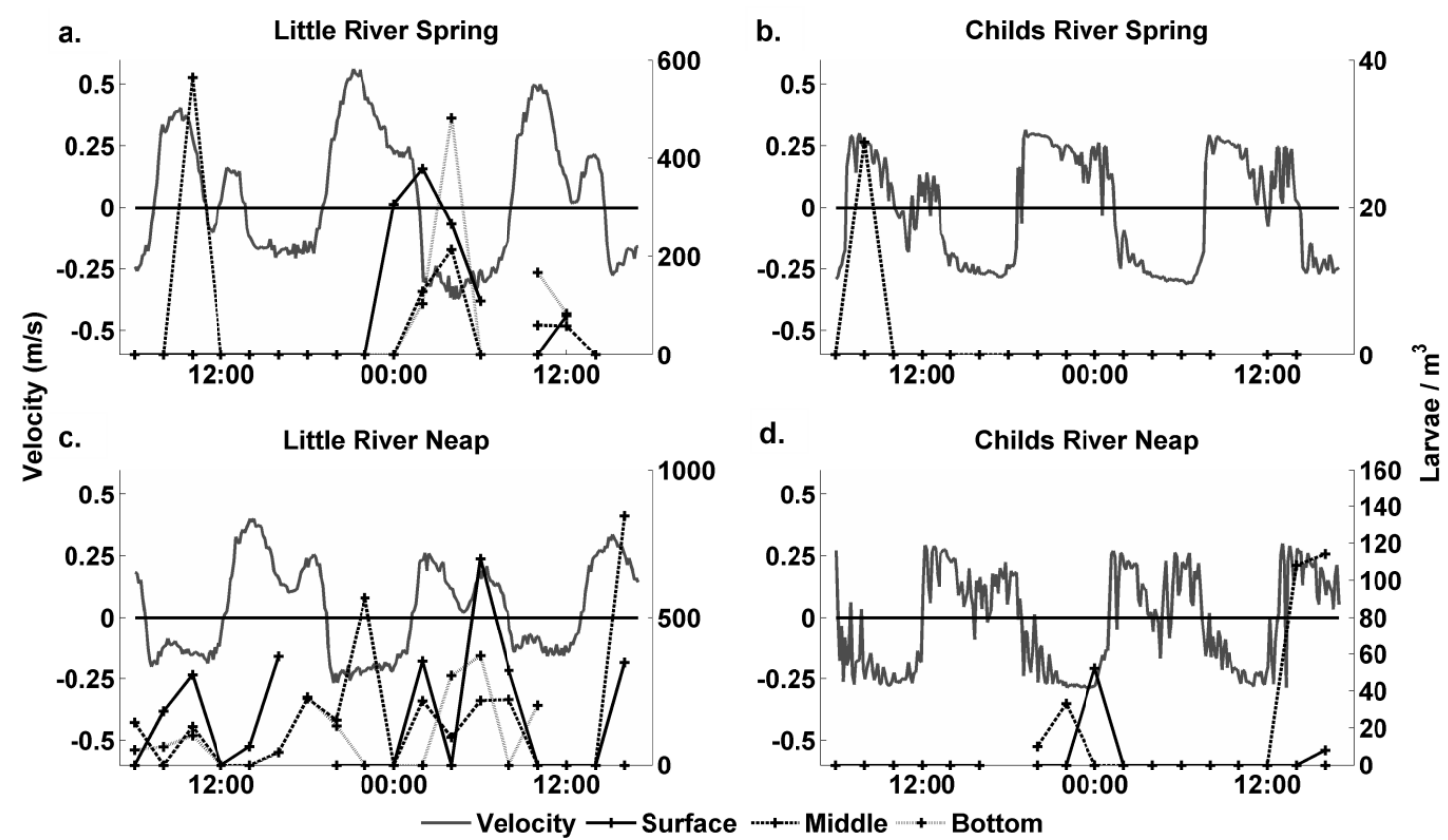

Figure D.2 Competent larval concentration and velocity time series for Anomia simplex pedi-veliger larvae during vertical distribution study. Concentration of larvae as estimated from measured larval images at surface, middle, and bottom depths is shown for (a) Little River spring tide (22-23 Jul 2009), (b) Little River neap tide (28-29 Jul 2009), (c) Childs River spring tide (22-23 Jul 2009) and (d) Childs River neap tide (28-29 Jul 2009). Velocity measurements were recorded from current meters at $0.5 \mathrm{~m}$ above the bottom every 7.5 minutes. Positive velocity corresponds to incoming tides. Solid black line represents zero velocity. 

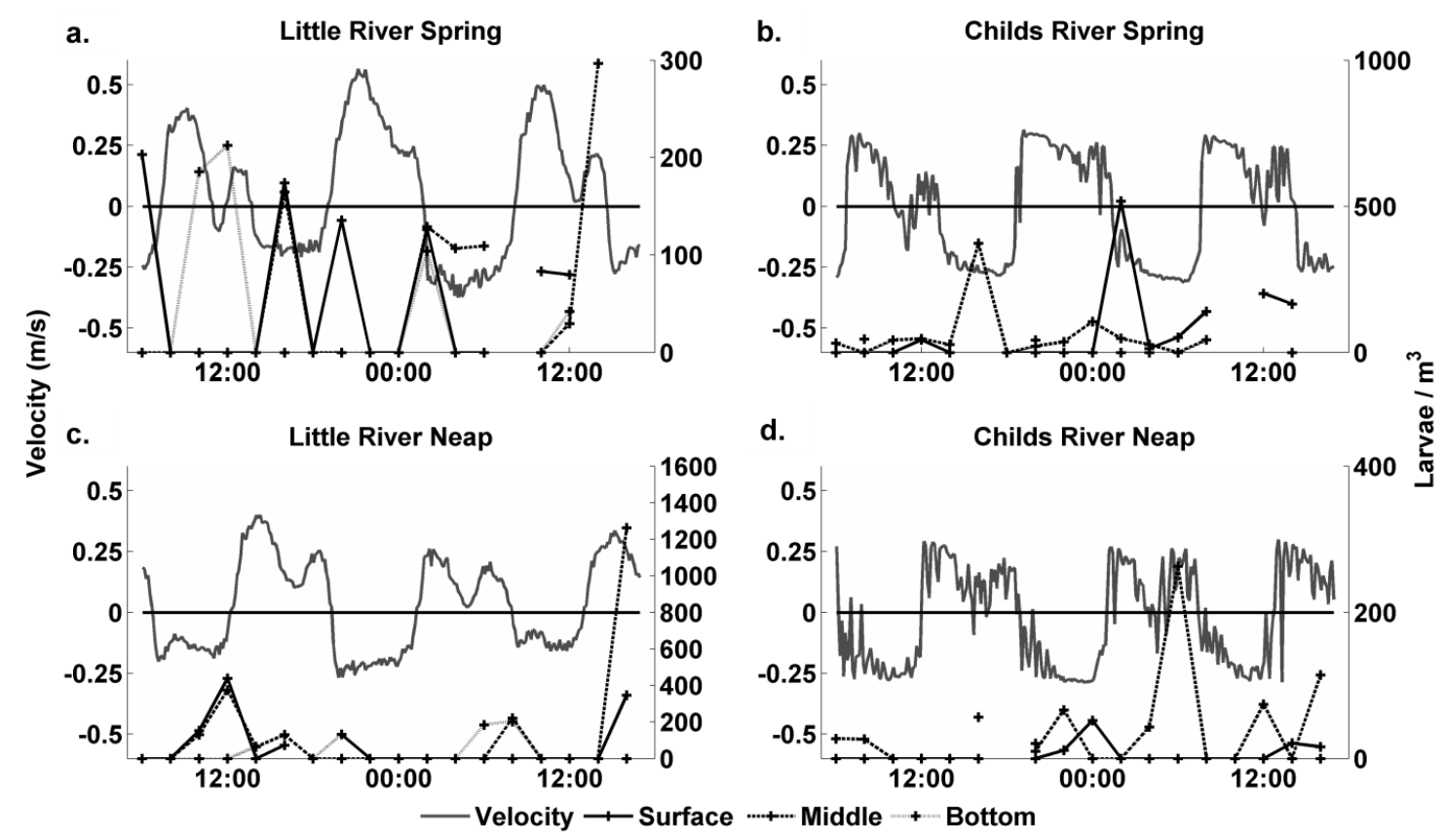

Figure D.3 Competent larval concentration and velocity time series for Geukensia demissa pedi-veliger larvae during vertical distribution study. Concentration of larvae as estimated from measured larval images at surface, middle, and bottom depths is shown for (a) Little River spring tide (22-23 Jul 2009), (b) Little River neap tide (28-29 Jul 2009), (c) Childs River spring tide (22-23 Jul 2009) and (d) Childs River neap tide (28-29 Jul 2009). Velocity measurements were recorded from current meters at $0.5 \mathrm{~m}$ above the bottom every 7.5 minutes. Positive velocity corresponds to incoming tides. Solid black line represents zero velocity. 


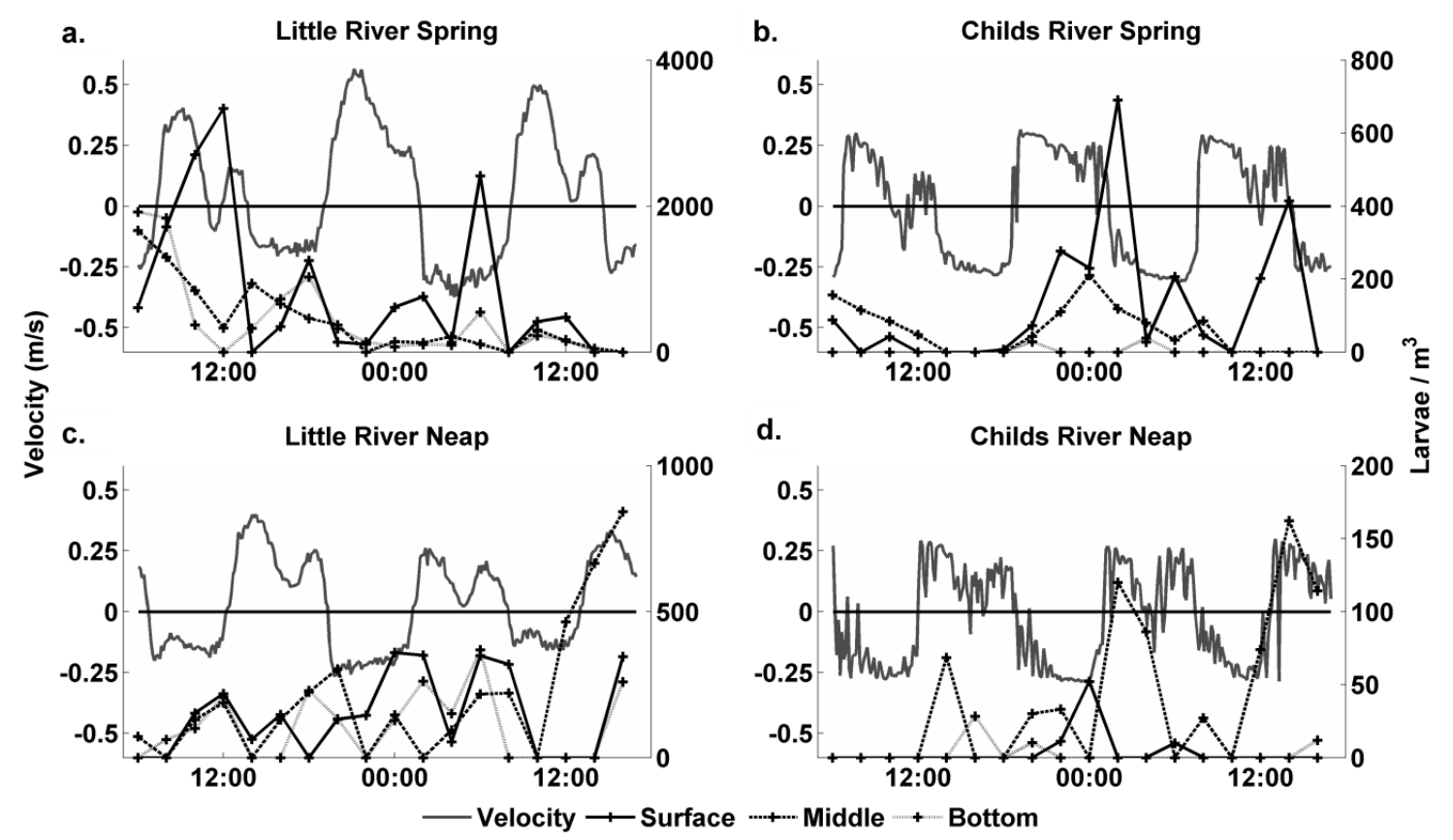

Figure D4 Competent larval concentration and velocity time series for Mercenaria mercenaria pedi-veliger larvae during vertical distribution study. Concentration of larvae as estimated from measured larval images at surface, middle, and bottom depths is shown for (a) Little River spring tide (22-23 Jul 2009), (b) Little River neap tide (28-29 Jul 2009), (c) Childs River spring tide (22-23 Jul 2009) and (d) Childs River neap tide (28-29 Jul 2009). Velocity measurements were recorded from current meters at $0.5 \mathrm{~m}$ above the bottom every 7.5 minutes. Positive velocity corresponds to incoming tides. Solid black line represents zero velocity. 


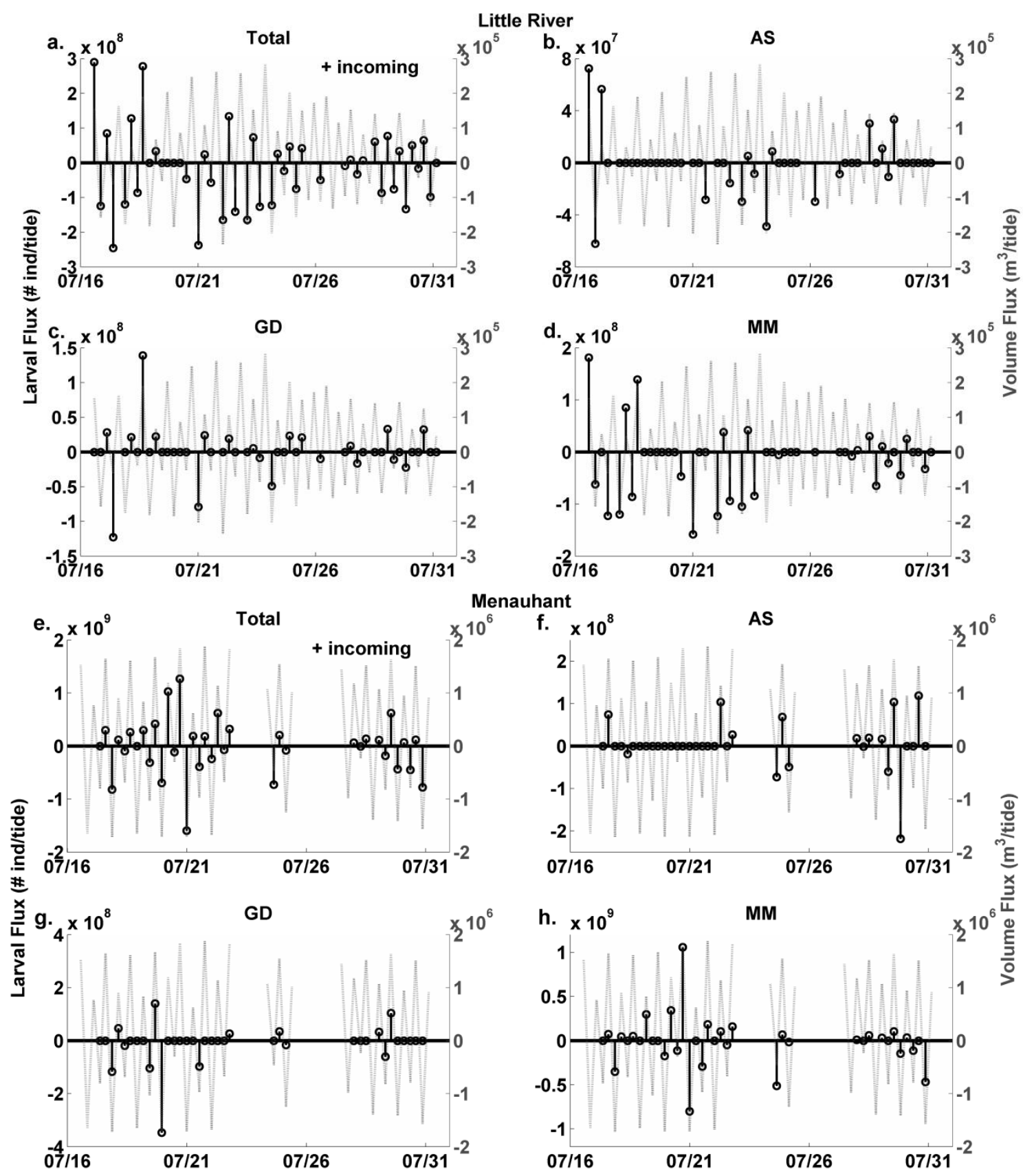

Figure D.5 Total larval flux and water volume exchange for pedi-veliger larvae for the Little River (a-d) and Menauhant (e-h) flux studies. See Figure 4.10 for description of data. Positive fluxes indicate larvae on incoming tides. $(\mathrm{a}, \mathrm{e})$ Total $=$ Total bivalves, $(\mathrm{b}, \mathrm{f})$ $\mathrm{AS}=$ Anomia simplex,$(\mathrm{c}, \mathrm{g}) \mathrm{GD}=$ Geukensia demissa,$(\mathrm{d}, \mathrm{h}) \mathrm{MM}=$ Mercenaria mercenaria. 

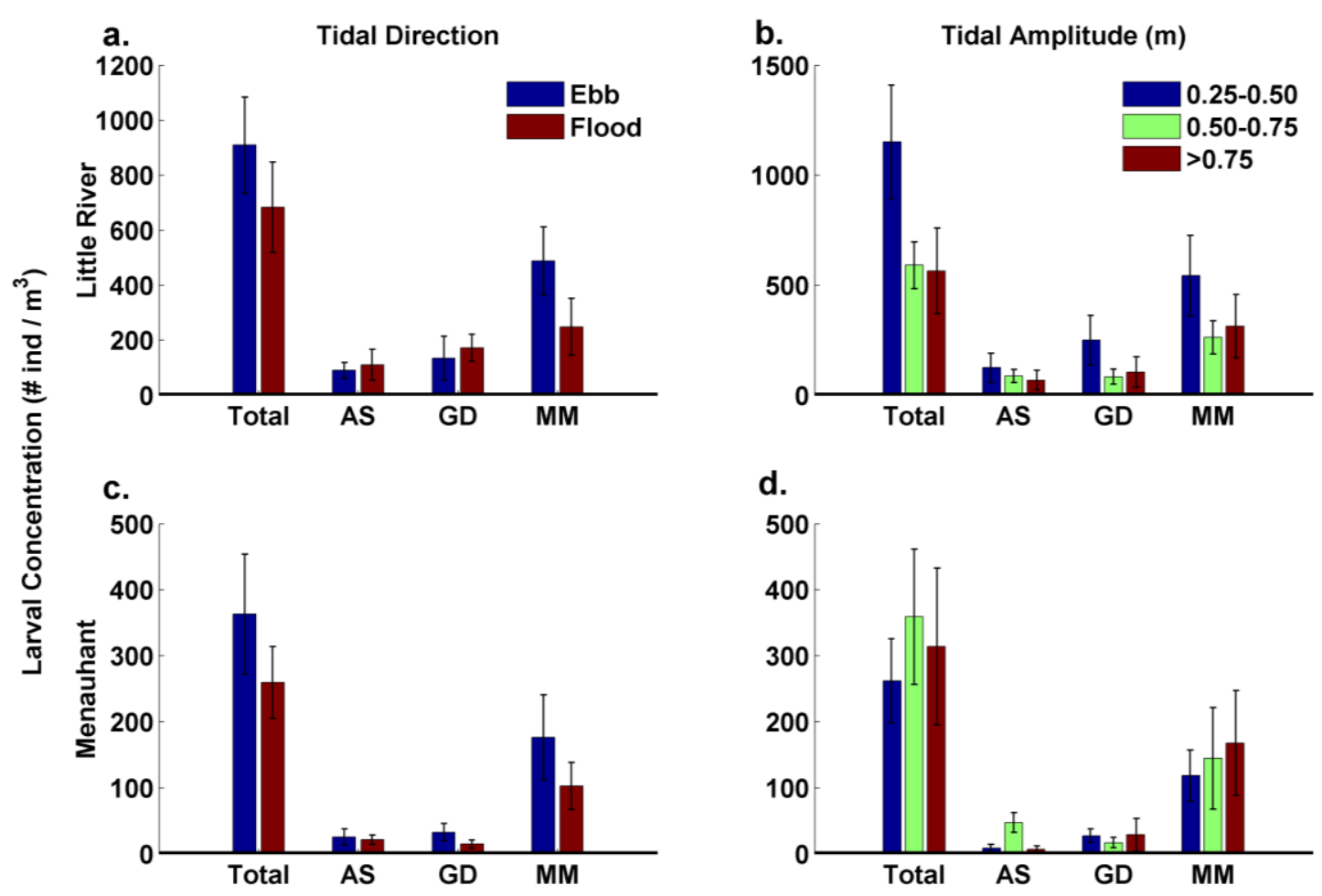

d.

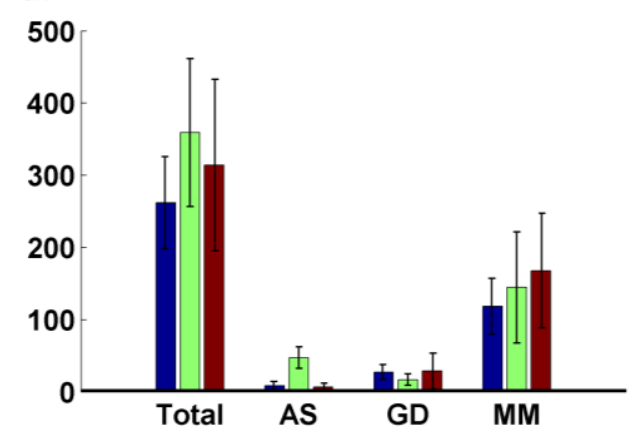

Figure D.6 Relationships of pedi-veliger larvae at Little River (a-b) and Menauhant (cd) to tidal features. Mean concentration and standard error of total larvae and for all three species pooled by tidal direction (first column) and tidal amplitude (second column) for the period. There were no significant affects. Total = total bivalve larvae; $\mathrm{AS}=A$. simplex, $\mathrm{GD}=$ G. demissa, $\mathrm{MM}=\mathrm{M}$. mercenaria . 